\title{
The impact of the long-term care reform in the Netherlands
}

Citation for published version (APA):

Jongen, W. (2017). The impact of the long-term care reform in the Netherlands: an accompanying analysis of an 'ongoing' reform. [Doctoral Thesis, Maastricht University]. Datawyse / Universitaire Pers Maastricht. https://doi.org/10.26481/dis.20170223wj

Document status and date:

Published: 01/01/2017

DOI:

10.26481/dis.20170223wj

Document Version:

Publisher's PDF, also known as Version of record

\section{Please check the document version of this publication:}

- A submitted manuscript is the version of the article upon submission and before peer-review. There can be important differences between the submitted version and the official published version of record.

People interested in the research are advised to contact the author for the final version of the publication, or visit the DOI to the publisher's website.

- The final author version and the galley proof are versions of the publication after peer review.

- The final published version features the final layout of the paper including the volume, issue and page numbers.

Link to publication

\footnotetext{
General rights rights.

- You may freely distribute the URL identifying the publication in the public portal. please follow below link for the End User Agreement:

www.umlib.nl/taverne-license

Take down policy

If you believe that this document breaches copyright please contact us at:

repository@maastrichtuniversity.nl

providing details and we will investigate your claim.
}

Copyright and moral rights for the publications made accessible in the public portal are retained by the authors and/or other copyright owners and it is a condition of accessing publications that users recognise and abide by the legal requirements associated with these

- Users may download and print one copy of any publication from the public portal for the purpose of private study or research.

- You may not further distribute the material or use it for any profit-making activity or commercial gain

If the publication is distributed under the terms of Article $25 \mathrm{fa}$ of the Dutch Copyright Act, indicated by the "Taverne" license above, 


\section{The impact of the}

long-term care reform in the Netherlands:

an accompanying analysis of an 'ongoing' reform

Wesley Jongen 
The research for this dissertation was performed at the Department of International Health within the School for Public Health and Primary Care (CAPHRI), Faculty of Health, Medicine and Life Sciences, Maastricht University.

Dissertation: The impact of the long-term care reform in the Netherlands: an accompanying analysis of an 'ongoing' reform

Author: Wesley Jongen

ISBN: 9789461596567

Production \& print: Datawyse | Universitaire Pers Maastricht

(c) Copyright: Wesley Jongen, Maastricht, the Netherlands, 2017.

All rights reserved. No part of this publication may be reproduced without permission of the copyright owner. 


\title{
The impact of the long-term care reform in the Netherlands:
}

\section{an accompanying analysis of an 'ongoing' reform}

\author{
Dissertation \\ to obtain the degree of Doctor \\ at Maastricht University, \\ on the authority of the Rector Magnificus Prof. dr. Rianne M. Letschert, \\ in accordance with the decision of the Board of Deans, \\ to be defended in public \\ on Thursday, 23 February 2017, at 16:00 hours
}

by

Wesley Jongen 
Supervisors

Prof. dr. H. Brand

Prof. dr. J.M.G.A. Schols

\section{Co-supervisor}

Dr. M.J. Commers

\section{Assessment Committee}

Prof. dr. G.I.J.M. Kempen (Chair)

Prof. dr. A. de Boer (VU Amsterdam)

Prof. dr. K.G. Luijkx (Tilburg University)

Prof. dr. J. Scheres 


\section{Table of Content}

Chapter 1 Introduction to this dissertation

Chapter 2 Evaluating interventions aimed at promoting social participation of older people: a review of the literature

Chapter 3 The influence of the economic crisis on quality of care for older people: system readiness for innovation in Europe

Chapter 4 The Dutch long-term care system in transition: implications for municipalities

Chapter 5 The impact of austerity-driven policy reforms on long-term care quality: evaluating the long-term care provision for older people in Belgium and the Netherlands using European quality benchmarks

Chapter 6 The Dutch long-term care reform: moral conflicts in executing the Social Support Act 2015

Chapter 7 Cross-border capacity assessment in dementia care

Chapter 8 Discussion of this dissertation

Valorization addendum

Summary

Samenvatting

Dankwoord

About the author 

Chapter

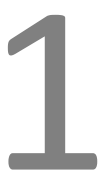

Introduction to this dissertation 
In 2007, a major reform of the Dutch long-term care system was realised, with the introduction of the Social Support Act (in Dutch: 'Wet maatschappelijke ondersteuning', Wmo). The reform implied a decentralization of government responsibilities in the longterm care field. The 2007 reform, and the process leading up to its entry into force, can be considered the start of a contentious policy drama; a struggle between the national government and the municipalities. The national government intended to bring care closer to its citizens, while municipalities were worried about impending budget cuts in the execution of their new responsibilities.

On January $1^{\text {st }}, 2015$, the latest Dutch long-term care reform entered into force. The 2015 reform can be seen as having a hybrid focus, characterized by, on the one hand, austerity measures intended to safeguard the long-term financial sustainability of the Dutch long-term care system, and on the other hand by a normative discussion about public values such as solidarity versus individual responsibility. More concretely, this entails the curbing of public expenditures on long-term care, a general shift in focus from residential to non-residential care provision ('deinstitutionalisation', or 'extramuralisation'), a further decentralization of non-residential care responsibilities from the national government to the municipalities, and an increased focus on informal care provision and social participation of vulnerable citizens. The 2015 reform can be seen as part of a more long-lasting 'market-oriented' reform of the Dutch healthcare system in general, which had its foundation in 1987 with the proposal of the Dekker Commission to introduce more (regulated) competition in the healthcare sector. As Maarse, Jeurissen \& Ruwaard (2016) point out, this market-oriented reform was directed at fostering efficiency, enhancing citizens' freedom of choice and reinforcing solidarity among citizens, while simultaneously upholding public values such as accessibility of care, quality of care and financial sustainability of the healthcare sector in general.

The studies in this dissertation have one major and overarching goal: to examine whether the intended results of the recent long-term care reform have been achieved.

\section{BACKGROUND OF THE DUTCH LONG-TERM CARE REFORM}

In order to put the reform of a nation's long-term care system into the right perspective, it is worth considering the traditional, pre-reform, characteristics of that system first. This is because a nation's institutional and policy traditions, in which its long-term care system is embedded, will influence the outcomes of any changes to that system.

The basis of the Dutch long-term care system was laid in 1968, when the Exceptional Medical Expenses Act was introduced (in Dutch: 'Algemene Wet Bijzondere Ziektekosten', AWBZ). The AWBZ was a statutory scheme of public long-term care insurance. As such, it was open-ended in nature, ensuring eligibility to every inhabitant of the Netherlands (Mot, 2010). Nevertheless, the AWBZ scheme has been adapted substantially throughout the years, in order to control costs (examples include changes in 
tariffs, co-payments and the width of the insured package) and to respond to new societal trends. Although initially being focused on residential care (notably nursing and disability care), the AWBZ scheme was extended throughout the years to include other types of care, such as home care, domestic care and psychiatric care. Moreover, in 1995 the 'personal budget' was introduced, offering the ability for beneficiaries to choose between either care in kind, or cash payments allowing for the private purchase of care. Later on, with the introduction of 'care-severity packages' (intended to categorize the provision of care into a needs-based manner), the focus of the AWBZ further evolved from being mainly supply-driven to demand-driven, implying a more flexible provision of care tailored to the specific needs of patients instead of provision of a fixed care package.

Despite such -still relatively moderate- policy changes, the first major reform of the Dutch long-term care system was realised in 2007, with the introduction of the Social Support Act (in Dutch: 'Wet maatschappelijke ondersteuning', Wmo). With the advent of the Wmo, domestic help was transferred from the AWBZ to this new Act. In contrast to the AWBZ, the Wmo is no insurance scheme, but a tax-based scheme. Thus, entitlements under the Wmo are largely influenced by the available funds. Moreover, the Wmo is not executed by the care administration offices under responsibility of the national government (as in the case of the AWBZ), but by the municipalities, which thus have relatively substantial policy discretion regarding the way they execute their responsibilities under the Wmo. Until 2015, the Dutch long-term care system was mainly divided between the AWBZ and the Wmo, whereby the former covered about 95 per cent of public long-term care expenses, and the Wmo the remaining 5 per cent (Maarse \& Jeurissen, 2016).

Under the recent 2015 Dutch long-term care reform, a large amount of long-term care responsibilities were transferred from the AWBZ to the Wmo and the Health Insurance Act (in Dutch: 'Zorgverzekeringswet', Zvw), while the remaining responsibilities under the AWBZ were replaced by the new Chronic Care Act (in Dutch: 'Wet langdurige zorg', WIz). These remaining responsibilities under the 'new AWBZ' are directed towards residential care for the most severe cases, thereby more or less going back to square one of the original AWBZ of the 1960s. As such, the 2015 reform can probably be considered as the most drastic reshuffling of the Dutch long-term care system.

Various efforts have been made to describe national long-term care systems in an internationally comparative way. At the same time, making international comparisons between long-term care sectors of different countries often proves to be difficult in practice, as a result of an apparent lack of reliable and comparative data due to exactly the unique character of a nation's long-term care sector (Genet et al., 2011; Carrera et al., 2013). Within the Assessing Needs of Care in European Nations (ANCIEN) project, attempts have been made to overcome part of this important research challenge by developing a new typology of long-term care systems in Europe. In fact, the ANCIEN project applies two different typologies: one typology focuses on the organisation and 
financing of long-term care systems, while the other typology focuses on the use and financing of long-term care (Kraus et al., 2011). In the first typology, the ANCIEN project classifies the Netherlands, Belgium and Germany under the same heading of long-term care systems as 'highly developed systems and quite generous public funding'. In the second typology, the ANCIEN project classifies the Netherlands under the cluster of countries with 'generous, accessible and formalised' long-term care systems (characterized by high public spending on long-term care (as a percentage of GDP), low private spending and a low use of informal care despite high support for informal care givers). In the same typology, Germany and Belgium are classified under the cluster of countries characterized as 'informal care oriented, low private financing' long-term care systems (low public spending on long-term care (as a percentage of GDP), low private spending, high use of informal care, as well as high support for informal care givers). Next to these two clusters, the ANCIEN typology applies two more clusters, both mainly informal care oriented, but with a difference in the degree of private financing and the underlying reasoning for the informal care provision. In line with the foregoing, although in more general terms, Pavolini \& Ranci (2008) make the distinction between 'service-led models' of long-term care on the one hand (mainly applying to the Netherlands, with a change towards a more mixed model due to the above mentioned reforms) and informal care-led models of long-term care (applying amongst others to Germany; no reference is made about Belgium in their study).

One can relate the above typologies to the more commonly used typologies of healthcare systems in general, comprising the Scandinavian model, the Continental model and the Mediterranean model (Kraus et al., 2010). Under those typologies, the Netherlands is generally classified under the Scandinavian model (or 'public model of care'), which is defined by the attribution of primary responsibility to the public sector for persons in need of care. Indeed, the underlying philosophy of the Dutch long-term care system (and indeed, the country's care system in general) is that the state bears responsibility for citizens in need of care. While informal care provision does play a role in the Dutch long-term care system, there are no legal obligations to provide such care. The general policy goal for long-term care has been formulated as follows: "To ensure that for persons with a long-term or chronic disorder of a physical, intellectual or psychological nature, care of good quality is available and that the cost level of this care is acceptable to society" (Mot, 2010). As such, the Scandinavian model is comparable to Pavolini \& Ranci's 'service-led model', as well as to the ANCIEN's cluster of 'generous, accessible and formalised' long-term care systems'. The other two models (Continental and Mediterranean) both share similarities with Pavolini \& Ranci's 'informal care-led model', as well as with the ANCIEN's informal care oriented clusters. An important difference, however, is that in the Continental model (or 'mixed model of care') to which Germany and Belgium are generally classified, the family is generally considered the preferred caring unit, although persons with more serious health problems have a legal entitlement to public services. In the Mediterranean model (or 'family model of care'), 
informal care provision is much more a necessity, due to the lack of sufficient formal care services. Moreover, in some of the countries classified under this model the family even has a legal duty to support relatives.

\section{AIMS OF THE STUDIES IN THIS DISSERTATION}

There are many studies that examine long-term care reforms (e.g.: Maarse \& Jeurissen, 2016; Gabriele \& Tediosi, 2014; Larkin et al., 2014; Chevreul \& Berg Brigham, 2013; Simou \& Koutsogeorgou, 2014), sometimes in an internationally comparative way (e.g.: Fernandez, Gori \& Wittenberg, 2015; Ranci \& Pavolini, 2013). Moreover, Ranci \& Pavolini (2015) remind us that reforms are often studied as "punctual events that are able to create discontinuity, marking a clear difference between before and after the reform". Such an approach assumes some kind of consistency and coherence in the change process. In practice, however, reforms often appear to be inconsistent in nature (Ranci \& Pavolini, 2015). Indeed, during its path, reforms often -due to political, societal, or economic factors- appear to be slowed down or accelerated, altered to a greater or lesser extent, fed with new normative discussions, or reversed altogether. There appears to be a gap in academic research regarding the complexities within the process of long-term care reforms.

The current study attempts to fill in part of this gap, by analysing an ongoing reform, by examining both the period leading up to the reform (in the aftermath of the economic crisis) and its first year of being into force. As such, the study provides a first insight of a recent reform, as it accompanied the reform process. As an overarching research aim, the studies in this dissertation examine to what extent the intended results of the recent Dutch long-term care reform have been achieved anno 2016. More specifically, this means addressing the following research questions:

1. How can the effectiveness of interventions aimed at promoting social participation of older people be properly evaluated?

2. What has been the influence of the recent economic crisis on the quality of longterm care for older people in Belgium and the Netherlands?

3. To what extent were Dutch municipalities prepared for the challenges resulting from their new responsibilities under the new long-term care reform?

4. Following the recent reforms, to what extent do the long-term care provisions in the Netherlands and Belgium meet European quality principles for long-term care?

5. To what extent did/do municipalities in the Netherlands take potential moral conflicts into account when implementing and executing the Social Support Act 2015? 


\section{APPROACH AND METHODS}

Based on the Oxford Dictionary a 'reform' implies that changes are made in something (especially an institution or practice) in order to improve it (Oxford Dictionaries, 2016). In other words, a reform foresees an improvement with regard to the status quo. However, this definition does not reveal anything about the extent of the change process. Hall's work on policy change provides a framework for understanding the extent of policy change by distinguishing three different levels of change: first-order policy changes (implying routine adjustments to existing policies), second-order policy changes (implying changes in the policy instruments used to achieve shared goals), and thirdorder policy changes (implying shifts in the goals themselves) (Baumgartner, 2012; Hall, 1993).

Whether a government issues first-, second- or third-order policy changes regarding its long-term care sector largely depends on the nature of the pressures underlying these changes. In general, three categories of explanatory factors for changes in countries' long-term care policies can be distinguished (Ranci \& Pavolini, 2015; Carrera et al., 2013):

Socio-demographic pressures: Available data clearly show a demography of progressive ageing, as well as double ageing, in most European countries. Where ageing generally refers to the growth of the share of people aged $65+$ in a population, double ageing refers here to the process wherein not only the share of people aged $65+$ in a population grows, but also the share of people aged $80+$ among those aged 65+. Such developments have a huge influence on countries' old-age dependency ratios.

- Financial pressures: An ageing society is likely to have a large impact on countries' healthcare, social care and pension systems. Indeed, Ranci \& Pavolini (2008) remind us that being "[f]aced with the challenges of an ageing society, many European countries have adopted innovative policies in order to find a balance between increasing care demands and curb public spending". At the same time, one can argue that not only structural developments such as ageing can lead to financial pressures, but also more abrupt short-term developments such as economic downturns.

- Socio-cultural pressures: This latter category relates to changing ways of thinking about care. This can entail new ways of thinking about, for example, the role of informal caregiving, the position of long-term care within the broader care system, but also about care in general. Indeed, more recently, the idea of 'positive health' as developed by Huber et al. (2011) is gaining importance. The concept of positive health considers health as "the ability to adapt and to self manage" (ibid.) instead of considering it under the traditional WHO definition as "a state of complete physical, mental and social well-being and not merely the absence of disease or infirmity" (WHO, 2006). The earlier work of Commers (2002) would 
seem to imply that the Huber definition of positive health is probably more appropriate within the context of Northern Europe, and the Netherlands in particular. As such, the concept of positive health is contributing to the ethical debate on whether we should only look at people's deficits or also to their capacities (Huber et al., 2011).

Other studies have considered to what results such policies changes or reforms actually lead, whether intended or unintended results. Also the results of policy changes or reforms can be categorized into key, overarching categories (Pavolini \& Ranci, 2008; Ranci \& Pavolini, 2015):

- Macro-institutional results: Results on the macro-level relate to changes in, for example, a country's overall long-term care coverage level, the overall expenses on long-term care provision, the overall allocation of resources within the longterm care sector as well as between the long-term care sector and other welfare policy fields, and the equitable access of citizens to long-term care provision.

- Meso-institutional results: Meso-level changes include, amongst others, the introduction of a split between financing and providing functions that has been the case in several countries, a growing range of service providers as a result of the introduction or reinforcement of market conditions in the long-term care sector, and changing working conditions in the long-term care sector.

- Micro-individual results: In the case of micro-individual results one can think of the impact of policy changes or reforms on individual person's access to longterm care, own financial contributions for long-term care, people's rights with regard to long-term care provision (such as the effectuation of persons' freedom of choice), the provision of informal care, and changing family situations as a result of informal care provision (e.g. the dilemma on how to reconcile work with the care for your children and the care for your dependent parent).

Carrera et al. (2013) point to a partial convergence of European countries' long-term care systems over the last two decades, implying that "while the universalist regimes [regimes with relatively high coverage levels (Ranci \& Pavolini, 2015)] have reduced the extension and generosity of their care systems, most of the residual care regimes [regimes with relatively low coverage levels (ibid.)] have expanded entitlements and public expenditures" (Ranci \& Pavolini, 2013). On the overall European level, then, one can witness a trend of increasing (or maintaining) entitlements to long-term care provision, coincided by a trend of decreases in actual long-term care service provision as a result of governments' retrenchment agendas. Ranci \& Pavolini captured this paradox under the heading of 'restricted universalism': "all people in need are explicitly entitled to access the same LTC services, but with a range of restrictions in the provision, quality or access to services" (Ranci \& Pavolini, 2015).

Despite the theoretical strength of the above-mentioned approaches, in practice it often proves problematic to examine long-term care reforms along such general terms, 
due to the existence of various typologies of long-term care systems, as well as to the inconsistent nature of reform paths.

Therefore, arguably more interesting than considering the Dutch long-term care reform in terms of general types of explanatory factors (the reform's 'input'), or in terms of general types of impact (the reform's 'outcome') is to examine the complexity of the reform process itself. As such, the studies in this dissertation provide accompanying analyses of the recent Dutch long-term care reform, thereby encompassing various aspects of this reform and applying these to its most prominent executers (being local governments and long-term care providers). A limited cross-border perspective/approach will be applied in several of the studies. The fact that the recent reform had created a new and unique context in which the accompanying analysis of this study was conducted, asked for an exploratory research approach: the specific conceptual models that were adhered to in this study, had not previously been applied to evaluate the impact of the recent Dutch long-term care reform. The conceptual models (as well as variations or combinations of these models) applied in conducting the studies, comprise the 'system readiness for innovation' model (Greenhalgh et al, 2004), Donabedian's (1988) quality of care model, the 'European quality framework for long-term care services' (European Partnership for the Wellbeing and Dignity of Older People, 2012), a 'principled public health ethics model' (Schröder-Bäck et al., 2009), and a 'capacity assessment model' (UNDP, 2008a; UNDP, 2008b; Aluttis, 2014; NSW, 2001).

\section{STRUCTURE OF THIS DISSERTATION}

Following this first chapter referred to as 'Introduction to this dissertation', Chapter 2 considers, as a prelude to the rest of the dissertation, the concept of social participation of older people, a concept that constitutes one of the core themes of the 2015 Dutch long-term care reform.

Chapter 3 examines the influence of the recent 2007/2008 economic crisis on the quality of long-term care for older people in Belgium and the Netherlands. For the study in Chapter 3, a qualitative (multiple case study) research design was applied, consisting of semi-structured qualitative interviews, supported by quantitative elements.

Chapter 4 examines the preparedness of Dutch municipalities for the challenges resulting from their new responsibilities under the 2015 long-term care decentralization. This chapter also gives a more detailed description of the different Dutch long-term care acts, both pre- and post-2015, as well as of the context of the recent changes (the latter also holds for chapters 5 and 6). For the study in Chapter 4, a qualitative research design was applied, consisting of semi-structured qualitative interviews.

Chapter 5 explores the quality of long-term care provision for older people in Belgium and the Netherlands following the recent long-term care policy changes in both 
countries. Also for the study in Chapter 5, a qualitative research design was applied, consisting of semi-structured qualitative interviews.

Chapter 6 explores the extent to which municipalities in the Netherlands have taken ethical dilemmas into account when implementing and executing the new social support policies that have resulted from the 2015 decentralization.

As such, chapters 3 and 4 are connected, in the sense that they both consider the pre-2015 period. The same holds for chapters 5 and 6 , that both consider the post-2015 period, following the formal entry into force of the new, above-mentioned, long-term care acts (the '2015 long-term care reform'). In the same vein, chapters 3 and 5 are connected in being primarily focused on the perspective of healthcare organizations, as well as chapters 4 and 6 , which both focus on the perspective of Dutch municipalities. For the study in Chapter 6, a mixed-method research design was applied, consisting of a document analysis, an online survey with open-ended questions and in-depth semistructured interviews.

Chapter 7 can be considered a case study, considering how cross-border cooperation initiatives can contribute to public health policy making in an individual country. In doing so, dementia care -being a key priority policy theme of the Dutch governmenthas been chosen as a case study. Also for the study in Chapter 7, a mixed-method research design was applied, consisting of an online survey with closed-end questions, and in-depth semi-structured interviews.

Finally, in Chapter 8 referred to as 'Discussion of this dissertation', we discuss the general findings of this dissertation, including an emphasis on strengths and limitations, which should foster and guide future research, and also provide recommendations for decision-makers in long-term care organizations, as well as policymakers of the longterm care sector, in both the Netherlands and other European countries. 


\section{REFERENCES}

Aluttis, C., Van den Broucke, S., Chiotan, C., Costongs, C., Michelsen, K., \& Brand, H. (2014). Public health and health promotion capacity at national and regional level: a review of conceptual frameworks. Journal of Public Health Research, 3(1): 37-42. doi:10.4081/jphr.2014.199

Baumgartner, F. R. (2012). Ideas and Policy Change. Governance: An International Journal of Policy, Administration, and Institution, 26(2): 239-258. doi:10.1111/gove.12007

Carrera, F., Pavolini, E., Ranci, C., \& Sabbatini, A. (2013). Long-Term Care Systems in Comparative Perspective: Care Needs, Informal and Formal Coverage, and Social Impacts in European Countries. In C. Ranci \& E. Pavolini (Eds.), Reforms in Long-Term Care Policies in Europe: Investigating Institutional Change and Social Impacts (pp. 23-52). New York: Springer-Verlag.

Chevreul, K., \& Berg Brigham, K. (2013). Financing long-term care for frail elderly in France: the ghost reform. Health Policy, 111(3): 213-220. doi:10.1016/j.healthpol.2013.05.013

Commers, M. J. (2002). Determinants of Health: Theory, Understanding, Portrayal, Policy. Dordrecht: Kluwer Academic Publishers.

Donabedian, A. (1988). The Quality of Care: How Can It Be Assessed? The Journal of the American Medical Association, 260(12): 1743-1748. doi:10.1001/jama.1988.03410120089033

European Partnership for the Wellbeing and Dignity of Older People. (2012). European Quality Framework for Long-term Care Services. Brussels: Age Platform Europe.

Fernandez, J.-L., Gori, C., \& Wittenberg, R., eds. (2015). Long-Term Care Reforms in OECD Countries. Bristol: Policy Press.

Gabriele, S., \& Tediosi, F. (2014). Intergovernmental relations and Long Term Care reforms: lessons from the Italian case. Health Policy, 116(1): 61-70. doi:10.1016/j.healthpol.2014.01.005

Genet, N., Boerma, W. G., Kringos, D. S., Bouman, A., Francke, A. L., Fagerström, C., Melchiorre, M. G., Greco, C., \& Devillé, W. (2011). Home Care in Europe: A Systematic Literature Review. BMC Health Services Research, 11(207). doi:10.1186/1472-6963-11-207

Greenhalgh, T., Robert, G., Macfarlane, F., Bate, P., \& Kyriakidou, O. (2004). Diffusion of Innovations in Service Organizations: Systematic Review and Recommendations. The Milbank Quarterly, 82(4): 581-629. doi:10.1111/j.0887-378X.2004.00325.x

Hall, P. A. (1993). Policy Paradigms, Social Learning, and the State: The Case of Economic Policymaking in Britain. Comparative Politics, 25(3): 275-296. doi:10.2307/422246

Huber, M., Knottnerus, J. A., Green, L., van der Horst, H., Jadad, A. R., Kromhout, D., Leonard, B., Lorig, K., Loureiro, M. I., van der Meer, J. W., Schnabel, P., Smith, R., van Weel, C., \& Smid, H. (2011). How should we define health? BMJ, 343(d4163). doi:10.1136/bmj.d4163

Kraus, M., Riedel, M., Mot, E., Willemé, P., Röhrling, G., \& Czypionka, T. (2010). A Typology of Long-Term Care Systems in Europe. Brussels: Centre for European Policy Studies.

Kraus, M., Czypionka, T., Riedel, M., Mot, E., \& Willemé, P. (2011). How European Nations Care for Their Elderly: A New Typology of Long-Term Care Systems. Brussels: Centre for European Policy Studies.

Larkin, D. J., Swanson, R. C., Fuller, S., \& Cortese, D. A. (2014). The Affordable Care Act : a case study for understanding and applying complexity concepts to health care reform. Journal of Evaluation in Clinical Practice, 22(1): 133-140. doi:10.1111/jep.12271

Maarse, J. A. M., \& Jeurissen, P. P. (2016). The policy and politics of the 2015 long-term care reform in the Netherlands. Health Policy, 120(3): 241-245. doi:10.1016/j.healthpol.2016.01.014

Maarse, H., Jeurissen, P., \& Ruwaard, D. (2016), Results of the market-oriented reform in the Netherlands: a review. Health Economics, Policy and Law, 11(2): 161-178. doi:10.1017/S1744133115000353

Mot, E. (2010). The Dutch system of long-term care. Brussels: Centre for European Policy Studies.

NSW Health. (2001). A framework for building capacity to improve health. Sydney: NSW Health Department.

Oxford Dictionaries. (2016). Oxford Dictionary of English. Retrieved from http://www.oxforddictionaries.com/ definition/english/reform (accessed September 5, 2016). 
Pavolini, E., \& Ranci, C. (2008). Restructuring the welfare state: reforms in long-term care in Western European countries. Journal of European Social Policy, 18(3): 246-259. doi:10.1177/0958928708091058

Ranci, C., \& Pavolini, E., eds. (2013). Reforms in Long-Term Care Policies in Europe: Investigating Institutional Change and Social Impacts. New York: Springer-Verlag.

Ranci, C., \& Pavolini, E. (2015). Not all that glitters is gold: Long-term care reforms in the last two decades in Europe. Journal of European Social Policy, 25(3): 270-285. doi:10.1177/0958928715588704

Simou, E., \& Koutsogeorgou, E. (2014). Effects of the economic crisis on health and healthcare in Greece in the literature from 2009 to 2013: a systematic review. Health Policy, 115(2-3): 111-119. doi: 10.1016/j.healthpol.2014.02.002

Schröder-Bäck, P., Brand, H., Escamilla, I., Davies, J. K., Hall, C., Hickey, K., Jelastopulu, E., Mechtler, R., \& Volf, J. (2009). Ethical evaluation of compulsory measles immunisation as a benchmark for good health management in the European Union. Central European Journal of Public Health, 17(4): 183-186.

UNDP. (2008a). Capacity Assessment practice note. New York: United Nations Development Programme.

UNDP. (2008b). Capacity Development practice note. New York: United Nations Development Programme.

World Health Organization (WHO). (2006). Constitution of the World Health Organization. Retrieved from http://www.who.int/governance/eb/who_constitution_en.pdf (accessed April 4, 2016). 



\section{Evaluating interventions aimed at promoting social participation of older people: a review of the literature}

Jongen, W., Schröder-Bäck, P., \& Brand, H. (2013). Evaluating interventions aimed at promoting social participation of older people: A review of the literature. Albanian Medical Journal, 1, 55-61. 


\section{ABSTRACT}

As a reaction to the growing amount of academic literature on the relationship between social participation and health outcomes such as quality of life, this article intends to explain how the effectiveness of interventions aimed at promoting social participation of older people can be evaluated, in order to identify good practices which are relevant for Europe. In doing so, this article assumes a positive relationship between social participation and the health of older people. Following a model for evaluating evidence on the effectiveness of health promotion interventions, this article analyses three systematic reviews for answering the above-mentioned research question. In general, group interventions with a strong interactive character, having an educational input or offering social support, targeted at specific groups of older people and including the older people in the development and implementation of the interventions, were considered as the most effective type of interventions. The systematic reviews analysed in this article, however, suffer from several serious weaknesses, concerning credibility of the research itself, completeness of the evaluated intervention outcomes, and transferability of the research evidence. Future research should be directed to more specific types of interventions promoting social participation and specifically to European interventions.

Keywords: older people, quality of life, social participation. 


\section{INTRODUCTION}

Public health interventions in Europe focused on health promotion for older people are often based on the WHO principle of active ageing, defined as "the process of optimizing opportunities for health, participation and security in order to enhance quality of life as people age" [1]. In this way, the adjective 'active' does not merely relate to being physically active, or being active in terms of employment, but also-and perhaps foremost when taking into account the often inevitable physical impairment and retirement of older people-in terms of social participation. During the last decade, academic literature on social participation of older people seems to point in the direction of a positive relationship with a variety of health outcomes like quality of life and wellbeing $[2,3,4]$.

An example of the way the EU has put social participation of older people on the agenda, was by declaring 2012 as the European Year for Active Ageing and Solidarity between Generations. The European Year aims to urge policymakers and other relevant stakeholders, like public health professionals, to take action aimed at promoting active ageing in three domains: social participation, employment and independent living.

In this article we intend to answer the following research question: "How can the effectiveness of interventions aimed at promoting social participation of older people be properly evaluated, in order to identify good practices which are relevant for Europe?" In doing so, we propose an approach for evaluating evidence on public health interventions. Interventions aimed at promoting social participation amongst older people are captured here under this broad heading of public health interventions, because social participation is considered in this article as a way of promoting health or preventing ill health in communities or populations-hereby following the definition of public health interventions as proposed by Rychetnik et al. [5]. The results of three systematic reviews will be compared on the basis of this approach. Finally, we will discuss whether the current scientific literature provides us with sufficient evidence for the potential identification of good practices relevant for Europe.

\section{METHODS}

Although in general the academic literature shows an increasing interest in the concept of social participation of older people, there is no consensus in the literature about the exact definition of the concept. Interestingly however, a study conducted by Levasseur et al. which aims at systematically reviewing definitions of social participation specifically targets older people. This study revealed that most of the forty-three definitions it considered are centred around the explicit notion of interaction between the respective individual and others in society, instead of mere participation in activities or being amongst others [6]. 
Next, in the introduction of this article, a positive relationship between social participation and health was assumed. At the same time, however, a growing part of the academic literature actually contests this relationship [2]. But, only few studies appear to have examined the specific influence of sex and age on the relationship between social participation and health. A striking example is the survey conducted in South Korea by Lee et al., whose results show that the effect of social participation on selfrated health rises as age advances. As the same survey shows a negative relationship between the degree of social participation and age-due to developments typically related to age, such as physical impairments, retirement or the loss of relatives -it urges social participation to be a basic consideration in health promotion strategies for older people [3]. These findings are similar to those found for the European region, in a study conducted by Sirven \& Debrand [2]. Defining this relationship into more detail would be beyond the scope of this article. It suffices here to state that good indications exist within the academic literature for the existence of a positive relationship between social participation and health status of older people.

When turning to interventions aimed at promoting social participation amongst older people, social participation as such does not seem to be an easy target for policy makers and public health professionals. Instead, many existing health promotion interventions geared at increasing social participation of older people do so within the context of preventing social isolation [7]. In this way, social participation activities are regarded as indicators "promoting good health by protecting against the negative effects associated with social isolation" [8]. Simultaneously, the bulk of evaluative literature considers interventions aimed at reducing social isolation, instead of improving social participation [9]. It is exactly for this reason that this article deals with systematic reviews of interventions aimed at reducing social isolation. These systematic reviews were chosen for the obvious reason that these were the only three systematic reviews that were found in the literature, following a simple PubMed search strategy. For analyzing the systematic reviews, we applied an approach for evaluating evidence on the effectiveness of public health interventions based on the work by Rychetnik et al. [5]. According to this approach, a critical appraisal of what constitutes best evidence in evaluative research generally focuses on three key considerations. First, one should consider whether the credibility of the evaluative research itself is sufficient in order to allow for sound evidence-based decisions on public health interventions. Next, the completeness of the evaluated intervention outcomes should be critically appraised. Finally, one should consider whether the research evidence is transferable.

\section{RESULTS}

In the remainder of this article, the three systematic reviews that are applied will be labelled A [10], B [11] and C [12], in the order of publication. Using three systematic 
reviews allows for interesting insights in the weaknesses of each review, and the added value of each consecutive review. Table 1 provides a, precise and literal, overview of the characteristics of the three systematic reviews.

Table 1. Characteristics of selected systematic reviews.

\begin{tabular}{|c|c|c|c|}
\hline & Systematic review A [10] & Systematic review B [11] & Systematic review C [12] \\
\hline \multicolumn{4}{|c|}{ Characteristics of systematic reviews themselves } \\
\hline Year of publication & 2003 & 2005 & 2011 \\
\hline Country of publication & United Kingdom & United Kingdom & United Kingdom \\
\hline Inclusion criteria & $\begin{array}{l}\text { Included studies that: } \\
\text { - "related to older people"; } \\
\text { - "considered interventions } \\
\text { targeting social isolation } \\
\text { and/or loneliness"; } \\
\text { - "described interventions } \\
\text { intended to achieve } \\
\text { health gain"; } \\
\text { - "recorded outcome } \\
\text { measures"; } \\
\text { - "were published in } \\
\text { English"; } \\
\text { - "were published between } \\
\text { 1982 and 2002". }\end{array}$ & $\begin{array}{l}\text { Included studies that: } \\
\text { - "related in full or in part } \\
\text { to older people"; } \\
\text { - "considered } \\
\text { interventions that were } \\
\text { intended to prevent or } \\
\text { alleviate social isolation } \\
\text { and/or loneliness in full } \\
\text { or in part"; } \\
\text { - "described health- } \\
\text { promoting interventions } \\
\text { that enabled older } \\
\text { people to increase } \\
\text { control over and to } \\
\text { improve their health"; } \\
\text { - "recorded some form of } \\
\text { outcome measures with } \\
\text { or without process } \\
\text { measures". }\end{array}$ & $\begin{array}{l}\text { Included studies that: } \\
\text { - "related in full/part to } \\
\text { older people"; } \\
\text { - "considered } \\
\text { interventions that } \\
\text { targeted people } \\
\text { identified as socially } \\
\text { isolated and/or lonely, } \\
\text { and stated a clear and } \\
\text { plausible aim to } \\
\text { alleviate this"; } \\
\text { - "recorded some form } \\
\text { of participant-level } \\
\text { outcome measure, } \\
\text { and reported sufficient } \\
\text { outcome data for } \\
\text { treatment effects to } \\
\text { be obtained"; } \\
\text { - "used a RCT or quasi- } \\
\text { experimental design } \\
\text { and included an } \\
\text { inactive control } \\
\text { group"; } \\
\text { - "were published in } \\
\text { English". }\end{array}$ \\
\hline \multicolumn{4}{|c|}{ Characteristics of studies included } \\
\hline $\begin{array}{l}\text { Number of studies } \\
\text { included }\end{array}$ & 17 & 30 & 32 \\
\hline Years of publication & $1982-2002$ & 1970-2002 & 1976-2009 \\
\hline $\begin{array}{l}\text { Countries were studies } \\
\text { were conducted }\end{array}$ & $\begin{array}{l}\text { USA (8) } \\
\text { Australia (3) } \\
\text { Canada (2) } \\
\text { The Netherlands (2) } \\
\text { Italy (1) } \\
\text { Sweden (1) }\end{array}$ & $\begin{array}{l}\text { USA (17) } \\
\text { Canada (3) } \\
\text { The Netherlands (3) } \\
\text { Sweden (2) } \\
\text { United Kingdom (2) } \\
\text { Denmark (2) } \\
\text { Germany (1) }\end{array}$ & $\begin{array}{l}\text { USA (17) } \\
\text { The Netherlands (6) } \\
\text { Canada (3) } \\
\text { Japan (2) } \\
\text { Sweden (2) } \\
\text { Finland (2) }\end{array}$ \\
\hline
\end{tabular}




\begin{tabular}{|c|c|c|c|}
\hline & Systematic review A [10] & Systematic review B [11] & Systematic review C [12] \\
\hline Study designs & $\begin{array}{l}\text { Randomized controlled } \\
\text { trials (6) } \\
\text { Quasi-experimental studies } \\
\text { (3) } \\
\text { Non-randomized post- } \\
\text { treatment/test survey (3) } \\
\text { Pre-post intervention } \\
\text { studies (2) } \\
\text { Cross-sectional survey (1) } \\
\text { Observational study (1) } \\
\text { Non-randomized matched } \\
\text { control trial (1) }\end{array}$ & $\begin{array}{l}\text { Randomized controlled } \\
\text { trials (16) } \\
\text { Non-randomised } \\
\text { controlled trials (10) } \\
\text { Other (4) }\end{array}$ & $\begin{array}{l}\text { Randomized controlled } \\
\text { trials (16) } \\
\text { Quasi-experimental } \\
\text { studies (16) }\end{array}$ \\
\hline Types of interventions & $\begin{array}{l}\text { Group interventions (6) } \\
\text { One-to-one interventions } \\
(5) \\
\text { Internet usage (4) } \\
\text { Service provision (2) }\end{array}$ & $\begin{array}{l}\text { Group interventions (17) } \\
\text { One-to-one interventions } \\
\text { (10) } \\
\text { Service provision (3) }\end{array}$ & $\begin{array}{l}\text { Group interventions (19) } \\
\text { One-to-one } \\
\text { interventions (11) } \\
\text { Service provision (1) } \\
\text { Mixed mode (1) }\end{array}$ \\
\hline
\end{tabular}

Generalizing from the three systematic reviews, it can be said that there is agreement within the available literature on the characteristics contributing to effective health promotion interventions aimed at reducing social isolation among older people. Interventions regarded as most effective were in the first place group interventions, that is, interventions with a strong interactive character between the participants and offered outside people's own houses. Within this category, especially interventions with a clear educational character or those offering social support, appeared to be effective. Examples for the former include discussion groups dealing with health-related issues or physical activity groups, while the latter typically refers to discussion groups with a more therapeutic character. Secondly, effective interventions appear to be focused on specific groups of older people, like those that have physical impairments, male or female, those with a cognitive impairment, those that have already lost their spouse etc. Thirdly, effective appear to be those interventions that allow the older people themselves to participate in the development and implementation phases of the interventions themselves, especially those older people that have a caring attitude towards others. Least effective appear to be one-to-one interventions, offered at people's own houses, like home-visiting and home nursing care arrangements. At the same time, this same literature agrees as well on the fact that although the interventions included in the systematic reviews may contain some of these characteristics, none of them seem to comprise all of these characteristics.

After having elaborated on the results of each of the systematic reviews, their evidence can now be evaluated, hereby following the model as outlined in the previous section of this article. Concerning credibility of the research, the three systematic reviews show large similarities. Firstly, in terms of their study design, being systematic reviews primarily based on RCTs, each could be referred to as approaching top level in the so-called evidence hierarchy. Secondly, regarding methodological flaws of the re- 
search, each of the reviews suffers from a bias towards studies published in English, (too) broad inclusion criteria, high degrees of heterogeneity among the included studies, and a limited number of high quality studies. Regarding the completeness of the interventions in the evaluated studies, striking is that only review $\mathrm{C}$ explicitly reports on health outcomes, while the other two reviews only report on health outcomes in an indirect way. On the one hand this is peculiar, as each of the reviews embraced the existence of a positive relationship between reducing social isolation and positive health outcomes. On the other hand, one could argue that this indirect reporting is obvious, as the prime outcome measure of each of the reviews is clearly stated as 'reducing social isolation'. Next, none of the systematic reviews reported in any meaningful way on the cost-effectiveness of the interventions they evaluated. Interestingly, the importance of sophisticated knowledge on the cost-effectiveness of such interventions is though widely recommended by the reviews. Finally, applicability and transferability of the research evidence seems to be of particular interest if one seeks to identify good practices for the European region. Information on applicability can only be extracted from review $B$. In review $C$, applicability appears to be captured together with transferability under the heading of generalizability. Review A does not discuss both terms at all. Nonetheless, a more detailed discussion about applicability would be desirable, as it would provide us with more detailed information on the settings of the intervention processes. Perhaps as a result of this flaw, transferability is generally considered insufficiently proven by the systematic reviews themselves, their own main argumentation being that the majority of studies were conducted in the United States of America. A more detailed overview of the above findings is provided in Table 2.

Table 2. Evaluation of evidence of selected systematic reviews.

\begin{tabular}{llll}
\hline & Systematic review A [10] & Systematic review B [11] & Systematic review C [12] \\
\hline $\begin{array}{llll}\text { Credibility of research } \\
\text { Study design }\end{array}$ & & \\
& Systematic review, based & Systematic review, based to & Systematic review, based \\
to a large extent on RCTs & a large extent on RCTs & to a large extent on RCTs \\
& $(6 / 17)$. & $(16 / 30)$. & $(16 / 32)$. \\
Methodological problems & - Limited number of & - High degree of & - High degree of \\
& interventions evaluated. & heterogeneity among & heterogeneity among \\
& - Bias towards studies & evaluated interventions. & evaluated \\
& published in English. & - Limited number of high & interventions. \\
& - Broad inclusion criteria. & quality studies. & - Limited number of high \\
& - Bias towards studies & quality studies. \\
& published in English, & - Bias towards studies \\
& despite the fact that the & published in English. \\
& English language was not & - Broad inclusion criteria. \\
& an inclusion criterion in & \\
& this review. & \\
& - Broad inclusion criteria. & \\
& &
\end{tabular}




\begin{tabular}{|c|c|c|c|}
\hline & Systematic review A [10] & Systematic review B [11] & Systematic review C [12] \\
\hline \multicolumn{4}{|c|}{ Completeness of intervention outcomes } \\
\hline $\begin{array}{l}\text { Information as required } \\
\text { by stakeholders }\end{array}$ & $\begin{array}{l}\text { - Only indirect reporting } \\
\text { on health outcomes. } \\
\text { - Recognition of limited } \\
\text { value of results overall, } \\
\text { due to limited number } \\
\text { of studies included. }\end{array}$ & $\begin{array}{l}\text { Only indirect reporting on } \\
\text { health outcomes. }\end{array}$ & $\begin{array}{l}\text { Clear reporting on health } \\
\text { outcomes (social, mental } \\
\text { and physical health). }\end{array}$ \\
\hline Unanticipated results & $\begin{array}{l}\text { Rejection of the broadly } \\
\text { supported effectiveness } \\
\text { of health promotion } \\
\text { interventions aimed at } \\
\text { reducing social isolation } \\
\text { among older people. }\end{array}$ & $\begin{array}{l}\text { No information on } \\
\text { unanticipated results. }\end{array}$ & $\begin{array}{l}\text { No information on } \\
\text { unanticipated results. }\end{array}$ \\
\hline Cost-effectiveness & $\begin{array}{l}\text { - Reports on cost- } \\
\text { effectiveness of two of } \\
\text { the interventions. } \\
\text { - Recognizes that cost- } \\
\text { effectiveness analyses } \\
\text { should indeed be } \\
\text { performed before } \\
\text { interventions are } \\
\text { implemented. }\end{array}$ & $\begin{array}{l}\text { No information provided on } \\
\text { cost-effectiveness. }\end{array}$ & $\begin{array}{l}\text { - No information } \\
\text { provided on cost- } \\
\text { effectiveness. } \\
\text { - Argues that, despite } \\
\text { growing evidence- } \\
\text { based support for the } \\
\text { effectiveness of health } \\
\text { promotion } \\
\text { interventions aimed at } \\
\text { reducing social isolation } \\
\text { among older people, } \\
\text { the cost-effectiveness } \\
\text { of successful } \\
\text { interventions continues } \\
\text { to be under- } \\
\text { researched. }\end{array}$ \\
\hline \multicolumn{4}{|c|}{ Transferability of research evidence } \\
\hline Applicability & $\begin{array}{l}\text { - No detailed information } \\
\text { on setting of } \\
\text { intervention process. } \\
\text { - No discussion about } \\
\text { applicability. }\end{array}$ & $\begin{array}{l}\text { - Detailed information on } \\
\text { setting of intervention } \\
\text { process. } \\
\text { - For most studies, the } \\
\text { imprecise definition of } \\
\text { the term 'social isolation' } \\
\text { considered as a } \\
\text { hampering factor for } \\
\text { making decisive } \\
\text { conclusions about } \\
\text { applicability. } \\
\text { - When considering the } \\
\text { adequate description of } \\
\text { interventions' processes, } \\
\text { only six interventions are } \\
\text { regarded as applicable in } \\
\text { other settings, while } \\
\text { three are considered } \\
\text { applicable in comparable } \\
\text { health systems. }\end{array}$ & $\begin{array}{l}\text { - No detailed information } \\
\text { on setting of } \\
\text { intervention process. } \\
\text { - No discussion about } \\
\text { applicability. }\end{array}$ \\
\hline
\end{tabular}




\begin{tabular}{|c|c|c|c|}
\hline & Systematic review A [10] & Systematic review B [11] & Systematic review C [12] \\
\hline Transferability & $\begin{array}{l}\text { No information provided } \\
\text { on transferability. }\end{array}$ & $\begin{array}{l}\text { - Transferability regarded } \\
\text { as doubtful, as most } \\
\text { studies are conducted in } \\
\text { the United States. } \\
\text { - Transferability of some } \\
\text { applicable studies' } \\
\text { findings doubtful because } \\
\text { of uncertainty on } \\
\text { representativeness of } \\
\text { study sample (but, } \\
\text { representativeness } \\
\text { considered as sufficient } \\
\text { for all effective } \\
\text { interventions regarded as } \\
\text { sufficient). }\end{array}$ & $\begin{array}{l}\text { Transferability regarded } \\
\text { as doubtful, as most } \\
\text { studies were conducted } \\
\text { in the United States. }\end{array}$ \\
\hline
\end{tabular}

\section{DISCUSSION}

This article has attempted to contribute to the growing amount of literature on the effectiveness of health promotion interventions aimed at increasing social participation among older people. Social participation was considered in this regard as having a positive influence on the health status and quality of life of older people.

The strength of this article is probably foremost its reliance on three systematic reviews, which gave a comprehensive insight into the available evidence on the topic in question. Although each of the systematic reviews did not depend solely on RCTs, this does not necessarily constitute a weakness in the quality of the evidence. Indeed, the academic literature generally depicts studies that are not RCTs as having a high risk of bias. On the other hand, many authors agree that low quality RCTs might be of less value than high quality non-randomized controlled trials [13]. However, due to the high degree of heterogeneity of the evaluated interventions, as well as due to a generally low quality of the studies included, each of the systematic reviews admitted the existence of a high risk of bias. Another weakness of the systematic reviews was the inappropriate range of outcomes in light of the research question of this article. On the other hand, the relative lack of in depth information on health outcomes and costeffectiveness measures may constitute possibilities for future research. The latter is particularly true for research with a clearer focus on specific kinds of interventions. A final weakness in the systematic reviews was its predominant reliance on quantitative outcome studies for making judgments about applicability and transferability. As is proposed by Rychetnik et al., qualitative, or at least quantitative observational studies, may be required to bridge the gap between the research evidence on the one hand and the practice of a local setting on the other hand [5].

Apart from the above-mentioned methodological flaws in the applied systematic reviews as well as in the studies they included, this article itself suffers from the problem 
of reverse causality. For example, older people who have a bad health condition may not be able to engage in, or uphold their level of, social participation in the first place. A solution to this problem may be to draw more attention to longitudinal studies, instead of the current focus on cross-sectional studies. A second limitation stems from the fact that the available evaluative research studies on health promotion interventions primarily deal with the concept of reducing social isolation instead of increasing social participation.

Nonetheless, this observation of a gap in the available research provides opportunities for future research. It may be interesting to step aside from research that encompasses all of these more general intervention categories, like group interventions and one-to-one interventions, and instead conduct a more in depth evaluation of the category that was identified as the most effective. Moreover, taking into account the initial European focus of this article, the fact that each of the currently available systematic reviews primarily evaluated interventions conducted in North-America, and the transferability problems identified due to this latter point, further research could be specifically geared towards European interventions. However, one should also take into account that the availability of sufficient numbers of high quality studies on such interventions is limited in many European countries. Moreover, if case such studies exist, they are often not published in English. Such practical problems substantially hamper the possibility for conducting the preferred research. Therefore, one could instead consider conducting research on one specific European country, and/or on the category that was identified as the most effective.

In summary, this category can be described as group interventions with a strong interactive character, particularly those with an educational input or offering social support. Moreover, such interventions should be focused on a specific group of older people and give these older people the opportunity to participate not only in the activities as such, but also in the development and implementation of the interventions. Certainly, the increase of social participation of socially isolated older people does not occur overnight, nor will its effects on health status and quality of life manifest itself immediately. However, referring for example to the current European Year of Active Ageing and the various local initiatives attached to it, the topic is becoming already firmly established on the policy agenda. Especially for policy makers and health professionals it is of key importance to remember that increasing social participation of older people is a process, which cannot simply rely on one social activity once in a while.

\section{COMPETING INTERESTS}

The authors declare that they have no competing interests. 


\section{REFERENCES}

1. World Health Organization (2012). What is "active ageing"? URL: http://www.who.int/ageing/active_ ageing/en/index.html

2. Sirven $N$, Debrand $T$. Social participation and healthy ageing: an international comparison using SHARE data. Soc Sci Med 2008;67(12):2017-2026.

3. Lee HY, Jang SN, Lee S, Cho SI, Park EO. The relationship between social participation and self-rated health by sex and age: a cross-sectional survey. Int J Nurs Stud 2008;45(7):1042-1054.

4. Gilmour H. Social participation and the health and well-being of Canadian seniors. Ottawa: Statistics Canada; 2012.

5. Rychetnik L, Frommer M, Hawe $P$, Shiell A. Criteria for evaluating evidence on public health interventions. J Epidemiol Community Health 2002;56:119-127.

6. Levasseur M, Richard L, Gauvin L, Raymond E. Inventory and analysis of definitions of social participation found in the aging literature: proposed taxonomy of social activities. Soc Sci Med 2010;71(12):21412149.

7. European Commission. Social participation and social isolation. Brussels: Eurostat; 2010.

8. Kawachi I, Berkman L. Social cohesion, social capital, and health. In: Kawachi I, Berkman L. Social Epidemiology. New York: Oxford University Press; 2000. p. 175-190.

9. Cornwell EY, Waite $\amalg$. Measuring social isolation among older adults using multiple indicators from the NSHAP study. J Gerontol B Psychol Sci Soc Sci 2009;64:38-46.

10. Findlay RA. Interventions to reduce social isolation amongst older people: where is the evidence? Ageing Soc 2003;23(05):647-658.

11. Cattan $\mathrm{M}$, White $\mathrm{M}$, Bond J, Learmouth A. Preventing social isolation and loneliness among older people: a systematic review of health promotion interventions. Ageing Soc 2005;25(1):41-67.

12. Dickens AP, Richards SH, Greaves CJ, Campbell JL. Interventions targeting social isolation in older people: a systematic review. BMC Public Health 2011;11(647).

13. Britton A, McKee M, Black N, McPherson K, Sanderson C, Bain C. Choosing between randomised and non-randomised studies: a systematic review. Health Technol Assess 1998;2(13):1-124. 



\section{Chapter}

\section{The influence of the economic crisis on quality of care for older people: system readiness for innovation in Europe}

Jongen, W., Burazeri, G., \& Brand, H. (2015). The Influence of the Economic Crisis on Quality of Care for Older People: System Readiness for Innovation in Europe. Innovation: The European Journal of Social Science Research, 28(2), pp. 167-191. doi: 10.1080/13511610.2015.1019839 


\section{ABSTRACT}

The aim of this study is to examine the influence of the recent economic crisis on the quality of long-term care for older people in Belgium and the Netherlands. A mixedmethod approach was applied, primarily focused on conducting semi-structured qualitative interviews with health professionals working in a management role in organizations providing long-term care for older people. The results show that Dutch organizations seem to be prepared for the influences of the economic crisis on the quality of its care provision primarily in terms of a sound system readiness. At the same time, Belgian organizations seem to be prepared for the influences of the economic crisis on the quality of its care provision primarily in terms of a favorable sociopolitical context. Comparing two countries allows for reciprocal lesson-drawing. The conclusion drawn in this study is that a sustainable long-term care system requires above all stability and structure.

Keywords: long-term care for older people, economic crisis, quality of care, system readiness for innovation, European public health. 


\section{INTRODUCTION}

"Old age is not a disease - it is strength and survivorship, triumph over all kinds of vicissitudes and disappointments, trials and illnesses". With this quote, Maggie Kuhn-an American activist (1905-1995) who used to fight age discrimination-captured quite well the ambiguity surrounding the term 'old age'. Most European societies are faced with the challenges of an ageing population and the aftermath of an economic crisis that started in 2007/2008. Government budget cuts put the quality of long-term care for older people under pressure. However, the current academic literature provides us with a fragmented picture of quality of long-term care systems for older people. Although numerous systematic reviews on the topic exist, most of them report low or heterogeneous methodological quality and inconsistent results of the studies they included (Antunes and Moreira 2011; Cameron et al. 2012; Comondore et al. 2009; Elkan et al. 2001; Gaskill et al. 2008; Low, Yap, and Brodaty 2011; MacAdam 2008; Mottram, Pitkala, and Lees 2002; Niederhauser et al. 2012; Wysocki et al. 2012). Moreover, the few systematic reviews focusing specifically on European countries still suffer from the lack of reliable and comparable data due to large differences in the structure of the European countries' long-term care systems for older people, leading to inefficient comprehensive European-wide research on these systems (Genet et al. 2011, 11).

\section{Study Objectives}

Within the Assessing Needs of Care in European Nations (ANCIEN) project, attempts have been made to overcome part of this problem of research inefficiency by developing a new typology of long-term care systems in Europe. Essentially, two related typologies can be distinguished: one based on the organisation and financing of care; the other based on the use and financing of care (Kraus et al. 2011). The approach taken by the ANCIEN project differs from existing typologies in the sense that the latter primarily tend to focus on broader definitions of health systems instead of specifically on longterm care systems for older people. Furthermore, in the development process of the ANCIEN typologies a substantive number of both new as well as older EU member states have been included, thereby having the possibility of relying on an empirical way of defining these typologies. Therefore, taking into account the European public health perspective applied by our study, it might be much more obvious to compare long-term care systems according to the new multifaceted typologies as proposed by the ANCIEN project, being specifically adapted to the European situation. Based on the ANCIEN framework, two countries-Belgium and the Netherlands-are selected as the study's geographical research area. Taking both ANCIEN typologies into account, it should first be noticed that these neighbouring countries share several similarities in the structure of their long-term care systems for older people. Looking at the 'organisation and financing' typology, the long-term care systems for older people of both countries can be 
characterised as 'highly developed systems' (in terms of patient friendliness) and by 'generous public funding' (Kraus et al. 2011). Also under the 'use and financing' typology, the systems in both countries share several similarities, such as low private expenditures as a share of long-term care spending and substantial support for informal care provision-not to be confused with mandatory measures such as filial responsibility laws. The most significant difference between both countries, however, relates to one specific part of the 'use and financing' typology: the actual provision of informal care, and correspondingly, the mix between formal and informal care provision. As this study explicitly deals with formal care provision, it might be interesting to see whether this specific difference in the long-term care system for older people between Belgium and the Netherlands might have an influence on the quality of care. Table 1 summarizes the Belgian and Dutch long-term care systems in terms of the two ANCIEN typologies.

Table 1. The Belgian and Dutch long-term care systems in terms of the ANCIEN typologies (Kraus et al. 2011).

\begin{tabular}{lll}
\hline & 'Organisation and financing' characteristics & 'Use and financing' characteristics \\
\hline Belgium & - High public funding & - Low private spending \\
& - High patient friendliness & - High informal care support \\
Netherlands & - High public funding & - Low private spending \\
& - High patient friendliness & - High informal care support \\
& & - Low informal care use \\
\hline
\end{tabular}

It is, however, not the quality of long-term care for older people as such, but instead the current challenges that are most likely to have a negative effect on this quality that this study is interested in. Although population ageing and healthcare workforce decline are generally recognised challenges in the academic literature, it might be exaggerated to consider these challenges as fundamental threats to the sustainable quality of longterm care systems-especially in the above-described types of countries that Belgium and the Netherlands belong to (Rechel et al. 2013). One could argue that population ageing and healthcare workforce decline are such gradual processes that governments have been able to anticipate them already years or even decades ago. It is a third challenge, namely the recent economic crisis, this study focuses on. In doing so, we argue that this crisis has had a much more direct and short-term influence on the quality of countries' long-term care system than more gradual developments such as population ageing and declining workforces, mainly due to austerity measures being the result of, or being accelerated by, this crisis. Indeed, in a period of economic crisis those that are hit hardest are typically vulnerable groups in society, being most dependent on public spending. Older people in need for long-term care constitute a prime example of such a vulnerable group. Strikingly, studies on the influence of the economic crisis on the quality of long-term care for older people still seem to be non-existent. Some studies examine the influence of the economic crisis on the quality of healthcare systems in general, but often merely from an ethical point of view (Molina-Mula and De Pedro-Gómez 
2013), or focused merely on healthcare resources and expenditures as indicators for quality (Nuti, Vainieri, and Frey 2012). Moreover, most of these studies focus on Southern European countries such as Italy and Greece (De Belvis et al. 2012; Kousoulis, Angelopoulou, and Lionis 2013; Kondilis et al. 2013).

\section{Research Question}

In this context, the aim of our study was to assess the influence of the recent economic crisis on the quality of long-term care for older people in Belgium and the Netherlands. Based on a combination of the theoretical models of Donabedian (1988)-on quality of care in terms of structure-processes-outcomes-and Greenhalgh et al. (2004)-on system readiness for innovation-we specifically assessed whether the organisations 'processes' in both countries are resilient to changes caused by the economic crisis. The intention of comparing both countries was not to make suggestions about which country 'performs best'. Instead, we intended to gain a better insight into the influence of specific aspects of organisations' processes on the quality of care, through the application of our theoretical framework in two countries with distinctively different long-term care systems for older people. We hypothesise that 'lesson-drawing' can be achieved by comparing two countries and that our theoretical framework can be applied to other countries and regions in Europe as well.

\section{METHODS}

Taking into account the variety of definitions of long-term care for older people it is important to first clarify exactly which definition is applied in this study. This is true all the more as we will consider two different geographical areas that often appear to apply slightly different concepts for the same type of care provision. Following the distinctions made in the introduction between different models of long-term care for older people, this study only takes into account formal, non-profit, provision of care. In doing so, no distinction will be made between private and public provision of care. Basically, we applied the term 'long-term care for older people' then as the overarching term in our study, encompassing both 'residential care' as well as 'home care'. The term 'residential care' is often used interchangeably with, and at other times distinctively from, the term 'nursing care'. Differences in definition often relate to the level of care provided, or in other words, the level of care dependency of the care receivers. In this study, we consider nursing care as a type of residential care, next to 'personal care'. This study will consider both types of residential care. The same holds for home care, which can also encompass both a 'nursing' component, as well as a 'personal care' component.

In this way, our definition of long-term care for older people corresponds well to the definition applied by the OECD, which considers long-term care as "a range of services 
needed for persons who are dependent on help with basic ADL. This central personal care component is frequently provided in combination with help with basic medical services such as help with wound dressing, pain management, medication, health monitoring, prevention, rehabilitation or services of palliative care" (OECD 2005, 17). Activities of daily living (ADLs) are defined as "self-care activities that a person must perform every day such as bathing, dressing, eating, getting in and out of bed or a chair, moving around, using the toilet, and controlling bladder and bowel functions" (OECD 2005, 17).

Finally, the term 'older people' is used, instead of the more commonly used 'elder$I^{\prime}$, because we argue that the former term has a more positive connotation than the latter. Older people constitute here those aged 65 or over.

\section{Theoretical Framework and Models applied}

When measuring quality of care, especially the framework suggested by Donabedian (1988) provides a useful insight. In his early work, Donabedian defined quality of care as "the kind of care which is expected to maximise an inclusive measure of patient welfare, after one has taken account of the balance of expected gains and losses that attend the process of care in all its parts" (as quoted in Legido-Quigley et al. 2008, 2). However, in later work, Donabedian (1988) rightfully claims that this definition may be considered in either a broader or a narrower fashion, depending on the level at which this quality is assessed. These levels consider both the setting in which care is provided as well as the actors involved in the care process. In this study, we will primarily focus on the organisational level of care provision. In doing so, we will specifically consider quality issues from the point of view of health professionals working in a management role in those organisations, such as site managers or heads of department. The reason for doing so and not focussing on the top management is that the latter might be too far removed from the actual care process.

After having defined quality of care, the next step is to determine how this quality should be assessed. Donabedian (1988) suggested that quality of care can be assessed by evaluating its structure, processes and outcomes, arguing that "good structure increases the likelihood of good process, and good process increases the likelihood of good outcome" (as quoted in Legido-Quigley et al. 2008, 10). In his model, Donabedian (1988) defined structure as the "attributes of the settings in which care occurs and the resources needed for health care" (as quoted in Legido-Quigley et al. 2008, 10). One might think of material resources (e.g. medical devices, drugs, financial resources), but also of intellectual resources (e.g. available evidence-based knowledge) and human resources (e.g. skilled health professionals). Process relates to the way healthcare resources and settings are used, or in other words: how are resources translated into desired outcomes? One can furthermore distinguish here between patient-related processes - such as patient safety measures - and organisation-related processes - such as efficiency measures. Finally, outcomes refer to the effects of care on the health and 
well-being of the care receivers, for example in terms of quality of life (Shaw and Kalo 2002; Legido-Quigley et al. 2008).

Although Donabedian's model for defining and assessing quality of care is broadly accepted within the academic literature, there appears to be less agreement on the relative importance of each of his three components. Initially, researchers seemed to be primarily focused on the 'structure' component of quality, for example by assessing the qualifications or the experience of health professionals (Legido-Quigley et al. 2008). However, focus seems to have shifted gradually towards the 'processes' and 'outcomes' components. In this study, we will specifically consider the (organisation-related) 'processes' component in assessing quality of long-term care for older people. Indeed, several authors argue that assessing processes provides much more insight into the overall quality of care than assessing outcomes, as the latter are not necessarily the result of the former (Brook, McGlynn and Shekelle 2000). Other, confounding, factors might be at stake as well, such as environmental, socioeconomic or lifestyle factors, especially when one takes into account that the time gap between processes and their intended outcomes may often be too long to make reasonable suggestions about their potential correlation in the first place. Finally, there are good indications that the processes component of quality of care causes most of the variation in overall assessments on quality care from a patient point of view, followed by structure, while outcomes seem to cause least of the variation (Rademakers, Delnoij, and De Boer 2011).

In order to conceptualise the 'processes' part of Donabedians's model for quality of care further, another theoretical model is integrated into Donabedian's model, namely the 'Conceptual Model for Considering the Determinants of Diffusion, Dissemination, and Implementation of Innovations' as developed by Greenhalgh et al. (2004). Although the latter model is quite extensive, we will specifically focus on two components of the model, that is, the distinction between 'system antecedents for innovation' and 'system readiness for innovation' as explanatory factors for potential differences in quality of care due to the influences of the economic crisis. We justify the application of the term 'innovation' here, instead of merely referring to 'change', as organisations may have been necessitated to be 'innovative' in their processes in order to resist the influences of the economic crisis. By combining elements of Greenhalgh et al.'s (2004) definition of 'innovation in service delivery and organization' and the European Commission's definition of 'social innovation' as stated on the website of DG Enterprise and Industry, we define 'innovation' here as: 'a new idea (in terms of the service delivery or the policy of an organisation) that is more effective than alternatives, that is being directed at improving quality of care outcomes, that is being directed at administrative efficiency and cost effectiveness, and that is being implemented by planned and coordinated actions'. System antecedents for innovation refer to the more structural and cultural contexts that organisations are subject to and which influence organisations' receptiveness towards successfully assimilating innovations. Assimilation refers here to the adoption of an innovation by all relevant stakeholders within the organisation and implementation 
into the organisations' regular work processes. However, even if an organisation is receptive towards assimilating innovations in general, this does not necessarily mean that it is able or willing to actually assimilate a specific type of innovation. The latter is referred to as 'system readiness for innovation' and is the one concept in the model by Greenhalgh et al. (2004) that is most related to the 'process' part of Donabedian's (1988) structure-process-outcome model for quality of care. Figure 1 provides a graphical representation of the conceptual model described above.

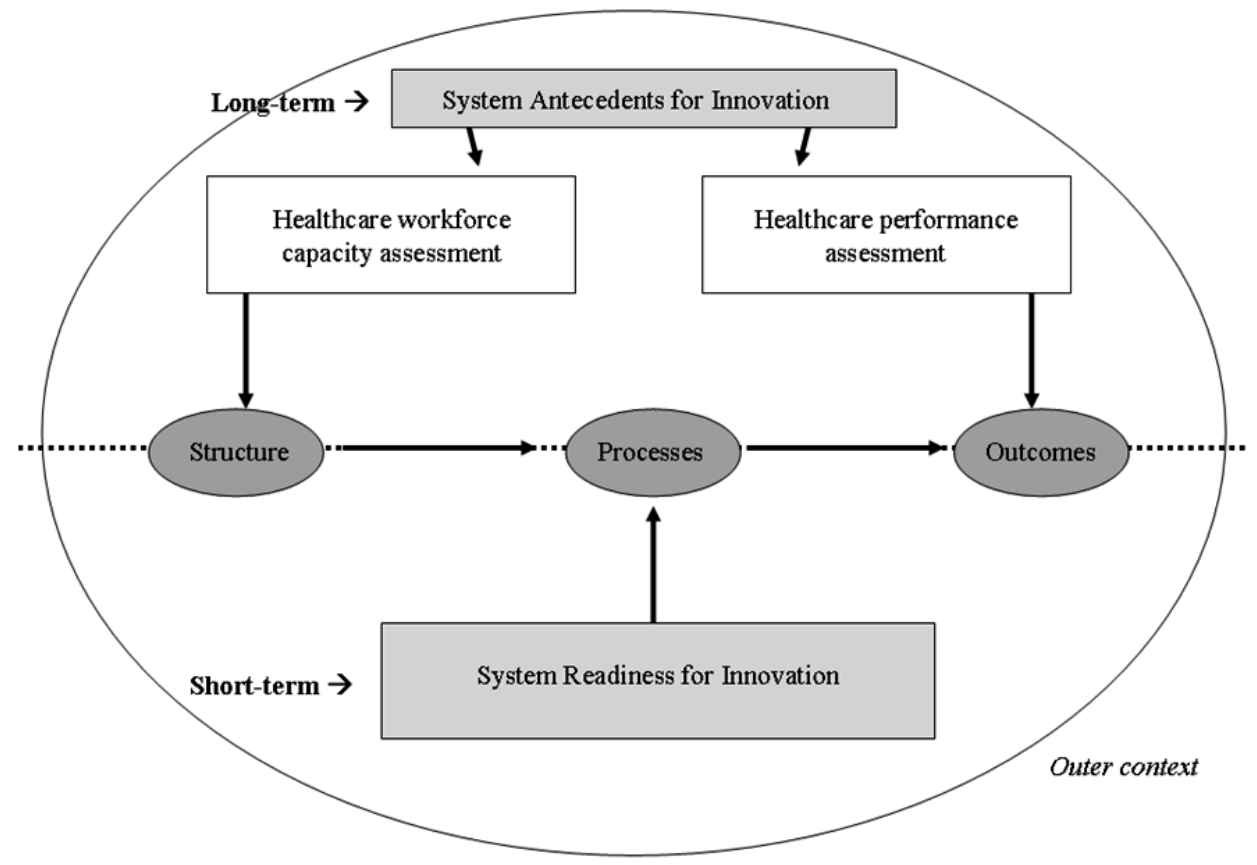

Figure 1. Integrated elements of Greenhalgh et al.'s (2004) conceptual model for considering the determinants of diffusion, dissemination, and implementation of innovations in health service delivery and organization (2004) and Donabedian's (1988) quality of care model (authors' own design).

\section{Instruments for Data Collection}

In order to actually assess the concept of system readiness in measurable terms, the concept had to be operationalised into validated measurable items. However, until recently, no study appeared to have made efforts to truly operationalise Greenhalgh et al.'s (2004) model. A study conducted by Cook et al. (2012) provides a first step in doing so, by suggesting concrete survey questions, interview questions and administrative data build for each component of Greenhalgh et al.'s (2004) model. These items were developed by conducting a systematic literature review and by applying an iterative 
process of team consensus. For each of the six elements of system readiness as proposed by Greenhalgh et al. (2004) Cook et al. (2012) however merely developed examples of interview questions, because of the complex nature of change processes within organisations. Indeed, it seems unlikely to capture the subtleties of such change processes by applying (merely) survey questions. Thus, assessing organisations' system readiness for innovation can best be achieved through applying qualitative research methods. Moreover, conducting semi-structured interviews, instead of open interviews, seemed to be the most logical option here, as interview items build around the six dimensions of system readiness allows for a reasonable degree of comparison. The latter is necessary, as we applied a multiple case-study approach, thereby broadly encompassing two different types of long-term for older people in two different regions. The questions as proposed by Cook et al. were slightly adapted to the specifics of our study, as the interview questions as suggested by cook et al. were focused on medical treatments. Finally, the interview questions were translated into Dutch. We did not apply back translation for the semi-structured interview questions, because of the rather flexible nature of the interview process, where the pre-defined interview questions primarily serve as a guideline. The six questions around system readiness were preceded by general questions on the extent and types of changes experienced by organisations, as well as on the recent developments (in the three years before the interviews were conducted) underlying these changes. For the operational definitions and suggested interview questions, as well as our adapted interview questions, see Table 2.

Table 2. System Readiness for Innovation: interview questions (authors' own modifications).

\begin{tabular}{|c|c|}
\hline General items & Interview questions \\
\hline Changes (Yes/No) & $\begin{array}{l}\text { Did recent developments (in the past three years) } \\
\text { necessitate you to make changes in the service } \\
\text { provision (policy) of your organisation? (Yes/No) }\end{array}$ \\
\hline (If yes on the previous question) Extent of changes & $\begin{array}{l}\text { On a scale from } 1 \text { (negligible change) to ten (big } \\
\text { change), to what extent did you make changes in the } \\
\text { service/policy of your organisation? }\end{array}$ \\
\hline Types of changes & $\begin{array}{l}\text { List the main areas of change taking place at your } \\
\text { organisation. }\end{array}$ \\
\hline $\begin{array}{l}\text { Recent developments (in the past three years) } \\
\text { underlying changes }\end{array}$ & $\begin{array}{l}\text { What kind of developments necessitated you to make } \\
\text { the changes you made in your organisation? }\end{array}$ \\
\hline
\end{tabular}




\begin{tabular}{|c|c|c|c|}
\hline $\begin{array}{l}\text { System Readiness for } \\
\text { Innovation: elements } \\
\text { (Greenhalgh et al. 2004, } \\
595 \text { ) }\end{array}$ & $\begin{array}{l}\text { Operationalised } \\
\text { definitions, as suggested } \\
\text { by Cook et al. }(2012,7)\end{array}$ & $\begin{array}{l}\text { Interview questions, as } \\
\text { suggested by Cook et al. } \\
(2012,7)\end{array}$ & $\begin{array}{l}\text { Adapted interview } \\
\text { questions }\end{array}$ \\
\hline Tension for change & $\begin{array}{l}\text { Perceived need for change } \\
\text { to an organisation's } \\
\text { current provision of } \\
\text { services. }\end{array}$ & $\begin{array}{l}\text { Did other providers in your } \\
\text { setting see a need to make } \\
\text { changes to the program } \\
\text { and treatment } \\
\text { approaches? }\end{array}$ & $\begin{array}{l}\text { Did other providers of } \\
\text { care for older people-- } \\
\text { both within your own } \\
\text { organisation, but also in } \\
\text { other organisations for } \\
\text { residential care or } \\
\text { homecare in your } \\
\text { surrounding-see a } \\
\text { similar necessity to make } \\
\text { similar changes (within } \\
\text { their organisation)? }\end{array}$ \\
\hline Innovation-system fit & $\begin{array}{l}\text { Compatibility of the } \\
\text { innovation with the } \\
\text { organisational setting and } \\
\text { structure. }\end{array}$ & $\begin{array}{l}\text { To what extent does [the } \\
\text { treatment] fit with the } \\
\text { interventions offered in } \\
\text { your treatment setting? }\end{array}$ & $\begin{array}{l}\text { To what extent do the } \\
\text { changes your } \\
\text { organisation made fit } \\
\text { with the structure of, and } \\
\text { conventional work } \\
\text { processes within, your } \\
\text { organisation? }\end{array}$ \\
\hline $\begin{array}{l}\text { Power balances } \\
\text { (supporters v. } \\
\text { opponents) }\end{array}$ & $\begin{array}{l}\text { Relative power of groups } \\
\text { invested in } \\
\text { implementation (e.g., } \\
\text { program staff, director, } \\
\text { management). }\end{array}$ & $\begin{array}{l}\text { Was there agreement } \\
\text { among providers, director } \\
\text { and management } \\
\text { regarding } \\
\text { implementation? }\end{array}$ & $\begin{array}{l}\text { Was there agreement } \\
\text { among different } \\
\text { management levels and } \\
\text { other related } \\
\text { stakeholders regarding } \\
\text { the implementation of } \\
\text { these changes? }\end{array}$ \\
\hline $\begin{array}{l}\text { Assessment of } \\
\text { implications }\end{array}$ & $\begin{array}{l}\text { Estimation of perceived } \\
\text { benefits and consequences } \\
\text { of implementation. }\end{array}$ & $\begin{array}{l}\text { Have there been any } \\
\text { unintended benefits or } \\
\text { consequences to } \\
\text { implementing [the } \\
\text { treatment]? }\end{array}$ & $\begin{array}{l}\text { Have there been any } \\
\text { unintended benefits or } \\
\text { consequences to } \\
\text { implementing the } \\
\text { changes? }\end{array}$ \\
\hline $\begin{array}{l}\text { Dedicated } \\
\text { time/resources }\end{array}$ & $\begin{array}{l}\text { Available means needed to } \\
\text { implement an innovation } \\
\text { (e.g., funding, time, access, } \\
\text { administrative support, } \\
\text { etc.). }\end{array}$ & $\begin{array}{l}\text { Was there sufficient time } \\
\text { and resources available to } \\
\text { implement [the } \\
\text { treatment]? }\end{array}$ & $\begin{array}{l}\text { Was there sufficient time } \\
\text { and resources available to } \\
\text { implement the changes? }\end{array}$ \\
\hline Monitoring and feedback & $\begin{array}{l}\text { Providers' formal and } \\
\text { informal opinions on } \\
\text { efforts to implement. }\end{array}$ & $\begin{array}{l}\text { Were there opportunities } \\
\text { for you to provide and } \\
\text { receive feedback about the } \\
\text { implementation process? }\end{array}$ & $\begin{array}{l}\text { Were there opportunities } \\
\text { for you to provide and } \\
\text { receive feedback about } \\
\text { the implementation } \\
\text { process? }\end{array}$ \\
\hline
\end{tabular}

\section{Study Population and Sampling}

The semi-structured interviews were conducted with health professionals working in a management role in organisations providing long-term care for older people. These health professionals provide an interesting target group for this study, as they are the ones that will first have to deal with changing government policies and regulations. As a 
result, the (potential future) impact of such changes on the quality of care might be much more directly apparent to them than to the final receivers of care. Also, in a more general sense, it is likely to assume that this target group is not so much concerned with the (more societal) issue of demographic change as such, which actually develops rather gradually, but much more with-more short-term-changes in national government policies and budgetary measures. In order to guarantee confidentiality, each of the participants was asked to sign an informed consent. Because of the interview approach-requiring actual contact between the researcher and the intervieweeanonymity could only be guaranteed towards the readers of this article by omitting persons' and organisations' names.

In total we interviewed eight representatives (health professionals working in a management role) of eight different organisations in the Belgian and Dutch provinces of Limburg. Six of the eight organisations provided both nursing care as well as personal care. The only exceptions were two Belgian organisations for home care, of which one provided merely nursing care, while the other provided merely personal care. We chose a multiple-case study approach, in order to allow for a reasonable degree of comparison, both between as within the two selected regions. Due to the fact that we applied a broad definition of long-term care, we managed to select sufficient organisations that were willing to participate in our research. In selecting these organisations, we tried to assure an equal division between the two regions and between types of organisation. As a result, we had to apply a purposive sampling technique. Through this approach, we managed to select four Belgian organisations and four Dutch organisations, subdivided into two residential care organisations and two organisations for home care in both countries. The multiple-case study approach does not impose strict rules about the number of cases required in order to meet the requisites of the replication strategy. Although Yin (2002) argues that six to ten cases should normally suffice, at least when the results of these cases turn out to be similar, much more relevant is considering when the saturation point is reached. Although the eight organisations were initially taken as a starting point, this number turned out to be sufficient for our research aim, due to the consistency in interview results within each region.

The two specific regions-as representative regions of the Netherlands and Belgium-were chosen because of the practical advantage of being border regions and because both areas thus share a certain common culture and history. Moreover, the southern part of the Dutch province of Limburg has strikingly been described by Ruwaard (2012) as "a testing ground for healthcare [which is] the perfect place to experiment with different ways of organising and financing healthcare".

\section{Data Analysis}

The qualitative data were analysed through the grounded theory approach of open, axial and selective coding, as developed by Glaser and Strauss (1967). This approach 
contains the principle of inductive reasoning, as well as a constant comparison method. As a way of supporting the findings of the qualitative part of the research, a limited quantitative assessment was made with regard to the structure and outcomes part of Donabedian's (1988) model, or, the 'system antecedents for innovation' in Greenhalgh et al.'s (2004) terms. As a way of assessing outcomes we considered statistical figures on current and projected ageing trends, old age dependency ratios and expenditures on long-term care for older people. As a way of assessing structure, we considered statistical figures on the current and projected healthcare workforce for long-term care for older people.

In short, for the reason of capturing subtle differences between two border regions, this study applies a mixed-method approach towards assessing quality of care for older people. In practical terms this means that the core of the research consisted of conducting semi-structured qualitative interviews (in a multiple case-study setting), supported by quantitative elements. In doing so, specific attention will be paid to the current societal challenges that are likely to affect that quality in the near future instead of considering quality as a static value. The underlying theoretical framework was developed by merging elements of two existing theoretical frameworks. The approach taken in this study could also be interesting for other countries, especially in cross-border regions, in the context of 'lesson-drawing'.

\section{RESULTS}

All of the respondents reported a certain type of change with regard to the service delivery or policy of their organisation since the beginning of the economic crisis. Striking are the differences, though often subtle, between the two regions in terms of types of changes, extent of changes, and developments underlying these changes.

\section{Types of Changes}

Coding of the interview data allowed us to categorise these different types of changes into three groups, that is, financial changes, material changes, and changes in service delivery. The latter point can be subdivided into an internal and an external component. Similarities between the two regions can especially be witnessed with regard to the financial changes, while the main differences are situated on the side of material changes and changes with respect to the external component of service delivery. Changes with respect to the internal component of service delivery are broadly similar in both regions, although subtle differences in their origin can be witnessed.

With regard to financial changes, respondents in both regions complained about budget restraints, although on Dutch side this was more pronounced than on Belgian 
side. Moreover, on Dutch side, specific issues such as increasing competition and worries about cost-effectiveness were consistently mentioned.

With regard to the internal component of service delivery, respondents in both regions reported a move towards a more patient-centred approach. However, striking is that this move seems to have a different origin in both regions. On Dutch side, organisations especially seek to distinguish themselves as a way of trying to meet the needs of a potentially new clientele, as the general expectation is that the share of people demanding higher levels of care ('nursing care') will grow in the near future, at the expense of the share of people demanding lower levels of care ('personal care'). This involves becoming less hospital-like and instead providing more hospitality by searching for new and innovative models of care delivery, focussed on a better mix between care, residence and well-being. On Belgian side, however, organisations seem to be bothered especially with improving and guaranteeing the quality of care for their existing clientele. In doing so, organisations aim to go back to 'basic' care, requiring mostly minor changes such as a better relation between client and employee, more flexibility of employees in order to reach higher productivity and a more proactive approach of the organisation allowing for a better assessment of clients' needs.

The previous point - the internal component of service delivery-has a direct influence on material changes. Indeed, once an organisation's product portfolio changes, this can have dramatic effects on the composition of an organisation's real estate. Obviously, this mainly holds for residential care organisations. On Dutch side, organisations in general tend to have a clear policy for their real estate, opting for decentralisation of their organisation into more, but smaller, locations that are more dispersed throughout the region. This entails furthermore a decentralisation of professionals' expertise on the one hand, and providing various types of care on the other hand-in line with the hospitality idea of not solely providing care. On Belgian side, residential care organisations do not seem to opt for such a strategy and even tend to choose for the opposite direction, namely that of merging into larger organisations, searching for more structure.

The external component of service delivery refers to the process of extramuralisation, defined here as "the shift from care provided in institutions to care provided at the client's home" (which is the definition used on the website of Statistics Netherlands). Although organisations in both regions witness this shift towards more home care and towards a situation wherein older people tend to live at home for longer, the way the Dutch organisations translate this process of extramuralisation into their daily practice is much more concrete than the way the Belgian organisations do so. This is reflected primarily in the cooperation with external stakeholders, such as through mergers between organisations for residential care and organisations for home care or by creating structural partnerships with similar providers of long-term care for older people and with municipalities. While the Belgian organisations also report increased cooperation, such as with hospitals, this cooperation appears to be much less structured than on Dutch side. 


\section{Extent of Changes}

Respondents were asked to estimate the extent of the changes as described above on a ten-point Likert scale, ranging from 'negligible change' to 'big change'. The scores that were given showed a larger difference between the mean scores of the Dutch and the Belgian organisations (1.15) than between the mean scores of the residential care and the home care organisations combined for the two countries (0.6). Although these scores point into a certain direction, they are obviously statistically not significant at all due to the small sample size. More interesting than the scores as such are, however, the argumentations behind them. Indeed, the Dutch organisations report about 'abrupt' and 'gigantic' changes on the short-term, about a 'trend break' and even about a 'revolution'. At the same time, all of the Dutch respondents recognise the existence of a lot of local variation in the extent of change. The Belgian organisations, on the other hand, give a much more positive picture by reporting about 'fine-tuning' instead of 'revolutions' or 'trend breaks'. In general, these organisations thus witness a much more gradual change process, focussed on practical things-such as searching for more structure, clearer divisions of tasks, and dealing with more complex situations-instead of utterly new situations with new care demands requiring innovative solutions.

\section{Developments underlying Changes}

Broadly two types of developments underlying these changes can be distinguished following the respondents' answers. On the one hand, more structural, long-term, developments, that can be divided into ageing, healthcare workforce capacity, and other structural developments (in Greenhalgh et al.'s (2004) terms these 'other structural developments' could be captured under the heading of 'outer context' (see Figure 1), referring to the socio-political climate). On the other hand, more abrupt short-term developments (or in other words, more recent developments), notably the economic crisis, that can be subdivided into direct consequences of the crisis and indirect consequences due to changing government policies as a result of the crisis.

\section{Ageing, Healthcare Workforce Capacity and Other Structural Developments}

Striking is that respondents in both regions do not attribute a major role to population ageing as a cause of changes. Respondents recognise that ageing (and especially 'double ageing ${ }^{1}$ ) obviously should spur action, but that current action is taken in a wrong way. Indeed, ageing is often described in terms having a negative connotation, such as 'ageism' (Aartsen et al. 2012), thereby stressing such aspects as rising healthcare costs due to older people's healthcare needs and portraying ageing thus primarily as a burden

\footnotetext{
1 'Double ageing' refers here to the process wherein not only the share of people aged $65+$ in a population grows, but also the share of people aged $80+$ within that group of people aged $65+$.
} 
to society. However, the respondents claim that this picture is exaggerated, as the ageing people of today (those currently aged around 65) have another mentality-being much more self-conscious and demanding-than those that are currently aged 80 or over. Thus, the respondents claim that ageing should be approached much more as a challenge, thereby stressing for example interventions aimed at promoting social participation of older people-as has been argued similarly by Jongen, Schröder-Bäck, and Brand (2013)-rather than merely their care needs. Respondents consider ageing to be a gradual process that, together with a related need for a higher workforce capacity in the field of long-term care for older people, has been predicted already long ago and that society should be able to respond to. What is more, some respondents even claim that these predictions are currently even shifting in the opposite direction: the ageing pattern shifts as people are physically and mentally able to stay home for longer, and the workforce capacity shows surpluses instead of shortages.

With regard to 'other' developments, respondents in both regions argued that their country has traditionally had a (too) high level of institutionalisation of older people in residential care homes. This critique was pronounced on Dutch side even more than on Belgian side. In the long run this is not only untenable in financial terms, but the older people of today often do not prefer such a care setting themselves. Thus, respondents in both regions argue that the process of extramuralisation that we described above could also be seen as a societal trend that is widely accepted by the population at large. However, in contrast to Belgium, consecutive national governments in the Netherlands have mainly reacted to this societal trend by decentralising responsibility for service delivery more and more towards municipalities, starting with household assistance (in 2007) and currently expanding to parts of the personal care field (especially with regard to support for the social participation of older people). In doing so, it has been argued that local governments are in a position to deliver care in a more flexible way and are better able to deploy informal caregivers ${ }^{2}$ than national governments-or, as Van der Veer, Schalk, and Gilsing (2011) put it, because municipalities are believed to be better able to customise public policy to local circumstances, and to realise made-to-measure service provision. In practice, however, the Dutch respondents witness an inefficient interplay between different organisations per client and a shrinking instead of growing supply of informal caregivers. Therefore, they opt for more structured approach towards Dutch healthcare in general, being less focused on curative care than it is right now - the latter is for example reflected in the composition of current insurance packages. A truly durable healthcare system, the Dutch respondents argue, should be much more preventive in nature. The economic crisis, they argue, has actually provided a chance to finally make such structural choices. At the same time these respondents notice that the way this is currently done is far too inconsiderate. Respondents on Belgian side-while taking less initiative to cooperate with other stakeholders in order to

\footnotetext{
2 'Informal caregivers' refers here to volunteers, family members and friends.
} 
deal with the extramuralisation process, as we described above-seemed to be far less concerned with their government's policy towards this societal trend.

\section{Direct and Indirect Consequences of the Economic Crisis}

The striking difference between the two regions in terms of developments underlying changes therefore primarily relates to the consequences of the crisis. In the Netherlands, all respondents reported immense consequences due to the crisis, comprising a pressure on the availability of potential informal caregivers and higher co-payments by clients. The former is mainly due, as argued by the Dutch respondents, to the fact that more and more (potential) informal caregivers have difficulties in maintaining their own household because of financial consequences due to the recent crisis. This is paradoxically, as we explained above that governments at the same time expect more and more of this group of carers. Similarly, higher co-payments lead to a situation wherein people in need of care, together with their family, make more conscious considerations as to the type and the level of care they actually apply for. As a result, the level of care required at the moment of application tends to rise. Indirect consequences the respondents consistently report comprise 'reckless' government austerity measures aimed at closing the budget deficit, resulting in stricter assessment procedures by the executive branches dealing with care applications. The economic crisis thus forces organisations to come up with creative, and innovative, solutions. Indeed, as argued by Maarse (2013), especially since the outbreak of the 2008 economic crisis, the Dutch government has changed its long-term care policy agenda from an 'extension agenda' into a 'retrenchment agenda'. In fact, at the time of writing a reform in the Dutch long-term care system is being prepared by the Dutch government, notably consisting of a decentralization of parts of the long-term care responsibilities from the national level to the municipal level, in combination with severe budget cuts. Our Dutch respondents argue that this intended reform has to a large extent been the result of, or has at least been accelerated significantly by, the economic crisis.

Strikingly, respondents in Belgium consistently report not to have felt any major consequences due to the crisis yet, although these consequences are expected by some of the respondents in due time. Currently, they still detect only minor direct consequences such as that clients have become a little more parsimonious on their care expenditures and that quite a number of clients try to deploy home nurses or domestic workers for the provision of personal care. The latter stems from the fact that there are no co-payments required for nursing care-while for personal care there is-and the co-payment rates for household care are relatively low as compared to those for personal care. With regard to indirect consequences of the crisis, the Belgian respondents also report shrinking resources because of government policies, but consider this to be a more gradual movement instead of 'abrupt' or 'reckless' as on Dutch side. As a result, these respondents claim that as a solution to these shrinking resources especially a societal switch in mindset is required, instead of 'creative' or 'innovative' solutions by 
organisations providing long-term care for older people. The problem is, they argue, that people in Belgium are still not used to paying for care or for living in a residential care setting.

The above results with regard to types of changes, extent of changes and developments underlying changes are summarised in a simplified manner in Table 3.

Table 3. Types of changes, extent of changes and developments underlying changes: summary of results.

\begin{tabular}{lll}
\hline General items & Belgium & Netherlands \\
\hline Changes (Yes/No) & Yes & Yes \\
(If yes on the previous & 6.6 (fine-tuning) & 7.75 (trend break) \\
question) Extent of changes & & \\
Types of changes & - Financial changes: budget restraints & - Financial changes: budget restraints \\
& - Material changes: organisations & - Material changes: organisations \\
& merge into larger organisations & decentralise into smaller locations \\
& - Changes in service delivery & - Changes in service delivery \\
& (internal): more patient-centred & (internal): more patient-centred \\
& approach (primarily towards & approach (primarily towards \\
& existing clientele) & potentially new clientele) \\
& - Changes in service delivery & - Changes in service delivery \\
& (external): little structured & (external): highly structured \\
& translation of extramuralisation & translation of extramuralisation \\
& process into daily practice & process into daily practice
\end{tabular}

Recent developments (in the past three years) underlying changes
Structural, long-term developments:

- Ageing: gradual process; often exaggerated

- Healthcare workforce capacity: shortages often exaggerated

- Other structural developments: High level of institutionalisation; respondents little concerned with government's policy towards societal trend of extramuralisation

Abrupt, short-term developments:

- Direct consequences of the economic crisis: only minor direct consequences, comprising clients becoming a little more parsimonious on their care expenditures

- Indirect consequences of the economic crisis: gradual process of shrinking resources due to government policies
Structural, long-term developments:

- Ageing: gradual process; often exaggerated

- Healthcare workforce capacity: shortages often exaggerated

- Other structural developments: High level of institutionalisation; respondents concerned with government's policy towards societal trend of extramuralisation

Abrupt, short-term developments:

- Direct consequences of the economic crisis: immense direct consequences, comprising a pressure on the availability of potential informal caregivers and higher co-payments by clients

- Indirect consequences of the economic crisis: reckless government austerity measures, forcing organisations to come up with creative and innovative solutions 


\section{System Readiness for Innovation}

Next, respondents were asked about the different dimensions of system readiness-or, the "conditions that indicate preparedness and capacity for implementation" (Cook et al. 2012, 10).

With regard to the first dimension, tension for change, Greenhalgh et al. $(2004,607)$ argue that "[i]f staff perceive that the current situation is intolerable, a potential innovation is more likely to be assimilated successfully". Respondents in both regions indicated that there was a clear tension for change, both within their own organisation at different departments, but also in their organisations' respective umbrella organisations and in other related organisations. The Belgian respondents emphasise that such a tension for change has existed in all provinces of Flanders ${ }^{3}$, while the Dutch respondents emphasise to have anticipated these changes even before the economic crisis.

Innovation-system fit implies that "[a]n innovation that fits with the organisation's existing values, norms, strategies, goals, skill mix, supporting technologies, and ways of working is more likely to be assimilated" (Greenhalgh et al. 2004, 608). Especially in Belgium this fit was clearly pronounced, most likely resulting from the fact that the Belgian respondents have characterised the changes as a gradual process, involving fine-tuning of existing work processes instead of fundamentally changing them. However, they do comment that although this fine-tuning has resulted in more structure from a management point of view, employees have had more problems with adapting to the new situation. The latter point is also pronounced by the Dutch respondents, albeit much more severely than on Belgian side. While the Belgian respondents primarily talk about small, practical adjustments in work processes that employees got used to relatively easily, the Dutch respondents talk about a necessity for training, and even of a switch in mindset, of personnel. The latter is mainly due to the occurrence of many changes on very short notice.

The power balances dimension refers to the assertion that "[i]f the supporters of the innovation outnumber and are more strategically placed than its opponents are, it is more likely to be assimilated" (Greenhalgh et al. 2004, 608). On Dutch side, one of the respondents declared that there had been some internal struggles, but that eventually the entire management felt the same sense of urgency. This same sense of urgency was felt among managers in all of the other organisations, both Belgian and Dutch, although the Dutch respondents consistently complained about the lack of such a sense of urgency among municipalities. Moreover, in line with the previous dimension, respondents witnessed some resistance among employees towards the changes, but due to the primarily top-down approach of decision-making this did not cause any major delays of

\footnotetext{
${ }^{3}$ In Belgium, primarily the communities (much more than the federal government) are responsible for longterm care for older people. No information was provided by the respondents on the situation in the French Community and the German-speaking Community, but only on the Flemish Community (of which the Belgian Province of Limburg is part).
} 
the change process. Most striking with regard to this dimension is, however, that respondents in both regions argue that there has been little choice for individual organisations in the first place, as most changes are due to government policy. The latter point was especially cited by the Dutch respondents.

The assessment of implications dimension implies that "[i]f the implications of the innovation (including its subsequent effects) are fully assessed and anticipated, the innovation is more likely to be assimilated" (Greenhalgh et al. 2004, 608). The Belgian respondents did not report any noteworthy unanticipated side effects of the implemented changes, something they attributed primarily to the quality of individual managers. The Dutch respondents primarily referred to the fact that the change process is still taking place and most of them actually expect such anticipated effects still to occur in due time. They recognise that creativity will be required and that it is often a matter of choosing between two evils, but the challenge lies in the fact that no one seems to be able to anticipate when the end of the change process is in sight. Anticipated in both regions-especially in the Netherlands-is the scenario that there may be a deficit of personnel in the short-term, as some employees might not get used to the new situation, or might no longer possess the required skills level. However, respondents expect this to turn into an advantage in the long-term, as this scenario provides the opportunity to immediately attract people that better fit into the new system, instead of retraining existing personnel.

With regard to dedicated time/resources Greenhalgh et al. $(2004,608)$ argue that "[i]f the innovation starts out with a budget and if the allocation of resources is both adequate and continuing, it is more likely to be assimilated". In both the Dutch as the Belgian organisations still sufficient resources seem to be available for the change processes, as most of them are still characterised by a strong solvency. At the same time, however, the Dutch respondents seriously worry about the sustainability of these available resources and the organisations' solvency in general, primarily as a result of the consequences of the economic crisis. None of the Belgian respondents seemed to share such a fear for the sustainability of their organisations' available resources. This attitude, according to the Belgian respondents themselves, stems from a twofold reason. First, the available government ${ }^{4}$ resources still allow for expansion of the number of Flemish residential care beds. Second, healthcare organisations-like residential care organisations - that want to carry out infrastructural changes are in Flanders financially supported by the government. With regard to dedicated time, respondents in the Netherlands - in contradiction to those in Belgium-did indicate that this has been an enormous problem for their organisations, and even more for municipalities. As a result, the respondents argue, the need for innovative thinking might eventually even be higher in municipalities than in organisations providing long-term care for older people.

\footnotetext{
${ }^{4}$ Government refers here to the Flemish Government.
} 
The monitoring and feedback dimension postulates that "[i]f the organization has tight systems and appropriate skills in place to monitor and evaluate the impact of the innovation (both anticipated and unanticipated), the innovation is more likely to be assimilated and sustained" (Greenhalgh et al. 2004, 608). Respondents in the Netherlands unambiguously confirm sufficient possibilities for managers to provide feedback and to receive feedback from their own employees through coaching leadership styles of management. Although the former also holds for the Belgian respondents, they do not seem to share a similar proactive attitude of obtaining feedback from their employees. Although the Belgian respondents do consider feedback from their employees to be desirable, they do not consider it their responsibility to stimulate them to provide it. Despite the resistance that was felt among some employees, the Belgian respondents observe a passive, disinterested attitude among these same employees when it comes to actually providing feedback on the change process. Finally, the Dutch respondents appear to attach great importance to the outcomes of scientific research. Indeed, much scientific evidence is readily available through local knowledge sharing initiatives involving public health policy makers, researchers and healthcare practitioners (Jansen et al. 2012). At the same time, these same respondents criticise other related organisations, as well as policymakers, for still not sufficiently applying scientific evidence in their daily practice.

The above results with regard to system readiness for innovation are summarised in a simplified manner in Table 4. Some explanation is required here, as one should consider these results within the right context. Based on the interview results, we argue that especially the Dutch organisations have developed a sound system readiness, in terms of being prepared for the eventual influence of the economic crisis on the quality of care provision for older people (of course, within the range of what is practically and legally possible for these organisations). This line of argumentation does not imply that the quality of care for older people in itself is better in the Netherlands than in Belgium. The interview results are about the resilience to changes specifically caused by the economic crisis. A lot of this resilience has to do with the timely recognition and identification of unintended consequences and with the (innovative) way of dealing with or preparing for these consequences. Relating this back to the six system readiness elements, one can indeed witness a much more pronounced sense of urgency among various stakeholders in the Dutch situation than in the Belgian situation ('power balances'), primarily with regard to the financial sustainability of the long-term care system in general and with regard to the impact that the current changes may have on both the organisations' own employees as on the care recipients ('unintended consequences' and 'time and resources'). The way the Dutch organisations deal with the (still largely uncertain) consequences of the change process might well be considered 'innovative', primarily reflected in organisations' transparent way of communicating about the change process ('monitoring and feedback'). At the same time one cannot simply conclude that the Belgian organisations do not have a sound system readiness for innovation, in terms 
of being prepared for the eventual influence of the economic crisis on the quality of care provision for older people. Indeed, these Belgian organisations have not (yet) been confronted with consequences of the economic crisis that are as tangible and concrete as in the Netherlands. The latter point can be particularly related to the Belgian organisations' self-proclaimed 'innovation-system fit'. The explanation for this difference in system readiness between the Dutch and the Belgian organisations can be twofold. On the one hand, one could argue that the Belgian organisations underestimate or neglect the challenges that are yet to come. On the other hand, one could argue that the Belgian long-term care system is already characterized by a sufficiently stable base, thereby limiting the need for long-term care organisations to be 'innovative' in the aftermath of the economic crisis.

\section{System Antecedents for Innovation}

As we argued before, part of an organisations' system readiness to innovate could be explained by long-term system antecedents for innovation-structural and cultural contexts that organisations are subject to. In our theoretical model we linked these system antecedents for innovation to Donabedian's (1988) structure and outcomes components of assessing quality of care (see Figure 1). With regard to the latter, the ageing of the bulk of European populations constitutes an already thoroughly researched phenomenon. However, it is not so much the (projected) ageing patterns that give insight into a country's ability to deal with its ageing population, but instead the (projected) old-age dependency ratio. The latter is defined here as "the ratio between the (projected) total number of elderly persons (aged 65 and over) and the (projected) number of persons of working age (from 15 to 64)" (Eurostat, n.d.). Figure 2 shows that, despite differing ageing patterns, the Netherlands and Belgium face a roughly similar old-age dependency ratio, at least until around 2020. From then on, the Dutch old-age dependency ratio is expected to grow above both the Belgian as well as the European old-age dependency ratio, while the gap between the Netherlands and Belgium ratios will continue to grow. 
Chapter 3

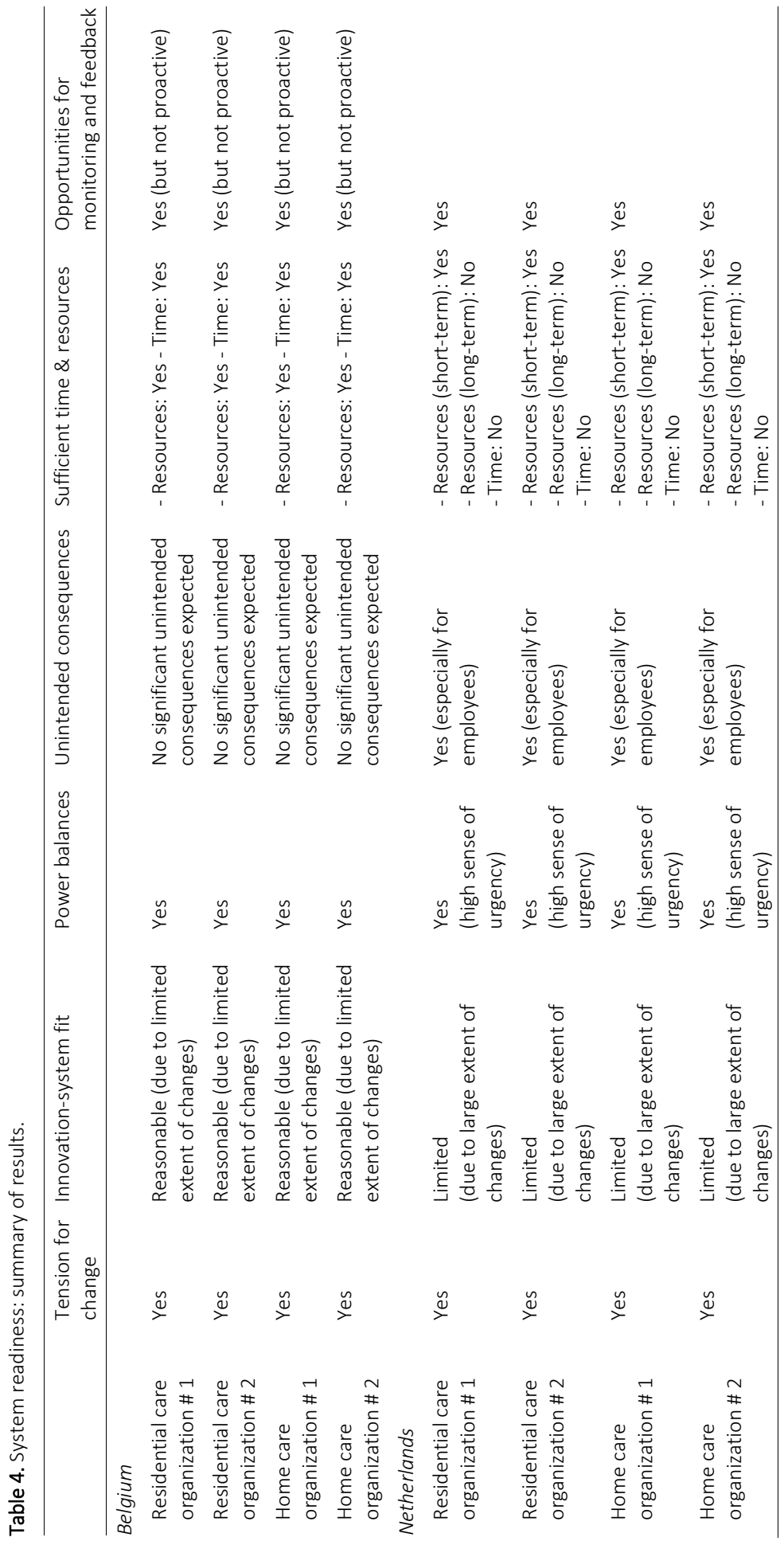




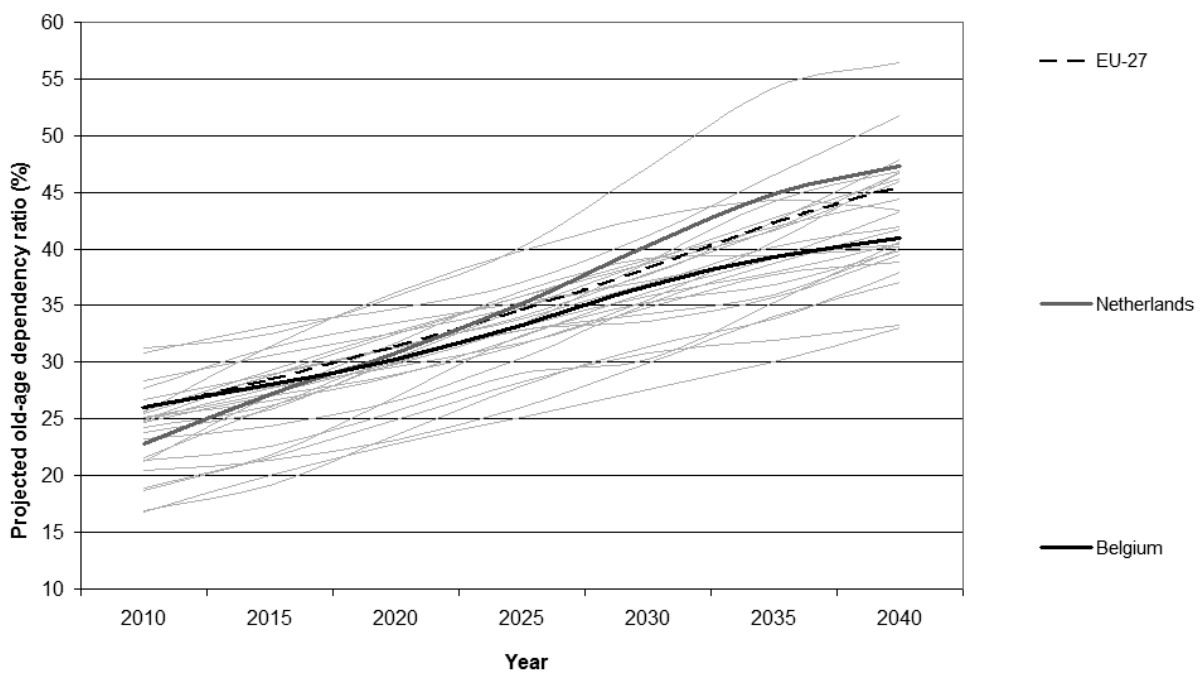

Figure 2. Projected old-age dependency ratio in EU-27 countries, authors' own composition (Eurostat, n.d.).

Concerning Donabedian's structure component of assessing quality of care, Figure 3 shows a still growing number of residential care beds in Belgium-defined in this Figure as 'nursing and elderly home beds' - as was indeed claimed by some of the Belgian respondents.

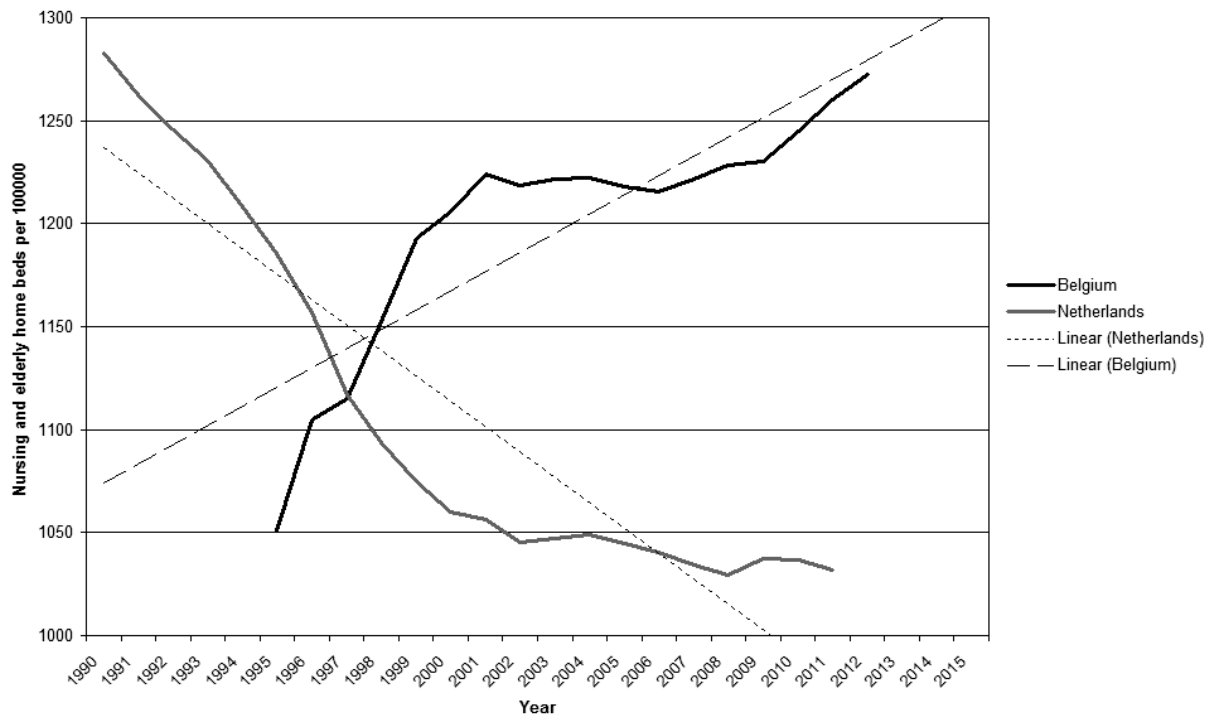

Figure 3. Nursing and elderly home beds per 100,000, including trend lines (WHO 2013). 
A potential indicator that could be used to make projections on future healthcare workforce capacity is the number of nurses graduated in given years. However, as is illustrated in Figure 4, the blurred pattern in the past three decades in both countries leaves little room for making predictions about future trends. While Belgium shows a gradual decline in the number of nurses graduated in the past three decades, the trend line for the Netherlands is more or less stable. In recent years, however, both countries show a sharp increase again in the number of nurses graduated.

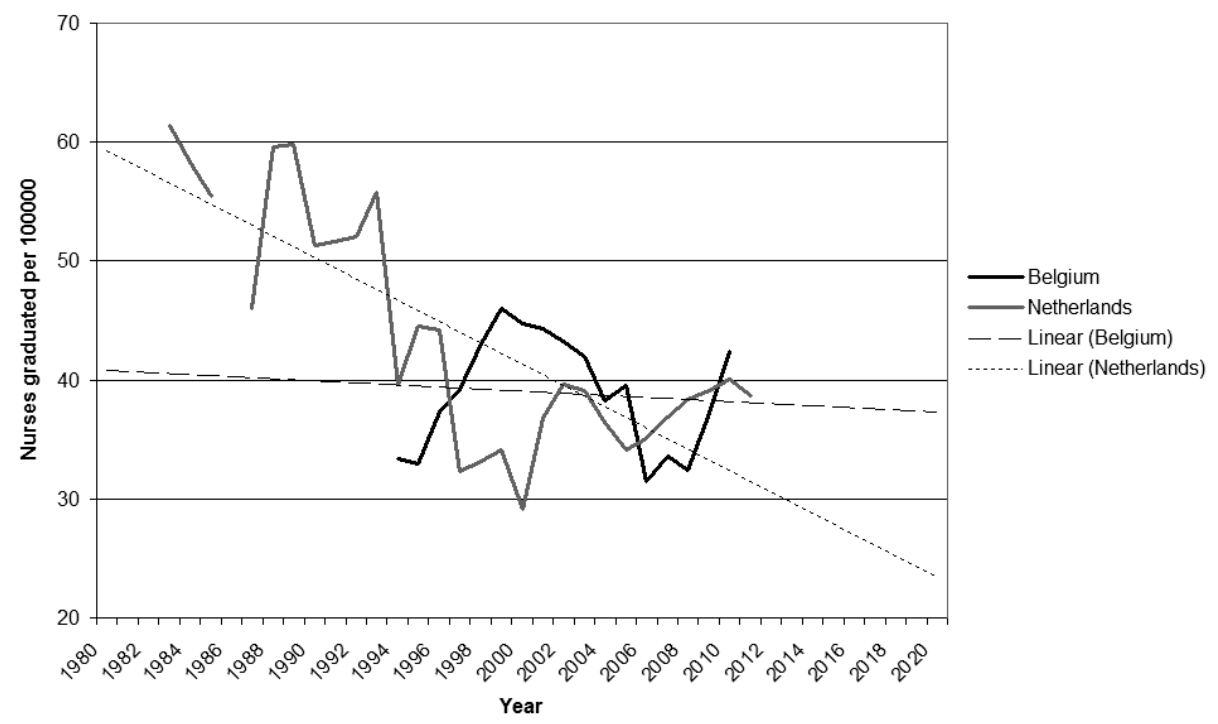

Figure 4. Nurses graduated per 100,000, including trend lines (WHO 2013).

However, European-wide or cross-border comparisons on healthcare workforce capacity are impeded by the fact that the nursing workforce in each country is subject to different educational requirements or different interpretations of the nursing profession in the first place (Mistiaen et al. 2011). Moreover, predicting the amount of nurses that will opt for a job specifically in long-term care for older people is even more infeasible.

What these figures tell us, however, are merely general trends in the two respective countries. As a result, they can merely be applied as a general support of some of the respondents' claims about the 'structure' (or inputs) and the 'outcomes' side of Donabedian's (1988) quality of care spectrum. These figures do not provide, however, any information on how successful individual organisations are in transforming certain inputs into certain outcomes-or in other words: on the 'processes' part of Donabedian's model. Neither do these figures take regional and local differences within a country into account, such as those between provinces or municipalities. 


\section{DISCUSSION}

In the first part of the preceding section we elaborated on the types of changes, extent of changes and developments underlying these changes occurring in the long-term care for older people in the Dutch and Belgian provinces of Limburg, specifically from the point of view of healthcare professionals working in a management position within long-term care organisations for older people. In this final section we aim to explain the origin of these differences by relating them to the different dimensions of system readiness for innovation and system antecedents for innovation of both regions that we elaborated on in the final part of the preceding section. In doing so, it should be taken into account that the starting point of both regions - in terms of types of changes, extent of changes, and developments underlying these changes-obviously differs.

\section{Principal Findings}

When considering the above results, there appears to be a direct link between changes and developments underlying these changes on the one hand and system readiness and system antecedents for innovation on the other hand. The more short-term developments our respondents reported on, notably the consequences of the economic crisis, coincided with our notion of system readiness for innovation-as linked to Donabedian's (1988) notion of 'processes'. The more long-term developments our respondents reported on, healthcare workforce capacity and ageing-related healthcare expenditure, coincided with our notion of system antecedents for innovation-as linked to Donabedian's notions of 'structure' and 'outcomes'. Interestingly, however, it were not so much these two structural processes that respondents in both countries worried about, but instead the socio-political developments captured under the heading of 'other structural developments' - coinciding with Greenhalgh et al.'s (2004) notion of 'outer context'. We deliberately called these developments 'other' structural developments in our analysis, in order to emphasise their difference from developments related to system antecedents for innovation. Indeed, there is only a thin line between the concepts of outer context and system antecedents for innovation as they are applied in this study. The key difference is situated in the fact that system antecedents refer to developments that are directly relevant to the organisations' immediate field of interestthat is, long-term care for older people-while outer context refers to the more general social and political situation outside of the organisations' direct field of interest. At the same time, however, these socio-political developments do have a clear, albeit indirect, influence on both organisations' system antecedents as well as their system readiness for innovation. As an example, a country's social context determines to a large extent how societies deal with such societal challenges as ageing and healthcare workforce capacity. This social context could, amongst others, be reflected in societies' accepted mix between the provision of formal and informal care. In the same vein, a country's 
political context determines to a large extent to what extent organisations are able to react to crises. This political context could, amongst others, be reflected in the structure $^{5}$ of the countries' healthcare systems at large. Exactly with regard to this outer context type of developments, there appeared to be a striking difference between the Netherlands and Belgium, causing much of the differences in types and extent of changes on the one hand and in system readiness towards the influences of the crisis on the other hand.

Indeed, with regard to system antecedents for innovation as defined in this studywhich we initially considered to be a prerequisite for system readiness-respondents in neither country appeared to worry much about the influence of trends in ageing and workforce capacity on the quality of care. This view is in line with the quantitative part on system antecedents that the previous section elaborated on. Although Belgium seemed to be in a slightly better position than the Netherlands in relative terms with regard to these operationalised items for system antecedents, these relative figures do not reveal much about a country's absolute level of care quality. A much more striking difference between the two countries might therefore be their differing mix between formal and informal care provision. Indeed, as is concluded by Willemé $(2010,7)$ "[a]mple formal care provision notwithstanding, care-dependent Belgian elderly also receive substantial informal care by relatives and friends. This places Belgium (together with France and Austria) somewhat outside the 'core' of European countries characterised by a trade-off between formal and informal care". At the same time, Mot et al. $(2010,7)$ conclude that in the Netherlands especially "institutional care plays a relatively heavy role compared to other countries", while "[i]nformal care for the elderly is relatively unimportant in the Netherlands" (2010, iv).

Although we considered the 'processes' part of Donabedian's (1988) model to be the most appropriate instrument to assess quality of care in this study (operationalising it by means of Greenhalgh et al.'s (2004) concept of system readiness), also these processes appeared to be determined to a large extent by outer context type of developments. Indeed, as Greenhalgh et al. $(2004,30)$ argue, the elements of system readiness for an innovation are particularly relevant to the early stages of assimilation. In addition, Greenhalgh et al. (2004) recognise that a number of additional elements are specifically associated with successful routinisation, such as organisational structure and funding. Such elements are largely determined by the structure of the healthcare system at large. With regard to the latter, again striking differences between the two countries can be witnessed. As can be seen in Figure 5, public funding for healthcare (general government expenditures and social security funds) is remarkably higher in the Netherlands than in Belgium, while private households' out-of-pocket expenditures are a much more common phenomenon in Belgium than in the Netherlands.

\footnotetext{
${ }^{5}$ Not to be confused with the notion of 'structure' as applied by Donabedian within the context of assessing quality of care.
} 


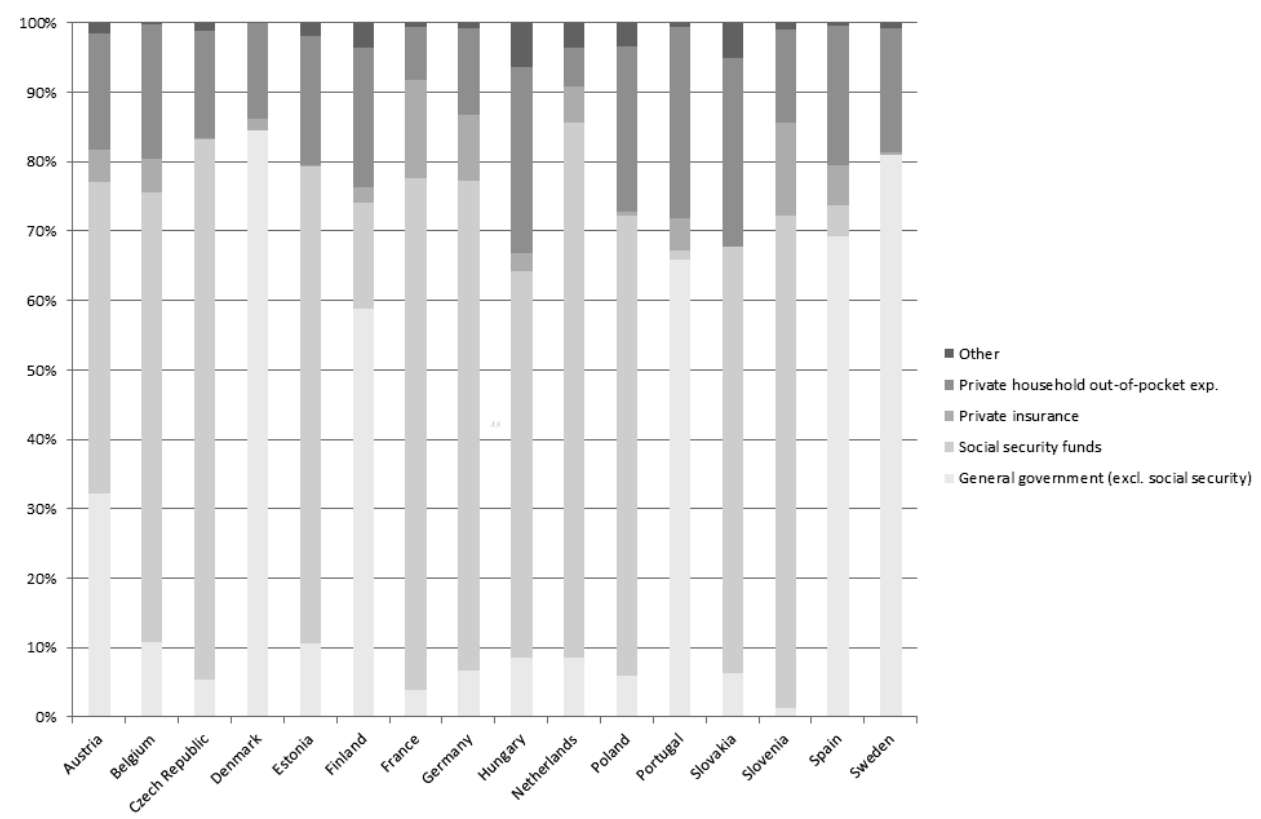

Figure 5. Health expenditure by financing agent, authors' own composition (OECD, n.d.).

In Belgium, long-term care is mainly offered as a service in kind, with practically no copayment for-both home and residential-nursing care (Willemé 2010, 8). However, as is argued by Willemé $(2010,5)$, not all out-of-pocket expenditures for long-term care are known in Belgium, as older people who are not entitled to subsidised home nursing care can purchase these services privately, primarily by means of so-called service cheques. These are vouchers that can be purchased relatively cheaply-as they are funded for about two-thirds by government subsidies - to pay for household care being offered by both public organisations as well as private firms that employ primarily lowskilled personnel (Willemé 2010, 5). Simultaneously, long-term care in the Netherlands is largely organised at national level (under the Exceptional Medical Expenses Act). Household care used to be part of this Act as well, but was shifted to the municipal level in 2007 (under the Social Support Act). In contradiction to the Exceptional Medical Expenses Act, the Social Support Act is not funded by (compulsory) social insurance, but by general taxes. In this way, the Social Support Act is influenced by the available funds, giving municipalities financial incentives to organise household care efficiently (Mot et al. 2010, iii). As mentioned before, also responsibility for parts of personal care will soon be shifted to the municipal level (especially with regard to support for the social participation of older people). Further elaborating on the Belgian and Dutch healthcare systems at large-beyond the mere long-term care system-would be beyond the scope of this study. 


\section{Conclusion}

As a conclusion, we argue that (while keeping in mind the above reservations) especially Dutch organisations providing long-term care for older people seem to be prepared in terms of a sound system readiness for the influences of the economic crisis on the quality of its care provision. At the same time, however, Belgian organisations seem to benefit primarily from a more favourable socio-political (or 'outer') context as a way of being prepared for the influences of the economic crisis on the quality of its care provision. While such comparisons may give an overly superficial picture of reality, one could conclude by arguing that a sustainable long-term care system requires in the first place stability and structure. Indeed, when looking at the views of care receivers, a study by Mot et al. (2012) suggests that Belgium scores most consistent among all indicators applied to measure long-term care related quality of life, while the Netherlands primarily tends to peak on one of these indicators, while scoring mediocre on all others (Mot et al. 2012). At the same time, while the progress towards 'innovativeness' in long-term care for older people may be higher in the Netherlands, the (forced) velocity of these changes may be too high. In the same vein, Brand et al. $(2013,1)$ argue that "[a]usterity measures introduced in many European countries [that have cut health budgets and have resulted in health policy reforms] as a consequence of the 2008-09 economic crisis have had many adverse effects on social determinants of health. ... [E]specially where health systems were less resilient or weak" (Brand et al. 2013, 1). Notwithstanding the complexity of the discussion on the future of long-term care in Western European countries such as Belgium and the Netherlands, this study has tried to contribute to this discussion by suggesting a conceptual model which facilitates European-wide, crossborder, comparisons in operationalised terms. As regards our own research area, the aftermath of the crisis that will unfold in the years to come will provide the ultimate test for our theory and will clarify further whether organisations providing long-term care for older people benefit more from a sound system readiness for innovation or from a sound socio-political context as a way of being prepared for the eventual impact of the recent economic crisis-and perhaps economic crises in general-on the quality of their care provision.

\section{Study Strengths and Limitations}

The principal strength of this study has been its in-depth, explorative, approach of a yet under-researched topic. Concerning the trustworthiness of the applied case study design, however, particularly the problem of transferability may be worth mentioning here. Because of its in-depth approach based on a specific setting in its specific context, single case-studies basically do not allow for a full generalisation of the findings. However, the application of a multiple-case study approach, and its application in two different geographical areas, has attempted to compensate for this problem of transfera- 
bility. In order to increase the evidence base further, we would therefore suggest to expand the approach chosen in this study to more European border regions. Finally, this study focused primarily on the views of organisations providing long-term care for older people. As a suggestion for further research we would opt for an extension to local governments' views. Especially in the Dutch context this might lead to valuable insights, due to the forthcoming decentralization of parts of the long-term care responsibilities to municipalities as a result of the intended long-term care reform that we shortly referred to above.

\section{COMPETING INTERESTS}

None declared. 


\section{REFERENCES}

Aartsen, M., Béland, D., Edmondson, R., Ginn, J., Komp, K., Nilsson, M., Perek-Bialas, J., Sorensen, P., and Weicht, B. 2012. Ageing in the light of crises: Economic crisis, demographic change, and the search for meaning. Paper prepared for the conference "Ageing in the light of crises: Economic crisis, demographic change, and the search for meaning", Umea, October 3-5.

Antunes, V., Moreira, J. P. 2011. Approaches to developing integrated care in Europe: a systematic literature review. Journal of Management \& Marketing in Healthcare 4 (2): 129-135. doi:10.1179/175330 $311 \times 13016677137743$.

Brand, H., Rosenkötter, N., Clemens, T., and Michelsen, K. 2013. Austerity policies in Europe-bad for health. BMJ 346. doi:10.1136/bmj.f3716.

Brook, R., McGlynn, E., and Shekelle, P. 2000. Defining and measuring quality of care: a perspective from US researchers. International Journal for Quality in Health Care 12 (4): 281-295. doi:10.1093/intqhc/ 12.4.281.

Cameron, I. D., Gillespie, L. D., Robertson, M. C., Murray, G. R., Hill, K. D., Cumming, R. G., and Kerse, N. 2012. Interventions for preventing falls in older people in care facilities and hospitals. Cochrane Database of Systematic Reviews 2012 (12): CD005465. doi:10.1002/14651858.CD005465.pub3.

Comondore, V. R., Devereaux, P. J., Zhou, Q., Stone, S. B., Busse, J. W., Ravindran, N. C., Burns, K. E. et al. 2009. Quality of care in for-profit and not-for-profit nursing homes: systematic review and meta-analysis. BMJ 339. doi:10.1136/bmj.b2732.

Cook, J. M., O’Donnell, C., Dinnen, S., Coyne, J. C., Ruzek, J. I., Schnurr, P. P. 2012. Measurement of a model of implementation for health care: toward a testable theory. Implementation Science 7. doi: 10.1186/17485908-7-59.

De Belvis, A. G., Ferrè, F., Specchia, M. L., Valerio, L., Fattore, G., and Ricciardi, W. 2012. The financial crisis in Italy: Implications for the healthcare sector. Health Policy 106 (1): 10-16. doi:10.1016/j.healthpol. 2012.04.003.

Donabedian, A. 1988. The quality of care: How can it be assessed? The Journal of the American Medical Association 260 (12):1743-1748.

Elkan, R., Kendrick, D., Dewey, M., Hewitt, M., Robinson, J., Blair, M., Williams, D., and Brummell, K. 2001. Effectiveness of home based support for older people: systematic review and meta-analysis. BMJ 323 (7315): 719-724.

Eurostat (EUROPOP2010; accessed June 20, 2013). http://epp.eurostat.ec.europa.eu/portal/page/portal/ population/data/database.

Gaskill, D., Black L. J., Isenring, E. A., Hassall, S., Sanders, F., and Bauer, J. D. 2008. Malnutrition prevalence and nutrition issues in residential aged care facilities. Australasian Journal on Ageing 27 (4): 189-194. doi:10.1111/j.1741-6612.2008.00324.x.

Genet, N., Boerma, W., Kringos, D. S., Bouman, A., Francke, A. L., Fagerström, C., Melchiorre, M. G., Greco, C., and Devillé, W. 2011. Home care in Europe: a systematic literature review. BMC Health Services Research 11. doi:10.1186/1472-6963-11-207.

Glaser, B. G., and Strauss, A. L. 1967. The Discovery of Grounded Research: Strategies for Qualitative Research. New York: Aldine De Gruyter.

Greenhalgh, T., Robert, G., Macfarlane, F., Bate, P., and Kyriakidou, O. 2004. Diffusion of Innovations in Service Organizations: Systematic Review and Recommendations. The Milbank Quarterly 82 (4): 581-629.

Jansen, M. W., De Leeuw, E., Hoeijmakers, M., and De Vries, N. K. 2012. Working at the nexus between public health policy, practice and research. Dynamics of knowledge sharing in the Netherlands. Health Research Policy and Systems 10. doi:10.1186/1478-4505-10-33.

Jongen, W., Schröder-Bäck, P., and Brand, H. 2013. Evaluating interventions aimed at promoting social participation of older people: A review of the literature. Albanian Medical Journal 1: 55-61. 
Kondilis, E., Giannakopoulos, S., Gavana, M., lerodiakonou, I., Waitzkin, H., and Benos, A. 2013. Economic Crisis, Restrictive Policies, and the Population's Health and Health Care: The Greek Case. American Journal of Public Health 103 (6): 973-979. doi:10.2105/AJPH.2012.301126.

Kousoulis, A. A., Angelopoulou, K. E., and Lionis, C. 2013. Exploring health care reform in a changing Europe: Lessons from Greece. European Journal of General Practice. doi:10.3109/13814788.2013.779663.

Kraus, M., Czypionka, T., Riedel, M., Mot, E., and Willemé, P. 2011. How European Nations Care for Their Elderly: A New Typology of Long-Term Care Systems. Brussels: Centre for European Policy Studies.

Legido-Quigley, H., McKee, M., Nolte, E., and Glinos, I. A. 2008. Assuring the quality of health care in the European Union. A case for action. Copenhagen: WHO Regional Office for Europe.

Low, L. F., Yap, M., and Brodaty, H. 2011. A systematic review of different models of home and community care services for older persons. BMC Health Services Research 11. doi:10.1186/1472-6963-11-93.

Maarse, H. 2013. The experience of searching long-term care for the elderly: client choice in long-term care in the Netherlands (project report). London: European Cross Border Care Collaborations (EUCBCC).

MacAdam, M. 2008. Frameworks of Integrated Care for the Elderly: A Systematic Review.

Ottawa: Canadian Policy Research Networks.

Mistiaen, P., Kroezen, M., Triemstra, M., and Francke, A. L. 2011. Verpleegkundigen en verzorgenden in internationaal perspectief. Een literatuurstudie naar rollen en posities van beroepsbeoefenaren in de verpleging en verzorging. Utrecht: NIVEL.

Molina-Mula, J., and De Pedro-Gómez, J. E. 2013. Impact of the politics of austerity in the quality of healthcare: ethical advice. Nursing Philosophy 14 (1): 53-60. doi:10.1111/nup.12000.

Mot, E., Aouragh, A., De Groot, M., and Mannaerts, H. 2010. The Long-Term Care System for the Elderly in the Netherlands. Brussels: Centre for European Policy Studies.

Mot, E., Faber, R., Geerts, J. and Willemé, P. 2012. Performance of Long-Term Care Systems in Europe. Brussels: Centre for European Policy Studies.

Mottram, P., Pitkala, K., and Lees, C. 2002. Institutional versus at-home long term care for functionally dependent older people. Cochrane Database of Systematic Reviews 2002 (1): CD003542.

Niederhauser, A., VanDeusen Lukas, C., Parker, V., Ayello, E. A., Zulkowski, K., and Berlowitz, D. 2012. Comprehensive programs for preventing pressure ulcers: a review of the literature. Advances in Skin \& Wound Care 25 (4): 167-188. doi:10.1097/01.ASW.0000413598.97566.d7.

Nuti, S., Vainieri, M., and Frey, M. 2012. Healthcare resources and expenditure in financial crisis: scenarios and managerial strategies. The Journal of Maternal-Fetal and Neonatal Medicine 25 (s4): 48-51. doi:10.3109/14767058.2012.715022.

OECD (Organisation for Economic Co-operation and Development) Stat Extracts (Health Expenditure and Financing; accessed June 20, 2013). http://stats.oecd.org/Index.aspx?DatasetCode=SHA.

Organisation for Economic Co-operation and Development. 2005. Long-Term Care for Older People. Paris: OECD.

Rademakers, J., Delnoij, D., and De Boer, D. 2011. Structure, process or outcome: which contributes most to patients' overall assessment of healthcare quality? BMJ Quality and Safety 20 (4): 326-331. doi:10.1136/ bmjqs.2010.042358.

Rechel, B., Grundy, E., Robine, J. M., Cylus, J. Mackenbach, J. P., Knai, C., and McKee, M. 2013. Ageing in the European Union. The Lancet 381 (9874): 1312-1322. doi:10.1016/S0140-6736(12)62087-X.

Ruwaard, D. 2012. De weg van nazorg naar voorzorg: buiten de gebaande paden. Maastricht: Maastricht University.

Shaw, C., and Kalo, I. 2002. A background for national quality policies in health systems. Copenhagen: WHO Regional Office for Europe.

Van der Veer, J., Schalk, J, and Gilsing, R. 2011. Decentralisatie: maatwerk of uniformiteit? Het Wmo-beleid van Nederlandse gemeenten. Beleid en Maatschappij 38 (3): 265-282.

WHO (World Health Organization) European Health for All Database (updated July 2013; accessed September 2, 2013). http://data.euro.who.int/hfadb/.

Willemé, P. 2010. The Long-Term Care System for the Elderly in Belgium. Brussels: Centre for European Policy Studies. 


\section{Chapter 3}

Wysocki, A., Butler, M., Kane, R. L., Kane, R. A., Shippee, T., and Sainfort, F. 2012. Long-Term Care for Older Adults: A Review of Home and Community-Based Services Versus Institutional Care. Comparative Effectiveness Reviews, no. 81.

Yin, R. K. 2002. Case Study Research: Design and Methods. London: Sage. 


\section{Chapter}

\section{The Dutch long-term care system in transition: implications for municipalities}

Jongen, W., Commers, M.J., Schols, J.M.G.A., \& Brand, H. (2015). The Dutch Long-Term Care System in Transition: Implications for Municipalities. Das Gesundheitswesen. doi: 10.1055/s-0035-1564251 


\section{ABSTRACT}

Introduction: The aim of this study is to examine the preparedness of Dutch municipalities (in terms of system readiness for innovation) for the challenges resulting from their new responsibilities under the long-term care reform of January 1, 2015.

Methods: A qualitative research approach was used by conducting semi-structured interviews with representatives of nine Dutch municipalities responsible for the longterm care of older people in their respective municipalities.

Results: Municipalities consider themselves to be largely prepared for their new responsibilities resulting from the long-term care reform. However, this perception mainly applies to practical changes (related to municipalities' organizational preparation for their new responsibilities) occurring in the short-term transition phase, not to the more long-term transformation phase.

Conclusion: We argue that municipalities highly underestimate the long-term challenges that lie ahead of them (such as the development of a dedicated 'participation society') and, in fact, seem to fear the uncertainty of the consequences of these challenges.

Key words: long-term care, reform, Netherlands, decentralization. 


\section{INTRODUCTION}

On January 1, 2015, the next step in the Dutch long-term care reform will enter into force. This new reform has largely been the result of, or at least been accelerated by, the global economic crisis that started in 2007/2008. The Dutch long-term care system used to fit quite well within what can be considered the Scandinavian model. The Assessing Needs of Care in European Countries (ANCIEN) project defined the Scandinavian model as a long-term care system characterized by high public funding, low private funding and a low use of informal care [1]. However, as argued by Maarse, especially since the outbreak of the 2008 economic crisis, the Dutch government has changed its long-term care policy agenda from an 'extension agenda' into a 'retrenchment agenda' [2]. Indeed, the financial sustainability of the Dutch long-term care system has long been a point of discussion, resulting already in 2007 in the decentralization of domestic help to the municipalities.

Before discussing the new reform in the Dutch long-term care system that will enter into force on January 1, 2015, first the basic structure of this system should shortly be explained. The current (pre-2015) Dutch long-term care system basically consists of two pillars. The first pillar includes services within the scope of the Algemene Wet Bijzondere Ziektekosten (AWBZ) / Exceptional Medical Expenses Act and falling under the responsibility of the national government. AWBZ services include all types of long-term care for people with severe limitations (due to disability, chronic illness or old age), including personal home care (related to activities of daily living), home nursing care, personal counseling (such as day care for the elderly) and residential care (for people living in a nursing home or a care home). For matters of categorization, the current AWBZ services are divided into several so-called 'care severity packages'. The second pillar of the Dutch long-term care system consists of services within the scope of the Wet maatschappelijke ondersteuning (Wmo) / Social Support Act, under the responsibility of the municipalities. Wmo services include domestic help (house cleaning and household services), home adaptations (such as installing an electrical stair lift) and other kinds of social care. Thus, in the current situation, AWBZ services could be characterized primarily as true healthcare services, while Wmo services could be characterized more as social care services.

Under the new reform, part of the services that used to be within the scope of the AWBZ will be transferred to the Wmo-and will henceforth fall under the responsibility of the municipalities. These services include those that are directed towards the social participation of people with severe limitations, notably personal counseling services. In fact, the decentralization of AWBZ services to the Wmo as explained above, is part of a larger process of decentralizations to municipalities called the ' 3 D's (or: three decentralizations) in the social domain'. Next to the long-term care decentralization, municipalities are also faced with decentralization in the field of youth care and decentralization in the field of labor participation of people with an occupational disability. 
Another part of the current ABWZ services will be transferred to the Zorgverzekeringswet $(Z v w)$ / Health Insurance Act-under the responsibility of the health insurers. These services include personal homecare and home nursing care. The Zvw Act and the AWBZ Act together constitute the Dutch health care insurance system. However, in the current (pre-2015) system, the Zvw Act hardly plays a role in the field of long-term care. Instead it covers the costs of regular medical care like GP visits, hospitalization and pharmacy prescriptions.

Finally, the remaining AWBZ services will be transformed into a new Act: the Wet langdurige zorg (WIz) / Long-term Care Act. Compared to the AWBZ Act, the new Wlz Act only arranges residential care for the most severe cases, thereby abolishing residential care for people with lower care-severity packages. Table 1 provides an overview of the various Acts we discussed above, including its main elements.

Table 1. Pre-2015 and post-2015 long-term care Acts.

\begin{tabular}{|c|c|c|c|}
\hline \multicolumn{2}{|c|}{ Pre-2015 long-term care system } & \multicolumn{2}{|c|}{ Post-2015 long-term care system } \\
\hline Act & Types of care included & Act & Types of care included \\
\hline $\begin{array}{l}\text { Algemene Wet Bijzondere } \\
\text { Ziektekosten (AWBZ) / } \\
\text { Exceptional Medical } \\
\text { Expenses Act } \\
\text { (under responsibility of } \\
\text { national government) }\end{array}$ & $\begin{array}{l}\text { All types of long-term } \\
\text { care for people with } \\
\text { severe limitations, } \\
\text { including personal home } \\
\text { care, home nursing care, } \\
\text { personal counseling and } \\
\text { residential care. }\end{array}$ & $\begin{array}{l}\text { Wet langdurige zorg (Wlz) / } \\
\text { Long-term Care Act } \\
\text { (under responsibility of } \\
\text { national government) }\end{array}$ & $\begin{array}{l}\text { Residential care for the } \\
\text { most severe cases. }\end{array}$ \\
\hline \multirow[t]{2}{*}{$\begin{array}{l}\text { Wet maatschappelijke } \\
\text { ondersteuning (Wmo) / } \\
\text { Social Support Act } \\
\text { (under responsibility of } \\
\text { municipalities) }\end{array}$} & $\begin{array}{l}\text { Domestic help and home } \\
\text { adaptations. }\end{array}$ & $\begin{array}{l}\text { Wet maatschappelijke } \\
\text { ondersteuning (Wmo) / } \\
\text { Social Support Act } \\
\text { (under responsibility of } \\
\text { municipalities) }\end{array}$ & $\begin{array}{l}\text { Domestic help, home } \\
\text { adaptations and social } \\
\text { participation of people } \\
\text { with severe limitations, } \\
\text { notably personal } \\
\text { counseling services. }\end{array}$ \\
\hline & & $\begin{array}{l}\text { Zorgverzekeringswet (Zvw) / } \\
\text { Health Insurance Act } \\
\text { (under responsibility of } \\
\text { health insurers) }\end{array}$ & $\begin{array}{l}\text { Personal homecare and } \\
\text { home nursing care. }\end{array}$ \\
\hline
\end{tabular}

The effects of the new reform on the organization of long-term care in the Netherlands are shown in Figure 1, which shows the shift of responsibilities between the various long-term care Acts in terms of relative expenses. 
Wmo

2005

2010

$20 \%$

2015

$6 \%$
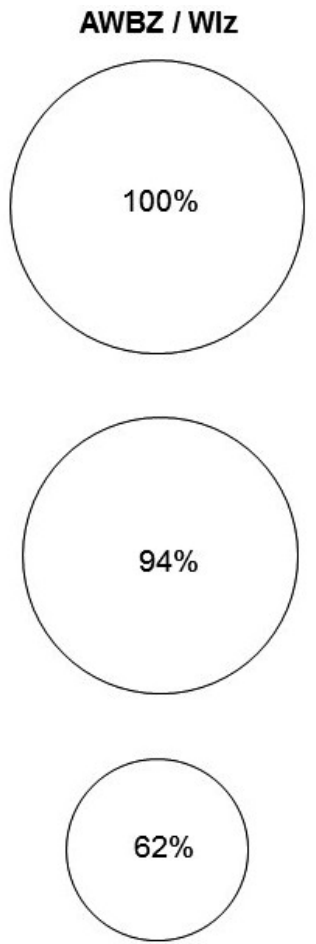

Zvw

$18 \%$

Figure 1. Transformations in the Dutch long-term care system (per long-term care Act).

- This figure is intended to give a rough overview of the main developments by approximation, as the complex nature and reform of the Dutch long-term care system is hard to capture in numbers.

- The figure is based on data derived from various Dutch Healthcare Performance Reports. The Dutch Healthcare Performance Report is an annual publication of the National Institute of Public Health and the Environment (RIVM).

The likely implications of the new reform in the Dutch long-term care system can be summarized as three main developments. First, we will witness a process of extramuralisation, whereby the aim is to provide care at home that is of an equivalent quality as to care provided in nursing and care homes. In fact, due to the budget cuts accompanying this process of extramuralisation (reflected in the limited scope of the new Wlz Act), residential care provision will decrease substantially. This means that (older) people with disabilities will stay longer at home. Second, due to the process of extramuralisation and the accompanying budget cuts, we will also witness a general shift in focus from formal care provision (the Netherlands has been typically characterized by a rather high degree of formal care provision compared to the rest of Europe [3]) to informal care provision (the Netherlands as a 'participation society' where people tend to take care for themselves and their relatives as much and as long as possible [4]). Although the Dutch residential care capacity is expected to decrease by $40 \%$ in the next 5 years [5], this decreasing level of residential care provision will not be substituted integrally by 
informal care provision. Therefore, one can expect the forced provision of informal care to rise drastically in the years to come. The latter is true all the more due to the accompanying budget cuts in the complete formal care sector (both residential and home care). This development means that (older) people with disabilities will not only stay longer at home, but also that the complexity of formal care to be delivered at home will rise. Third, next to a general decrease in government responsibility for long-term care, this responsibility is decentralizing. The responsibility that remains at the national level, under the new Wlz Act, is only intended for the most severe cases. The renewed responsibilities at the municipal level will be directed more and more to the coordination between the medical and the social domain, with a focus on social care.

As further argued by Maarse, the new reform of the Dutch long-term care system is rather unique, as this reform is not only about improving quality or efficiency of the long-term care system as such. Instead, this reform also contains a strong normative discussion about solidarity versus individual responsibility and thus also about the relationship between state and individual [2]. Because of this unique character of its new reform (characterized by major changes of its long-term care system taking place at a relatively rapid pace, starting in times of a severe economic crisis and entering into force in the wake of this crisis) the Dutch can be considered as frontrunners in Europe, whether positive or negative. While the reasons for shifting from one long-term care model to another are primarily rooted in political decisions, this article focuses on the implications that the new Dutch long-term care reform will have in practice. Specifically, we focus on the implications for municipalities as a result of the decentralizations in the social domain (notably the long-term care decentralization). We do so by answering the following research question: "To what extent are Dutch municipalities, in terms of system readiness for innovation, prepared for the challenges resulting from their new responsibilities under the new long-term care reform?" In order to answer this research question we will identify the main challenges that different stakeholders-notably care recipients, informal caregivers, long-term care organizations and the municipalities themselves - will be faced with in the new (post-2015) situation.

\section{METHODS}

In the preceding part we discussed long-term care in the Netherlands in a rather general way, due to the complexity of the Dutch long-term care system. Indeed, the various long-term care Acts we discussed encompass both long-term care for older people, as well as long-term care for disabled people. The Wmo Act even encompasses a part of the Dutch youth care. As a result, splitting up these different types of long-term care is often difficult, particularly in quantitative terms such as health care expenditures and number of patients/clients involved. However, in the remaining part of this article we do specifically consider the new (post-2015) system of long-term care for older people, 
for two main reasons. First, the bulk of long-term care expenditure in the Netherlands is dedicated to care for older people. The National Institute of Public Health and the Environment (RIVM) estimates that spending on care for older people is twice as high as spending on care for disabled people [6]. Moreover, although Figure 1 excludes youth care, youth care would comprise only $5 \%$ of the total long-term care spending if it was included in this figure [7]. The current trend of population ageing only reinforces this relative importance of care for older people in the total Dutch long-term care spending. Second, it is primarily this type of care that municipalities will be faced with in the new (post-2015) decentralized situation. As a result, the term 'long-term care for older people' will be applied in the remaining part of this article, encompassing both its residential care and its home care variant, as well as its formal and its informal care variant. To be more precise, the term long-term care for older people as applied in this article, relates to all the types of long-term care for older people as referred to in the various relevant (post-2015) Acts we discussed before (the Wmo Act, the Wlz Act and the Zvw Act).

In order to conceptualise the implications of the new long-term care reform for municipalities we applied the 'Conceptual Model for Considering the Determinants of Diffusion, Dissemination, and Implementation of Innovations' as developed by Greenhalgh et al. [8]. As this model is quite extensive, we specifically focused on the concept of 'system readiness for innovation', as indicative factor for municipalities' readiness for the challenges resulting from their new long-term care responsibilities under the 2015 Wmo Act. Based on elements of Greenhalgh et al.'s definition for 'innovation in service delivery and organization', as well as on elements of the European Commission's definition for 'social innovation', we define innovation here as a new idea (in terms of the service delivery or the policy of an organisation) that is more effective than alternatives, that is being directed at improving quality of care outcomes, that is being directed at administrative efficiency and cost effectiveness, and that is being implemented by planned and coordinated actions. By applying the concept of 'system antecedents for innovation', Greenhalgh et al. refer in their model to the more structural and cultural contexts that organisations are subject to and which influence organisations' receptiveness towards successfully assimilating innovations in general. Assimilation refers to the adoption of an innovation by all relevant stakeholders within an organisation and the implementation into the organisation's regular work processes. However, applying the concept of system antecedents for innovation would be beyond the scope of our study. Indeed, even if an organisation is receptive towards assimilating innovations in general, this does not necessarily mean that it is able or willing to actually assimilate a specific type of innovation. The ability or willingness to assimilate a specific type of innovation is what is referred to by Greenhalgh et al. as 'system readiness for innovation'. Greenhalgh et al. further specified the concept of system readiness into six components: tension for change, innovation-system fit, power balances, assessment of implications, dedicated time and resources, monitoring and feedback. 
In order to examine the system readiness of municipalities for their new responsibilities, the concept of system readiness had to be operationalised into measurable items. A study conducted by Cook et al. suggests concrete survey and interview questions for each part of Greenhalgh et al.'s model [9]. For each of the six system readiness components merely examples of qualitative interview questions, and thus no quantitative survey questions, were developed. Indeed, Cook et al. argue that organisations' system readiness for innovation can best be examined by applying qualitative research methods, as the complexity of change processes within organizations are hard to capture through quantitative research methods. For our study, we slightly adjusted the interview questions, as the questions as suggested by Cook et al. were specified to medical types of care and thus not to the more social type of care that is relevant for our study. As we conducted interviews with nine different municipalities, a semi-structured instead of an open interview approach seemed to be the most feasible option, as the former approach allows for a fair degree of comparison for each of the six system readiness components. The six questions around system readiness were preceded by a general question on the exact types of changes experienced by the different municipalities in the process of long-term care decentralization. Table 2 provides an overview of the operationalized definitions and accompanying interview questions for the six system readiness components as suggested by Cook et al., as well as our own-slightly adjusted-interview questions.

The semi-structured interviews were conducted with representatives of nine Dutch municipalities (politicians or policy advisors) responsible for the policy domain longterm care for older people. In most cases one representative per municipality was present during the interview; in one case, two representatives were present. These representatives provide an interesting target group for this study, as they are the ones in charge of implementing the decentralized policies in their respective municipality. Nonetheless, though the views of representatives of the participating municipalities provide an indication of their municipality's readiness, these cannot be considered a complete assessment of that readiness. For matters of representativeness, the municipalities were selected on the basis of number of inhabitants, thereby reflecting the overall Dutch municipalities' population categories as formulated by Statistics Netherlands (the Dutch statistical office) which are divided as follows: about $1 / 3$ of Dutch municipalities count less than 20.000 inhabitants, over $40 \%$ of municipalities count between $20.000-50.000$ inhabitants, $10 \%$ of municipalities count between $50.000-100.000$ inhabitants and less than $10 \%$ of municipalities count more than 100.000 inhabitants [10]. Because of the interview approach-requiring actual contact between the researcher and the interviewee-anonymity and confidentiality could only be guaranteed by omitting persons' and municipalities' names. 
Table 2. System Readiness for Innovation: interview questions (incl. authors' own modifications).

\begin{tabular}{|c|c|c|c|}
\hline $\begin{array}{l}\text { System Readiness for } \\
\text { Innovation } \\
\text { components [8] }\end{array}$ & $\begin{array}{l}\text { Operationalised } \\
\text { definitions, as suggested } \\
\text { by Cook et al. [9] }\end{array}$ & $\begin{array}{l}\text { Interview questions, } \\
\text { as suggested by Cook et al. } \\
\text { [9] }\end{array}$ & $\begin{array}{l}\text { Adjusted interview } \\
\text { questions for } \\
\text { present study }\end{array}$ \\
\hline Tension for change & $\begin{array}{l}\text { Perceived need for change } \\
\text { to an organisation's } \\
\text { current provision of } \\
\text { services. }\end{array}$ & $\begin{array}{l}\text { Did other providers in your } \\
\text { setting see a need to make } \\
\text { changes to the program } \\
\text { and treatment } \\
\text { approaches? }\end{array}$ & $\begin{array}{l}\text { Did other organisations in } \\
\text { your surrounding (both } \\
\text { other municipalities, but } \\
\text { also other organisations } \\
\text { involved in the care for } \\
\text { older people-see a } \\
\text { similar necessity to make } \\
\text { similar changes (within } \\
\text { their organisation)? }\end{array}$ \\
\hline Innovation-system fit & $\begin{array}{l}\text { Compatibility of the } \\
\text { innovation with the } \\
\text { organisational setting and } \\
\text { structure. }\end{array}$ & $\begin{array}{l}\text { To what extent does [the } \\
\text { treatment] fit with the } \\
\text { interventions offered in } \\
\text { your treatment setting? }\end{array}$ & $\begin{array}{l}\text { To what extent do the } \\
\text { changes your organisation } \\
\text { made fit with the } \\
\text { structure of, and } \\
\text { conventional work } \\
\text { processes within, your } \\
\text { organisation? }\end{array}$ \\
\hline $\begin{array}{l}\text { Power balances } \\
\text { (supporters v. } \\
\text { opponents) }\end{array}$ & $\begin{array}{l}\text { Relative power of groups } \\
\text { invested in } \\
\text { implementation (e.g., } \\
\text { program staff, director, } \\
\text { management). }\end{array}$ & $\begin{array}{l}\text { Was there agreement } \\
\text { among providers, director } \\
\text { and management } \\
\text { regarding } \\
\text { implementation? }\end{array}$ & $\begin{array}{l}\text { Was there agreement } \\
\text { among different } \\
\text { management levels and } \\
\text { other related } \\
\text { stakeholders regarding } \\
\text { the implementation of } \\
\text { these changes? }\end{array}$ \\
\hline $\begin{array}{l}\text { Assessment of } \\
\text { implications }\end{array}$ & $\begin{array}{l}\text { Estimation of perceived } \\
\text { benefits and consequences } \\
\text { of implementation. }\end{array}$ & $\begin{array}{l}\text { Have there been any } \\
\text { unintended benefits or } \\
\text { consequences to } \\
\text { implementing [the } \\
\text { treatment]? }\end{array}$ & $\begin{array}{l}\text { Have there been any } \\
\text { unintended benefits or } \\
\text { consequences to } \\
\text { implementing the } \\
\text { changes? }\end{array}$ \\
\hline $\begin{array}{l}\text { Dedicated } \\
\text { time/resources }\end{array}$ & $\begin{array}{l}\text { Available means needed to } \\
\text { implement an innovation } \\
\text { (e.g., funding, time, access, } \\
\text { administrative support, } \\
\text { etc.). }\end{array}$ & $\begin{array}{l}\text { Was there sufficient time } \\
\text { and resources available to } \\
\text { implement [the } \\
\text { treatment]? }\end{array}$ & $\begin{array}{l}\text { Was there sufficient time } \\
\text { and resources available to } \\
\text { implement the changes? }\end{array}$ \\
\hline Monitoring and feedback & $\begin{array}{l}\text { Providers' formal and } \\
\text { informal opinions on } \\
\text { efforts to implement. }\end{array}$ & $\begin{array}{l}\text { Were there opportunities } \\
\text { for you to provide and } \\
\text { receive feedback about the } \\
\text { implementation process? }\end{array}$ & $\begin{array}{l}\text { Were there opportunities } \\
\text { for you to provide and } \\
\text { receive feedback about } \\
\text { the implementation } \\
\text { process? }\end{array}$ \\
\hline
\end{tabular}

The qualitative data were analyzed by applying the grounded theory approach of open, axial, and selective coding [11]. This approach is based on the principle of inductive reasoning, as well as on a constant comparison method. 


\section{RESULTS}

The system readiness interview results are summarized schematically in a simplified manner in Table 3. The current section elaborates on these results, as well as on the results of the general interview item on types of changes. The following is a description of the respondents' answers and opinions, unless explicitly stated otherwise. Moreover, no striking differences have been reported between larger and smaller municipalities, unless explicitly mentioned otherwise. Indeed, the municipalities we interviewed appeared to be largely equal in terms of age distribution of its inhabitants [10]. Moreover, budget allocation from the national government to the municipalities for the execution of the Wmo Act is based on an objective allocation model based on, amongst others, demographical, physical and socio-economical characteristics of municipalities, as well as actual health care usage of its inhabitants.

Table 3. System readiness interview results of selected municipalities.

\begin{tabular}{|c|c|c|c|c|c|}
\hline $\begin{array}{l}\text { Tension } \\
\text { change }\end{array}$ & $\begin{array}{l}\text { rlnnovation- } \\
\text { system fit }\end{array}$ & $\begin{array}{l}\text { Power } \\
\text { balances }\end{array}$ & $\begin{array}{l}\text { Assessment of } \\
\text { implications }\end{array}$ & $\begin{array}{l}\text { Dedicated time/ } \\
\text { resources }\end{array}$ & $\begin{array}{l}\text { Monitoring } \\
\text { and feedback }\end{array}$ \\
\hline \multicolumn{6}{|l|}{$<20.000$ inhabitants } \\
\hline Municipality \# 1 Yes & Limited & Yes & Yes & No & Yes \\
\hline Municipality \# 2 Yes & Reasonable & Yes & $\begin{array}{l}\text { Short-term: Yes } \\
\text { Long-term: No }\end{array}$ & $\begin{array}{l}\text { Time: No } \\
\text { Resources: Yes }\end{array}$ & Yes \\
\hline Municipality \# 3 Yes & Limited & Yes & $\begin{array}{l}\text { Short-term: Yes } \\
\text { Long-term: No }\end{array}$ & $\begin{array}{l}\text { Time: No } \\
\text { Resources: Yes }\end{array}$ & Yes \\
\hline \multicolumn{6}{|c|}{$20.000-50.000$ inhabitants } \\
\hline Municipality \# 4 Yes & Reasonable & No & Neutral & No & Yes \\
\hline Municipality \# 5 Yes & Not at all & No & $\begin{array}{l}\text { Care recipients: } \\
\text { Yes } \\
\text { Municipal } \\
\text { organization: No }\end{array}$ & Yes & Yes \\
\hline Municipality \# 6 Yes & Limited & Yes & N/A & N/A & Yes \\
\hline Municipality \# 7 Yes & Reasonable & Yes & Neutral & No & Yes \\
\hline \multicolumn{6}{|c|}{$50.000-100.000$ inhabitants } \\
\hline Municipality \# 8 Yes & Reasonable & Yes & $\begin{array}{l}\text { Care recipients: } \\
\text { Yes } \\
\text { Municipal } \\
\text { organization: No }\end{array}$ & $\begin{array}{l}\text { Time: No } \\
\text { Resources: Yes }\end{array}$ & Yes \\
\hline \multicolumn{6}{|l|}{$100.000>$ inhabitants } \\
\hline Municipality \# 9 Yes & Limited & Yes & Neutral & $\begin{array}{l}\text { Time: No } \\
\text { Resources: Yes }\end{array}$ & Yes \\
\hline
\end{tabular}

This table summarizes in a simplified way the results of the nine semi-structured interviews, structured according to the six (adjusted) system readiness interview questions as mentioned in the last column of Table 2.

With regard to the types of changes municipalities will be faced with in light of the new long-term care reform, five main developments can be identified. First, our respondents 
pointed to the growing necessity for more integral ways of working ('decompartmentalization') within the own municipal organization. On the one hand, this means better cooperation and coordination within the new social domain (between the focus areas of the three decentralizations mentioned before). On the other hand, this also means better cooperation and coordination between the social domain and the rest of the municipal organization, as the social domain will constitute the majority of municipalities' responsibilities in the new (post-2015) situation.

Second, our respondents emphasized the need for better cooperation and coordination between different organizations in the field of long-term care: between municipalities themselves (more regional cooperation), between municipalities and long-term care organizations, between municipalities and individual care recipients and their social networks, and between formal care organizations (such as professional home care organizations) and informal care organizations (such as the support centres for informal caregivers). With regard to the latter, municipalities have an important task in stimulating the complementarity between the two types of long-term care organizations. In the new (post-2015 situation) formal care should be (as much as is practically possible) complementary to informal care and not the other way around. Better cooperation and coordination among these various stakeholders in the field of long-term care will be necessary in order to spend the declining long-term care budgets as efficiently as possible. Simultaneously, this development of an intensified cooperation and coordination between relevant stakeholders should lead to a better quality of long-term care according to our respondents.

Third, as more and more will be expected of informal caregivers, municipalities will have to assure suitable support measures for informal caregivers. On the one hand, this can take the form of developing policy measures geared towards a better consistency in the total informal care supply, in order to mobilize underutilized informal care capacity. On the other hand, municipalities will also have to provide support for individual informal caregivers, both practical support (such as facilitating home modifications for people who want to provide informal care to their relatives at home, organizing respite care and emotional support), as well as preventive support (such as schooling for informal caregivers).

Fourth, our respondents point to the development of the neighbourhood-based model of long-term care provision. This implies providing care close to people's own environment and with fewer resources. In practice this means that care will be provided at home for as long as possible, whereby more responsibility will be expected of people themselves and of their social networks. Long-term care will no longer be provided as a standard package, but customized according to people's individual needs, according to the principle of achieving equity instead of equality between care recipients.

Finally, municipalities will be forced to change their attitude towards long-term care provision from being reactive to proactive in nature. This change of attitude requires a new vision: from being a government that merely responds to peoples' self-proclaimed 
healthcare needs, municipalities will have to fulfil a more preventive role in the background, thereby facilitating people's own initiatives and signalling problems in the early phases of people's care process.

After discussing in a general way the types of changes municipalities are faced with in light of the new reform, respondents were asked about their own organizations' 'system readiness for innovation', or in other words: to what extent are municipalities prepared for the challenges resulting from their new responsibilities under the new long-term care reform? Each of the six system readiness components will be discussed in detail in the following.

With regard to tension for change, the same sense of urgency was experienced by all respondents. In fact, this common sense of urgency is the logical result of the top-down manner in which the new long-term care reform is implemented. Due to the decentralization imposed by the national government, municipalities do not have another choice than to accept and implement their new responsibilities. They have a limited degree of freedom in how to implement these new responsibilities. Besides the rather straightforward, shared tension for change, however, most municipalities also pointed to a greater necessity for cooperation with other municipalities as a way of sharing common challenges. This kind of regional cooperation in the social domain was in fact already given form after the 2007 decentralization of domestic help to the municipalities, when some municipalities in the same region started to develop Wmo policy plans under a common framework. However, even in the case of common Wmo policy plans, the exact execution of this policy will remain different between municipalities.

Most respondents reported a reasonable innovation-system fit, implying that in their estimation the internal municipal organization has adapted relatively smoothly to its new tasks through timely internal reorganizations whereby a wide array of stakeholders were involved. However, at the same time most respondents indicate that the real challenge will be the new way of working that will be expected of employees throughout the whole municipal organization. As we mentioned earlier, this new way of working primarily implies a more integral way of working (within the social domain and between the social domain and the rest of the organization), whereby municipal employees will be required to adapt to the neighbourhood-based model of providing longterm care and have a greater responsibility for signalling problems among care recipients. Thus, respondents might underestimate their organizations' innovation-system fit when considered from a more long-term perspective.

Concerning power balances, most respondents reported a relatively smooth attainment of agreement about the implementation of changes within their organization; both among different management levels as well as with other related stakeholders such as (health and social) care organizations. Agreement between different management levels within the municipal organization is a rather straightforward consequence of the sense of urgency that we mentioned before. This sense of urgency has sufficiently been experienced throughout municipal organizations, at all levels (both manage- 
ment and executive level) as well as at all relevant departments. With regard to other stakeholders, most municipalities emphasised the transparency of the change process, enabling the involvement and participation of a broad array of stakeholders-notably care recipients, informal caregivers and long-term care organizations-for example by means of public information and consultation sessions. Not surprisingly, some resistance towards the new reform has been experienced due to personal fears for negative consequences such as possible loss of employment for some municipal employees and the concrete implications for people in need of care.

Indeed, most respondents estimated that the implementation of the new long-term care reform will have several negative unintended implications. One can distinguish here between unintended implications for care recipients, on the one hand, and unintended implications for the municipal organisations themselves on the other hand. The rapid pace at which the reform has to be implemented causes unintended consequences for municipalities themselves, such as short-term difficulties in assuring personnel with the right expertise. This holds particularly for the smaller municipalities. However, as most municipalities agree with the core principles of the new reform (care provision closer to individual citizens as well more efficient provision of care), these unintended consequences are only expected in the transition period (late 2014 - 2015). After that, the advantages of a more efficient long-term care provision that is organised closer to individual citizens are expected to outweigh possible remaining disadvantages (e.g. single municipalities struggling to carry out their new long-term care responsibilities properly). Our respondents expect more fundamental problems among care recipients, because of the general lower level of care provision. Many care recipients and their (future) network of informal caregivers are still not sufficiently aware of the implications the impending changes may have for their personal situation-to a large extent they cannot even know yet. Transformation of people's expectations and adapting to a new reality of care provision requires more time, since these are gradual processes.

With regard to dedicated time and resources for implementing their new responsibilities, respondents generally considered the available timeframe to be far from sufficient. First and foremost, the transition process itself requires practical adaptations such as hiring new personnel or retraining the current (particularly executive) personnel in order to be ready for January 1, 2015. However, the biggest challenge according to our interviewees lies in the transformation process subsequent to the transition process. This point has been explained by pointing to the apparent lack of a proper civil society in the Netherlands. Indeed, as we mentioned earlier, the Netherlands have traditionally been characterized by a rather low degree of informal care provision as compared to other European countries. According to a European Commission study, the Netherlands is among the countries in Europe with the lowest percentage of people taking care of an older relative (less, in this regard, than only five countries: Ireland, Hungary, Germany, Slovakia and Austria), while neighboring country Belgium is among the EU countries with the highest percentage of people taking care of an older relative 
(only surpassed in this regard by four countries: France, Italy, Czech Republic and Romania) [12]. Transforming to a new long-term care reality requires more time and effort than just adapting rules and organizational structures. It requires a switch in mindset by all involved: municipal employees (adapting to new, more integral, ways of working), care recipients (adapting to a situation wherein less care will be available) and informal caregivers (adapting to a situation wherein more and more is expected from them). In addition to questions about the available time, respondents were asked about available resources. Our respondents generally considered the available financial resources for the transition process to be sufficient. Importantly, however, respondents were commenting hereupon the extent of the financial resources currently available for the implementation of the ongoing change process (including the kind of practical adaptations that we referred to above) and thus not to the financial resources that are available to municipalities as of 2015-1-1 for the actual execution of their new responsibilities.

Finally, with regard to opportunities for providing and receiving feedback about the implementation process, most respondents reported sufficient opportunities for feedback within the municipal organization about the internal implementation process. According to our respondents this can be explained by the relative horizontal organization of, and thus limited hierarchy within, Dutch municipalities. At the same time, our respondents considered opportunities for feedback of municipal organizations within the larger national reform process as almost non-existing, which is again a rather straightforward consequence of the top-down manner in which the new long-term care reform is imposed by the national government. In other words, municipalities do not have much choice but to accept their new responsibilities, but they have a relatively high degree of flexibility concerning the way in which they implement and execute their new duties.

\section{DISCUSSION}

In this study, it has become clear that municipalities consider themselves to be largely prepared for their new responsibilities resulting from the long-term care reform. However, from the interview results several remaining challenges can be identified which could manifest themselves as obstacles in the reform process.

A first challenge relates to the organizational functioning of the municipalities themselves. The fact that municipalities will get several new responsibilities due to the three decentralizations in the social domain will require new expertise and skills. A major activity therefore has been the adaptation of the internal organization to make them suitable for implementation of the new policies. Most municipalities have anticipated this timely through internal reorganizations. On the one hand this included the retraining of personnel or acquiring new staff with the right skills. On the other hand, municipalities have become more aware of the necessity of working towards more integral 
ways of operating, both among the three new tasks and between the social domain and the rest of the organization. The social domain will involve more than half of the municipalities' tasks in the new situation-influencing other policy domains directly or indirectly-and most interviewees therefore characterized the new reform as the most fundamental reform ever in the history of Dutch municipalities. At the same time, the three decentralizations are accompanied by severe budget cuts (especially in the case of the long-term care decentralization). However, most municipalities indicated that these budget cuts have (at least so far) not severely affected their internal organization-instead it will be particularly people in need of care and their informal caregivers that will be affected by these budget cuts due to the decreasing level of public service support. More integral ways of working are considered as a way of increasing efficiency precisely in order to be prepared for possible future financial difficulties. A remaining problem is that physical organizational changes such as reorganizations and training of personnel are only short-term measures to get practically prepared for the new responsibilities as of 1-1-2015. More important will be to get employees really acquainted with the new of social thinking and working, because this requires a switch in employees' mindset.

As a second challenge, our interviewees referred to the dilemma of how to deal with an increasing burden on the shoulders of informal caregivers in a country where informal care provision is not so common. As a solution to this challenge, municipalities refer to a variety of support measures that exist. On the level of official policies, municipalities have a legal duty to provide appropriate support to informal caregivers. This duty is enshrined both in the old (pre-2015) as in the new (2015) Wmo legal text. These formal obligations aside, our interviewees indicated that municipalities should shift their focus to more preventive methods of support in order to reduce the pressure on informal caregivers and avoid overload (or, in other words, to work towards a more pro-active long-term care system). This entails, among other things, working towards more coherence in the existing, though often fragmented, range of informal care support measures. The Netherlands Institute for Social Research (SCP) emphasizes the importance of recognition and customized support for informal caregivers by municipalities, healthcare professionals and employers [13]. A remaining problem is that although preventive methods of support-like education-are widely considered as the most effective way of reducing pressure on informal caregivers and to avoid overload, actual support is still particularly reactive in nature (notably in the form of respite care) instead of preventive. Moreover, support for informal caregivers is still not given enough concrete shape in the various policy documents. Also, ethical dilemmas that informal caregivers are faced with are largely neglected in policy documents such as the general Wmo legal text, the municipal Wmo policy plans and the texts of the municipal coalition agreements following the 2015 municipal elections. Indeed, as recognized by most interviewees, much more focus should be placed on issues like emotional support, psy- 
chosocial issues of care recipients (such as dementia), recognizing one's own limitations as informal caregiver and signalization of care recipients' problems 'below the surface'.

A third challenge recognized by the interviewees relates to the people in need of care. As explained in the previous two paragraphs, the long-term care decentralization is accompanied by severe budget cuts and by a higher responsibility on the shoulders of people who are not professionally trained for this purpose (the informal caregivers). Consequently, one can wonder to what extent municipalities will be able to assure the quality of care, especially to vulnerable people, in this new situation. Although municipalities expect some problems in the short term (complaints from people that were eligible for certain types of care in the old situation but not anymore in the new situation), the expectation is that in the longer term those in need of care will only benefit from the new situation due to the subsidiarity principle. The subsidiarity principle entails that decisions are taken as closely as possible to and together with the citizen. According to the principle of subsidiarity, municipalities are thus expected to know best what the specific needs of their inhabitants are. At the same time, a general assumption of municipalities is that people in need of care prefer to live at home for as long as possible. Municipalities make this assertion concrete by deploying 'neighbourhood teams', whereby several organizations-for formal as well as informal care-will work together in a local team under the coordination of the municipality and a new performance type of district nurse. An important precondition for the well-functioning of this neighbourhood-based model is smooth cooperation in the different levels of the care process: first, cooperation between formal care organizations and informal care organizations, whereby formal care should support informal care and not the other way around; second, cooperation between municipalities and organizations for formal and informal care, whereby the municipalities should be recognized as the coordinating factor; finally, cooperation between municipalities and its inhabitants in need of care (including their social network), whereby municipalities should be able to identify the needs of their inhabitants. These types of cooperation are considered as indispensable in guaranteeing, and even increasing, the quality of long-term care provision. A remaining problem is that, similar to the informal caregivers, the ethical dilemmas faced by care recipients themselves are also largely neglected in relevant policy documents. A relevant consideration in this respect is whether informal caregivers are sufficiently capable of providing the appropriate kind of care to their relatives taking into account the fundamental ethical principles of beneficence (doing what one considers best for the care recipient) and autonomy (knowing what the care recipient wants him/herself).

A fourth challenge relates to the formal care organizations, both home care and residential care organizations. As a result of the decentralizations in the social domain (notably the long-term care decentralization), formal care organizations see parts of the tasks that used to be within the scope of the AWBZ shift towards the Wmo and thus under the responsibility of municipalities (notably in the field of personal counseling). In addition, formal care organizations also see parts of their former tasks shift towards the 
Zvw (notably in the field of home nursing care) and finally, some of their tasks will disappear altogether due to the government's budget cuts. A concrete example of the latter is that residential care for patients with lower care severity packages will gradually be phased out in the period 2015 to 2017 and be abolished as of 2017. Formal care organizations are thus pretty much forced to reconsider their core business and/or to search for cooperation with other types of organizations. Therefore, nowadays a general trend is that many professional care organizations are currently deploying more generalist ways of working (outside their typical core business) and/or actively search cooperation with other (formal or informal) care organizations. Mergers between organizations for residential care and organizations for home care are currently not an uncommon phenomenon. A remaining problem may be that the division between the different types of organizations for formal care will become less clear, leading not only to fierce competition between organizations of the same kind but also to competition between organizations that used to be part of different sectors. At the same time, the complexity of formal care provision will rise, as formal care will only be available for the most severe cases. For formal care organizations this development leads to a situation wherein they increasingly will be forced to refuse care to people in need of care, while the number of people in need of care is only growing due to population ageing. This dilemma is reflected in the growing waiting lists for admission to residential care, accompanied by a growing number of empty beds in these residential care settings [14]. Even more extreme cases have been reported, such as of older people living in a residential care setting being forced to move due to the closure of their nursing or care home [15].

Finally, much of the above relates to the overall challenge of achieving economic efficiency in long-term care. Indeed, much of the recent political choices as outlined above are the result of consecutive governments' worries about the sustainability of the Dutch long-term care system due to population ageing. This argument has been reinforced by the decreasing healthcare workforce in the Netherlands, and by the economic crisis, which has speeded up much of the unpopular austerity measures that had to be taken. In various policy domains, decentralization has been considered as the answer to necessary budget cuts in general by various European national governments. The Council of Europe outlines several examples supporting this argument [16]. First, local governments are expected to work much more effectively and efficiently than national governments due to their better insight in their inhabitants' needs. Second, municipalities are expected to have a direct interest in ensuring transparency and accountability to their inhabitants, which also leads to benchmarking (e.g. learning from best practices in other municipalities). Finally, municipalities are expected to be in a better position for seeking regional cooperation, leading to cost savings due to collective purchasing and shared services. However, the main difficulty for municipalities has been to combine their new tasks in the social domain together with extra budget cuts on top of the savings that the decentralization is expected to generate in itself. Municipalities have re- 
sponded to this efficiency challenge in a twofold manner. On the one hand, many municipalities indeed actively seek regional cooperation with other municipalities. For many municipalities this means for example formulating collective Wmo policy plans and achieving economies of scale by collectively purchasing formal care services. For some municipalities it also means sharing executive services. A general trend that can be witnessed in these cooperation agreements is that smaller municipalities tend to connect with the initiatives of larger municipalities. Although this trend does not apply to every small municipality, we believe that it may be an indication that there are de facto limits to the abilities of small municipalities to decentralize such policies.

In general, however, municipalities respond to the efficiency challenge in a more passive way, by stressing citizens' own responsibility to take care of themselves and each other. Municipalities typically tend to stress the preventive character of this approach: from being a reactive government to becoming a proactive government that conveys a message and facilitates citizens' own initiatives, primarily within the context of the neighbourhood-based model.

In conclusion, we argue that municipalities' own perceptions about their system readiness for their new long-term care responsibilities are not fully in line with the actual challenges that still lie ahead of them. A clear distinction in our respondents' perceptions can be made between changes that will occur in the transition period up till January 1,2015 , and changes that will occur in the transformation period thereafter (from January 1, 2015 forward). Earlier, we mentioned that no striking differences between larger and smaller municipalities have been reported, which may be the logical result of the top-down manner in which the new long-term care decentralization is imposed by the national government. All municipalities thus witness the same sense of urgency.

Indeed, the things that are necessary for enabling municipalities to technically start with a new, decentralized, law (notably the Wmo Act) are relatively easier to arrange than reaching the final aims of this new law, which is establishing a new attitude and behaviour of citizens with regard to the way long-term care will be provided in the Dutch society henceforth. Typically, the changes occurring in the transition period are thus above all practical in nature, and deal with municipalities' organizational preparation for their new responsibilities. With regard to these transitional changes, municipalities seem to be reasonably well prepared, although the pace of the long-term decentralization is generally considered as too high. However, regarding the changes that will occur in the transformation period, municipalities seem to underestimate the remaining challenges that lie ahead, and seem to fear the uncertainty of the consequences of that process. As we argued before, it is particularly the vulnerable citizen in society (and not the municipal organizations themselves) that will eventually face the consequences of these remaining challenges and the uncertainty surrounding them. Moreover, as municipalities are to a large extent free to choose how to implement their new Wmo responsibilities, actual performance may differ considerably between municipalities. One could 
then wonder how credible a system is in which one municipality decides differently on the care needs of a specific human being than another municipality.

Finally, collaboration on different levels has been reported frequently as a comprehensive solution to various challenges: collaboration within neighbourhood teams has been considered as a way of facilitating the patient-centeredness of the care process; collaboration between healthcare organizations has been considered as a way of securing their right to exist; and collaboration between municipalities has been considered as a way of reaching efficiency gains in the long-term care process. However, collaboration as such could be considered as a challenge, as the new long-term care system requires above all a complete switch in people's and organizations' mindset. As we already argued before, this is a process that typically takes a lot of time-especially in a country with still one of the highest rates of formal care provision in Europe.

The principle strength of this study has been its in-depth, explorative approach of a currently evolving reform. At the same time, the recent nature of this development can be considered a limitation of this study due to consequent absence of quantitative research data. As a suggestion for further research, we would therefore opt for a followup at a later point in time or for an extension of the research approach chosen for this study to other European countries facing similar challenges due to retrenchments in their long-term care system. Moreover, while this study has been conducted from the perspective of municipalities, it may be worthwhile to consider the actual implications of the new long-term care reform in the Netherlands from the perspective of people in need of care and their social networks. Particularly, municipalities' approaches with regard to support for informal caregivers might be worth exploring further, as we argued that informal care provision is not so common in the Netherlands and ethical dilemmas that informal caregivers are faced with are largely neglected in current Dutch policy documents.

\section{ACKNOWLEDGEMENT}

We would like to acknowledge and thank Christoph Aluttis, MSc (Department of International Health, Maastricht University) for translating parts of the text into German.

\section{COMPETING INTERESTS}

The authors have no conflict of interest to disclose. 


\section{REFERENCES}

1 Kraus M, Czypionka T, Riedel M et al. How European Nations Care for Their Elderly: A New Typology of Long-Term Care Systems. ENEPRI Research Report No. 91; Brussels: European Network of Economic Policy Research Institutes (ENEPRI); 2010

2 Maarse $H$. The experience of searching long-term care for the elderly: client choice in long-term care in the Netherlands. European Cross Border Care Collaborations (EUCBCC) Project Report; 2013

3 Pommer E, Woittiez I, Stevens J. Comparing care: The care of the elderly in ten EU countries. The Hague: The Netherlands Institute for Social Research/SCP; 2007

4 Delsen L. From welfare state to participation society. Welfare state reform in the Netherlands: 20032010. NiCE Working Paper 12-103; Nijmegen: Nijmegen Center for Economics (NiCE); 2014

5 Berenschot. Extramuralisering ouderenzorg. Doorrekening gevolgen beleidslijn Achmea en Agis voor VV\&T (06.06.2013). Internet: http://www.zorgvisie.nl/PageFiles/82368/001_1370871513356.pdf; Accessed: 20.10 .2014

6 National Institute of Public Health and the Environment (RIVM). Zorguitgaven. Internet: http://www.eengezondernederland.nl/Heden_en_verleden/Zorg/Zorguitgaven; Accessed: 22.06.20157 Ministry of Health, Welfare and Sport. Hervorming langdurige zorg (infographic). Internet: http://hervorminglangdurigezorg.nl/external/files/Infographic_HLZ_-_01082014.pdf; $\quad$ Accessed: 22.06.2015

8 Greenhalgh T, Robert G, Macfarlane F et al. Diffusion of Innovations in Service Organizations: Systematic Review and Recommendations. Milbank Q 2004; 82(4): 581-629

9 Cook JM, O'Donnell C, Dinnen S et al. Measurement of a model of implementation for health care: toward a testable theory. Implement Sci 2012; DOI: 10.1186/1748-5908-7-59

10 Statistics Netherlands. Demografische kerncijfers per gemeente 2013. The Hague/Heerlen: Statistics Netherlands/CBS; 201311 Glaser BG, Strauss AL. The Discovery of Grounded Research: Strategies for Qualitative Research. New York: Aldine De Gruyter; 1967

12 National Institute of Public Health and the Environment (RIVM). Mantelzorg: Zijn er verschillen tussen Nederland en andere landen (updated 23.06.2014). Internet: http://www.nationaalkompas.nl/participatie/ mantelzorg/mantelzorg-verschillen-internationaal/; Accessed: 20.10.2014

13 The Netherlands Institute for Social Research. Hulp geboden. The Hague: The Netherlands Institute for Social Research/SCP; 2014

14 NRC.nl. Duizenden wachtenden bij zorginstellingen (25.08.2014). Internet: http://www.nrc.nl/nieuws/ 2014/08/25/ruim-tienduizenden-wachtenden-bij-zorginstellingen/; Accessed: 18.10.2014

15 NRC Handelsblad. Verplicht verhuizen wekt zorg (03.04.2014). Internet: http://www.nrc.nl/handelsblad/ van/2014/april/03/zorginstellingen-verplicht-verhuizen-wekt-zorg-1365667; Accessed: 16.10.2014

16 Council of Europe. Local and regional authorities responding to the economic crisis (updated 29.10.2014). Internet: https://www.vng.nl/onderwerpenindex/decentralisaties-sociaal-domein/nieuws/ decentralisatie-goed-antwoord-op-economische-crisis; Accessed: 20.10.2014 


\title{
Chapter
}

\author{
The impact of austerity-driven policy \\ reforms on long-term care quality: \\ evaluating the long-term care provision for \\ older people in Belgium and the Netherlands \\ using European quality benchmarks
}

Janssen, D., Jongen, W., \& Schröder-Bäck, P. (2016). The impact of austerity-driven policy reforms on long-term care quality: evaluating the long-term care provision for older people in Belgium and the Netherlands using European quality benchmarks. Journal of Aging Studies, 38, 92-104. doi: 10.1016/j.jaging.2016.05.003 


\section{ABSTRACT}

In this case study, European quality benchmarks were used to explore the contemporary quality of the long-term care provision for older people in the Belgian region of Flanders and the Netherlands following recent policy reforms. Semi-structured qualitative interviews were conducted with various experts on the long-term care provision. The results show that in the wake of the economic crisis and the reforms that followed, certain vulnerable groups of older people in Belgium and the Netherlands are at risk of being deprived of long-term care that is available, affordable and person-centred. Various suggestions were provided on how to improve the quality of the long-term care provision. The main conclusion drawn in this study is that while national and regional governments set the stage through regulatory frameworks and financing mechanisms, it is subsequently up to long-term care organisations, local social networks and informal caregivers to give substance to a high quality long-term care provision. An increased reliance on social networks and informal caregivers is seen as vital to ensure the sustainability of the long-term care systems in Belgium and in the Netherlands, although this simultaneously introduces new predicaments and difficulties. Structural governmental measures have to be introduced to support and protect informal caregivers and informal care networks.

Key words: long-term care, austerity, policy reforms, quality of care, quality benchmarks. 


\section{INTRODUCTION}

With the baby boom generation - the large cohort of citizens born after the Second World War, between 1946 and 1964 - gradually reaching retirement age, the beginning of an unprecedented shift in Europe's demographic composition is marked. Populations in Europe are ageing, as both the absolute number of older citizens and the relative number of older citizens (i.e. the proportion of older citizens as a percentage of the total population) are steadily growing (European Commission, 2012; Rechel et al., 2013). This rise in the number of senior citizens within Europe will inevitably lead to a significant increase in the number of frail older people with functional disabilities and limitations, in turn leading to an increasing demand and need for long-term social and medical care (Bonneux, Van der Gaag, \& Bijwaart, 2012; Christensen, Doblhammer, Rau, \& Vaupel, 2009; Ferri et al., 2005; Karim-Kos et al., 2008; Lafortune \& Balestat, 2007; Puts, Deeg, Hoeymans, Nusselder, \& Schellevis, 2008). The demographic changes will also lead to a decreasing availability of potential formal and informal caregivers (Rechel, Doyle, Grundy, \& M. Mckee, 2009), and many contemporary financing mechanisms for long-term care will no longer be sustainable due to decreasing financial contributions to social insurance schemes from a gradually shrinking professional workforce (European Commission, 2013). In addition to the aforementioned developments, most countries in Europe are currently also dealing with austerity measures resulting from the recent economic crisis, exacerbating the strain on health systems further and necessitating critical evaluation of the way long-term care services are organised and financed (European Commission, 2015; Geerts, Willemé, \& Mot, 2012; Swartz, 2013). In an attempt to ensure the sustainability of their long-term care systems, several European countries have recently implemented fundamental long-term care reforms (European Commission, 2014a), whereas in some other European countries similar reforms are currently under consideration (European Commission, 2015). However, one challenge when implementing such austerity-driven reforms, is maintaining an adequate level of quality of the care provision (European Commission, 2014a). Assessing how recent policy reforms throughout Europe have impacted the quality of the long-term care provision, has proven to be not an easy task, as quality measurement in long-term care lags some way behind quality measurement in other healthcare sectors (European Commission, 2014a). This is partly due to heterogeneity in the way long-term care systems for older people are structured across Europe (Genet et al., 2011), and the lack of common definitions of long-term care and its constituent parts of social and medical care and the borderline between them (European Commission, 2014a). Furthermore, a substantial share of long-term care is provided in people's own homes by informal caregivers, making it difficult for national governments to comprehensively and adequately monitor the quality of the provided care (European Commission, 2014a). Lastly, there seems to be a lack of consensus within Europe on how to conceptualise quality in the field of longterm care (European Commission, 2014a). Consequently, the current academic litera- 
ture provides us with a fragmented picture of quality of long-term care systems for older people in Europe (Jongen, Burazeri, \& Brand, 2015).

\section{Study objectives}

The current study aims to explore the contemporary quality of the long-term care provision in the Netherlands and the Belgian region of Flanders, a country and a region where recently substantial long-term care reforms were implemented as a response to the economic crisis and the anticipated demographic changes (European Commission, 2014b, 2014c, 2014d, 2014e). In addition to the similar socio-economic characteristics and the practical advantage of a shared language, the Netherlands and the Belgian region of Flanders form an interesting basis for comparison due to their geographic position and a certain common culture and history they thus share (Jongen et al., 2015).

Prior to the economic crisis and the recent reforms, the long-term care systems of both Belgium and the Netherlands were seen as highly developed in terms of patient friendliness, and characterised by a high degree of public funding (Kraus, Czypionka, Riedel, Mot, \& Willemé, 2011). The Netherlands used to lead the European charts in terms of public expenditure on long-term care, with governmental long-term care expenditures equalling 3.5\% of GDP in 2009 (Rodrigues, Huber, \& Lamura, 2012). With $1.9 \%$ of GDP spent on long-term care, Belgium was spending substantially less on longterm care than the Netherlands, although still far more than the European average (Rodrigues et al., 2012). Private expenditures on long-term care used to be relatively low in both countries and extensive support for informal caregivers was available. In the Netherlands, public social protection arrangements used to financially cover a large variety of care services for a large group of needy citizens, while in Belgium financial support was similarly offered for a large variety of care services, but for a limited group of needy citizens (Colombo, Llenia-Nozal, Mercier, \& Tjadens, 2011). Rodrigues et al. (2012) found that in Belgium people aged $80+$ were almost three times as likely to be at risk of poverty compared to older people in the Netherlands, and that housing costs for Belgian seniors in proportion to their income were among the highest in Europe. Lastly, prior to the reforms there was quite a high reliance on informal caregivers in the longterm care provision in Belgium, while the contributions of informal caregivers in the Dutch care provision were rather minimal (Kraus et al., 2011). As the reforms introduced substantial changes in the way long-term care is organised and financed in both countries, it is plausible that many of the findings of Kraus et al. (2011), Colombo et al. (2011) and Rodrigues et al. (2012) on the Dutch and Belgian long-term care systems no longer hold true.

In Belgium, the sixth state reform that came into force in July 2014, encompassed a substantial transfer of responsibilities related to older people and long-term care from the federal state to the communities, which are the regional political entities based on the linguistic division in Belgium (European Commission, 2014c). As a consequence of 
this decentralisation, residential facilities and cash benefit schemes for long-term care are now completely regulated at the regional level (Cès, 2014). The Belgian government's argumentation behind this shift in responsibilities is that it enables the care provision to be more efficient and better adjusted to local needs, ensuring affordable high-quality care to both citizens and those employed in the long-term care sector (European Commission, 2014c). Simultaneously, several structural cost-saving measures have accompanied recent reforms intended to limit health care expenses. In doing so, the Belgian government states that it is adhering to the country-specific recommendations of 2013 as proposed in the European Semester regarding the sustainability of public finances and social security for the elderly (European Commission, 2014c; Council of the European Union, 2013).

In the Netherlands, various responsibilities and competences for long-term care that were previously organised at national level, were transferred to the municipalities and health insurance companies on January 1, 2015 (European Commission, 2014d, 2014e). The Dutch reforms encompass that care for the most fragile and vulnerable older citizens - those in need of round-the-clock care and assistance - is now organised and financed at national level, while the municipalities are responsible for ensuring and facilitating social inclusion and independence for older citizens, supporting informal caregivers and providing household care. Health insurance companies - funded through compulsory social insurance - are tasked with the provision of nursing services, medical treatments and palliative care for older people living at home (European Commission, 2014d, 2014e). The Dutch government states that the reforms are aimed at providing more tailor-made care, delivered closer to home (European Commission, 2014e). The reforms in the Netherlands involve structural cuts of approximately 3.5 to 3.7 billion euro on expenditures on long-term care (European Commission, 2014d, 2014e). As argued by Maarse (2013), the Dutch government has been pursuing a "retrenchment agenda" rather than an "extension agenda" in the field of long-term care since the onset of the economic crisis in 2008. Similar to Belgium, the Dutch government states that by implementing structural austerity measures, it is endorsing the country-specific recommendations within the European Semester on containing the costs of long-term care (European Commission, 2014d).

While the quality of the long-term care provision is generally substantially affected by the way long-term care is organised and financed (European Commission, 2015; Hardy, 2015), it remains unclear how exactly the recent reforms and the accompanying austerity measures in Belgium and the Netherlands have affected the quality of longterm care for older people. The recent reforms have thus created the premise for exploring and assessing the contemporary quality of the long-term care provision in both countries. 


\section{Research question}

Against the background of recent long-term care reforms in Belgium and the Netherlands, the primary aim of the current study is to evaluate the Dutch and Belgian longterm care provisions in terms of adherence to established European quality benchmarks, to find out if and how the reforms have ensured and incorporated quality principles for long-term care. The research aim of this study can be translated into the following research question: "Following the recent reforms, to what extent do the long-term care provisions in the Netherlands and Belgium meet European quality principles for long-term care?" The intention is to obtain a profound understanding of how the reforms have affected older people in need of care, but also their families, informal caregivers and healthcare professionals. Through comparison of Belgium and the Netherlands our aim is not to determine which country "performs best", but to explore in a heuristic manner the topic of quality in the long-term care provision, generating valuable insights, theories and hypotheses on what possible further alterations to long-term care policy would be needed to improve the quality of the long-term care provision and to facilitate good practice identification and exchange in a European context.

\section{METHODS}

\section{Theoretical framework and conceptual model}

As indicated by Jongen et al. (2015), due to the variety of definitions of long-term care for older people it is necessary to first elaborate on the exact definition that is applied in the current study. Within our study, long-term care is defined as a range of services and provisions for people who, due to mental frailty, physical frailty and/or disability over an extended time period, have become dependent on assistance to engage in daily living activities and/or are in need of permanent nursing care (European Commission, 2014a). Daily living activities can be self-care activities - such as going to the toilet, eating, getting dressed, entering and exiting the bed, moving around the house, and taking a shower or a bath (OECD, 2015) - and instrumental daily living activities, which are activities related to the capacity to live independently, such as grocery shopping, financial management, domestic labour, cooking a meal, and using communication technologies like the internet or the telephone (European Commission, 2014a). As such, both nursing care of a more medical nature and social, personal care are incorporated in the definition of long-term care that is adhered to in the current study. Furthermore, we take into account both formal and informal caregiving when assessing the quality of the longterm care provision, and both institutional and home care will be included in the analysis. In doing so, we aim to capture the quality of the long-term care provision in a holis- 
tic manner. Finally, when using the term "older people" in the current study, we refer to those aged 65 or over (Jongen et al., 2015).

In order to evaluate the quality of the long-term care provision for older people, an understanding is needed of what the concept of quality actually means in this context. The topic of quality in long-term care has started gaining more attention on a European level in recent years, and fruitful attempts have since been undertaken to scrutinise and define what constitutes quality in long-term care (AGE Platform Europe, 2010; Dandi et al., 2012; European Commission, 2014a; Mot, Faber, Geerts, \& Willemé, 2012). This process has been greatly facilitated by the EU-supported WeDO project (European Partnership for the Wellbeing and Dignity of Older People, 2012), which was launched in 2010; led by a coalition of 18 organisations from 12 European Union (EU) Member States, the WeDO project brought together a heterogeneous collective of stakeholders involved in the field of long-term care, with the aim of improving the quality of services for older people in need of care and assistance and to fight elder abuse through a participatory approach (European Partnership for the Wellbeing and Dignity of Older People, 2012). Through the collective efforts of these participating stakeholders, the WeDO project resulted in the development of the "European Quality Framework for LongTerm Care Services" (European Partnership for the Wellbeing and Dignity of Older People, 2012), a framework that seeks to ensure a common vision and analysis on longterm care and strives to improve the quality of life of older people in need of care and assistance on a European level. The framework furthermore aims to assist in the development of sustainable and equitable solutions to improve the wellbeing and dignity of older people by facilitating good practice exchange both between and within countries, while advocating for the inclusion of older people's opinions in deciding on how to improve the quality of the long-term care provision (i.e. a participatory approach). Of great relevance for the current study is the fact that the European Quality Framework for Long-Term Care Services endorses a list of 11 key quality principles that long-term care services for dependent older people should adhere to (European Partnership for the Wellbeing and Dignity of Older People, 2012). These quality principles are relevant for all stakeholders in the field of long-term care, and can be seen as quality benchmarks on EU, national, regional and local level (European Partnership for the Wellbeing and Dignity of Older People, 2012). While all 11 quality principles of the European Quality Framework for Long-Term Care Services were seen as pertinent and important, due to pragmatic reasons and time constraints we decided to make a more concise selection of quality principles that were to be included in our study. By focusing on a few quality principles we were able to explore these key quality dimensions in a more detailed and comprehensive manner. We engaged in expert consultation with colleagues from AGE Platform Europe - a non-governmental organisation concerned with the wellbeing and interests of older people in Europe - to select several quality principles for inclusion in our study. AGE Platform Europe expressed a special interest in the quality principles affordability, availability and person-centredness in the context of the recent policy 
reforms in Belgium and the Netherlands; there were indications that these quality principles in particular were substantially affected by the austerity measures and the process of decentralisation accompanying the reforms. In the current study, we therefore adopted the three quality principles affordability, availability and person-centredness of the European Quality Framework for Long-Term Care Services (European Partnership for the Wellbeing and Dignity of Older People, 2012) to define what constitutes quality in long-term care and to evaluate the contemporary quality of the long-term care provision in Belgium and the Netherlands. Table 1 provides a brief overview of each quality principle.

Table 1. The three selected quality principles of the European Quality Framework for Long-Term Care Services (European Partnership for the Wellbeing and Dignity of Older People, 2012).

\begin{tabular}{ll}
\hline Quality principle & Explanation \\
\hline Person-centredness & $\begin{array}{l}\text { A care recipient's unique character, interests, life history, social and health needs, } \\
\text { intellectual and physical capacities, family circumstances and preferences should form } \\
\text { the basis for the provided care. Long-term care services should furthermore be driven } \\
\text { by the needs of caregivers and family members of older people when necessary and } \\
\text { appropriate. Healthcare staff should be provided with the necessary support, } \\
\text { resources and facilities to provide person-centred care. } \\
\text { A long-term care service should have the professional capacity and geographical } \\
\text { coverage to improve the health, wellbeing and independence of everyone in need of } \\
\text { long-term care and assistance. Long waiting lists should be non-existent when the } \\
\text { principle of availability is adhered to. Availability also encompasses the freedom to } \\
\text { choose between different care provision options, regardless of the personal care } \\
\text { needs, situation or place of residence of the beneficiary. } \\
\text { Having access to essential long-term care services should not depend on one's } \\
\text { financial means. Long-term care services for older people should be provided either } \\
\text { free of charge, or at a price which is affordable to the care recipient without } \\
\text { compromising on quality of life, dignity and freedom of choice (endorsing the concept } \\
\text { of universal access). Furthermore, financial support provided by collective social } \\
\text { protection systems or in-kind support should be available so people can receive the } \\
\text { long-term care they need without disproportionately impoverishing themselves or } \\
\text { their families. }\end{array}$ \\
\end{tabular}

Using this conceptual framework of what constitutes quality in the long-term care provision for older people, we aimed to answer our research question and meet the research objectives of the current study. Specifically, we aimed to:

- explore and describe to what extent the long-term care provisions in the Netherlands and Belgium meet the three quality principles of long-term care after recent reforms

- explore and describe how the reforms have affected older people in need of care, but also their families, informal caregivers and healthcare professionals

- explore what possible alterations in the way long-term care is organised and financed could improve the quality of the care provision in Belgium and the Netherlands 


\section{Research type and design}

We operationalised our study through a qualitative research approach (Denzin \& Lincoln, 2011). By adopting such a qualitative research approach, we were able to explore the complexity of the issue of quality of the long-term care provision in the specific context of the recent reforms in Belgium and the Netherlands. Furthermore, our study incorporated both exploratory and descriptive elements (Neumann, 2014). The fact that the study was conducted on a new topic in an unprecedented context asked for an exploratory approach; the specific concept of quality we adhered to (European Partnership for the Wellbeing and Dignity of Older People, 2012) had not previously been applied to evaluate the quality of the Dutch and Belgian long-term care provisions, and the reforms had created a new and unique context in which the study was conducted. Through a complementary descriptive approach we aimed to present a highly accurate picture of the specific details of the contemporary situation in both countries. The research design best fitting our research approach and research objectives was deemed to be a case study with two countries. Case study research creates opportunities to elaborate on a situation holistically, capturing its complexity while incorporating multiple perspectives (Neuman, 2014). Furthermore, case study research is highly heuristic as it provides opportunities for further learning, discovery, or problem solving - and has high conceptual validity, meaning that it enables one to "identify concepts that are of greatest interest and move toward their core or essential meaning in abstract theory" (Neuman, 2014, p. 42).

\section{Instruments for data collection}

It appeared that the quality principles of the European Quality Framework for LongTerm Care Services (European Partnership for the Wellbeing and Dignity of Older People, 2012) had not been previously operationalised into validated measurable items or interview questions. We argued that in order to capture possible complexities and subtleties linked to the topic of quality of the long-term care provision, a qualitative case study design (Denzin and Lincoln, 2011) with semi-structured interviews would be most appropriate within our study. Using semi-structured interviews allowed for a reasonable degree of comparison between the two different long-term care systems for older people in the two countries that were being evaluated (Jongen et al., 2015), while simultaneously granting a certain degree of flexibility to continuously adjust and optimise the process of data collection (Boeije, 2005). The latter is important as the subject matter and our relationship to it is an evolving process (Neuman, 2014, p. 218). We developed interview questions that were constructed around the three selected quality principles of the European Quality Framework for Long-Term Care Services (European Partnership for the Wellbeing and Dignity of Older People, 2012), and aimed to operationalise each quality principle through three interview questions that collectively accurately captured 
that quality principle's essence. Additionally we incorporated one more question covering the thoughts and suggestions of our participants on how to further improve the quality of the long-term care provision in their country. The interview questions were then translated into Dutch and pre-tested individually with two independent healthcare professionals from academic backgrounds to safeguard validity. Application of a backtranslation procedure of the interview questions was considered to be superfluous, due to the rather flexible nature of the interview process, with the interview questions serving primarily as a guideline (Jongen et al., 2015). The interviews were recorded on audio to facilitate processing of the data later on. Table 2 provides an overview of the interview questions that were used to guide the semi-structured interviews within our study.

Table 2. Quality of the long-term care provision: interview questions.

\begin{tabular}{|c|c|}
\hline Quality principle & Corresponding interview question(s) \\
\hline Person-centredness & $\begin{array}{l}\text { - To what extent are long-term care services tailored to the unique personal situation } \\
\text { of older people? } \\
\text { - To what extent are the needs and capacities of formal caregivers, informal } \\
\text { caregivers and family members respected? } \\
\text { - Does the way long-term care is currently financed contribute to a person-tailored } \\
\text { care delivery? }\end{array}$ \\
\hline Availability & $\begin{array}{l}\text { - How does the way long-term care is financed influence the availability of care } \\
\text { services for older people? } \\
\text { - Are both medical long-term care and personal long-term care available to everyone } \\
\text { in need of these types of care? } \\
\text { - Do people have sufficient freedom of choice between different care providers, } \\
\text { regardless of their care demands or place of residence? }\end{array}$ \\
\hline Affordability & $\begin{array}{l}\text { - What role do individual financial contributions play within the long-term care } \\
\text { provision? } \\
\text { - Are the individual financial contributions for obtaining long-term care affordable for } \\
\text { everyone in need of this care, without compromises to quality of life, freedom of } \\
\text { choice and human dignity? } \\
\text { - Are people able to receive the long-term care they need without disproportionately } \\
\text { impoverishing themselves or their families? }\end{array}$ \\
\hline $\begin{array}{l}\text { Suggestions on how to } \\
\text { improve the quality of } \\
\text { the long-term care } \\
\text { provision }\end{array}$ & $\begin{array}{l}\text { What changes are needed to improve the quality of the long-term care provision } \\
\text { according to you? }\end{array}$ \\
\hline
\end{tabular}

\section{Study population and sampling}

The semi-structured interviews were conducted with experts in the field of long-term care. We defined experts as professionals who through study and/or experience had obtained profound knowledge and insights in a particular topic or field. More specifically, we aimed to identify experts in Belgium and the Netherlands who were able to provide comprehensive insights on how the recent changes in long-term care policy had affected large groups of dependent older people - and to a certain extent their families and their caregivers - in everyday practice. As such, we opted for applying a theoretical 
sampling technique to get cases that would help reveal features that were theoretically important for the specific setting and topic of our study (Neuman, 2014). Potential experts were identified and contacted by utilising the professional network of AGE Platform Europe. Additionally, in both Belgium and the Netherlands multiple (academic) research institutes, organisations providing long-term care for older people and advocacy organisations representing the interests and wellbeing of older people on a national or regional level were approached. In total, 14 Dutch and 25 Belgian organisations and individual experts were contacted, resulting in 5 Dutch experts and 4 Belgian experts participating in our study. Noteworthy is the fact that especially in Belgium, several organisations and experts declined to participate in the study by arguing that due to the recentness, magnitude and nature of the reforms, they had lost sight on the contemporary quality of the long-term care provision and were thus not able to elaborate on it. Paradoxically, this further emphasised the importance of the current study. Awareness of the geographic coverage of the sample of participants was considered to be important, as inherent to the decentralisation process of long-term care responsibilities in both countries, there could be relevant differences in long-term care quality on a local or regional level. In the Netherlands we included participants from multiple provinces and municipalities, and the experts indicated that they were able to elaborate on the quality of the long-term care provision on a national level. In Belgium, we merely included participants from the region of Flanders. We deliberately chose not to include the other regions of Belgium, as long-term care competences predominantly lie with the regional authorities, and Wallonia and Flanders can be seen as distinctly different in terms of long-term care policy. It might therefore be better to assess long-term care quality for the Belgian regions separately, instead of aiming to assess the quality of the long-term care provision for the federal state of Belgium as a whole. When interpreting the results of the current study, one must therefore be aware that findings for Belgium mainly apply to the region of Flanders, while the insights obtained for the Netherlands can generally be applied on a national level.

Several of the experts participating in our study were involved in the field of longterm care on multiple levels, meaning they fulfilled multiple professional roles at multiple organisations or institutions. Table 3 provides a simplified overview of the professional backgrounds of the participants of our study.

Amongst the interviewed experts were 2 Dutch and 2 Belgian directors of long-term care organisations. The two Belgian long-term care organisations were specialised in extramural nursing and personal care, with each organisation covering one of the 5 provinces of Flanders. The two Dutch long-term care organisations both provided a broad range of intramural and extramural long-term care amenities on a municipal level. The advocacy organisations in the Netherlands included in the study were a national knowledge and expertise institute on long-term care, an advocacy group for informal caregivers and a national patient federation. One of the Belgian advocacy organisations included was a federation that represents nursing and retirement homes, local 
and regional service providers and day care centres in the long-term care sector. The other Belgian respondent linked to an advocacy organisation was amongst other things a taskforce member on long-term care for an international non-profit organisation concerned with the wellbeing of elderly.

Table 3. The professional profiles of the experts who participated in our study.

\begin{tabular}{|c|c|c|c|c|}
\hline Country & $\begin{array}{l}\text { Participant } \\
\text { identifier }\end{array}$ & $\begin{array}{l}\text { Professor / academic } \\
\text { researcher in long-term } \\
\text { care or a closely related } \\
\text { field }\end{array}$ & $\begin{array}{l}\text { Representative of an } \\
\text { advocacy organisation } \\
\text { concerned with the } \\
\text { (health-related) interests } \\
\text { and wellbeing of older } \\
\text { people }\end{array}$ & $\begin{array}{l}\text { Director of an } \\
\text { organisation providing } \\
\text { long-term care for older } \\
\text { people }\end{array}$ \\
\hline \multirow[t]{5}{*}{ The Netherlands } & 1 & $\checkmark$ & & $\checkmark$ \\
\hline & 2 & $\checkmark$ & $\checkmark$ & \\
\hline & 3 & $\checkmark$ & & $\checkmark$ \\
\hline & 4 & & $\checkmark$ & \\
\hline & 5 & & $\checkmark$ & \\
\hline \multirow[t]{4}{*}{ Belgium } & 6 & & $\checkmark$ & \\
\hline & 7 & & & $\checkmark$ \\
\hline & 8 & $\checkmark$ & $\checkmark$ & \\
\hline & 9 & & & $\checkmark$ \\
\hline
\end{tabular}

Although ideally one conducts interviews and gathers data until a level of empirical saturation is reached, in practice this is not always possible or practical. Furthermore, even with a small sample one can produce a study with depth and significance (Baker \& Edwards, 2012). We argued that by including a small, heterogeneous collective of knowledgeable experts on the topic of long-term care for older people, the contemporary quality of the long-term care provision in the Belgian region of Flanders and the Netherlands could be explored from multiple angles and in a heuristic manner, generating valuable insights and enabling a process of lesson-drawing on a European level.

To ensure confidentiality, all participants were asked to sign an informed consent form. Due to the theoretical sampling technique used and the interview procedure requiring actual face-to-face contact between the researcher and the interviewees, anonymity could only be guaranteed to the extent that names of persons and organisations were omitted upon publication of this article.

\section{Data analysis}

The audio files from the interviews were analysed through the application of directed content analysis (Hsieh \& Shannon, 2005). The directed approach to content analysis works with prior formulated, theoretical derived aspects of analysis (Hsieh \& Shannon 2005; Mayring, 2000). This results in this form of content analysis being rather deduc- 
tive in nature (Mayring, 2000). We opted for using the directed approach to content analysis as it enabled us to adhere to our conceptual framework of quality in long-term care (European Partnership for the Wellbeing and Dignity of Older People, 2012) when interpreting and categorising the research data (Hsieh \& Shannon, 2005; Mayring, 2000). The three selected quality principles of the European Quality Framework for Long-Term Care Services (European Partnership for the Wellbeing and Dignity of Older People 2012) were used as initial coding categories (Potter \& Levine-Donnerstein, 1999). Using these predetermined coding categories, relevant findings from the audiorecordings were transcribed and categorised. Relevant data that could not be coded immediately were identified and analysed to determine if they represented a new category or a subcategory of an existing code (Hsieh \& Shannon, 2005).

\section{RESULTS}

In the following subsections, the results of our study will be presented in the same order as the different quality principles were previously introduced in Table 1 . The different subcategories per quality principle were formulated based on the interview findings. The direct respondents' quotes are the authors' own translations from Dutch to English.

\section{Person-centredness}

\section{Assessing and meeting an older person's long-term care needs}

In theory, the long-term care benefit entitlements older people receive in Belgium and the Netherlands are need-based. Still, both the Dutch and Belgian respondents argue that the long-term care provision is mainly supply-steered rather than demand-steered. Often the care one receives and the setting in which this care is provided are not guided by an individual's preferences and care needs, but rather by financial restrictions. In both countries, when an older person requests a form of long-term care, his or her care needs are assessed and categorised in accordance with predefined categories of a care severity classification system; each category corresponds to a different level of care and reimbursement. Still, this does not guarantee that people actually receive the care they need or the care they are entitled to. Due to budgetary constraints, the Flemish government has stopped acknowledging the highest intramural care severity category, as this category is linked to the highest rate of reimbursement. Older people meeting the criteria for this category - meaning they have severe functional limitations and high care demands - are now categorised as if they had lower care demands, which also results in a lower financial benefit entitlement. Consequently, long-term care providers are struggling to meet the high long-term care demands of this group with the limited financial means that are made available by the government for this purpose. In the 
Netherlands, similar discrepancies between the assessed care needs and the care that is actually provided can be observed in extramural settings.

Furthermore, according to the respondents, the Flemish and Dutch governments merely look at the level of disability when assessing a person's long-term care needs. There is insufficient attention for various factors that could contribute to a more person-centred care delivery, such as an individual's unique preferences, background and interests. In practice, it is up to long-term care professionals and social networks to give substance to a person-centred care delivery. Multiple Dutch respondents argue that despite budgetary constraints, it is still possible in this day and era to provide long-term care that is largely tailored to the individual needs of a recipient, although it does require a certain degree of flexibility and creativity from long-term care service providers and - in the case of the Netherlands - municipalities.

\section{The needs of family members and caregivers}

The quality principle person-centredness encompasses that long-term care services should also be driven by the needs of relatives and caregivers of older people when necessary and appropriate. In both countries, the strain on formal caregivers has been steadily increasing since the onset of the economic crisis. Especially in Belgium, some respondents expressed profound concerns about the working conditions of formal caregivers in the long-term care sector, as working in this sector is seen as both emotionally and physically burdensome. Night shifts are common practice for many longterm care professionals. Furthermore, the long-term care demands in both intramural and extramural settings have been steadily increasing over the last couple of years. As there generally is no budget available to hire additional staff, many long-term care professionals are confronted with a steadily increasing workload. This is furthermore aggravated by the aforementioned fact of the Flemish government not acknowledging the highest care severity category any longer; the budget that is made available for the most frail and dependent older citizens is not aligned with the actual care demands of this group. One Belgian respondent stated that formal caregivers should be allowed more flexible working conditions and an alleviated workload, as this respondent fears that many formal caregivers will not be able to work until retirement age under the current conditions.

The contributions of informal caregivers are seen by the respondents as indispensable to ensure the sustainability of the long-term care provision in both Belgium and the Netherlands, but at the same time informal caregivers face numerous difficulties. They are at risk of becoming socially isolated, and many of them experience a deterioration of their own physical and mental health when structurally providing informal care. Furthermore, many informal caregivers risk losing part of their income and pension rights when their informal care responsibilities force them to give up working hours. The respondents feel there is a lack of social support and financial protection for informal caregivers in both Belgium and the Netherlands. 


\section{Funding schemes and person-centredness}

In the Netherlands, people who are entitled to receive long-term care can choose to receive a personal budget instead of in-kind benefits. Generally, this is seen by the Dutch respondents as a phenomenon that contributes to a person-centred care delivery, as it provides people a degree of freedom and autonomy in purchasing the care services of their preference. The Flemish government is currently pursuing a financing system quite similar to that of the Netherlands, in which care recipients receive a personal budget and become responsible for managing their own long-term care expenses. This Belgian system of "person-tailored financing" is expected to be introduced in 2018.

\section{Availability}

\section{Intramural long-term care capacity}

In both Belgium and the Netherlands one can observe a shift away from institutional long-term care towards long-term care delivery in people's own homes; a phenomenon referred to as "ageing in place". However, this shift seems to be far more rigorous in the Netherlands. While the Flemish government does stimulate ageing in place and is increasingly relying on informal caregivers and local networks to meet the population's care demands extramurally, it still invests in additional intramural care capacity due to the sheer (anticipated) growth of the number of frail older citizens. Multiple respondents reported that between 2015 and 2018, the Flemish government aims at realising approximately 8,400 new intramural residential units in addition to the 75,000 existing ones. In contrast, as part of the recent reforms in the Netherlands, the Dutch government has started rigorously decreasing the intramural long-term care capacity; the amount of beds in nursing homes and care homes is being reduced from approximately 165,000 in the year 2015 to 100,000 in the year 2017. When interpreting the aforementioned data it is furthermore important to note that the Flanders region has approximately 7,6 million inhabitants, whereas the Netherlands has approximately 16,9 million inhabitants. While in previous years older people with light to moderate functional limitations and care demands in the Netherlands were eligible to reside in care homes and/or nursing homes if they so desired - often also for social reasons, e.g. to counter social isolation and loneliness, or for the sense of security from having healthcare personnel around -, within the new long-term care system in the Netherlands, residential long-term care is reserved solely for those with the most severe functional limitations and the highest care demands. Essentially one could state that care homes and other living arrangements for older people with mild to moderate limitations (such as service flats) are completely disappearing, while only nursing homes remain. In Flanders, older people still have a greater variety of living arrangements available to them (e.g. nursing homes, care homes, service flats, assisted living facilities), and the government tries to keep up with the demands by investing in real estate. 


\section{Local initiatives}

In the Netherlands, local initiatives such as "care cooperatives" and "city villages" are gradually emerging to complement the efforts of municipalities in the field of long-term care. Care cooperatives are collectives of older people and care professionals, who make their own arrangements with regard to living, wellbeing and care. The recent reforms have introduced a regulatory framework which allows these care cooperatives to officially take over certain long-term care responsibilities from the municipalities and to receive funding from the government for this purpose. In addition to care cooperatives, there is also an increase in the number of city villages. City villages are social networks within a small community - often confined to a certain quarter within a bigger city - which actively try to provide support, stimulate cohesion and mobilise volunteers to meet certain social (care) needs of the frail older people in the respective area. As both city villages and care cooperatives in the Netherlands operate locally, and both phenomena are rather new, the geographical coverage of these initiatives is still limited, although rapidly expanding. Similar initiatives were not mentioned by the Belgian respondents, although they did indicate that there is a diverse array of care services and social services available to older people which are provided by the government and long-term care organisations. Still, in both countries multiple respondents expressed particular concerns about the availability of adequate care and support for people from lower socio-economic backgrounds, who often lack the assertiveness and the connections to mobilise the care they need within their social network. The respondents argue it might also be more difficult to effectuate initiatives such as city villages and care cooperatives in disadvantaged neighbourhoods and in communities where social cohesion is lacking.

\section{Freedom of choice}

The Dutch respondents were remarkably united in their claim that the importance of freedom of choice is generally overrated in the long-term care provision, and that for most older people in need of long-term care and assistance, the freedom to choose between different care providers is not so important. One respondent emphasised that older people generally do not have the tools and insights to make an informed choice between different care providers. Furthermore, this respondent stated that "the healthcare system is not a market, and the patient is not a customer". Older people want to receive effective care and want to be treated with respect, and they generally do not mind which care provider facilitates in these needs.

For intramural long-term care, freedom of choice is seen as nearly non-existent in the Netherlands. Once a care recipient reaches a level of care dependency that justifies and allows institutionalisation, his or her care demands have usually grown so high that the urgency of being admitted in any intramural care facility that has a bed available generally prevails over the principle of freedom of choice. Furthermore, in both Belgium and the Netherlands, older people with severe psychogeriatric morbidity - e.g. Korsa- 
koff's syndrome or certain types of dementia - can only be admitted in a very limited number of long-term care facilities which are specialised in dealing with the specific needs of this group. Freedom of choice often does not play a role in these cases as the urgent needs of a recipient dominate the principle of freedom of choice. For extramural nursing care, older people in Belgium can usually choose between various care organisations, while in the Netherlands the choice is often limited to the local nursing team that has been assigned by one's health insurer.

\section{Waiting lists for long-term care}

For Belgium some respondents indicated there are generally waiting lists for residential long-term care and medical procedures in the hospital. In the Netherlands, the possibility to receive a personal budget instead of in-kind benefits has proven to be very efficient to reduce the waiting lists for intramural long-term care, as many people opt to receive care at home when given the choice. The Dutch respondents do fear that population ageing in combination with the sharp reduction of intramural care capacity will lead to increasing waiting lists for institutional long-term care in the coming years. Currently the waiting lists for institutional care in the Netherlands are very short, but the respondents argue that this is partly due to the very strict eligibility criteria. The current situation in the Netherlands seems to be that there is a group of older people who would benefit from institutionalisation - as their care demands are not adequately met in their home setting - but who simultaneously do not meet the government's criteria to be admitted in a nursing home. While officially these people are not on a waiting list, some respondents argue that they should be.

\section{Affordability}

\section{Affordability of institutional long-term care}

Multiple Belgian respondents mentioned that within nursing homes, the costs of board and lodging - i.e. the costs of meals and accommodation - have increased by $20 \%$ over the past five years. Currently, the average price to reside in a nursing home is around 1,500 euro per month, and this price is expected to further increase to 1,800 euro per month within the next couple of years. As an average pension equals around 1,200 euro per month in Flanders, this steep increase in residential lodging costs is seen as problematic by the respondents. Although the Flemish government does provide financial support in the form of housing subsidies, the respondents state that these subsidies are not sufficient for many people to meet their lodging expenses. Consequently, older people often have to use their savings, sell their house or depend on financial support from their children when they are institutionalised. In addition to the costs of board and lodging, there are the costs of healthcare staff, medication and medical equipment. As mentioned in one of the preceding subsections, older people in Belgium who need longterm care are assessed and categorised using a care severity classification system. 
Based on the assigned care severity category, a predetermined budget is made available by the government to meet the care needs of a recipient. One respondent stated that this budget usually covers the most basic care proceedings and personnel costs. Longterm care organisations are free to hire additional staff and to intensify the level of care provided, but any supplementary costs that exceed the government's budget have to be covered by the organisation. In practice these costs are charged directly to the residents. As stated before, since a couple of years the Flemish government has stopped acknowledging the highest intramural care severity category, as this category is linked to the highest rate of reimbursement. Essentially this means that the government has substantially reduced the available budget for the most fragile and dependent older citizens, forcing long-term care organisations to either provide the necessary care without adequate reimbursement or to demand greater financial contributions from care recipients.

The Dutch government requires co-payments to cover the costs of care, board and lodging when people are institutionalised. The government takes into account both one's income and one's assets to determine the height of these co-payments. If someone has substantial assets and a relatively low income, then the government will require that one's assets are partly used to cover the co-payments. Still, the current system in the Netherlands does protect older people from losing their house or from running into problems with paying off their mortgage. Multiple Dutch respondents feel that the required co-payments are fair and reasonable, and that not all long-term care services should be financed collectively. These respondents state that just because someone reaches a certain age and develops a certain care need, this should not necessarily imply that suddenly all his or her needs have to be met and paid for by society.

\section{Affordability of extramural long-term care}

In both the Netherlands and Belgium, extramural nursing care is completely covered by social insurance, and no co-payments are required. This does not apply to personal care and domestic assistance, for which in both countries co-payments are required. In Belgium, the rates of personal care and domestic assistance are fixed by the government. Older people in Belgium can purchase service vouchers with which they can obtain assistance with instrumental daily living activities (e.g. ironing, grocery shopping) and special transportation services in case of mobility problems. These service vouchers are heavily subsidised by the government and exempted from tax, resulting in older people effectively paying a fee of around six euro per hour of service obtained.

Since the recent reforms in the Netherlands one's financial means and social network play a more significant role in obtaining social support and personal care services, and the respondents report that especially for the group of older people who are unable to mobilise their social network, affordability is becoming an issue. Due to budgetary constraints, many municipalities in the Netherlands are unable to meet all the social and personal care needs of older people. Consequently, the Dutch respondents have noticed 
a vast increase in the number of for-profit organisations trying to fill this apparent gap in the market. The services provided by these organisations include paid companionship, assistance with household chores and other personal care tasks. Many of these services are however seen as too expensive for older people with a low socioeconomic status, while this group would arguably benefit most from obtaining these services.

\section{Suggestions for improving the quality of the long-term care provision}

The participants of our study provided various suggestions on how to further improve the quality of the long-term care provision in their country. While some of these recommendations have already been partly covered in the preceding subsections, a comprehensive summary of all relevant recommendations for both Belgium and the Netherlands can be found in Table 4. We included suggestions that were supported by multiple respondents, as well as suggestions that were merely mentioned by a single respondent.

Table 4. Summary of recommendations on how to improve the quality of the long-term care provision.

\begin{tabular}{|c|c|}
\hline Country & Suggestions on how to improve the quality of the long-term care provision \\
\hline \multicolumn{2}{|c|}{$\begin{array}{l}\text { The Netherlands A greater emphasis on healthy ageing and initiatives with a preventive focus - supported by } \\
\text { technological innovations and home adaptations - is recommended. Housing corporations } \\
\text { should carry an increased responsibility in the realisation of a sufficient supply of suitable } \\
\text { housing arrangements, i.e. houses with special adaptations to support older persons' } \\
\text { capacities to live independently. Technological innovations could furthermore contribute to a } \\
\text { decreasing necessity of caregivers having to physically attend to a care recipient's needs. }\end{array}$} \\
\hline & $\begin{array}{l}\text { The national government, the municipalities and the health insurers should increase their } \\
\text { collective efforts in supporting informal caregivers and equipping social networks and local } \\
\text { communities for adequately addressing the care needs of dependent older people. }\end{array}$ \\
\hline & $\begin{array}{l}\text { Long-term care organisations and municipalities have to be creative and flexible in meeting } \\
\text { their responsibilities in the field of long-term care. Municipalities and long-term care } \\
\text { organisations should actively explore and adopt good practice approaches for dealing with the } \\
\text { recent changes in the long-term care sector. }\end{array}$ \\
\hline & $\begin{array}{l}\text { As the emphasis on self-care is increasing, municipalities should launch initiatives to improve } \\
\text { older persons' self-management skills, health literacy and computer literacy. }\end{array}$ \\
\hline & $\begin{array}{l}\text { The priority of healthcare professionals in the extramural long-term care sector should be to } \\
\text { support, coach and coordinate volunteers and informal caregivers on a local level. Informal } \\
\text { caregivers should be trained, instructed and supervised by professionals as their } \\
\text { responsibilities in the care provision are increasing. The government should set up the } \\
\text { required infrastructure for this process. }\end{array}$ \\
\hline & $\begin{array}{l}\text { Currently there are no quality requirements for informal caregivers, even though many of } \\
\text { them are paid for their contributions with public means (through a beneficiary's personal } \\
\text { budget which is paid for by the government). Therefore, the government should consider } \\
\text { introducing a qualification and certification system for informal caregivers, to ensure certain } \\
\text { quality standards are met when pubic money is spent on care. }\end{array}$ \\
\hline & $\begin{array}{l}\text { The generation of young and active senior citizens (aged } 60-70 \text { ) should be mobilised to } \\
\text { support their old and frail neighbours. Together with municipalities these young senior } \\
\text { citizens have a key role to play in setting up initiatives like city villages (a good practice } \\
\text { example here being the city of Amsterdam, where so far } 22 \text { city villages have been founded). }\end{array}$ \\
\hline & $\begin{array}{l}\text { The expediency within long-term care organisations should be increased by getting rid of } \\
\text { unnecessary bureaucratic administrative proceedings. All steps within the care process } \\
\text { should have a proven added value and should contribute to a better care delivery. }\end{array}$ \\
\hline
\end{tabular}




\begin{tabular}{|c|c|}
\hline Country & Suggestions on how to improve the quality of the long-term care provision \\
\hline \multirow[t]{8}{*}{ Belgium } & $\begin{array}{l}\text { The federal and regional governments should revamp and simplify the regulatory framework in } \\
\text { the field of long-term care to allow for a more flexible service delivery with less bureaucratic } \\
\text { bottlenecks interfering with the care delivery process. }\end{array}$ \\
\hline & $\begin{array}{l}\text { There should be more collaboration and dialogue between the federal and regional } \\
\text { governments and the various actors in the field of long-term care. The Belgian respondents } \\
\text { feel the long-term care sector would benefit from more collaboration in assessing the exact } \\
\text { care needs of each individual care recipient and for consequently developing a treatment plan } \\
\text { that is supported by all relevant actors. }\end{array}$ \\
\hline & $\begin{array}{l}\text { Adherence to a financing system in which the allocation of financial resources and staffing } \\
\text { corresponds to the actual care needs of the care recipients in a uniform and non-arbitrary } \\
\text { manner, without differentiating between different age groups. }\end{array}$ \\
\hline & $\begin{array}{l}\text { The regional governments in Belgium should facilitate the transition of the long-term care } \\
\text { system by actively supporting the development of digital healthcare platforms. Concretely, } \\
\text { an expansion of functionalities of the already existing Flemish and national e-health } \\
\text { platforms is suggested. }\end{array}$ \\
\hline & $\begin{array}{l}\text { The federal and regional governments should invest in supplementary arrangement to } \\
\text { reduce the strain on informal caregivers. More concretely, the government should invest in } \\
\text { psychosocial support for informal caregivers, possibly through dedicated social support } \\
\text { networks. Informal caregivers should also be better protected from losing their pension } \\
\text { rights and social benefits when having to care for a dependent family member or loved one. }\end{array}$ \\
\hline & $\begin{array}{l}\text { An increased focus on prevention of morbidity in old age, by stimulating active ageing and } \\
\text { age-friendly environments. Specific areas that require more attention are healthy nutrition, } \\
\text { physical activity and self-care activities. }\end{array}$ \\
\hline & $\begin{array}{l}\text { The financing mechanisms behind long-term care should be reorganised in a way that } \\
\text { supports investments in innovative solutions. }\end{array}$ \\
\hline & $\begin{array}{l}\text { The government should develop a system to monitor the safety of patients within the long- } \\
\text { term care sector, as one correspondent feels there are currently too many incidents } \\
\text { jeopardising older people's health. This monitoring system should cover both institutional } \\
\text { care settings and extramural care settings. }\end{array}$ \\
\hline
\end{tabular}

Note: Suggestions that were supported by at least two respondents are written in boldface.

\section{DISCUSSION}

By utilising the expertise and insights of multiple experts involved in the field of longterm care, the current study has put forward an overview of the contemporary quality of the long-term care provisions for older people in the Netherlands and the Belgian region of Flanders following recent policy reforms. In this final section, we will summarise the principal findings of the current study and move towards their broader implications.

\section{Principal findings}

After analysing and categorising the data, some noteworthy similarities between Belgium and the Netherlands were uncovered, as well as some distinct differences. In both countries it seems that certain vulnerable groups of older people - particularly those 
from lower socio-economic backgrounds - face increasing difficulties regarding the affordability of long-term care services. In the Netherlands concerns regarding affordability seem most pronounced for personal long-term care in extramural settings, while in Belgium issues with affordability are most visible in intramural settings, due to the continuously increasing costs of institutionalisation. In both countries, accessibility and availability of long-term care services are seen as potentially problematic for older people who lack a supportive social network, and in the Netherlands it furthermore seems to vary widely between municipalities whether certain care services are available and accessible. Although respondents in both countries state that the long-term care provisions in their country are predominantly supply-steered rather than demand-steered, the Dutch regulatory framework currently seems to be more flexible than its Flemish counterpart for allowing a person-centred and comprehensive long-term care delivery. In both countries there are concerns about the increasing strain on caregivers, although in the Netherlands these concerns seem more pronounced for informal caregivers, whereas in Belgium these concerns are more pronounced for formal caregivers. One of the more striking differences between the two countries relates to the availability of residential units in nursing homes and care homes; while the Flemish government invests in additional intramural residential units, the Dutch government is reducing the intramural long-term care capacity by approximately $40 \%$ within a two year timespan.

The Dutch respondents all emphasised the value and necessity of decentralising responsibilities in the long-term care sector and reducing public expenditures on long-term care. They argued that organising and providing care on a local level with support of volunteers, social networks and informal caregivers is the only suitable solution to ensure the sustainability of the long-term care provision. The Dutch government is however criticised by the participants for the rigorous manner and fast pace with which the recent reforms have been implemented. The Dutch respondents feel that the rate at which the intramural long-term care capacity is being reduced, greatly exceeds the rate at which new local social structures are being created and strengthened. Consequently, many municipalities, social networks and informal caregivers are ill-equipped to meet their increased responsibilities in the field of long-term care. In contrast, the long-term care provision in Belgium seems to be undergoing a more incremental transition, with various competences being transferred from the federal to the regional level over a timespan of multiple years. Furthermore, the budget cuts accompanying the transition of the longterm care system in Belgium seem to have been less rigorous and precipitous than the budget cuts that have accompanied the Dutch long-term care reform.

Both the Belgian and Dutch experts evaluate their government's idealistic and ideological reasoning behind the reforms - to ensure tailor-made care, delivered closer to home, with the support of a caring and involved society - as being mainly rhetoric, with the real driving force behind the reforms being the need for austerity measures. Schröder-Bäck, Stjernberg and Borg (2013) state that in the wake of the Eurozone public debt crisis, cutbacks on healthcare expenditure and social welfare benefits are often seen by 
decision makers as a short-term solution to alleviate budgetary pressure. This in turn is viewed by others to be a breach of the European Union's overarching health-related values of solidarity, universality, equity and access to good quality care. Schröder-Bäck et al. argue that although these values offer us some degree of orientation, in times of tough decision making they might not provide the concrete guidance we seek as a society. Instead, the 'accountability for reasonableness' approach of procedural justice by Daniels and Sabin (2008) is proposed to be taken into consideration when making decisions on health and healthcare policy in times of economic turmoil. This approach offers a minimal ethical standard when a scarcity of resources leads to an inability to satisfy all needs that might exist in a society. Daniels and Sabin emphasise that a fair and deliberative process should proceed complex resource allocation decisions. This encompasses that any decisions that are made, as well as the reasoning behind these decisions, have to be completely transparent to the public. Furthermore, the reasons by which decisions are made have to be relevant and agreed on by all relevant stakeholders involved. Decisions should be subjectable to revision if new valid arguments are introduced, and one must refrain from discrimination and stigmatisation. Using this accountability for reasonableness perspective to evaluate the recent long-term care reforms in Belgium and the Netherlands, it seems there is ample room for improvement. In both Belgium and the Netherlands it seems that consensus amongst relevant stakeholders for the chosen course of action within the long-term care sector is largely missing, as informal caregivers, long-term care organisations and municipalities have proclaimed to experience substantial difficulties to cope with the reforms. Under the premise of a more qualitative, person-centred care delivery, the consequences of the reforms have been predominantly negative when looking at the availability, person-centredness and affordability of long-term care. Still, some promising initiatives are gradually emerging (e.g. city villages in the Netherlands), and in due time these initiatives could help ameliorate the quality of the care provision, although the geographic coverage and social reach of these initiatives still have to increase vastly. Investing in these initiatives might seem counterintuitive to policy makers in times of economic crisis, but relatively modest investments in these initiatives could alleviate budgetary pressure on the long term, as they facilitate the transition of long-term care responsibilities from the formal to the informal care sector. In Belgium the main difficulties jeopardising quality of care are the high housing costs in intramural settings and the decreasing budgets allocated to the care of the most frail senior citizens. Small improvements in Belgium might be underway, such as the person-tailored financing system which is scheduled to be introduced as part of the ongoing reforms.

\section{Broader implications and conclusions}

While the primary aim of this study was to evaluate the quality of the long-term care provision in Belgium and the Netherlands, we argue that the obtained insights trans- 
cend the borders of the countries under evaluation. Many countries are currently confronted with similar predicaments on how to reorganise their long-term care systems in a sustainable manner. Analysing the contemporary situation in Belgium and the Netherlands and critically evaluating the approaches chosen by the Belgian and Dutch governments allows for a process of lesson-drawing on an international level. Ensuring that the various quality principles are met within the long-term care provision seems to depend on a dynamic interplay between different actors; while national and regional governments set the stage through the regulatory frameworks and financing mechanisms they introduce, it is subsequently up to long-term care organisations, local social networks, formal and informal caregivers, municipalities and health insurers to give substance to a high quality long-term care provision.

We conclude by arguing that new and creative approaches to long-term care are needed to meet the increasing care demands of older people throughout Europe. This implies that regulatory frameworks should provide the necessary flexibility to explore new initiatives within the long-term care provision. Furthermore, when confronted with demographic changes of this magnitude, it is important to ensure that older people remain healthy and independent as long as possible. This requires a holistic approach, with additional investments in age-friendly environments, technological innovations and home adaptations, and greater emphasis on healthy nutrition, physical activity and selfcare activities amongst the elderly. Also, it seems that throughout Europe, informal caregivers have an increasingly important role to play in meeting the care demands of dependent senior citizens (Naiditch, Triantafillou, Di Santo, Carretero, \& Hirsch Durrett, 2013). This underlines the importance of supportive measures to improve the quality of the care provided by informal caregivers, but also to ensure their wellbeing. The collective efforts of informal caregivers can substantially alleviate the strain on the formal care sector and contribute to a sustainable long-term care delivery, but at the same time it is clear that an increased reliance on informal caregivers can be highly problematic. Providing informal care frequently takes a heavy toll on a caregiver's mental and physical health; many informal caregivers are structurally overburdened and are furthermore at risk of suffering severe adverse social and financial consequences. Therefore, governmental support measures for informal caregivers should include both practical support, such as the facilitation of home modifications for people who want to provide informal care to their relatives at home, as well as preventive support, such as special education for informal caregivers (Jongen, Commers, Schols, \& Brand, 2015). In line with the findings of Nies, Leichsenring and Mak (2013), we argue that these support measures have to be tailored to the individual needs and expectations of informal caregivers, while simultaneously taking into account the divergent cultural, social and religious values across Europe which guide and influence public opinion on who should take on certain care responsibilities and what form this care should take. Regarding informal care and improving the financial viability and sustainability of the long-term care provision, we also argue that the generation of active and healthy senior citizens 
should be mobilised to provide structural supplementary peer support for the frailer members of their communities. Other countries, like Japan, already have broad experience in implementing similar "mobilisation strategies" on a larger scale (Hayashi, 2015), offering valuable insights and lessons for the Dutch and Flemish governments.

\section{Study limitations and suggestions for further research}

In both countries, the long-term care reforms that created the premise for conducting the current study came into force fairly recently. The current study offers a provisional exploration of how quality of care has been affected by the reforms. Still, several Belgian and Dutch respondents stated that it will take several years before one can accurately assess what the exact consequences of the recent policy reforms have been for the quality of the long-term care provision. As a suggestion for further research, we opt for continued evaluation of the quality of the long-term care provisions in both countries in years to come, while incorporating the same quality principles that were used in the current study.

The current explorative study can also be seen as a pilot-study for operationalising some of the quality principles of the European Quality Framework for Long-Term Care Services (European Partnership for the Wellbeing and Dignity of Older People, 2012) into interview questions. We encourage other researchers to further develop the proposed interview questions and to explore additional ways of operationalising the quality principles of the European Quality Framework for Long-Term Care Services (European Partnership for the Wellbeing and Dignity of Older People, 2012).

\section{ACKNOWLEDGEMENTS}

We would like to acknowledge and thank AGE Platform Europe for their support and expert advice during the research process. We express particular gratitude towards Maude Luherne for aiding in the process of identifying suitable experts for the interviews and for her assistance in the operationalization of this study. Lastly, we would like to acknowledge and thank the experts and organisations that participated in our study and whose contributions were invaluable for establishing this article. This research did not receive any specific grant from funding agencies in the public, commercial, or notfor-profit sectors.

\section{COMPETING INTERESTS}

None declared. 


\section{REFERENCES}

AGE Platform Europe. 2010. European Charter on the Rights and Responsibilities of Older People in Need of Long-term Care and Assistance. Brussels: AGE Platform Europe.

Baker, S. E., and R. Edwards. 2012. How Many Qualitative Interviews is Enough? NCRM Discussion Paper 2273. Southampton: National Centre for Research Methods.

Boeije, H. 2005. Analyseren in kwalitatief onderzoek [Analysing in Qualitative Research]. Den Haag: Boom Lemma.

Bonneux, L., N. Van der Gaag, and G. Bijwaart. 2012. Demographic Epidemiologic Projections of Long-term Care Needs in Selected European Countries: Germany, Spain, the Netherlands and Poland. Brussels: Centre for European Policy Studies.

Cès, S. 2014. Long-term Care - the Problem of Sustainable Financing. Comments Paper-Belgium. Accessed April 23, 2015. http://ec.europa.eu/social/main.jsp?catld=1024\&langld=en\&newsld=2097\&moreDocuments= yes\&tableName=news.

Christensen, K., Doblhammer, G., Rau, R., \& Vaupel, J. W. (2009). Ageing Populations: the Challenges Ahead." The Lancet 374 (9696): 1196-1208. doi:10.1016/S0140-6736(09)61460-4.

Colombo, F., A. Llenia-Nozal, J. Mercier, and F. Tjadens. 2011. Help Wanted? Providing and Paying for Longterm Care. Paris: OECD.

Council of the European Union. 2013. "Council Recommendation of 9 July 2013 on the National Reform Programme 2013 of Belgium and delivering a Council opinion on the Stability Programme of Belgium, 2012-2016." Official Journal of the European Union C217 (56): 5-9.

Dandi, R., G. Casanova, R. Lillini, M. Volpe, A. Giulio De Belvis, M. Avolio, and F. Pelone. 2012. Long-term Care Quality Assurance Policies in European Countries. Brussels: Centre for European Policy Studies.

Daniels, N., and J. E. Sabin. 2008. "Accountability for reasonableness: an update." BMJ 337: a1850. doi: http://dx.doi.org/10.1136/bmj.a1850.

Denzin, N. K., and Y. S. Lincoln. 2011. The SAGE Handbook of Qualitative Research. Thousand Oaks, CA: SAGE Publications.

European Commission. 2012. The 2012 Ageing Report: Economic and Budgetary Projections for the EU27 Member States (2010-2060). Brussels: European Commission.

European Commission. 2013. Long-term Care in Ageing Societies - Challenges and Policy Options. Commission Staff Working Document (2013) 41. Brussels: European Commission.

European Commission. 2014a. Adequate Social Protection for Long-Term Care Needs in an Ageing Society Report Jointly Prepared by the Social Protection Committee and the European Commission Services. Brussels: European Commission.

European Commission. 2014b. Belgium's Stability Programme (2014-2017). Brussels: European Commission.

European Commission. 2014c. National Reform Programme 2014 Belgium. Brussels: European Commission.

European Commission. 2014d. National Reform Programme 2014 The Netherlands. Brussels: European Commission.

European Commission. 2014e. Stability Programme of the Netherlands. Brussels: European Commission.

European Commission. 2015. Peer Review in Social Protection and Social Inclusion. Long-term Care - The Problem of Sustainable Financing. Synthesis Report. Luxembourg: European Commission.

European Partnership for the Wellbeing and Dignity of Older People. 2012. European Quality Framework for Long-term Care Services. Brussels: Age Platform Europe.

Ferri, C. P., M. Prince, C. Brayne, H. Brodaty, L. Fratiglioni, M. Ganguli, K. Hall, et al. 2005. "Global Prevalence of Dementia: a Delphi Consensus Study." The Lancet 366 (9503): 2112-2117.

Geerts, J., P. Willemé, and E. Mot. 2012. Long-Term Care Use and Supply in Europe: Projections for Germany, the Netherlands, Spain and Poland. Brussels: Centre for European Policy Studies.

Genet, N., W. G. Boerma, D. S. Kringos, A. Bouman, A. L. Francke, C. Fagerström, M. G. Melchiorre, C. Greco, and W. Devillé. 2011. "Home Care in Europe: A Systematic Literature Review." BMC Health Services Research 11: 207. doi:10.1186/1472-6963-11-207. 


\section{Chapter 5}

Hardy, R. 2015. "What Price in Human Suffering? How Austerity Has Affected Social Care." The Guardian, April 28. http://www.theguardian.com/social-care-network/2015/apr/28/austerity-cuts-social-care-sufferingelection.

Hayashi, M. 2015. “Japan's Long-term Care Policy for Older People: The Emergence of Innovative "Mobilization" Initiatives Following the 2005 Reforms." Journal of Aging Studies 33: 11-21.

Hsieh, H., and S. E. Shannon. 2005. "Three Approaches to Qualitative Content Analysis." Qualitative Health Research 15 (9): 1277-1288. doi:10.1177/1049732305276687.

Jongen, W., G. Burazeri, and H. Brand. 2015. "The Influence of the Economic Crisis on Quality of Care for Older People: System Readiness for Innovation in Europe." Innovation: The European Journal of Social Science Research 28 (2): 167-191. doi:10.1080/13511610.2015.1019839.

Jongen, W., M. J. Commers, J. M. G. A. Schols, and H. Brand. 2015. "The Dutch Long-Term Care System in Transition: Implications for Municipalities." Das Gesundheitswesen. doi: 10.1055/s-0035-1564251 [Epub ahead of print].

Karim-Kos, H. E., E. de Vries, I. Soerjomataram, V. Lemmens, S. Siesling, and J. W. W. Coebergh. 2008. "Recent Trends of Cancer in Europe: a Combined Approach of Incidence, Survival and Mortality for 17 Cancer Sites since the 1990s." European Journal of Cancer 44: 1345-1389. doi:10.1016/j.ejca.2007.12.015.

Kraus, M., T. Czypionka, M. Riedel, E. Mot, and P. Willemé. 2011. How European Nations Care for Their Elderly: A New Typology of Long-Term Care Systems. Brussels: Centre for European Policy Studies.

Lafortune, G., and G. Balestat. 2007. Trends in Severe Disability among Elderly People: Assessing the Evidence in 12 OECD Countries and the Future Implications. Paris: OECD.

Maarse, H. 2013. The Experience of Searching Long-Term Care for the Elderly: Client Choice in Long-Term Care in the Netherlands. European Cross Border Care collaborations (EUCBCC) Project Report.

Mayring, P. 2000. "Qualitative Content Analysis." Forum: Qualitative Social Research 1 (2). Accessed May 27, 2015. http://www.qualitative-research.net/index.php/fqs/article/view/1089/2386.

Mot, E., R. Faber, J. Geerts, and P. Willemé. 2012. Performance of Long-term Care Systems in Europe. Brussels: Centre for European Policy Studies.

Naiditch, M., J. Triantafillou, P. Di Santo, S. Carretero, and E. Hirsch Durrett. 2013. "User Perspectives in LongTerm Care and the Role of Informal Carers." In Long-Term Care in Europe, edited by K. Leichsenring, J. Billings, and $\mathrm{H}$. Nies, 45-80. Basingstoke: Palgrave Macmillen.

Neuman, W. L. 2014. Social Research Methods: Qualitative and Quantitative Approaches. Harlow: Pearson Education Limited.

Nies, H., K. Leichsenring, and S. Mak. 2013. "The Emerging Identity of Long-Term Care Systems in Europe." In Long-Term Care in Europe, edited by K. Leichsenring, J. Billings, and H. Nies, 19-41. Basingstoke: Palgrave Macmillen.

OECD (Organisation for Economic Co-operation and Development). 2005. Long-term Care for Older People. Paris: OECD.

Potter, W. J., and D. Levine-Donnerstein. 1999. "Rethinking Validity and Reliability in Content Analysis." Journal of Applied Communication Research 27 (3): 258-284. doi:10.1080/00909889909365539.

Puts, M. T. E., D. J. H. Deeg, N. Hoeymans, W. J. Nusselder, and F. G. Schellevis. 2008. "Changes in the Prevalence of Chronic Disease and the Association with Disability in the Older Dutch Population between 1987 and 2001." Age and Ageing 37: 187-193. doi:10.1093/ageing/afm185.

Rechel, B., Y. Doyle, E. Grundy, and M. Mckee. 2009. How can Health Systems Respond to Population Ageing? Copenhagen: WHO Regional Office for Europe.

Rechel, B., E. Grundy, J. Robine, J. Cylus, J. P. Mackenbach, C. Knai, and M. McKee. 2013. "Ageing in the European Union." The Lancet 381 (9874): 1312-1322. doi:10.1016/S0140-6736(12)62087-X.

Rodrigues, R., M. Huber and G. Lamura. 2012. Facts and Figures on Healthy Ageing and Long-term Care. Vienna: European Centre for Social Welfare Policy and Research.

Schröder-Bäck, P., L. Stjernberg, and A. Borg. 2013. "Values and Ethics amidst the Economic Crisis." European Journal of Public Health 23 (5): 723-724.

Swartz, K. 2013. "Searching for a balance of responsibilities: OECD countries' changing elderly assistance policies." Annual Review of Public Health 34: 397-412. 


\section{Chapter}

\section{The Dutch long-term care reform: moral conflicts in executing the Social Support Act 2015}

Jongen, W., Schols, J.M.G.A., \& Schröder-Bäck, P. (submitted). The Dutch long-term care reform: moral conflicts in executing the Social Support Act 2015. 


\section{ABSTRACT}

On 1 January 2015, a new long-term care reform entered into force in the Netherlands, entailing amongst others a decentralization of long-term care responsibilities from the national government to the municipalities by means of a new law: the Social Support Act 2015. Given the often disputed nature of the reform, being characterized on the one hand by severe budget cuts and on the other hand by a normative reorientation towards a participation society, this article examines to what extent municipalities in the Netherlands take (potential) moral conflicts into account in their execution of the Social Support Act 2015. In doing so, the article applies a 'coherentist' approach (consisting of both rights-based and consequentialist strands of ethical reasoning), thereby putting six ethical principles at the core (non-maleficence \& beneficence, social beneficence, respect for autonomy, social justice, efficiency and proportionality). It is argued that while municipalities are indeed aware of (potential) moral conflicts, the nature of the new law itself leaves insufficient room for municipalities to act in a sufficiently proactive and supportive/empowering manner on these challenges.

Keywords: long-term care reform, moral conflicts, ethical reasoning. 


\section{INTRODUCTION}

\section{Background}

In 2006, the Council of the European Union made reference to "a set of values that are shared across Europe" in its "Council Conclusions on Common Values and Principles in European Health Systems' (Council of the European Union, 2006). The Council Conclusions stipulate that "[t]he health systems of the European Union are a central part of Europe's high levels of social protection, and contribute to social cohesion and social justice as well as to sustainable development. The overarching values of universality, access to good quality care, equity, and solidarity have been widely accepted in the work of the different EU institutions" (ibid.). This set of values was subsequently reinforced a year later in the European Commission's 'White Paper Together for Health: A Strategic Approach for the EU 2008-2013' (Commission of the European Communities, 2007), comprising the EU's health strategy supporting the overall 'Europe 2020' strategy (Commission of the European Communities, 2010).

The healthcare sector, and more specifically the long-term care sector, has always been a source for ethical debate. Typical ethical issues (or moral conflicts) in long-term care decision-making include the debate on whether we should only look at people's deficits or also to their rest capacities (Huber et al., 2011), "the nature and significance of the elder's diminished capacity for self-care and independent living", the question "whether an older adult should continue to live at home", "the obligation of the elder to recognize and respect the limits that family members may justifiably set on their caregiving responsibilities", a loss of autonomy "when the decision is made to change either the elder's place of living or support services" and "the balance to be struck between independence and safety" (MacCullough, 2016).

However, as argued by Ranci and Pavolini (2013), "[o]ver the past two decades, many changes have happened to the social welfare policies of various industrial countries. Citizens have seen their pensions, unemployment benefits, and general healthcare policies shrink as 'belt tightening' measures are enforced". At the same time, Ranci and Pavolini (2013) argue, "long-term care has seen a general growth in public financing, an expansion of beneficiaries, and, more generally, an attempt to define larger social responsibilities and related social rights". Consequently, Pavolini and Ranci (2008) conclude that "[f]aced with the problems associated with an ageing society, many European countries have adopted innovative policies to achieve a better balance between the need to expand social care and the imperative to curb public spending". The adoption of such innovative policies is referred to here as reforms in long-term care policies.

The unfold of long-term care reforms even seems to be exacerbated in the aftermath of the 2008 economic crisis, when many European countries introduced austerity measures that in many cases appeared to have adverse effects on health systems and/or social determinants of health (Brand et al., 2013; Karanikolos et al., 2013; Arie, 
2013; McKee et al., 2012; Quaglio et al., 2013). Moreover, Schröder-Bäck et al. argue that "[t]he current protracted economic crisis is giving rise to the scarcity of public health resources in Europe. In response to budgetary pressures and the Eurozone public debt crisis, decision makers resort to a short-term solution: the introduction of austerity measures in diverse policy fields. Health and social policy tend to be easy targets in this regard, and budget cuts often include a reduction of healthcare expenditure or social welfare benefits" (Schröder-Bäck et al., 2013). Jongen et al. (2015a) add to this that "this crisis has had a much more direct and short-term influence on the quality of countries' long-term care system than more gradual developments such as population aging and declining workforces, mainly due to austerity measures being the result of, or being accelerated by, this crisis".

Also the Council Conclusions make reference to this changing context of many European countries' long-term care system, by stating that "[i]t is an essential feature of all our systems that we aim to make them financially sustainable in a way which safeguards these values into the future" (Council of the European Union, 2006). Moreover, the document stresses patient empowerment, by stating that "[a]II EU health systems aim to be patient-centred. This means they aim to involve patients in their treatment, to be transparent with them, and to offer them choices where this is possible, e.g. a choice between different health care service providers" (ibid.). At the same time, the Council Conclusions acknowledge that "[d]emographic challenges and new medical technologies can give rise to difficult questions (of ethics and affordability), which all EU Member States must answer. [...] All systems have to deal with the challenge of prioritising health care in a way that balances the needs of individual patients with the financial resources available to treat the whole population" (ibid.).

Although sharing some characteristics, every long-term care reform is embedded within peculiar national traditions and is therefore unique. This is true all the more for the latest Dutch long-term care reform, that entered into force on 1 January 2015, and which can be considered as the latest major step in a more all-encompassing 'market-oriented reform' of the Dutch healthcare system in general. The 2015 reform can be characterized as having a "hybrid structure" (Maarse et al., 2016), characterized, on the one hand, by a "reign in expenditure growth to safeguard the fiscal sustainability of LTC" (Maarse and Jeurissen, 2016), and on the other hand by a "multiplicity of regulations to safeguard public values" (Maarse et al., 2016). More concretely, as argued by Maarse and Jeurissen (2016), the 2015 long-term care reform consists of four interrelated pillars: expenditure cuts, a shift from residential to non-residential care, decentralization of non-residential care (implying a transfer of responsibilities in that policy domain from the national government to the municipalities), and a normative reorientation. The latter refers to the notion that "[u]niversal access and solidarity in LTC-financing can only be upheld as its normative cornerstone, if people, where possible, take on more individual and social responsibility. The underlying policy assumption is that various social care services may be provided by family members and local community networks" (Maarse and Jeurissen, 
2016). Indeed, a general shift in focus from formal care provision to informal care provision is added by Jongen et al. (2015b) as a key element of the 2015 Dutch long-term care reform. It is, however, exactly this normative reorientation, and its underlying assumption of an increased informal care provision, that is often disputed. As argued by Maarse and Jeurissen (2016): "An important line of criticism is not only that informal care is already provided at a large scale, but also that the potential of 'unexplored' informal care is overestimated. Furthermore, the negative externalities for caregivers who deliver informal care are underestimated". Moreover, while residential care remains under the responsibility of the national government after the entry into force of the 2015 long-term care reform, and a large part of non-residential care came under the responsibility of the health insurers, it is the municipalities that became under the Social Support Act 2015 (SSC 2015) [in Dutch: Wet maatschappelijke ondersteuning (Wmo) 2015] responsible for particularly those parts of non-residential care dealing with support directed towards the social participation of people with severe limitations (in the wordings of the official legal text of the Social Support Act 2015 (authors' own translation): "people with disabilities, chronic mental or psychosocial problems"), as well as with support for informal caregivers (Jongen et al., 2015b). Indeed, the official legal text of the Social Support Act 2015 stipulates that "citizens who themselves or together with people in their immediate environment are not sufficiently self-sufficient or insufficiently able to participate [in society], must be able to rely on organized support by the government" (authors' own translation). However, municipalities have a large discretion in making this obligation to provide support concrete (the so-called 'postcode [zip code] rationing'), which may lead to unequal access to long-term care in different municipalities (Maarse and Jeurissen, 2016).

\section{Literature research}

So far, the academic literature has not extensively scrutinized the potential moral conflicts resulting from the implementation of the Social Support Act 2015, and is more about organization and logistics than about ethics. The available literature either touches upon mere elements of an all-encompassing ethical debate, or upon the perspective of specific groups. As an example of the former, van der Aa et al. (2014) consider the presumed impact of the 2015 long-term care reform on such elements as good quality of care and solidarity. Van der Aa et al. argue that the above-mentioned 'zip code rationing' might well lead to differences between municipalities in the degree of solidarity as perceived by citizens ('zip code solidarity'). Furthermore, van der Aa et al. argue that it should not be taken for granted that municipalities, by simply making an efficiency move, can guarantee an equal level of care quality with the decreased budget they are faced with for executing their new long-term care tasks. Next, Grootegoed and Tonkens (2015) consider the impact of the Dutch shift in focus from formal to informal care provision on such elements as respect for autonomy or human dignity and argue that "the turn to voluntarism does not always prompt recognition of the needs and autono- 
my of vulnerable citizens" and furthermore that "the virtues of voluntarism may be overstated by policy makers and that the bases of recognition should be reconsidered as welfare states implement reform". Examples of literature focusing on the perspective of specific groups include the articles by Dwarswaard et al. (2015) and Dwarswaard and Van de Bovenkamp (2015) on, respectively, self-management support considered from the perspective of patients and the ethical dilemmas faced by nurses in providing selfmanagement support (whereby self-management is defined as "the involvement of patients in their own care process" (ibid.), and in that way relates to the abovementioned notion of individual responsibility).

\section{Study objectives and research questions}

No comprehensive ethical approach towards the impact of the Social Support Act 2015, however, appears yet to exist. The current study intends to fill in this gap, by answering the following research question: To what extent did/do municipalities in the Netherlands take potential moral conflicts into account when implementing and executing the Social Support Act 2015?

As the core of the 2015 Dutch long-term care reform is characterized by, on the one hand, severe budget cuts, and, on the other hand, by a normative reorientation towards a participation society wherein people are expected to take on more individual and social responsibility (Maarse and Jeurissen, 2016; Jongen et al., 2015b), we additionally formulated the following sub-research questions: 1 . How do municipalities divide scarce resources in the social domain in a fair way?; 2. How do municipalities empower citizens towards a participation society? In answering both research questions we consider the potential moral conflicts experienced by municipalities, as executers of the Social Support Act 2015, with regard to those entitled (or proclaim to be entitled) to receive support on the basis of the Social Support Act 2015, as well as with regard to relatives providing informal care to the previous group. Despite the fact that the nature, as well as corresponding reforms, of individual countries' long-term care systems differ, the systematic approach of assessing moral conflicts resulting from the introduction of new long-term policies as applied in this study could also be transferred to other countries were long-term care reforms are being implemented. At the same time, several policy lessons could be derived from the experiences of Dutch municipalities with the 2015 long-term care reform.

\section{METHODS}

\section{Research type and design}

To answer our research question, a mixed-method research approach was chosen. First, a document analysis was conducted, in order to explore if, and to what extent, ethical 
values and principles are literally incorporated in the legal text of the Social Support Act 2015. For this analysis we only considered the primary source (the legal text itself) and no other, secondary documents (such as municipal policy documents). Second, policy advisors (responsible for the long-term care policy domain) of all 390 Dutch municipalities were invited to complete an online survey. Henceforth, no sampling technique had to be applied, although of course we had to compile a mail distribution list consisting of either the general e-mail addresses of municipalities, or the e-mail addresses of the specific departments the intended policy advisors are working. In some smaller municipalities these policy advisors were not only responsible for the long-term care policy domain, but for the whole social domain (next to the long-term care decentralization, municipalities were simultaneously also faced with decentralizations in the field of youth care and in the field of labor participation of people with an occupational disability); in large municipalities more than one person might be responsible for the longterm care policy domain. However, in our explanatory notes we specifically asked to forward our demand to one of the intended policy advisors, in order to avoid multiple respondents from the same municipality. The reason for choosing policy advisors, instead of politicians, had to do with the potential political bias that politicians might have with regard to the topic of this study. Indeed, the potential ethical implications surrounding the long-term care decentralization constitutes a politically sensitive issue in many municipalities, as clearly came to the forefront in one of the two test-interviews, which was conducted with the major of a municipality (the other test-interview was conducted with a professor of old age medicine). Moreover, while each municipality also has several so-called 'Social Support Act consultants' [in Dutch: Wmo consulenten], who do the actual fieldwork, implying the one-to-one contact with individual (potential) clients, these employees are believed to lack an overarching helicopter view. In principle, participation in the online survey was anonymous, except when a respondent declared to be willing to participate in an in-depth telephonic interview. These in-depth interviews constituted the third step in our mixed-method research approach, and were intended to expand on the survey, instead of asking new questions. Anonymity of these respondents has been guaranteed by omitting persons' and municipalities' names here.

\section{Theoretical framework and conceptual model}

For the analysis of the potential moral conflicts surrounding the implementation and execution of the Social Support Act 2015, we applied a 'coherentist' approach (consisting of both rights-based and consequentialist strands of ethical reasoning) as offered by Schröder-Bäck et al. (2012), thereby putting six ethical principles at the core that are considered to capture the specificities of the current study (non-maleficence $\&$ beneficence, health maximisation / social beneficence, respect for autonomy, social justice, efficiency and proportionality). Taking into account the variety of seemingly similar concepts such as 'ethical dilemmas', 'moral conflicts', 'moral dilemmas', et cetera, it 
should however first be clarified which definition is applied in this study and what is meant with it. Given the heavily-loaded connotation of the term 'ethical dilemma', we prefer the term 'moral conflict' here. Subsequently, based on the Stanford Encyclopedia of Philosophy (McConnell, 2014), we define a 'moral conflict' as follows: A moral conflict appears if one thinks one has good moral reasons to do one thing, but also good moral reasons to not do it, or do something that is in conflict with it. So either decision is not perfect. Or, in other words: a moral conflict arises if the moral norms and values we would like to follow guide us to conflicting/opposing actions. A coherentist ethical approach, then, implies that an ethical analysis "should be based on a variety of plausible norms and values" and that none of the traditional ethical approaches is therefore superior to the other (Schröder-Bäck et al., 2012). Instead, they all contribute important moral insights. Schröder-Bäck et al. (2012) add to this that "their norms do weigh prima facie the same and need to be plausibly unfolded and specified in a given setting. When they are contextualised and specified they develop their normative weight and power". This prima facie status of the ethical principles thus "supports the process of careful ethical deliberation and reflection". Moreover, specifying the more 'overarching' ethical approaches into a concise set of ethical principles is considered as a useful, practical, tool for medical and public health ethics (Schröder-Bäck et al., 2009). Each of these six principles will be discussed in detail in the following.

Non-maleficence and beneficence: non-maleficence implies that "a healthcare professional should act in such a way that he or she does no harm, even if her patient or client requests this" (Schröder-Bäck et al., 2014). Beneficence is connected to nonmaleficence, the only difference being that non-maleficence involves the omission of harmful action and beneficence actively contributes to the well-being of others (ibid.). Because of their intimate connection, both principles are considered under one heading here. Considering the overarching approaches to ethical reasoning as mentioned above, the principles of non-maleficence and beneficence correspond to the 'do no harm' principle under the consequentialist approach to ethical reasoning.

Health maximisation / social beneficence: although in the literature one can find either of these terms, we refer to social beneficence as the norm that says that it is a moral goal to improve the wellbeing of people on an aggregated population level. Social beneficence resembles in a significant way the consequentialist principle of utilitarianism. Utilitarianism is the ethical theory that requests from an action or omission to be in such a way that the maximization of best consequences would follow.

Respect for autonomy: the 'respect for autonomy' principle implies a tempering of the "paternalistic benevolence contained in the principles of non-maleficence and beneficence" (Schröder-Bäck et al., 2014). In that way, the 'respect for autonomy' principle is closely related to the 'human dignity' principle under the rights-based approach to ethical reasoning. Moreover, without taking into account the 'respect for autonomy' principle, it would under the principle of health maximisation / social beneficence alone be allowed "to use individuals (or whole groups) for other than their own ends and even 
sacrifice them if only this provided a greater net benefit, i.e. maximised health" (Schröder-Bäck et al., 2009).

Social justice: the principle of (social) justice as referred to under the rights-based approach to ethical reasoning can be considered another side constraint to the principle of health maximisation / social beneficence. As Schröder-Bäck et al. (2009) put it: "It does not only matter to enhance the net-benefit; it also matters how the benefits and burdens are distributed". Moreover, this also includes "a fair distribution of health outcomes in societies, which is often discussed in terms of public health as "health equity"' (Schröder-Bäck et al., 2014), which is considered by Daniels as a matter of fairness and justice (Daniels, 2008). In fact, the principle of 'equity' constitutes the core of the values of the 'Council Conclusions on Common Values and Principles in European Health Systems'. As Schröder-Bäck et al. (2012) put it: "The other three overarching values can be conceptualised as specifications of equity (and of social justice). Access to good quality of care and universality can be seen as a reiteration of the core demands of equity and justice", while "solidarity is seen as a characteristic that describes the willingness of members of communities to be committed to the principle of justice or to each other". In short, one could argue thus that "[j] ustice approaches in health care often demand nothing more than universal access to good quality care" (ibid.). Or, as the World Health Organization (WHO) puts it: "universal health coverage (UHC) is defined as ensuring that all people can use the promotive, preventive, curative, rehabilitative and palliative health services they need, of sufficient quality to be effective, while also ensuring that the use of these services does not expose the user to financial hardship" (WHO, 2016).

Efficiency: efficiency requires the efficient use and distribution of scarce health resources (Schröder-Bäck et al., 2009).

Proportionality: the principle of proportionality, finally, emphasizes that it is "essential to show that the probable public health benefits outweigh the infringed general moral considerations. All of the positive features and benefits must be balanced against the negative features and effects" (Schröder-Bäck et al., 2009). In their 'ethical criteria for immunization programmes', Verweij and Dawson (2004) combine the principles of efficiency and proportionality under one heading, by stating that a "programme's burden/benefit ratio should be favourable in comparison with alternative [...] options".

\section{Data collection}

For the document analysis, we specifically considered the presence of the values as stipulated by the 'Council Conclusions on Common values and principles in European Union Health Systems', as well as the six ethical principles elaborated on above. Next, for the survey and in-depth interviews, these principles have been broken down into representative survey/interview questions, allowing for a structured and comparative analysis of potential moral conflicts. Schröder-Bäck et al. (2014) applied a similar approach within the context of developing a curriculum for a short course on ethics in 
public health programmes, by suggesting a checklist consisting of several questions around each of the ethical principles they applied in their study (largely comparable to the six principles as applied in the current study). With the respective author of that study, one question for each of the above six principles was chosen, adapting them to the specificities of the current study, and translated into Dutch (see Table 1 for the final survey/interview questions).

Table 1. Survey/interview questions

Part 1: Identifying potential moral conflicts

Q1: According to you, what are the most important moral conflicts (if any) your municipality has been faced with in the context of implementing and executing the Social Support Act 2015?

\begin{tabular}{|c|c|c|}
\hline Ethical principles & $\begin{array}{l}\text { Original selected 'check marks' } \\
\text { (Schröder-Bäck et al., 2014) }\end{array}$ & Adapted questions \\
\hline $\begin{array}{l}\text { Ethical principle 1: } \\
\text { Non-maleficence \& } \\
\text { beneficence }\end{array}$ & $\begin{array}{l}\text { Overall, for both non-maleficence and } \\
\text { beneficence, is it possible to assess } \\
\text { whether more benefit than } \\
\text { harm is produced by intervening (or not } \\
\text { intervening) and, if so, on what side } \\
\text { (benefit or harm) does the equation } \\
\text { finally fall? }\end{array}$ & $\begin{array}{l}\text { Q2: According to you, will more people } \\
\text { (both care recipients as informal } \\
\text { caregivers) have advantage or } \\
\text { disadvantage as a result of the } \\
\text { introduction of the Social Support Act } \\
2015 \text { ? How do these advantages and } \\
\text { disadvantages look like? }\end{array}$ \\
\hline
\end{tabular}

Ethical principle 2: Health maximization / social beneficence Does it [the proposed intervention] have a sustainable, long-term effect on the public's health?

Q3: According to you, will the Social Support Act 2015 have a sustainable, long-term, effect on the quality of life of the entire (older) population?

Ethical principle 3: Efficiency

Ethical principle 4: Respect for autonomy

Does the intervention promote the exercise of autonomy?

Q4: According to you, how does your saved money can be used for other goodsmunicipality deal with the availability of the Social Support Act 2015?

Q5: According to you, does the Social Support Act 2015 provide sufficient
Ethical principle 5: (Social) justice
Does the intervention promote rather than endanger fair (and real) equality of opportunity and participation in social action?

Are costs and utility proportional? the scarce resources that are available for opportunity for people's freedom of choice with regard to the care and support they wish to receive (and the way how they receive it)?

Q6: According to you, do people under the Social Support Act 2015 have an equal opportunity to live their lives the way they want (or, in other words: is the freedom of choice as mentioned in the previous question also practically possible for every person)?

Q7: According to you, will costs and utility under the Social Support Act 2015 be proportional?

Part 2: Dealing with moral conflicts

Q8: According to you, how does your municipality deal with the moral conflicts as identified under part 1? Or, in other words: what are your municipality's solutions to these moral conflicts?

Q9: According to you, are there, for your municipality, alternative ways of executing the Social Support Act 2015, that will lead to less moral conflicts? 
The reason for choosing merely one question per category had to do with the practical limitations of using open-ended questions in an online survey: based on Andrews (2004) as well as on two test-interviews we conducted, the response rate to open-ended survey questions is considered to be substantially lower than in the case of closed-ended survey questions, especially when the number of questions would be too high. The questions covering each of the six ethical principles were preceded by a general question on the identification of potential moral conflicts (intended to trigger respondents, before directing them into the six predefined categories), and followed by two general questions on the way (if applicable) municipalities deal with the identified moral conflicts.

\section{Data analysis}

The document analysis implied a scrutinization of the presence (or non-presence) of the values and principles elaborated on above in the legal text of the Social Support Act 2015 , either in terms of a literal incorporation in the legal text, or in terms of indirect referrals to the respective values and principles.

The data of the surveys and interviews were analysed through the application of a directed approach to qualitative content analysis (Hsieh and Shannon, 2005). We chose for this approach, as it allows for an analysis that "starts with a theory or relevant research findings as guidance for initial codes" (ibid.). In that way, we were enabled to directly apply our theoretical framework of ethical reasoning in the interpretation and categorisation of the research data, with the six predefined ethical principles as initial coding categories. Within each of these categories, we clustered the respondents' answers in 'dominant response clusters' as a way of quantifying to some extent our qualitative survey results. This approach allowed for an organized inclusion of the main results in this article. Obviously, qualitative results can never completely be quantified, as each specific answer remains unique. Therefore, in order to add some extra weight to our results, we included direct respondents' quotes to several of the dominant response clusters.

\section{RESULTS}

\section{Document analysis}

In terms of the values as stipulated by the 'Council Conclusions on Common values and principles in European Union Health Systems', the legal text of the Social Support Act 2015 only literally makes reference to the value of 'access to good quality care', although quality of care should be understood here as 'good quality of (social) support'. Indeed, as was explained in the previous chapter, the Dutch long-term care system is, as of 1 January 2015, divided into three laws, of which the Social Support Act 2015 constitutes the one mainly dealing with social types of care (directed at increasing or main- 
taining the self-sufficiency and social participation of vulnerable citizens) instead of traditional healthcare. The municipalities' responsibility under this law can therefore best be understood as providing adequate social support services instead of providing actual healthcare services. Nevertheless, this focus on social types of care instead of traditional types of healthcare, or on 'well-being' instead of 'health' as a desired outcome of support, does not imply that the Social Support Act 2015 should not be based on certain key ethical values or principles. Also the Council Conclusions (2006) go further than traditional healthcare, by implying that " $\mathrm{t}]$ he health systems of the European Union are a central part of Europe's high levels of social protection, and contribute to social cohesion and social justice as well as to sustainable development". With regard to good quality of social support, then, Article 2.1.1 of the Social Support Act 2015 stipulates that "[t]he municipal council is responsible for the quality and continuity of services" (authors' own translation), while Article 3.1 continues by stating that "[t]he provider shall ensure the provision of good quality services" (authors' own translation). Services either refer here to 'general services' (in Dutch: algemene voorzieningen), or to 'customized services' (in Dutch: maatwerkvoorzieningen). The latter, subsequently, is defined in the legal text as a "range of services, tools, home adaptations and other measures, tailored to the needs, personal characteristics and capabilities of a person" (authors' own translation). Solidarity is by definition an important component of this law, and is referred to in the first sentence of the legal text, which points out that "citizens bear a personal responsibility for the way they organize their lives and participate in society, and that may be expected of citizens to support each other in doing so to the best of their ability" (authors' own translation). The values of universality and the, more overarching, value of equity (being part of the principle of social justice in our theoretical framework) are indirectly referred to in the introduction of the legal text by stating that "citizens who themselves or together with people in their immediate environment are not sufficiently self-sufficient or insufficiently able to participate [in society], must be able to rely on organized support by the government" (authors' own translation). As a result of the limited literal inclusion of these ethical values, it is not surprising that the more specified ethical principles derived from these values are hardly included in literal terms in the legal text neither. The only exception here is the 'respect for autonomy' principle, that could be derived from the wording of Article 2.1.2 (4.c), which stipulates that municipalities in their social support policy should specifically take the freedom of choice into account of those citizens that are entitled to customized support services.

\section{Survey and interviews}

Having considered the literal inclusion of the ethical values and principles in the legal text of the Social Support Act 2015, a next step in our research process was to examine to what extent municipal policy advisors consider the execution of the Social Support Act 2015 to be in compliance with the six ethical principles as applied in this study. In 
totality 70 policy advisors completed the survey, constituting 18 per cent of Dutch municipalities. In total, ten of these respondents also appeared to be willing to participate in an in-depth interview. The results of the surveys and in-depth interviews are described question by question in the following section and discussed simultaneously (as the in-depth interviews were intended to expand on the survey results instead of asking new questions). Given the number of respondents, only those answers that most frequently resulted from our analysis (the 'dominant response clusters' mentioned above) are discussed here. The direct respondents' quotes that are included are believed to represent the respective cluster best and are the authors' own translations from Dutch to English.

Question 1 (general identification of moral conflicts). Although not all respondents confirmed the existence of moral conflicts with regard to the implementation and execution of the Social Support Act 2015, most respondents did identify one or more moral conflicts. In general, our respondents identified three types of moral conflicts. First, the conflict of adhering to the Social Support Act's underlying theory of moving towards a participation society vs. the limited budget and time-frame that is offered to municipalities for supporting this change process. Indeed, the theoretical idea of moving towards a society wherein citizens take up more individual and social responsibility and where care and support is provided on a customized basis and closer to home, is considered by many as a positive normative development. However, the severe budget cuts that accompany the long-term care decentralization (expected to lead to budgetary shortfalls), as well as the rapidity of the reform process, hamper municipalities' opportunities for supporting this development. Or, as one respondent put it: "Pragmatism prevails over quality demands". Second, respondents identified the conflict of how to efficiently coordinate responsibilities between the three different long-term care Acts. The fact that municipalities under the long-term care reform only got responsibility for parts of the long-term care sector might lead to unclarity and confusion, not the least among (potential) recipients of care/support, regarding under which Act one is entitled to care/support. Moreover, some respondents indicated that an insufficient coordination between the three laws sometimes results in a lack of incentives among municipalities to invest in prevention and informal care support, as the financial benefits of these investments might not be evident for the 'own law', but only for the 'other laws'. The third moral conflict identified relates to the correct assessment of citizens' selfsufficiency and their ability to social participation vs. their care/support needs and the urge to empowerment. The fact that municipalities have a large policy discretion in executing their responsibilities under the Social Support Act 2015 even complicates this point, as similar situations might well lead to different assessments in different municipalities. Particularly difficult, then, is how to justify these differences to citizens.

Question 2 (ethical principle 1: non-maleficence and beneficence). Most respondents appeared to have a rather neutral stance when it comes to assessing the nonmaleficence and beneficence of the Social Support Act 2015, arguing that the Act leads 
to advantages for some and disadvantages for others, especially on the short-term. Or, as one respondent put it: "It depends on the individual perception of people whether they experience the introduction of the new Social Support Act as an advantage or a disadvantage". Moreover, getting used to a new situation always takes time, especially for those citizens that were already entitled to care or support under the pre-2015 situation. Advantages primarily include the provision of customized care closer to home, in line with people's specific living conditions, instead of standard care provisions like in the pre-2015 situation. Disadvantages primarily include the, already above-mentioned, high degree of policy discretion of municipalities regarding their allocation of support measures - which tends to lead to perceptions of 'unfairness' or 'subjectivity' among citizens-, a lower level of formal care provision as experienced by individual citizens and consequently the increasing burden on informal caregivers.

Question 3 (ethical principle 2: health maximization / social beneficence). The decreasing level of formal care provision can also be considered as a disadvantage on a societal level, when considering the more long-term expected consequences of the implementation of the Social Support Act 2015. At the same time, a decreasing level of formal care provision is not considered by all respondents as a disadvantageous development. As one respondent put it: "If we execute it [the Social Support Act 2015] well, this will increase quality of life. However, this also entails that we should carefully deal with informal caregivers". One of the more long-term advantages is indeed believed to be the creation of a better awareness and appreciation among citizens about care in general, as a result of the diminishing resources for formal care provision, leading to a more inclusive society-characterized by the emergence of a new quality of lifewherein people have a better esteem of their own possibilities as well as a better appreciation of each other. At the same time, many respondents pointed out that this 'emergence of a new quality of life' is not so much due to the Social Support Act 2015 (or the long-term care reform in general), but more to overarching trends such as demographical developments (people get older and older), technological developments in healthcare (which facilitate people in achieving a decent quality of life) and changing ways of thinking about care in general (such as other perspectives on civic engagement and patient empowerment). As one respondent put it: "The quality of life has always had a different standard than the generation before". Or, as another respondent put it: "Laws don't have an influence on quality of life".

Question 4 (ethical principle 3: respect for autonomy). Respect for autonomy was considered by most respondents as being sufficiently covered by the Social Support Act 2015, specifically through the inclusion of the freedom of choice as mentioned under Article 2.1.2 of the Social Support Act 2015. Concretely, the freedom of choice as referred to in Article 2.1.2 implies either the choice between several by the municipality selected providers (when one is entitled to customized care services) or a fully open choice (when one is entitled to a personal budget). Yet, respondents did put several remarks to this freedom of choice. First, due to the large discretion municipalities have 
in executing the Social Support Act 2015, the interpretation of freedom of choice differs between municipalities (indeed, some municipalities offer a larger selection of providers than others). As one respondent put it: "The new Social Support Act isn't designed as to 'support wishes', nor as a 'right to support'. Therefore, there is a strong dependence on supplemental local rules". Second, in practice, freedom of choice is not always considered as an added value by people, especially by vulnerable people that are often just looking for good quality support. As one respondent put it: "For that [freedom of choice] there is little attention among people. Moreover, it is questionable whether that is actually needed; people merely want good quality care instead of freedom of choice" (author's own translation).

Question 5 (ethical principle 4: social justice). In line with the previous question, the question about social justice was basically about people's capabilities of making use of their right to freedom of choice. Answers to this question were divided. On the one hand, many respondents considered the majority of people that are entitled to support under the Social Support Act 2015 to be indeed capable of making use of their right to freedom of choice. Moreover, when necessary, support is offered to clients by the municipality. As one respondent put it: "The municipality is actively cooperating with 'client supporters' to facilitate people as good as possible in their freedom of choice" (these 'client supporters' are people that work independently from the municipality). On the other hand, other respondents emphasized that not everyone, especially vulnerable groups in society, are capable of applying their freedom of choice, neither has everyone a social network at her/his disposal to support them in doing so. Moreover, freedom of choice depends to some extent on people's own resources. Indeed, under the Social Support Act 2015, the own financial contributions people are expected to pay for the care/support they receive have grown as compared to the pre-2015 situation, which might lead to the avoidance of care/support (De Koster, 2016). As a result, respondents argue, differences in society grow when it comes to the possibility of people to make use of their freedom of choice under the Social Support Act 2015. As one respondent put it: "A barrier to care is created, that leads to a split in society: if you have money you can buy care yourself; if you little money you'll have to do it with a stripped care system".

Question 6 (ethical principle 5: efficiency). With regard to the allocation of scarce resources, respondents' views could be divided into three main groups. One part considered the budget available for the execution of their long-term care responsibilities, which was substantially lowered as compared to the pre-2015 situation, to be leading in the allocation of resources, implying that care/support demands are (according to these respondents) considered more critically-on the basis of stricter indications-as compared to the pre-2015 situation. As one respondent put it: "The resources are distributed as indicated by the national government". Moreover, some municipalities try to focus on general (collective) support services instead of on customized (individual) support services in order to remain within their budgetary margins. A second groups con- 
sidered demand to be key in decision-making, implying that as much as possible is done to do what is necessary, at least for the most vulnerable groups. In case of shortages, solutions are (according to these respondents) considered to be the appeal to general municipal resources or the transfer of resources from other policy domains within the municipality. Indeed, many municipalities are currently searching for more integral ways of working between the different parts of the social domain within their municipality (Jongen et al., 2015b). One respondent formulated it as follows: "It starts with the client and we do what is necessary; many roads lead to Rome". A third, though smaller, group took a more neutral stance and considered the underlying idea of the long-term care reform (truly progressing towards a participation society) to be key in decision-making, implying that 'new', 'creative', or 'innovative' solutions have to be sought in balancing between a limited budget and the existing (or even growing) care/support demand. One respondent covered this point by stating that we should "learn people how to fish instead of supplying the fish". Apart from an increased focus on prevention (e.g. by supporting, or cooperating with, citizens' initiatives and/or informal care organizations), it remains however unclear what is exactly meant by 'innovative solutions'.

Question 7 (ethical principle 6: proportionality). Next, respondents were asked whether they think the Social Support Act 2015 can be considered as a proportionate measure for the goals it intends to pursue. In general, respondents considered this proportionality indeed to be present, thereby primarily making the comparison to the pre-2015 situation, which was considered by many as 'unfair' and 'untenable' due to the often exaggerated care demands of people (the so-called 'claim-mentality'). Or, in the words of one respondent: "A greater reliance on an own network / own resources will eventually replace the claim-mentality ('I am entitled to') and thus be cheaper". Another group of respondents considered the underlying idea of the decentralization (providing care and support on a customized basis and closer to home) as a positive normative development, while being worried about the budget cuts that accompanied the decentralization. As one respondent put it: "There will only be a balance in case of sufficient budget and autonomy for municipalities". For this group of respondents, the Social Support Act 2015 is considered to be putting a disproportionate burden on society. For part of this latter group, this disproportionality is likely to reduce in the longerterm, due to a gradually reducing 'claim-mentality' within society. For another part, however, the reduction of long-term care costs in the longer-term will not be the result of a more efficient provision of long-term care, but will simply be the result of the mere fact of less available financial resources (and thus less possibilities), leading logically to less expenses in the long-term care sector.

Question 8 (dealing with moral conflicts). The last two questions of the survey referred to the way municipalities deal with the identified moral conflicts. In general, most respondents pointed to the importance of communication and transparency here. On the basis of regular deliberations, meetings and conversations with both care/support providers, surrounding municipalities, care/support recipients and their 
informal caregivers, and other stakeholders, the execution of the Social Support Act 2015 is evaluated regularly and adapted where necessary. Moreover, although the large discretion that municipalities have in assessing citizens' care/support needs is considered by many citizens as unfair or subjective (as we mentioned before), the best way of dealing with this discretion according to our respondents is to critically assess each individual situation in-depth, offer customized support where possible, be open and transparent towards care/support recipients and their informal caregivers, and thoroughly explain the choices made where necessary. As one respondent captured it: "Continue discussions, while in the meantime also ensuring that the necessary care delivery continues".

Question 9 (dealing with moral conflicts: alternatives). Subsequently, respondents were asked whether they foresaw alternatives with regard to the execution of municipalities' long-term care responsibilities. Many pointed to the unlikelihood of such an option, as the Social Support Act 2015 is an established fact by law. Others argued that neither option would be perfect and that turning to an alternative law now would be going back to square one. Most respondents, however, interpreted this question not so much in terms of alternatives to the Social Support Act 2015 in itself, but in terms of possible alternatives in the execution of this law. Most of these respondents pointed to the potential release of more financial resources by the national government. At the same time, respondents acknowledged that although the availability of more financial resources would make life easier, it would not dissolve moral conflicts. A second alternative would be a clearer delineation between (or integration of) the different longterm care Acts. Respondents argued for example that it would have made more sense if the complete package of non-residential care services was put under responsibility of either the municipalities, or the health insurers. Currently, the majority of nonresidential care services is under responsibility of the health insurers, and only a small part under responsibility of the municipalities. Finally, respondents pointed to the need for more innovative and unorthodox solutions, arguing that the Social Support Act 2015 is not an aim in itself, but a means to deliver good care/support. Or, as one respondent put it: "Every law has an Article 5", implying that governments should sometimes turn a blind eye in the execution of policies.

\section{DISCUSSION}

\section{Principal findings and conclusions}

The aim of this study has been to examine to what extent municipalities in the Netherlands take/took potential moral conflicts into account when implementing and executing the Social Support Act 2015. We intend to answer our research question by relating the results corresponding to each of the six principles of our theoretical framework back 
to the coherentist approach of ethical reasoning this framework was based on. As was mentioned before, the coherentist approach is based on two main strands of ethical reasoning, being the 'rights-based approach' and the 'consequentialist approach'. Within a consequentialist approach, "actions are judged for their outcome and overall produced value" (Schröder-Bäck et al., 2012). This approach is basically founded on such principles as 'health maximisation' and 'do no harm' (ibid.), corresponding to the principles of non-maleficence \& beneficence and social beneficence in our theoretical framework. In a public health context a consequentialist approach to ethical reasoning implies that health should be maximised, "as long as health maximisation is not endangering the maximisation of the overall utility of people" (ibid.). As was described in the previous chapter, most of our respondents appeared to have a rather neutral stance with regard to assessing the non-maleficence and beneficence of the Social Support Act 2015, emphasizing that it depends to a large extent on the individual perception of people whether they experience the introduction of the new Social Support Act as an advantage or a disadvantage. With regard to social beneficence we found that, despite worries about the decreasing level of formal care provision, most respondents considered the creation of a better awareness and appreciation among citizens about care in general to be one of the more long-term advantages of the Social Support Act 2015. At the same time there are also doubts about the impact that a law can have on such developments as new ways of thinking about long-term care (referred to above as a 'normative reorientation' towards long-term care). Indeed, concepts such as the concept of 'positive health' as developed by Huber et al. (2011) are gaining importance within the healthcare sector. The concept of 'positive health' considers health as "the ability to adapt and to self manage" (ibid.) instead of considering it under the traditional WHO definition as "a state of complete physical, mental and social well-being and not merely the absence of disease or infirmity" (WHO, 2006).

A rights-based approach is basically founded on such principles as 'human dignity' and 'justice', corresponding to the principles of respect for autonomy and social justice of our theoretical framework, and claims that "persons have rights to fair equality of opportunity" (Schröder-Bäck et al., 2012). In a public health context this implies that people have a right to (equal opportunity) "to receive appropriate healthcare and live in environments in which social determinants of health are distributed in a fair way" (ibid.). As we saw in the previous chapter, most respondents considered respect for autonomy to be sufficiently covered by the Social Support Act 2015, mainly by its emphasis on freedom of choice. At the same time, however, our respondents pointed out that exactly freedom of choice is something that is not always of added value in a context wherein people are often just looking for good quality support. Moreover, while social justice (people's capabilities of making use of their right to freedom of choice) was considered to be sufficiently present for the majority of people, it is also exactly this point that respondents appeared to be most worried about in light of the Social Support Act 2015 , especially when applying it to vulnerable groups in society. Indeed, the legal 
text of the Social Support Act 2015 hardly stresses the importance of such notions as 'equity', one of the core underlying values of the principle of social justice. Although the legal text stipulates that "citizens who themselves or together with people in their immediate environment are not sufficiently self-sufficient or insufficiently able to participate [in society], must be able to rely on organized support by the government", it remains unclear when exactly someone is 'insufficiently self-sufficient', 'insufficiently able to participate in society', and (in case someone is entitled to support) when one is entitled to 'general services' and when to 'customized services'. Indeed, as was argued by Maarse and Jeurissen (2016), municipalities actually have a large policy discretion with regard to the allocation of support measures (the so-called 'zip code rationing'), which may lead to unequal access to long-term care. In fact, this point was one of the three main moral conflicts as identified by our respondents under question 1 of the survey. Moreover, as argued by Van der Aa et al. (2014), with the advent of the Social Support Act 2015 a shift can be witnessed from a 'right to care' to a 'right to customized support'. Next, although solidarity is by definition an important component of the Social Support Act 2015, the Act foresees a shift from formal to informal solidarity (Van der Aa et al., 2014). It remains, however, doubtful how much can be expected of this informal solidarity. As Maarse and Jeurissen (2016) already pointed out, "the potential of 'unexplored' informal care is overestimated. Furthermore, the negative externalities for caregivers who deliver intense informal care are underestimated". Finally, the legal text of the Social Support Act 2015 stipulates that "it is desirable to set new rules, in order to bring citizens' rights and duties more in line with each other" (authors' own translation), which tends to imply a decreasing government responsibility for citizens' rights to equality of opportunities regarding access to good quality care/support.

Our first sub-research question was specifically directed towards the way municipalities divide scarce resources in the social domain in a fair way. As we saw in the previous chapter, our respondents' views towards principles of efficiency and proportionality were quite divergent. On the one hand, the availability of less public resources for longterm care and the higher own financial contributions people are expected to pay for the care/support they receive might eventually lead to a more conscious use of care (and in that way contribute to the normative reorientation of creating a true participation society). On the other hand, however, these developments might unconsciously lead to the creation of an access barrier to care (especially for the less affluent in society) or to the avoidance of necessary care. In fact, the conflict of adhering to the Social Support Act's underlying theory of moving towards a participation society while at the same time having to deal with the limited budget and time-frame that is offered to municipalities for supporting this change process was one of the three main moral conflicts as identified by our respondents under question 1 of the survey. Moreover, within the context of the Social Support Act 2015 'efficiency' might primarily be understood as a way of justifying the budget cuts that accompanied the long-term care decentralization, instead of as a moral obligation to efficiently use scarce health resources. At least part of 
the solution to the dilemma of how municipalities then can divide scarce resources in the social domain in a fair way might be provided by the 'accountability for reasonableness' approach of procedural justice by Daniels and Sabin (2008), which offers a "minimum ethical standard in times of economic downturn characterized by scarcity of resources and when not all needs are being satisfied" (Schröder-Bäck et al., 2013). The accountability for reasonableness approach requires certain conditions to be met in order for a process of allocating scarce healthcare resources to be 'fair': the process (including the reasoning behind it) has to be transparent to the public, the reasons by which decisions were made have to be relevant, and it should be possible to revise any decision in case of new evidence or arguments (ibid.). These conditions are quite in line with our results under question 8 (dealing with moral conflicts), emphasizing the importance of communication and transparency in the process of dealing with moral conflicts (such as the division of scarce resources).

Finally, in order to answer our second sub-research question (regarding the way municipalities empower citizens towards a participation society), it has to be determined how the kind of efficiency goals as discussed under the previous sub-question can be reconciled with moving towards a participation society; or, in other words, does the latter lead to the former, or does the former require the latter? Is thus "participation" a good value or a fig leaf or metaphor for a liberalist mindset? We argue that although participation is an intended goal of the Social Support Act 2015, citizens are insufficiently supported to achieve that participation. As we argued before, 'support' under the Social Support Act 2015 is intended to be limited to those citizens who themselves or together with people in their immediate environment are not sufficiently selfsufficient or insufficiently able to participate. Or, as Maarse and Jeurissen (2016) put it: "The WMO 2015 gives applicants a right to publicly funded support if they cannot run a household on their own and/or participate in social life". However, proactively supporting citizens towards the initial goal of creating a participation society (e.g. by focusing on preventive measures), is much less pronounced in the legal text of the Social Support Act 2015. Article 2.1.2 (c, d and e) points in general terms at, respectively, the early determination of citizens' support needs, the prevention of citizens' reliance on support, and the provision of general support services (provided without the prior examination of the recipient's need, characteristics and capabilities). However, how to achieve these points is left to the municipalities' discretion. In the same vein, Article 2.1.2b points out that "the different categories of informal caregivers should be enabled as much as possible to perform their duties as informal caregiver" (authors' own translation), but this point is not specified in the remainder of the legal text. This point is therefore, we argue, much less concrete as compared to the old 2007 Social Support Act (under which municipalities where merely responsible for domestic help), where support for informal caregivers was concretized in such sub-themes as information, advice, emotional support, education, practical support, respite care, financial support and material support. At the same time, this high degree of policy discretion for municipali- 
ties under the 2015 Social Support Act gives room for 'innovative and unorthodox solutions', as was indicated by several of our respondents, although this may require the availability of more financial resources and/or a clearer delineation between (or integration of) the different long-term care Acts (the latter being one of the three main moral conflicts as identified by our respondents under question 1 of the survey).

Coming back to our main research question ("To what extent did/do municipalities in the Netherlands take potential moral conflicts into account when implementing and executing the Social Support Act 2015?"), we conclude by arguing that while municipalities are indeed aware of (potential) moral conflicts, the nature of the new law itself leaves insufficient room for municipalities to act in a sufficiently proactive and supportive/empowering manner on these challenges, as well as on the long-term aim of the Social Support Act 2015 of achieving a true participation society. The reasoning behind this argumentation is that although the new law appears to emphasise such ethical principles as social beneficence and respect for autonomy, the lack of emphasis on notions of social justice threatens to impede the effectuation of the intended goals in practice. Moreover, the Social Support Act 2015 seems to be mainly directed towards achieving a certain outcome (the maximisation of social beneficence through the creation of a participation society), instead of stipulating how that outcome should exactly be achieved in a fair manner. As such, the Social Support Act 2015 insufficiently seems to provide equality of opportunity with regard to long-term care access, both between citizens within the same municipality, as (and perhaps especially) between different municipalities. At the more short-term, taking into account a minimum set of ethical principles allows for the allocation of (seemingly scarce) resources that is, at the least, as fair as possible.

\section{Study strengths and limitations and suggestions for further research}

The principle strength of this study has been the application of a broad ethical approach towards scrutinizing a new, and still sensitive, policy responsibility of Dutch municipalities. We have shown that taking into account a minimum set of ethical principles, raises awareness of (potential) moral conflicts within the context of the new Social Support Act. Being aware of such conflicts, at its turn, helps in executing the new responsibilities under the Social Support Act in an appropriate manner (or in justifying decisions towards citizens) and gives room for municipalities to act in a as proactively as possible manner on the challenges resulting from these new responsibilities. Next, the fact that all Dutch municipalities were invited to participate in our study led to a reasonable response rate, in terms of reaching a saturation point in our data analysis. At the same time, the limited response rate to the invitation for a telephonic interview might have led to a certain selection bias, as not all respondents have given the same level of indepth explanation to their survey answers. Moreover, it might have been valuable if additional questions were added to the in-depth interviews, although also the semi- 
structured character of these interviews already allowed for a certain (though limited) degree of further exploration within and beyond the initial interview items. Finally, also our argument with regard to the allegedly insufficient support with regard to achieving a participation society leaves room for further research, as this is exactly a topic that holds a more long-term perspective. As such, it may be worth considering within a number of years to what extent the Social Support Act 2015 actually contributed (or not) to the creation of a true participation society.

\section{COMPETING INTERESTS}

None declared. 


\section{REFERENCES}

Andrews, M. (2004), 'Who Is Being Heard? Response Bias in Open-ended Responses in a Large Government Employee Survey', Public Opinion Quarterly, 69: 3760-66.

Arie, S. (2013), 'Has austerity brought Europe to the brink of a health disaster?', BMJ, 346(f3773).

Brand, H., Rosenkötter, N., Clemens, T., and Michelsen, K. (2013), 'Austerity Policies in Europe-Bad for Health', BMJ, 346(f3716).

Commission of the European Communities. (2007), White Paper. Together for Health: A Strategic Approach for the EU 2008-2013. Brussels: Commission of the European Communities.

Commission of the European Communities. (2010), Europe 2020: A strategy for smart, sustainable and inclusive growth. Brussels: Commission of the European Communities.

Council of the European Union. (2006), 'Council conclusions on common values and principles in European Union health systems (2006/C 146/01)', Official Journal of the European Union, 2006;49:C 146/1-3.

Daniels, N. (2008), Just Health: Meeting Health Needs Fairly. Cambridge: Cambridge University Press.

Daniels, N., and Sabin, J.E. (2008), 'Accountability for reasonableness: an update', BMJ, 337(a1850).

De Koster, Y. (2016). 'Kwart zorggebruikers mijdt dure zorg' [Quarter of care users avoids expensive care], Binnenlands Bestuur, February 10, 2016. http://www.binnenlandsbestuur.nl/sociaal/nieuws/kwartzorggebruikers-mijdt-dure-zorg.9518647.lynkx (accessed April 1, 2016).

Dwarswaard, J., and Van de Bovenkamp, H. (2015), 'Self-management support: A qualitative study of ethical dilemmas experienced by nurses', Patient Education and Counseling, 98(9): 1131-6.

Dwarswaard, J., Bakker, E.J., van Staa, A, and Boeije, H.R. (2015), 'Self-management support from the perspective of patients with a chronic condition: a thematic synthesis of qualitative studies', Health Expectations, doi: 10.1111/hex.12346 [Epub ahead of print].

Grootegoed, E., and Tonkens, E. (2015), 'Disabled and elderly citizens' perceptions and experiences of voluntarism as an alternative to publically financed care in the Netherlands', Health and Social Care in the Community, doi: 10.1111/hsc.12299 [Epub ahead of print].

Hsieh, H., and Shannon, S.E. (2005), 'Three Approaches to Qualitative Content Analysis', Qualitative Health Research, 15(9): 1277-88.

Huber, M., Knottnerus, J.A., Green, L., van der Horst, H., Jadad, A.R., Kromhout, D., Leonard, B., Lorig, K., Loureiro, M.I., van der Meer, J.W., Schnabel, P., Smith, R., van Weel, C., and Smid, H. (2011), 'How should we define health?', BMJ, 343(d4163).

Jongen, W., Burazeri, C., and Brand, H. (2015a), 'The influence of the economic crisis on quality of care for older people: system readiness for innovation in Europe', Innovation: The European Journal of Social Science Research, 28(2): 167-91.

Jongen, W., Commers, M.J., Schols, J.M.G.A, and Brand, H. (2015b), 'The Dutch Long-Term Care System in Transition: Implications for Municipalities', Das Gesundheitswesen, doi: 10.1055/s-0035-1564251 [Epub ahead of print].

Karanikolos, M., Mladovsky, P., Cylus, J., Thomson, S., Basu, S., Stuckler, D., Mackenbach, J.P., and McKee, M. (2013), 'Financial crisis, austerity, and health in Europe', The Lancet, 381(9874):1323-31.

Maarse, H., Jeurissen, P., and Ruwaard, D. (2016), 'Results of the market-oriented reform in the Netherlands: a review', Health Economics, Policy and Law, 11(2): 161-78.

Maarse, J.A.M., and Jeurissen, P.P. (2016), 'The policy and politics of the 2015 long-term care reform in the Netherlands', Health Policy, 120(3): 241-5.

MacCullough, L.B. (2016), 'Long-Term Care Ethics - Ethical Issues In Long-term Care Decision-making', Medicine Encyclopedia, http://medicine.jrank.org/pages/1063/Long-Term-Care-Ethics.html (accessed March 21, 2016).

McConnell, T. (2014), 'Moral Dilemmas', The Stanford Encyclopedia of Philosophy, Fall 2014 Edition, http://plato.stanford.edu/archives/fall2014/entries/moral-dilemmas/ (accessed March 21, 2016).

McKee, M., Karanikolos, M., Belcher, P., and Stuckler, D. (2012), 'Austerity: a failed experiment on the people of Europe', Clinical Medicine, 12(4): 346-50. 


\section{Chapter 6}

Pavolini, E., and Ranci, C. (2008), 'Restructuring the welfare state: reforms in long-term care in Western European countries', Journal of European Social Policy, 18(3): 246-59.

Quaglio, G., Karapiperis, T., Van Woensel, L., Arnold, E., and McDaid, D. (2013), 'Austerity and health in Europe', Health Policy, 113(1-2): 13-9.

Ranci, C., and Pavolini, E., eds. (2013), Reforms in Long-Term Care Policies in Europe, New York: SpringerVerlag.

Schröder-Bäck, P., Brand, H., Escamilla, I., Davies, J.K., Hall, C., Hickey, K., Jelastopulu, E., Mechtler, R., and Volf, J. (2009), 'Ethical evaluation of compulsory measles immunisation as a benchmark for good health management in the European Union', Central European Journal of Public Health, 17(4): 183-6

Schröder-Bäck, P., Clemens, T., Michelsen, K., Schulte in den Bäumen, T, Sørensen, K., Borrett, G., and Brand, H. (2012), 'Public health ethical perspectives on the values of the European Commission's White Paper "Together for Health"', Central European Journal of Public Health, 20(2): 95-100.

Schröder-Bäck, P., Stjernberg, L., and Borg, A.M. (2013), 'Values and ethics amidst the economic crisis', European Journal of Public Health, 23(5): 723-4.

Schröder-Back, P., Duncan, P., Sherlaw, W., Brall, C., and Czabanowska, K. (2014), 'Teaching seven principles for public health ethics: towards a curriculum for a short course on ethics in public health programmes', BMC Medical Ethics, 15(73).

Van der Aa, M.J., Evers, S.M.A.A., Klosse, S., and Maarse, J.A.M. (2014), 'Hervorming van de langdurige zorg. Blijft de solidariteit behouden?' [Reform of long-term care. Will solidarity be maintained?], Nederlands Tijdschrift voor Geneeskunde, 158(A8253).

Verweij, M., and Dawson, A. (2004), 'Ethical principles for collective immunisation programmes', Vaccine, 22(23-24): 3122-6.

World Health Organization (WHO). (2006), 'Constitution of the World Health Organization', http://www.who.int/governance/eb/who_constitution_en.pdf (accessed April 4, 2016).

World Health Organization (WHO). (2016), 'What is universal coverage?', http://www.who.int/health_financing/ universal_coverage_definition/en/ (accessed March 21, 2016). 


\section{Chapter}

\section{Cross-border capacity assessment in dementia care}

Jongen, W., Commers, M.J., Schols, J.M.G.A., Burazeri, G., \& Brand, H. (in press). Crossborder capacity assessment in dementia care. Das Gesundheitswesen. 


\section{ABSTRACT}

Introduction: Within the Euregio Meuse-Rhine, cross-border cooperation in the healthcare sector has taken place at different occasions and on different levels. However, it still proves to be difficult to keep an overview of the existing structures and activities in this Euregio within specific healthcare fields, for instance dementia care. The aim of this study is to examine to what extent cooperation in the Dutch province of Limburg in the field of dementia care can be considered Euregionally oriented.

Methods: In order to create more cross-border transparency within the Euregional dementia care field, we conducted a capacity assessment analysis. Capacity assessment is the first step in the further development of healthcare capacities by mapping current as well as desired capacities. Although we related the model as applied in this study explicitly to dementia care in the Euregio Meuse-Rhine, the model could be applicable in other cross-border settings and/or healthcare fields as well.

Results: Despite the apparently well-functioning system of regional dementia care networks within the Dutch province of Limburg, none of the respondents declared to have structural contacts with similar organizations in the other (German and Belgian) parts of the Euregio. Moreover, many of our respondents argued that cross-border cooperation in the field of dementia care could be interesting in various ways, but at the same time there is currently no direct necessity to actively pursue such cooperation.

Discussion: Despite the absence of structural cross-border cooperation initiatives in the field of dementia care in the Euregio Meuse-Rhine, some suggestions can be made for the formulation of a potential capacity development response on the basis of the results of the capacity assessment as conducted in this study (showing gaps between current and desired capacities). Even if it is subsequently decided not to formulate a concrete capacity development response (for example due to the lack of a mutual objective need amongst organizations to engage in cross-border cooperation), a capacity assessment offers at the least a reflection on an organization's own performance as well as it provides for transparency between organizations. The main opportunities for the formulation of a capacity development response on a Euregional level in the field of dementia care, are related to knowledge development and the creation of partnerships.

Keywords: capacity assessment, cross-border cooperation, dementia care. 


\section{INTRODUCTION}

On January 1, 2015, the Netherlands have witnessed a major reform of its long-term care system, characterized by (amongst others) a decentralization of long-term care responsibilities from the national government to the municipalities, accompanied by severe budget cuts in the long-term care sector. With regard to long-term care, the province of Limburg (particularly the southern part) has an interesting position within the Netherlands due to its above average aging pattern and its above-average percentage of inhabitants with one or more chronic diseases [1], even if adjusted for age and gender [2]. Moreover, due to its unique geographical location, in the proximity of both Germany and Belgium, Limburg can be considered within the Netherlands as an interesting testing ground for cross-border cooperation initiatives. Limburg is situated in the heart of the Euregio Meuse-Rhine (EMR), a cross-border cooperation arrangement between regional governments. The EMR contains 3,9 million inhabitants and comprises apart from the Dutch province of Limburg also the Belgian province of Limburg, the Belgian province of Liege, the German-speaking Community of Belgium and the Aachen region. In fact, cross-border cooperation has been given shape in many European internal border areas by the creation of such Euregios. Within the healthcare sector, Directive 2011/24/EU on 'patients' rights to cross-border health' even stimulates Member States to 'facilitate cooperation in cross-border healthcare provision at regional and local level' (Art. 10). Indeed, various good examples of such cross-border cooperation exist [3]. At the same time, as argued by Glinos, Wismar \& Palm, cross-border cooperation in healthcare is no easy endeavor, as 'health care actors are rooted in their respective health systems and follow domestic rules, priorities and incentives' [4]. Also within the EMR setting, cross-border cooperation in the healthcare sector has taken place at different occasions and on different levels. Within the healthcare sector, particularly worth mentioning is the euPrevent|EMR programme, a Euregional network in the field of cross-border health prevention. However, despite the existence of networks such as euPrevent|EMR it still proves to be difficult to keep an overview of the existing structures and activities within specific healthcare fields, for instance dementia care, which is a key priority policy theme of both the Dutch province of Limburg as of the EMR. Indeed, as the population ages, a large and increasing number of people are living with dementia worldwide [5]. Also in the EMR region, more and more organizations active in the healthcare sector are searching for cooperation partners across the border, as appears for example from the numerous euPrevent|EMR projects and programs. However, in practice it often proves to be difficult to identify the right cooperation partners, especially as capacities within the healthcare sector have developed incrementally, but in different ways, in the different EMR regions. Although no single definition for the concept of 'capacities' (within the healthcare sector) exists, the concept at least consists of several dimensions (on the individual, organizational and societal level), such as financial resources, supportive laws, policies, strategies and procedures, well-functioning 
organizations, and educated and skilled professionals, required to plan, implement and review (health) strategies [6]. Moreover, in each region of each country, capacity development of professionals and organizations is an ongoing process, in order to meet new political, societal, or demographic challenges.

Capacity development has been described as 'the process through which individuals, organizations and societies obtain, strengthen and maintain the capabilities to set and achieve their own development objectives over time' [7]. Within the healthcare sector, capacity development has been defined as '[a]n approach to the development of sustainable skills, organisational structures, resources and commitment to health improvement in health and other sectors, to prolong and multiply health gains many times over' [8]. As Aluttis et al. suggest, this definition indicates that capacity building 'is not aimed at directly improving the population's health status, but at ensuring that the conditions are in place to achieve health improvement and to ensure that this can be multiplied and sustained over time, independent of external events' [9]. A first step in the further development of healthcare capacities, then, is the process of capacity assessment, in order to map current as well as desired capacities. Such a capacity assessment provides the necessary insights required to formulate capacity development objectives. Or, as a process that 'serves to provide an input for formulating a capacity development response that addresses those capacities that could be strengthened and that optimises existing capacities that are already strong and well founded. It can also set the baseline for continuous monitoring and evaluation of progress against relevant indicators and help create a solid foundation for long-term planning, implementation and sustainable results' [6].

In the Netherlands, cooperation in the field of dementia care is structured into more than 80 well-functioning regional dementia care networks. These networks were initiated by the Dutch government in 2008 by the so-called Ketenzorg Dementie (integrated dementia care) policy, in an attempt to integrate the care and support for people with dementia-as well as the support for their informal caregivers-into a system of multidisciplinary regional dementia care partnerships. The Dutch province of Limburg contains five such regional networks. Little is, however, known about the cross-border, Euregional, activities of these regional networks and the organizations involved. Various capacity development instruments have been developed in various sectors and for various purposes. However, no such tool appears to be developed specifically for the healthcare sector in a cross-border setting, which creates the premise for exploring this field in the current study.

This study specifically focuses on this first step of the capacity development process, whereby capacity assessment can be considered here as a useful method to provide for the necessary cross-border transparency within Euregional dementia care. In this study, we conducted a Euregionally oriented capacity assessment in dementia care in the Dutch province of Limburg. As such, this study intends to answer the following research question: To what extent can cooperation in Limburg in dementia care be considered 
Euregionally oriented? As a sub-question we considered if and how, based on our capacity assessment results, suggestions could be made for the formulation of a potential capacity development response?

\section{METHODS}

The capacity assessment model as applied in this study is essentially based on elements of the Capacity Assessment Framework as developed by the United Nations Development Programme (UNDP) [6,7]. That framework is not static in nature, but offers sufficient elements as building blocks for the development of a tailor-made capacity assessment and, eventually, a capacity development approach. Not every organization will decide to opt for the latter option, because of various reasons (such as a lack of resources, a lack of priority, etc.). However, even if it is decided not to formulate a concrete capacity development response, a capacity assessment offers at the least a reflection on an organization's own performance as well as it provides for transparency between organizations.

The UNDP model focuses on several so-called 'functional capacities' that 'are needed to create, manage and review policies, legislations, strategies and programmes across levels of capacity (enabling environment, organizational, individual) and across core issues (institutional arrangements, leadership, knowledge, accountability)' [6]. The five functional capacities as addressed in the UNDP Capacity Assessment Framework are summarized in the text box below.

The five functional capacities as addressed in the UNDP Capacity Assessment Framework [6]:

- Capacity to engage stakeholders

- Capacity to assess a situation and define a vision and mandate

- Capacity to formulate policies and strategies

- Capacity to budget, manage and implement

- Capacity to evaluate

For the 'capacity assessment part' of this study we focused on this functional capacities dimension of the UNDP model, which we considered cyclical in nature here, being in line with the idea that organizations' capacities in the field of (cross-border) cooperation initiatives can be divided into stages (ranging from the initiation of first contacts, to the development of concrete cooperation projects, to the formation of a stable partnership that is regularly evaluated).

For the 'capacity development part' of this study we applied the 'core domains for public health capacity' as defined by Aluttis et al., which in its turn are partly based on 
the 'capacity building framework' as developed by the New South Wales (NSW) Health Department [10]. Although the Aluttis model and the NSW Health model thus partly overlap, we took the Aluttis model as a starting point, as the Aluttis model is specifically focused on the healthcare sector, takes country specific contexts into account (for example political contexts, as well as the different nature of healthcare systems) and is more comprehensive than the NSW Health mode. Table 1 gives an overview of the way the seven core domains are defined in this study, being largely in line with the original definitions as suggested by Aluttis et al. [9].

Table 1. Core domains for public health capacity (derived from Aluttis et al. [9] and processed into own table).

\begin{tabular}{|c|c|}
\hline Domain & Definition \\
\hline Organizational structure & $\begin{array}{l}\text { The infrastructural ability of the system to contribute to goals of public } \\
\text { health. }\end{array}$ \\
\hline Workforce & $\begin{array}{l}\text { Qualified human resources with sufficient skills and knowledge; this also } \\
\text { includes the availability of training options. }\end{array}$ \\
\hline Resources & $\begin{array}{l}\text { The allocation and provision of human and financial resources necessary to } \\
\text { carry out public health activities. }\end{array}$ \\
\hline Partnerships & Collaboration between organizations for effective public health practice. \\
\hline Knowledge development & $\begin{array}{l}\text { The knowledge base that provides information on the health of the } \\
\text { population and that supports evidence-based public health policy and } \\
\text { interventions at all levels. }\end{array}$ \\
\hline Leadership and governance & $\begin{array}{l}\text { The ability and willingness of governments [or other relevant stakeholders] } \\
\text { to improve public health by developing and implementing effective public } \\
\text { health policies and by expressing qualities in leaderships and strategic } \\
\text { thinking. }\end{array}$ \\
\hline $\begin{array}{l}\text { Country specific context with } \\
\text { relevance for public health }\end{array}$ & $\begin{array}{l}\text { The political context and other characteristics of a country that may have } \\
\text { an influence on public health policies and capacity building efforts. }\end{array}$ \\
\hline
\end{tabular}

In short, the 'functional capacities' dimension (as based on the UNDP model) gives an insight into the stage(s) at which change or improvement should or could occur (derived from the gap between current and desired capacities); the 'core domains for public health capacity' dimension (as based on the Aluttis model) suggests ways of achieving this change.

For this study, we applied a mixed-method research approach, consisting of two subsequent steps [11]. First, participants were asked to complete an online quantitative survey. The survey questions were directly derived from the original UNDP model (divided into five categories/subscales) as discussed above and translated into Dutch [7]. Although we related the model in this study explicitly to dementia care, the model could be applicable in other healthcare fields as well due to its general setup. In that way, dementia care could be considered a test-case for application of this model in a cross-border setting. The questions are cyclical in nature, following the five categories of functional capacities as described above, implying that a respondent only reaches a next category when the previous category has been answered positively. Prior to the actual study, two test-interviews were conducted with scientific representatives in the 
long-term care field in Limburg, in order to test our questionnaire. Participants were asked to answer each question on a five-point Likert scale, ranging from 'completely unable' to 'completely able'. Moreover, respondents had the opportunity to select a 'cannot answer this question' option. Moreover, each question had to be answered twice: on the one hand considered from the own regional situation (assessment of (potential) involvement in dementia care networks within Limburg), and on the other hand considered from the broader Euregional situation (assessment of (potential) involvement in dementia care networks in the EMR). Although a lot was already known about the regional Limburg situation, including the regional situation in our quantitative survey allowed for assessing possible correlations between 'regional' and 'Euregional' scores. As a second step in our mixed-method approach, participants were asked for an in-depth, semi-structured, interview after completion of the online questionnaire. The underlying reasons for this qualitative part of the study were twofold: on the one hand it allowed us to discuss, in-depth, the main findings of the quantitative survey; on the other hand, it allowed us to confront respondents with an additional set of qualitative questions (as mentioned in Table 2) that were not covered in the survey, but gradually turned out to be of much relevance.

Table 2. Additional qualitative interview questions.

1. To what extent are you familiar with (the work of) organizations in the dementia care field in the other parts of the Euregio (Belgian province of Limburg, the Belgian province of Liege, the German-speaking Community of Belgium and the Aachen region)?

2. To what extent do you consider cross-border between your organization and organizations in the dementia care field in the other parts of the Euregio as potentially beneficial?

3. What do you consider as the main barriers in searching for / realizing more such cross-border cooperation (if desired)?

4. What do you consider as the main requirements for achieving more such cross-border cooperation (if desired)?

5. What are your expectations with regard to your organization's potential future realization or expansion of cross-border cooperation initiatives?

In contrast to the 'functional capacities' dimension (specifically geared towards the capacity assessment part of our study), the 'core domains for public health capacity' dimension (specifically geared towards the capacity development part of our study) were not explicitly included in the survey and interview questions, but instead derived from the survey and interview results. According to the UNDP model, a potential capacity development response is ideally only defined when those organizations involved in a capacity assessment process discuss the results of the assessment with each other. Only based on these results it can be decided to set priorities (or not) for a potential capacity development response. Therefore, this study focuses on the capacity assessment process; only suggestions will be made for a potential capacity development response.

Twenty representatives of various types of organizations involved in dementia care in the Dutch province of Limburg were approached for participation in this study. First, 
the coordinators of the five sub-regional dementia care networks in the province of Limburg were approached. Subsequently, we applied a snowball sampling technique, by asking each of these five representatives to provide use with three more respondents in their respective region. To be able to guarantee confidentiality, each of our respondents was asked to sign an informed consent. Because of our mixed-method research approach, anonymity of our respondents can only be guaranteed toward the readers of this article by omitting persons' and organizations' names. Of the 20 participants in the quantitative part of the study, 15 agreed to cooperate on the subsequent qualitative part of the study.

\section{Analyses}

For the quantitative part of the study, limited statistical analyses were performed: mean values and their respective 95\% confidence intervals were calculated for both the 'Limburg' as the 'Euregio' responses. Furthermore, Spearman's rho (a non-parametric version of Pearson's correlation coefficient) was used to assess the linear association between the overall summary score of 'Limburg' and 'Euregio' responses. SPSS (Statistical Package for Social Sciences, version 15.0) was used for the statistical analyses.

Conversely, the qualitative interview data were analyzed by applying the grounded theory approach of open, axial, and selective coding, implying the principle of inductive reasoning and a constant comparison method [12].

\section{RESULTS}

The descriptive, quantitative, survey results of the 'Limburg' part of our study are shown in Table 3. Fourteen respondents answered all questions with a numerical score, having an average score of 3.8 per question for the five categories combined. The missing answers were mainly due to respondents skipping one or more questions.

Table 3. Descriptive statistics for the overall summary score and the summary scores of each category for the 'Limburg' responses.

\begin{tabular}{lcccccc}
\hline Parameter & $1^{\text {st }}$ subscale & $2^{\text {nd }}$ subscale & $3^{\text {rd }}$ subscale & $4^{\text {th }}$ subscale & $5^{\text {th }}$ subscale & Overall scale \\
\hline Valid number & 17 & 18 & 15 & 18 & 18 & 14 \\
Missing values & 3 & 2 & 5 & 2 & 2 & 6 \\
Mean & 22.1 & 14.8 & 14.7 & 11.8 & 12.1 & 76.1 \\
Median & 24.0 & 15.0 & 16.0 & 12.0 & 12.0 & 80.5 \\
Standard deviation & 5.1 & 2.7 & 3.1 & 2.8 & 2.4 & 14.0 \\
Minimum & 11.0 & 8.0 & 9.0 & 8.0 & 6.0 & 43.0 \\
Maximum & 30.0 & 19.0 & 19.0 & 15.0 & 15.0 & 93.0 \\
\hline
\end{tabular}


The descriptive, quantitative, survey results of the 'Euregional' part of our study are shown in Table 4. Only ten respondents answered all questions with a numerical score, having an average score of 2.4 per question for the five categories combined. The missing answers were mainly due to respondents choosing the 'cannot answer' option.

Table 4. Descriptive statistics for the overall summary score and the summary scores of each category for the 'Euregio' responses.

\begin{tabular}{lllllll}
\hline Parameter & $1^{\text {st }}$ subscale & $2^{\text {nd }}$ subscale & $3^{\text {rd }}$ subscale & $4^{\text {th }}$ subscale & $5^{\text {th }}$ subscale & Overall scale \\
\hline Valid number & 13 & 13 & 10 & 12 & 12 & 10 \\
Missing values & 7 & 7 & 10 & 8 & 8 & 10 \\
Mean & 13.3 & 8.5 & 9.3 & 8.0 & 7.8 & 48.8 \\
Median & 12.0 & 8.0 & 8.0 & 8.0 & 7.5 & 52.0 \\
Standard deviation & 5.5 & 3.4 & 3.9 & 3.4 & 3.5 & 19.4 \\
Minimum & 6.0 & 4.0 & 4.0 & 3.0 & 3.0 & 20.0 \\
Maximum & 22.0 & 14.0 & 14.0 & 13.0 & 13.0 & 74.0 \\
\hline
\end{tabular}

The results of the Spearman's rho test (assessing a possible correlation between the overall summary score of the regional and Euregional responses) show a moderate yet borderline statistically significant correlation (Spearman's rho $=0.664, P=0.051$ ).

In the qualitative part of the study we found that despite the apparent wellfunctioning system of the regional dementia care networks within the Netherlands, the situation is completely different when considered from a broader, Euregional, perspective. As a first step of the qualitative part of the study we discussed in-depth respondents' answers to the quantitative survey questions. Concerning the 'capacity to engage stakeholders' in Euregional dementia care, each of the respondents declared to have no structural contacts with similar organizations in the other (German and Belgian) parts of the Euregio. This holds both for the regional dementia care networks, as for the individual organizations within these networks. Only in a few occasional cases some of the respondents had some contacts with similar organizations abroad, but only because of personal interests or pre-existing personal contacts abroad, and on an occasional basis. As one of the respondents reported": "I have once participated in a Euregional conference (about ethics I thought). And the fact that I live in Belgium and work in the Netherlands helps in being aware of what is happening in both countries". The main reasons for not having structural contacts abroad were either having no mandate to do so, or because of non-awareness ("never thought about it actually", "I can't say that I currentIy miss the Euregional cooperation", as two of the respondents put it), or because of non-interest and/or non-priority (most of the regional dementia care networks, for example, are struggling to either broaden their network in their own respective region, or to guarantee structural, long-term, cooperation).

\footnotetext{
${ }^{1}$ All of the respondents' quotes are the authors' own translations from Dutch to English.
} 
As a result of the answers to the 'capacity to engage stakeholders' category, there were no response options in the other categories due to the cyclical nature of the questions as explained above. Merely concerning the 'capacity to assess a situation and define a vision and mandate', some respondents declared to occasionally consider policy documents of similar organizations abroad. As one of the respondents put it: "Having a look at each other's' vision is one thing, but a shared vision is still one step too far. [During a symposium in Germany] we listened to each other's stories and entered into dialogues with each other, but to talk about a similar vision...". There have, however, been no cases reported of comparing policies with foreign partners or defining common policies. Moreover, those respondents that occasionally considered foreign policy documents did not limit this approach to the Euregio, but also considered policy documents of organizations in the rest of Europe or even the rest of the world.

In order to gain more insight into the above conclusions for the Euregional situation we confronted our respondents with an additional set of five qualitative questions (as mentioned in Table 2). While the original questions were mainly based on capacity in terms of an actual situation (that appeared to be almost non-existing when considered from a Euregional perspective), the additional set of questions was much more based on a potentially desired situation. The first of these questions was focused on whether or not being familiar with (the work of) organizations in their field in the other parts of the Euregio. While most of the respondents reported to be unfamiliar with (the work of) such foreign organizations, some respondents reported to have some knowledge about this, which is in line with the results mentioned in the previous paragraph. Apart from knowledge acquired by reading reports or policy documents, knowledge was acquired by attending Euregional symposia focused on a particular theme, notably on 'dementia friendly communities' initiatives or on informal care - the latter being indeed a much more common phenomenon in Belgium and Germany than in the Netherlands [13]. Or, as one respondent put it: "I know about it [the work of similar organizations in the other parts of the Euregio], but I am also well aware of the fact that I don't know by far as much about those regions than about my own region or the surrounding regions [within the Netherlands]".

The next question was focused on respondents' views about the potential advantages of cooperating with similar organizations in the other parts of the Euregio. General conclusion was that primarily healthcare professionals and municipalities, instead of clients, could benefit from such cross border cooperation. Examples included the exchange of knowledge and best practices. As one of the respondents reported: "There might well be things happening in the Euregion of which we would say, gee, interesting, we never thought about thát. So I think we would never reject such information. If we would get information or possibilities we would make use of it, but it is currently not up to us". Some respondents argued that obtaining such knowledge requires exchange projects for employees of healthcare organizations and municipalities in order to experience the work culture in foreign organizations. Others argued that 
such knowledge can equally be obtained without actual contact across the border - for example by making use of comparative studies. Next, respondents pointed to the potential advantage of benchmarking one's own organization's or region's performance to that of other, foreign, organizations or regions, within the context of mutual learning. Again, there appears to be no direct added value of limiting such initiatives to the Euregional context. As one of the respondents argued: "It would be good to consider the functioning of the elderly care system elsewhere, on a national level, or on Euregional level, that doesn't matter so much". Our respondents believe that clients only benefit in an indirect way from such initiatives, as a result of a better quality of care they may eventually lead to. Potential advantages in terms of cross border patient mobility-as referred to in Directive 2011/24/EU - are much less obvious in the field of long-term care than for example in the field of medical care. In fact, long-term care is explicitly excluded from this Directive (Recital 14). A number of respondents, finally, reported to see no direct advantages of more cross-border cooperation in the field of dementia care, as the functioning of the regional dementia care networks in Limburg is in general highly valued by most of the participating organizations, whereby organizations already learn a lot from each other due to the multidisciplinary approach of the networks. As one respondent put it: "At the moment we are still busy enough with ourselves and we are satisfied with the connections and contacts we have and there are still sufficient opportunities to expand these. So we haven't yet had the need to have a look across the border (so really the national border)".

With regard to the third question, the main barriers in searching for more crossborder cooperation (if desired) lie according to our respondents in the fact that the differences in healthcare systems between the three countries often impede practical cooperation with organizations across the border. Or, as one respondent reported: "There are cultural differences. These are very concrete barriers". Moreover, many organizations have to deal with scarce resources (especially, as argued by Jongen et al. [14], after the entry into force of the Dutch long-term care reform), which means setting priorities; cross-border cooperation mostly is not such a priority. Or, as one respondent put it: "You know, there is currently so much going on within our own healthcare system, which costs me so much time and energy, that I wouldn't even want to think about it [Euregional cooperation]". Finally, as reported before, many of our respondents argued that cross-border cooperation could be interesting in various ways, but there is currently no direct necessity to actively pursue such cooperation in the field of dementia care.

With regard to the question on what is needed to achieve more cross-border cooperation (if desired), our respondents mainly pointed to the importance of a third party taking the lead in this. Such a third party should ideally be a neutral organization, with a broad view on the long-term care sector in different countries. This 'umbrella' organization should act as a 'driving force', being capable of not only connecting organizations, but also triggering organizations to actively participate. As one respondent put it: "I 
think the incentive [stimulation of cross-border knowledge sharing] must come from euPrevent, or similar organizations working Euregionally". Another respondent suggested a role for the regional government: "The Province [Dutch Province of Limburg] could play an important role. [...] The Province has a lot of Euregional contacts and I think they could do a lot of preparatory work. Being able to break new grounds. Eventually the work, depending on the goals set, will have to be done by, let's say, the 'specialist' organizations". Moreover, in order to come to a solid, long-term, cooperation model, searching for win-win situations (wherein the interests of all countries involved are met) is a prerequisite. Next, even though cross-border contacts may well be facilitated by a third party, concrete cross-border initiatives should eventually be developed in a bottom-up manner by organizations themselves. Finally, any system facilitating crossborder cooperation should be flexible in nature, as cooperation needs may often appear spontaneously as a result of recent, sometimes unforeseen, developments in the healthcare sector.

Concerning organizations' expectations with regard to their potential future realisation or expansion of cross-border cooperation initiatives (last question), our respondents reported not to expect any significant developments in the near future. However, respondents were prone to possible developments in the longer-term, under the aforementioned conditions. As one respondent summarized quite well: "We are still in a situation wherein we have limited resources and are dependent of budgets of health insurers. [...] However, we are involved in a regional dementia care network in order to improve the quality of care, together with other healthcare organizations. So if this [improvement of care quality] could be achieved with a Euregional approach I would be equally interested in that as well".

\section{DISCUSSION}

In this final section, we discuss the principal findings of the current study (relating to our main research question) and move towards their broader implications (in terms of suggestions for the formulation of a potential capacity development response).

\section{Principal findings}

With regard to our first research question (Euregionally oriented capacity assessment in dementia care), it can be concluded that although well-functioning multidisciplinary regional dementia care networks exist within the Netherlands, no such structural cooperation appeared to exist in a cross-border Euregional setting. The absence of such cross-border cooperation initiatives is mainly due to the fact that there appeared to be no direct sense of urgency among respondents to develop such initiatives, and organizations are consequently unwilling to make capacity available for such purposes. At the 
same time, respondents appeared to be willing to consider participation in cross-border initiatives in cases of direct relevance. Cross-border cooperation, they argued, should not be an aim in itself, but is only of added value when there is a direct necessity to search for additional knowhow. An example of the latter is that a lot of organizations reported to be interested in experiences from other countries that have recently had a similar long-term care reform and/or decentralization situation as in the Netherlands, as this is a completely new situation Dutch organizations now have to deal with. This reform is, as argued by Jongen et al., 'characterized by major changes of its long-term care system taking place at a relatively rapid pace, starting in times of a severe economic crisis and entering into force in the wake of this crisis', and 'accompanied by severe budget cuts' [14]. The existence of barriers for cooperation in health and social service delivery across borders in largely publicly-subsidized services has become clear in this study. Substantial efforts to overcome these barriers will only be made if organizations are convinced of the added value to do so. This conclusion is in line with the findings of Glinos, Wismar \& Palm, indicating that several factors are needed to initiate and maintain cross-border cooperation, including 'an objective need as CBC [cross-border collaboration] must serve a concrete purpose'; 'committed individuals who invest time and effort in the cross-border cooperation project; shared interests among partners to ensure that all are working towards a common goal which cannot be obtained separately; external support from local stakeholders, public authorities and funding institutions; and a governance structure which suits the purposes, partners and health systems involved in the cross-border cooperation' [4].

With regard to the results of the Spearman's rho test we found a moderately positive correlation between the quantitative responses of the 'Limburg' scores and those of the 'Euregio' scores, implying that organizations which score high on regional cooperation also tend to score higher on Euregional cooperation than those organizations which score low on regional cooperation. This result (although on the border of statistical significance) is in line with our qualitative findings: those respondents that reported to have some knowledge about, or some contacts with, Euregional organizations were those respondents that were also actively engaged within the Dutch regional dementia care networks. In other words: cross-border cooperation also requires personal engagement of employees willing and motivated to be actively engaged in network collaboration. Moreover, the mean values indicated that respondents were more involved in regional cooperation than in Euregional cooperation, which is in line with our qualitative findings. With regard to these mean values, it has to be added that the Euregio scores were less normally distributed than the Limburg answers (or, in other words, more variance in answers in the Euregio scores than in the Limburg scores). Although also these results match with our qualitative findings, the mean values as such are of little statistical significance due to the low number of valid responses among the already low number of respondents. 


\section{Broader implications}

With regard to our sub research question then (suggestions for the formulation of a potential capacity development response), indeed some suggestions can be made for the formulation of a potential capacity development response, based on the results of the Euregionally oriented capacity assessment as conducted in this study. Even if organizations do not decide to opt for the formulation of concrete capacity development objectives, these suggestions at the least provide the opportunity for a self-reflection on the functioning of individuals, organizations and societies, as well as transparency between individuals, organizations and societies about each other's functioning (e.g. for benchmarking or mutual learning aims). Important to emphasize here is that the suggestions that are made are based on an aggregated conclusion for approaching dementia as a societal problem or a societal challenge on the Euregional level. The conclusion (capacity development response) for individual organizations can and will differ from this aggregated conclusion, depending on the specific current and desired capacities (and the gap between them) applying to that organization.

The main opportunities for the formulation of a capacity development response on a Euregional level in the field of dementia care, are-in terms of Aluttis et al.'s core domains for public health capacity - situated within the domains 'knowledge development', 'partnerships' and (primarily resulting from the former two domains) 'organisational structure' and 'leadership and governance'. 'Knowledge development' (primarily in terms of knowledge sharing) was considered by the majority of our respondents as the most obvious reason for potentially considering the work of similar organizations across the border. However, in order to come to a situation wherein knowledge sharing can be organized in a structural way, instead of on an ad-hoc basis, it is key to further develop already existing (or create new) suitable Euregional cooperation structures ('partnerships'). In order to stimulate organizations to create or further develop such partnerships, the existence of a genuinely shared interest is, in line with the findings of Glinos, Wismar \& Palm [4], indispensable. Moreover, also in line with the findings of Glinos, Wismar \& Palm [4], it requires a governance structure within each of the individual organizations involved, that suits the purposes of the respective cross-border cooperation initiative ('organisational structure'). Most of the individual organizations we interviewed, however, currently lack the existence of an objective need for crossborder cooperation, as well as the existence of a governance structure that is suitable for structural cross-border cooperation initiatives, mainly as a result of other, more prevalent, priorities. Much is therefore in this respect expected of those organizations that already somehow fulfill an overarching 'umbrella' role (such as the dementia care networks on a regional Limburg level). Regardless of which organization could and would like to fulfill this role, it is clear that the majority of respondents consider the intervention of a third party as facilitator as a precondition for their potential future involvement in cross-border cooperation projects or structures ('leadership and gov- 
ernance'). Preconditions for making progress within the aforementioned core domains, then, are the available financial and human resources an organization has at its disposal ('resources' and 'workforce'). Both financial and human resources are currently scarce in many organizations active in the long-term care sector, especially as a result of the budget cuts accompanying the current Dutch long-term care reform. Moreover, most of these organizations do not appear to have any budget available for cross-border cooperation initiatives, due to a lack of priority of such initiatives. However, even with limited resources, tangible results can be achieved within individual organizations. An example includes the appointment of a dedicated employee within an organization, who will be allowed to devote a limited amount of time on cross-border cooperation initiatives (minimally by maintaining cross-border contacts and sharing relevant information with these contacts). The resources for creating and maintaining a truly structural crossborder partnership are most likely to be found with external funders, such as local governments and/or private investors. Finally, there are some external factors that organizations are unlikely to influence, but that are nonetheless worth taking into account when formulating a potential capacity development response. Most noteworthy in the case of a potential Euregional approach in the field of dementia care is the mere fact that national healthcare systems differ. These differences often impede the cooperation across borders in a practical way, for example due to differences in policy priorities between governments or due to different funding channels for projects ('country specific context').

\section{Study limitations and suggestions for further research}

Although the principle strength of this study has been its structured and cyclical approach of assessing the capacities of organizations (thereby separating true structural networks from mere ad-hoc, coincident, contacts) in a yet unexplored setting (dementia care in a cross-border setting), its quantitative approach has probably been its largest weakness. Indeed, despite the positive test-results prior to the actual study, respondents declared the survey questions to be too abstract. At the same time, this quantitative flaw has been captured to a large extent-at least for answering our first research question-by the qualitative part of the study, as the latter allowed to discuss in-depth respondents' survey results and to extend the scope of the survey from mere current capacity assessment to the assessment of potentially desired capacities. Particularly in still undeveloped networks such as in the case of Euregional cooperation in dementia care, the latter may be worth considering, for example by triggering organizations by sharing best practice experiences or by giving advice on how to potentially develop capacity - possibly in predefined categories such as the core domains for public health capacity, as suggested by Aluttis et al. [9]. Another potential weakness of this study has been the fact that no capacity assessments have been performed in the other EMR regions and that it was focused merely on dementia care and no other healthcare fields. 
However, it is particularly this weakness that provides opportunities for further research, particularly as respondents themselves pointed to the potential added value of conducting capacity assessments related to other topics. Therefore, we suggest conducting capacity assessments (based on current as well as potentially desired capacities) in a number of neighboring countries (within the context of this study, notably the Netherlands, Germany and Belgium), thereby ideally encompassing a broader array of topics than merely dementia.

\section{ACKNOWLEDGEMENTS}

We would like to acknowledge and thank euPrevent|EMR and the Dutch Province of Limburg for facilitating and supporting this study. Both euPrevent|EMR and the Province of Limburg played no role in the analysis and interpretation of data, or writing of the study. Finally, we would like to acknowledge and thank Timo Clemens, MSc (Department of International Health, Maastricht University) for translating parts of the text into German.

\section{COMPETING INTERESTS}

The authors have no conflict of interest to disclose. 


\section{REFERENCES}

1 National Institute of Public Health and the Environment (RIVM). Vergrijzing: Zijn er in Nederland verschillen naar regio? Internet: http://www.nationaalkompas.nl/bevolking/vergrijzing/zijn-er-in-nederlandverschillen-naar-regio/; Accessed: 18.01.2016

2 National Institute of Public Health and the Environment (RIVM). Eén of meer chronische ziekten 2012. Internet: http://www.zorgatlas.nl/gezondheid-en-ziekte/ziekten-en-aandoeningen/chronische-ziektenen-multimorbiditeit/een-of-meer-chronische-ziekten\#breadcrumb; Accessed: 19.01.2016

3 McKee $M$, Busse $R$, Baeten $R$ et al. Cross-border Health Care Collaboration in the European Union: Placing the patient at the centre. Eurohealth 2013; 19(4): 3-5

4 Glinos IA, Wismar M, Palm W. Cross-border collaboration in health care: when does it work? Eur J Public Health 2014; 24(Suppl. 2)

5 Livingston G, Frankish H. A global perspective on dementia care: a Lancet Commission. Lancet 2015; 386(9997): 933-934

6 UNDP. Capacity Assessment practice note. New York: United Nations Development Programme; 2008

7 UNDP. Capacity Development practice note. New York: United Nations Development Programme; 2008

8 Hawe $P$, Noort $M$, King L et al. Multiplying health gains: the critical role of capacity-building within public health programs. Health Policy 1997; 39(1): 29-42

9 Aluttis C, Van den Broucke S, Chiotan C et al. Public health and health promotion capacity at national and regional level: a review of conceptual frameworks. J Public Health Res 2014; 3(1): 37-42

10 NSW Health. A framework for building capacity to improve health. Sydney: NSW Health Department; 2001

11 Creswell JW. Research design: Qualitative, quantitative, and mixed methods approaches. Los Angeles: Sage; 2009

12 Glaser BG, Strauss AL. The Discovery of Grounded Research: Strategies for Qualitative Research. New York: Aldine De Gruyter; 1967

13 Jongen W, Burazeri G, Brand $H$. The Influence of the Economic Crisis on Quality of Care for Older People: System Readiness for Innovation in Europe. CIEJ 2015; 28(2): 167-191

14 Jongen W, Commers MJ, Schols JMGA et al. The Dutch Long-Term Care System in Transition: Implications for Municipalities. Gesundheitswesen 2015 [Epub ahead of print] 

Chapter

Discussion of this dissertation 
As stated in the Introduction to this dissertation, the investigative focus of this dissertation has been to explore specific dimensions of the recent Dutch long-term care reform. More specifically, the various studies were designed with a focus upon the most prominent executors of the 2015 Reform (i.e. local governments and long-term care providers) and include a limited cross-border perspective/approach. In this concluding chapter, the main findings of the dissertation are presented, focusing on the research questions presented in the Introduction. The main findings are presented in the form of six main statements, each corresponding to a specific study of this dissertation, followed by a short elaboration of each of them.

After an examination of the six key areas in the findings, the overall implications of the research work are considered by discussing the main findings in a contextualized way in order to meet the overarching research aim of this dissertation: examining whether the intended results of the recent Dutch long-term care reform have been achieved anno 2016. Relating the main findings to important current developments also allowed for the formulation of several recommendations for policy makers and/or public health professionals in the long-term care sector in the Netherlands as well as other European countries.

Finally, this chapter discusses the strengths and limitations of the research work, in an attempt to stimulate and guide future research: both ongoing accompanying analyses on the ongoing unfolding of the Dutch reform, as well as research in other European countries as to learn from the strengths and flaws of the Dutch experience.

\section{MAIN STATEMENTS BASED ON PRINCIPAL RESEARCH FINDINGS}

The most effective type of interventions aimed at promoting social participation amongst older people are considered to be group interventions with a strong interactive character, having an educational input or offering social support, targeted at specific groups of older people and including the older people in the development and implementation of the interventions.

In the study of Chapter 2, we showed that public health interventions in Europe focusing on health promotion for older people are often based on the WHO principle of active ageing, encompassing such domains as social participation, employment and independent living. In our study, we specifically focused on the notion of 'social participation' as an indicator for the quality of life of older people. Being 'active', we found, does not merely relate to being physically active, or being active in terms of employment, but also and perhaps foremost -taking into account the often inevitable physical impairment and retirement of older people- in terms of social participation. Moreover, good indications exist within the academic literature for the existence of a positive relation- 
ship between social participation and the health status of older people (Sirven and Debrand, 2008; Lee et al., 2008; Gilmour, 2012).

The initial aim of the study of Chapter 2 was to investigate how the effectiveness of interventions aimed at promoting social participation of older people can be properly evaluated, with the aim of identifying 'good practice' interventions that are relevant for European countries. As an answer to this research question, we argued that -primarily based on the work of Rychetnik et al. (2002) - a critical appraisal of what constitutes best evidence in evaluative research on public health interventions generally focuses on considerations with regard to the credibility of the evaluative research itself, the completeness of the evaluated intervention outcomes, and the transferability of the research evidence. In the course of writing this dissertation, however, primarily the secondary aim of the study -identifying good practice interventions aimed at promoting social participation- appeared to be of growing importance, as social participation became an ever more pronounced buzz word on the Dutch policy agenda in the run-up to the forthcoming reform.

When turning to interventions aimed at promoting social participation amongst older people, social participation as such does not seem to be an easy target for policy makers and public health professionals. Instead, many existing health promotion interventions geared at increasing social participation of older people do so within the context of preventing social isolation. The Dutch long-term care reform (described in detail in the studies of Chapters 5 and 6) can be considered as covering both sides of the coin, as on the one hand people are encouraged to continue to live home for longer, while at the same time social participation of these same people is encouraged. Both developments do not necessarily have to contradict each other, although one can simultaneously wonder whether, and how, they could reinforce each other. Or, as an example (without suggesting that all vulnerable elderly living at home are isolated): how can people who are already isolated be sufficiently encouraged to participate more in society? Indeed, coming back to 'good practice' examples, our study showed that in general group interventions with a strong interactive character, having an educational input or offering social support, targeted at specific groups of older people (like those that have physical impairments, male or female, those with a cognitive impairment, those that have already lost their spouse etc.) and including the older people in the development and implementation of the interventions, were considered as the most effective type of interventions aimed at promoting social participation amongst older people. Least effective seemed to be one-to-one interventions, offered at people's own houses, like home-visits and home nursing care arrangements (Findlay, 2003; Cattan et al., 2005; Dickens et al., 2011). These conclusions, particularly the latter point, are in line with the findings of Bouman et al. (2008) in a study on the effectiveness of a home visiting program on health-related measures in a population of older people with poor health status. The study showed that the home visiting program did not appear to have any effect on the health status of older people with poor health and is probably not beneficial for 
such persons. The findings of Bouman et al. (2008) were subsequently reinforced during a symposium on the complexity of primary care for older people in a vulnerable position (Van Rossum, 2014), as well as in a systematic review conducted by Mayo-Wilson et al. (2014).

Although the study of Chapter 2 did not provide us with a definite answer to the potential paradox of encouraging living home for longer, while at the same time encouraging social participation of these same people, at the least it cleared the road for continuing our accompanying analysis of the Dutch long-term care reform. As was proposed by Rychetnik et al. (2002), qualitative, or at least quantitative observational studies, may be required to bridge the gap between the research evidence on the one hand and the practice of a local setting on the other hand. Indeed, the remainder of our accompanying analysis is pretty much focused on such local settings, as well as on predominantly qualitative research methods. Moreover, the study's suggestions for further research specifically called for research on (individual) European countries.

Dutch long-term care organizations' 'innovative' response to the economic crisis has mainly been the result of a 'forced' sense of urgency, as well as a disproportionate time-frame for conducting changes and concerns about the sustainable availability of sufficient financial resources.

The aim of the study of Chapter 3 was to examine the influence of the recent economic crisis on the quality of long-term care for older people in Belgium and the Netherlands. As such, the study was conducted two years before the actual entry into force of the 2015 Dutch long-term care reform, giving us the opportunity now to reflect on the then prevailing perceptions. In general, respondents in this study (being representatives of organizations providing long-term care for older people) pointed out that an economic crisis has a much more abrupt and short-term influence on the quality of a country's long-term care provision, than more long-term developments such as population aging. Indeed, while aging is often described in negative connotations -portraying aging primarily as a burden to society due to rising health-care costs (Aartsen et al., 2012)-, respondents claimed that such connotations tend to be exaggerated. The reasoning for this argument is twofold: on the one hand, population ageing is a gradual process, allowing for timely anticipation by policy makers; on the other hand, it was argued, the current generation of older people has a different mentality -being much more selfconscious and less willing to depend on residential care provision- than former generations. Thus, respondents claimed that aging should be approached much more as a challenge, thereby stressing, for example, interventions aimed at promoting social participation of older people rather than merely their care needs. So far, as became apparent in the studies of the following chapters, the above corresponds to the approach that has been chosen in the 2015 long-term care reform, being pretty much focused on a normative reorientation towards achieving a 'participation society' wherein people 
are expected to take care of themselves and their relatives as much and as long as possible (Delsen, 2014; Maarse and Jeurissen, 2016).

Indeed, Dutch organizations seem to have adopted a much more 'innovative' approach than their Belgian counterparts in dealing with the consequences of a change process considered to be accelerated by the economic crisis. Obviously, this argument does not imply that the quality of care for older people is better in the Netherlands than in Belgium. The explanation for this difference in 'innovativeness' between the Dutch and the Belgian organizations can rather be twofold. On the one hand, one could argue that the Belgian organizations underestimated or neglected the challenges that were about to come. On the other hand, one could argue that there was a lower sense of urgency among Belgian organizations to be 'innovative' in responding to the economic crisis. In the aftermath of the crisis, and especially in the course of the unfolding of the Dutch long-term care reform (as described in the studies of the following Chapters), it became apparent that the latter explanation is more accurate. An often heard comment is that change only occurs when there is a necessity to change (in line with Greenhalgh et al.'s (2004) notion of 'tension for change', 2004), and indeed it seemed that the aforementioned Dutch 'innovativeness' was powerfully shaped by the upcoming changes in the long-term care sector as imposed by the national government. Belgian organizations, on the contrary, had at the time of writing the article not (yet) been confronted with consequences of the economic crisis that were as tangible and concrete as in the Netherlands. Another explanatory factor could be found in the sociopolitical context underlying the Dutch and the Belgian long-term care systems, being reflected amongst others in a society's accepted mix between the provision of formal and informal care. Indeed, informal care provision appeared to be much more common in Belgium than in the Netherlands (Willemé, 2010; Mot et al., 2010).

As was argued before, societal trends such as population ageing and increasing longterm care costs are rather gradual developments that do not spur action overnight. As was pointed out in the Introduction to this dissertation, consecutive Dutch governments have in fact reacted to such societal trends by means of a more long-lasting 'marketoriented' reform of the Dutch healthcare system in general, having its roots in the 1980s (Maarse et al., 2016). A key example here is the gradual decentralization of longterm care responsibilities towards municipalities, based on the idea that local governments are in a better position to deliver care in a flexible, tailor-made, way than the national government (Van der Veer, Schalk, and Gilsing, 2011). The Dutch respondents in this study, however, witnessed in practice an inefficient interplay between different organizations per client and a shrinking instead of growing amount of informal caregivers. A truly durable health-care system, they argued, should be much more preventive in nature and the economic crisis had actually provided a chance to finally make structural choices in that direction. Instead, the approach chosen by the Dutch government (characterized amongst others by 'reckless' austerity measures), was regarded as too inconsiderate and the (forced) velocity of changes too high, in line with Maarse's (2013) 
argumentation that especially since the outbreak of the 2008 economic crisis, the Dutch government has changed its long-term care policy agenda from an 'extension agenda' into a 'retrenchment agenda'. Finally, while Greenhalgh et al. (2004) argue that a social innovation is more likely to be assimilated if it "starts out with a budget and if the allocation of resources is both adequate and continuing", the Dutch respondents were seriously worried about the sustainability of the available resources.

Municipalities were largely prepared for their new responsibilities under the 2015 long-term care reform in organizational terms, but underestimated the long-term societal challenges that lie ahead of them.

In the study of Chapter 4, conducted in the course of 2014, we assessed municipalities' readiness for the challenges resulting from their new long-term care responsibilities under the upcoming 2015 long-term care reform. Although by the time of conducting the study of Chapter 4 the exact shape of the reform was already much more concrete than at the time of conducting the study of Chapter 3, the expectations as identified in the study of Chapter 3 appeared to be largely correct. These expectations comprised a shift from residential care to home care provision, a shift from formal to informal care provision, a decentralisation of responsibilities to municipalities, and an accompanying set of government budget cuts.

New insights arising from the study of Chapter 4 primarily related to the envisaged way of executing the reform. In fact, the types of changes as identified by the respondents in this study (being representatives of municipalities) can be captured under two headings here: those relating to the functioning of the municipal organizations themselves, and those relating to the creation of a participation society wherein people are expected to take up more responsibility for their themselves and for each other. Under the first category, respondents pointed to the growing necessity for more integral ways of working within the own municipal organization as well as for a better cooperation and coordination between different organizations in the field of long-term care -the latter point being based on the idea that in the new (post-2015) situation formal care should be (as much as is practically possible) complementary to informal care and not the other way around. In practice, intensified cooperation and coordination between relevant stakeholders is expected to lead to better quality of long-term care according to our respondents, as care will be provided in a much more customized way based on people's actual care needs. Moreover, decentralization as such has been considered as the answer to necessary budget cuts in general, as local governments are expected to work much more effectively and efficiently than national governments due to better insight in their inhabitants' needs, and because they are more closely related to the relevant stakeholders (Council of Europe, 2014).

Under the second category of changes, respondents pointed to the fact that more and more will be expected of informal caregivers in their relatives' care process and that municipalities will have to assure suitable support measures for informal caregivers 
in order to facilitate that development (SCP, 2014). Municipalities will be forced to change their attitude towards long-term care provision from being reactive to proactive in nature: from being a government that merely responds to peoples' self-proclaimed healthcare needs, to a government that facilitates people's own initiatives and that signals problems in the early phases of people's care process.

A general conclusion of this study was hence that municipalities considered themselves to be largely prepared for their new responsibilities resulting from the long-term care reform, but that this perception mainly applied to practical changes (related to municipalities' organizational preparation for their new responsibilities) occurring in the short-term transition phase instead of to the more long-term transformation phase wherein such challenges as the development of a true participation society lie ahead. Indeed, the things that are necessary for enabling municipalities to technically start with a new, decentralized, law (notably the Wmo Act) are relatively easier to arrange than reaching the final aims of this new law, which relies upon new attitudes and behaviours among citizens with regard to the way long-term care will be provided in the Dutch society henceforth. This conclusion is in line with the argument made by Lapré (2015) that the 2015 Dutch long-term care reform has mainly been a reorganization instead of a real reform. Lapré argues that while the reform should have challenged the foundations of the current system by raising a fundamental discussion on what people and society are responsible for themselves, in practice it mainly encompassed a splitting of funding streams and a shrinkage of care packages.

In general, municipalities appear to embrace the core principles of the new reform, being on the one hand the belief that a better quality of care can be achieved when care is arranged and provided closer to individual citizens, and on the other hand the need for a more efficient provision of care. However, it remains to be seen which of these principles will prevail in the further unfolding of the long-term care reform. To a large extent, municipalities appeared to be aware of several remaining challenges, while uncertainty as to the exact unfolding of these challenges prevailed. Although most respondents estimated that the implementation of the new long-term care reform will have several negative unintended implications, they argued that these implications will most likely be primarily related to the care recipients instead of to the functioning of the municipal organizations themselves. Obviously, several challenges relating to the functioning of the municipal organizations themselves were reported as well, mainly applying to the combination of new long-term care responsibilities with accompanying budget cuts. However, in general respondents argued that their internal municipal organization had adapted relatively smoothly to its new tasks through timely internal reorganizations and that the budget cuts had (at least so far) not severely affected their internal organization. The reason why most unintended consequences were foreseen for the care recipients, could be attributed to the generally decreasing level of public care support. Many care recipients and their (future) network of informal caregivers were not considered to be sufficiently aware of the implications that the impending 
changes may have for their personal situation -and of course, to a large extent they could not even know yet at that time. Transformation of people's expectations and their adaptation to a new reality of care provision requires more time, since these are gradual processes. Another challenge, then, relates to the dilemma of how to deal with an increasing burden on the shoulders of informal caregivers in a country where informal care provision is not so common (RIVM, 2014). As a solution to this challenge, municipalities in our study referred to a variety of existing support measures and the legal duty of municipalities to sufficiently support informal caregivers. However, worries remained about the lack of preventive support measures, the concreteness of support measures, and the lack of attention for ethical dilemmas surrounding the expectations of informal care provision.

Overall, our conclusions in the study of Chapter 4 appeared to be in line with the findings of Maarse and Jeurissen (2016), indicating that municipalities on the one hand supported the reform (as well as their own upgraded role in long-term care), while at the same time casting doubts on the feasibility of the expenditure cuts. Indeed, while the State Secretary for Health considers the existence of implementation problems municipalities experience in the decentralization process as transitional, the media regularly report on municipalities failing to provide tailor-made services and on mass lay-offs and worse conditions of employment (ibid.).

In the wake of the recent reforms, certain vulnerable groups of older people in Belgium and the Netherlands are at risk of being deprived of long-term care that is person-centered, available and affordable.

In the study of Chapter 5, European quality benchmarks for long-term care (notably focusing on the quality principles person-centeredness, availability and affordability) were used to explore the contemporary quality of long-term care provision for older people in the Belgian region of Flanders and the Netherlands following recent policy reforms in both countries, in order to find out if and how these reforms have incorporated (or maintained) such quality principles. In doing so, the underlying assumption of the study was that a major challenge when implementing austerity-driven reforms is maintaining an adequate level of quality of care provision (European Commission, 2014). The results of this study showed some noteworthy similarities between Belgium and the Netherlands, as well as some distinct differences. Here, we will elaborate on the most striking Dutch results, in light of the overarching topic of this dissertation. Interestingly in comparison to the preceding three chapters is that Chapter 5 considers the immediate period after entry into force of the 2015 Dutch reform. As such, the study had an explorative character, as the recentness of the reform still impedes the drawing of clear-cut conclusions on changes in long-term care quality pre- and post-reform.

General conclusion of the study in Chapter 5 was that in the wake of the recent long-term care reforms, certain vulnerable groups of older people in Belgium and the Netherlands (particularly those from lower socio-economic backgrounds) are at risk of 
being deprived of long-term care that is available, affordable and person-centered. While national and regional governments set the stage through regulatory frameworks and financing mechanisms, an increased reliance on social networks and informal caregivers is seen as vital to ensure the sustainability of the long-term care systems in Belgium and in the Netherlands. Simultaneously, a greater reliance on local social networks and informal caregivers to give substance to a high quality long-term care provision introduces new challenges. As a way of responding to these new challenges, structural governmental measures have to be introduced to support and protect informal caregivers and informal care networks. As such, our conclusions were in line with the findings of both Naiditch et al. (2013), indicating that throughout Europe, informal caregivers have an increasingly important role to play in meeting the care demands of dependent older citizens, as well as with those of Nies, Leichsenring and Mak (2013), indicating that support measures have to be tailored to the individual needs and expectations of informal caregivers, while simultaneously taking into account the divergent cultural, social and religious values across Europe which guide and influence public opinion on who should take on certain care responsibilities and what form this care should take.

With regard to the quality principle 'person-centeredness', it was argued by respondents (being experts in the field of long-term care) in both countries that the longterm care provisions in their country are predominantly supply-driven rather than demand-driven, as the care that one receives and the setting in which this care is provided is often not guided by an individual's preferences and care needs, but rather by financial restrictions. Moreover, in both countries it was recognized that the contributions of informal caregivers are seen by the respondents as indispensable to ensure the sustainability of the long-term care provision, but that at the same time informal caregivers face numerous difficulties. Among other things, they are at risk of becoming socially isolated, and many of them experience a deterioration of their own physical and mental health when structurally providing informal care. Furthermore, many informal caregivers risk losing part of their income and pension rights when their informal care responsibilities force them to give up working hours. Our respondents therefore argued that there is a lack of social support and financial protection for informal caregivers.

In both countries, availability of long-term care services (the second quality principle applied in our study) is seen as potentially problematic for older people who lack a supportive social network, and in the Netherlands it furthermore seems to vary widely between municipalities whether certain care services are available and accessible, due to the large policy discretion municipalities have in executing their new long-term care responsibilities. More specifically, availability was considered in terms of intramural long-term care capacity, the success of local (citizens') initiatives, the importance of freedom of choice, and the length of waiting lists for long-term care. One of the more striking differences between the two countries relates to the availability of beds in nursing homes and care homes; while the Flemish government is investing in additional intramural long-term care capacity, the Dutch government is reducing the intramural 
long-term care capacity vastly. Indeed, as shown by Figure 3 in Chapter 3, the number of nursing and elderly home beds has been higher in Belgium than in the Netherlands since the mid-1990s and the difference between the two countries growing ever since (WHO, 2013). One should, however, keep in mind that differences in definition might have an influence on such, accumulated, figures (in the Belgian metadata of the respective database, 'nursing and elderly home beds' is defined as 'beds in rest and care homes', while in the Dutch metadata it is defined as 'beds in nursing homes and residential care homes for the elderly') (ibid.). And although the waiting lists for institutional care in the Netherlands are currently relatively short, respondents argue that this is mainly due to the stricter eligibility criteria that have been a result of the recent reform. With regard to freedom of choice, respondents claimed that the importance of freedom of choice is generally overrated in long-term care provision, and that for most older people in need of long-term care or support, the freedom to choose between different care providers is of less importance: older people want to receive effective care (preferably nearby), want to be treated with respect, and generally do not mind which care provider facilitates these needs. Next, in line with the observation in the study of Chapter 4 (being that as a result of the recent Dutch reform, municipalities are expected to proactively facilitate people's own initiatives), worth mentioning here are the concerns expressed by respondents in the current study about the availability of adequate care and support for people from lower socio-economic backgrounds. These people often lack the assertiveness and the connections to mobilise the care they need within their social network. These respondents argued subsequently that it might be more difficult to effectuate citizens' initiatives in disadvantaged neighbourhoods and in communities where social cohesion is lacking.

Finally, in both countries it seems that certain vulnerable groups of older people particularly those from lower socio-economic backgrounds- face increasing difficulties regarding the affordability of long-term care services (the third quality principle we applied). Since the recent reforms in the Netherlands, the financial means and social network of an elderly person play a more significant role in obtaining social support and personal care services, and respondents reported that especially for the group of older people who are unable to mobilise their social network, affordability is becoming an issue. Indeed, due to budgetary constraints, many municipalities in the Netherlands are unable to meet all the social and personal care needs of older people. Consequently, the Dutch respondents have noticed a vast increase in the number of for-profit organisations trying to fill this apparent gap in the market. The services provided by these organisations include paid companionship, assistance with household chores and other personal care tasks. Many of these services are however seen as too expensive for older people with a low socioeconomic status, while this group would arguably benefit most from obtaining such services (Mackenbach et al., 2008).

Several authors remind us that not only the Netherlands and Belgium, but many European welfare states, are currently under pressure to replace their current, compre- 
hensive, welfare schemes with selective and conditional entitlements (Grootegoed \& Tonkens, 2015; Newman \& Tonkens, 2011; León, 2014). As a result, vulnerable citizens' needs are increasingly being framed as private responsibilities (Grootegoed \& Tonkens, 2015; Eliasoph, 2011). Furthermore, Carrera et al. (2013) argue that the functioning of long-term care systems has an enormous impact on social inequality. The results of their study show that "[i]n several European countries, older people's access to healthcare is negatively related to their health status" (ibid.). Or, in other words, people with chronic health problems and/or disabilities have a higher access barrier than those without. Although comparing the intended reforms of European countries was beyond the scope of this dissertation, this option would provide interesting opportunities for further research. Simultaneously, Carrera et al. (2013) remind us that the availability of information necessary for making international comparison is still insufficient. As an explanation for this lack of information, the authors point to, amongst others, the complexity of the different national long-term care systems, the different types of interventions, and the often blurred line between different welfare state sectors (such as between the social care sector and the health care sector).

While Dutch municipalities are aware of (potential) moral conflicts in executing the Social Support Act 2015, the nature of the new law itself leaves insufficient room for municipalities to act in a sufficiently proactive and supportive/empowering manner on these conflicts.

For the study of Chapter 6, a comprehensive ethical approach was applied for assessing Dutch municipalities' way of implementing and executing the Social Support Act 2015. This new law has been the result of the decentralization process, being part of the 2015 Dutch long-term care reform. As the study was conducted in the beginning of 2016, it allowed us to examine the moral conflicts municipalities potentially experienced in the first year of executing their new long-term care responsibilities. The new Social Support Act proved an excellent example (and as such an excellent testing ground) for the observation that "[f]aced with the problems associated with an ageing society, many European countries have adopted innovative policies to achieve a better balance between the need to expand social care and the imperative to curb public spending" (Pavolini \& Ranci, 2008). Moreover, it allowed us to explore the observation that austerity measures [in the long-term care field] in many cases appear to have adverse effects on health systems and/or social determinants of health (Brand et al., 2013; Karanikolos et al., 2013; Arie, 2013; McKee et al., 2012; Quaglio et al., 2013). Main conclusion drawn in this study was that while municipalities are indeed aware of (potential) moral conflicts in executing the new Social Support Act, the nature of the new law itself leaves insufficient room for municipalities to act in a proactive and supportive/empowering manner to these challenges, as well as on the Act's long-term aim of achieving a true participation society, wherein people are expected to take on more individual and social responsibility in fulfilling long-term care needs. The reasoning behind this line of argument is 
that although the new law appears to emphasise such ethical principles as social beneficence and respect for autonomy, the lack of emphasis on notions of social justice threatens to impede the effectuation of the intended goals in practice. This conclusion was largely in line with the findings of Van der Aa et al. (2014) and Grootegoed \& Tonkens (2015), who respectively considered the impact of the long-term care reform on such elements as good quality of care and solidarity (both considered under the heading of social justice in the study of Chapter 6) and respect for autonomy. Moreover, the Social Support Act 2015 seems to be mainly directed towards achieving a certain outcome (the maximisation of social beneficence through the creation of a participation society), instead of stipulating how that outcome should exactly be achieved in a fair manner. As such, the Social Support Act 2015 insufficiently seems to provide equality of opportunity with regard to long-term care access, both between citizens within the same municipality, as (and perhaps especially) between different municipalities.

For the analysis of the potential moral conflicts surrounding the implementation and execution of the Social Support Act 2015, we applied a 'coherentist' approach (consisting of both rights-based and consequentialist strands of ethical reasoning), thereby putting six ethical principles at the core that were considered to capture the specificities of this study: non-maleficence \& beneficence, health maximisation / social beneficence, respect for autonomy, social justice, efficiency and proportionality (Schröder-Bäck, $2009,2012,2014)$. Core of this set of principles appeared to be the rights-based principle of social justice, that could be related to the set of values as emphasized by the Council Conclusions on Common Values and Principles in European Health Systems Council of the European Union, 2006). Indeed, the Council Conclusions stipulate that "[t]he health systems of the European Union are a central part of Europe's high levels of social protection, and contribute to social cohesion and social justice as well as to sustainable development. The overarching values of universality, access to good quality care, equity, and solidarity have been widely accepted in the work of the different EU institutions" (ibid). Or, in other words: "[j]ustice approaches in health care often demand nothing more than universal access to good quality care" (Schröder-Bäck et al. (2012). Or, while principles such as (social) beneficence relate to the maximisation of (public) health outcomes, social justice can be considered as a side constraint to such principles, as it not only considers the overall (public) health benefit, but also the way benefits and burdens are distributed throughout society.

In general, our respondents in this study (being representatives of municipalities) identified three types of moral conflicts in executing the new Social Support Act. First, the conflict of adhering to the Social Support Act's underlying theory of moving towards a participation society vs. the limited budget and time-frame that is offered to municipalities for supporting this change process. Second, respondents identified the conflict of how to efficiently coordinate responsibilities between the Social Support Act 2015 and other long-term care Acts. The third moral conflict identified, related to municipalities' assessment of citizens' self-sufficiency and their ability to social participation vs. 
their care/support needs. The fact that municipalities have a large policy discretion in executing their responsibilities under the Social Support Act 2015 even complicates the later point, as similar situations might well lead to different assessments in different municipalities.

When relating these identified conflicts to the ethical approach applied, it appeared that most of our respondents emphasized that it depends to a large extent on the individual perception of those people who are entitled (or proclaim to be entitled) to receive support on the basis of the Social Support Act people, whether they experience the introduction of the new Social Support Act as an advantage or a disadvantage. Moreover, despite worries about the decreasing level of formal care provision, most respondents considered the creation of a better awareness and appreciation among citizens about care in general to be one of the more long-term advantages of the Social Support Act 2015. At the same time there were doubts about the impact that a law can have on such developments as new ways of thinking about long-term care.

With regard to the more rights-based principles of respect for autonomy and social justice, most respondents considered the former to be sufficiently covered by the Social Support Act 2015, mainly by its emphasis on freedom of choice. At the same time, however, our respondents pointed out that exactly freedom of choice is something that is not always of added value in a context wherein people are often just looking for good quality support. Moreover, while social justice (people's capabilities of making use of their right to freedom of choice) was considered to be sufficiently present for the majority of people, it is also exactly this point that respondents appeared to be most worried about in light of the Social Support Act 2015, especially when applying it to vulnerable groups in society. Indeed, the legal text of the Social Support Act 2015 hardly stresses the importance of such notions as 'equity', one of the core underlying values of the principle of social justice.

Considering the principle of efficiency, related to the way municipalities divide scarce resources in the social domain in a fair way, it appeared that within the context of the Social Support Act 2015 'efficiency' might primarily be understood as a way of justifying the budget cuts that accompanied the long-term care decentralization, instead of as a moral obligation to efficiently use scarce health resources. Indeed, as was pointed out by Maarse \& Jeurissen (2016), within the context of the 2015 long-term care reform the Dutch government is often criticized for "being over-optimistic about the efficiency gains of decentralization" (Maarse \& Jeurissen, 2016). Finally, we considered how these kinds of efficiency goals can be reconciled with moving towards a participation society; or, in other words, does the latter lead to the former, or does the former require the latter? Is thus 'participation' a good value or a fig leaf or metaphor for a liberalist mindset? We argued that although increasing social participation is an intended goal of the Social Support Act 2015, citizens are insufficiently supported to achieve that kind of participation. 
Our conclusions offer an interesting component to a debate that might encompass elements of the work of Huber et al. (2011), Molina-Mula and De Pedro-Gómez (2013) and Daniels and Sabin (2008). Huber et al. (2011) predominantly advocate the concept of 'positive' health in current public health approaches, thereby emphasizing people's abilities instead of their deficits, including their ability to adapt and to self-manage. Molina-Mula and De Pedro-Gómez (2013) predominantly advocate a human rights approach in the restructuring of health systems management, arguing that in many countries healthcare is currently "debated through discourses regarding costs and economic values and not on the basis of their healthcare needs". Daniels and Sabin, finally, propose a minimal ethical standard that should be taken into account in the process of allocating scarce health resources, in order to allocate these resources in a 'fair' way. Our study adds a comprehensive ethical perspective -specifically directed towards the long-term care sector- to this debate. The debate itself, falling outside the immediate scope of the study in Chapter 6, will be picked up in the 'Overall implications \& policy recommendations' subchapter.

Cross-border cooperation in public health should not be an aim in itself, but is only of added value when there is a direct necessity to search for additional know-how.

Within the healthcare sector, Directive 2011/24/EU on 'patients' rights to cross-border health' stimulates EU Member States to "facilitate cooperation in cross-border healthcare provision at regional and local level" (Art. 10). Indeed, various good examples of such cross-border cooperation exist (McKee et al., 2013). At the same time, as argued by Glinos, Wismar \& Palm (2014), cross-border cooperation in healthcare is no easy endeavor, as "health care actors are rooted in their respective health systems and follow domestic rules, priorities and incentives".

Also within the Euregio Meuse-Rhine (the cooperation arrangement between various local Belgian, German and Dutch border regions), cross-border cooperation in the healthcare sector has taken place at different occasions and on different levels; the study of Chapter 7, which served as a case-study, examined to what extent this also applies to the field of dementia care. Apart from the apparent societal importance of dementia care, this topic was chosen as the main theme in our study because of the Dutch 'good practice' initiative of structuring cooperation in the field of dementia care into regional dementia care networks. These networks were initiated by the Dutch government in 2008 by the so-called Ketenzorg Dementie (integrated dementia care) policy, in an attempt to integrate the care and support for people with dementia -as well as the support for their informal caregivers- into a system of multidisciplinary regional dementia care partnerships. The Dutch province of Limburg contains five such regional networks. Little is, however, known about the cross-border, Euregional, activities of these regional networks and the organizations involved. 
Despite the interest that respondents (being representatives of various organizations involved in dementia care) showed in learning more about the way dementia care is organized in other countries, our results showed that structural cross-border cooperation in that field was practically non-existent in the Euregio Meuse-Rhine. The absence of such cross-border cooperation initiatives appeared to be mainly due to the absence of a direct sense of urgency among respondents to develop such initiatives. Indeed, while many respondents reported to be interested in experiences from other countries, for example (and in line with the overall topic of this dissertation) with regard to the implementation of long-term care reforms, organizations are often unwilling or unable to make capacity available for such initiatives. Both financial and human resources are currently scarce in many organizations active in the long-term care sector, especially as a result of the budget cuts accompanying the current Dutch long-term care reform. Considered from that angle, it could be argued that the reform has hindered crossborder knowledge sharing. Our conclusions were in line with the findings of Glinos, Wismar \& Palm (2014), indicating that several factors are needed to initiate and maintain cross-border cooperation, including the existence of a concrete purpose, committed individuals, a shared interest among partners that cannot be achieved without the cross-border cooperation initiative, and a governance structure that suits the purposes, partners and health systems involved in the cross-border cooperation. If such preconditions are in place, 'knowledge development' (primarily in terms of knowledge sharing) was considered by the majority of our respondents as the most obvious reason for potentially considering the work of similar organizations across the border.

\section{OVERALL IMPLICATIONS \& POLICY RECOMMENDATIONS}

Overarching, it appeared from the principal findings of the various studies that the value and necessity of decentralising responsibilities in the long-term care sector and reducing public expenditures on long-term care are widely accepted within Dutch society. Organising and providing care on a local level with support of volunteers, social networks and informal caregivers is a new, emerging, reality that probably constitutes the only suitable solution to ensure the sustainability of long-term care provision in the Netherlands. As such, the chosen reform path can be considered to follow (at least partly) a normal evolution process. Simultaneously, the Dutch national government is criticised for the rigorous manner and fast pace with which the recent reforms have been implemented. Recent research shows that the prevalence of common basic care problems amongst elderly (such as pressure ulcers, incontinence, malnutrition, falls, and use of restraints) has not further declined in 2015 after several years of positive developments, meaning that the quality of adequate basic care provision is at stake (Halfens et al., 2016). The researchers argue that the attention paid to such problems appears to be declining, possibly as a result of the attention that is demanded by the big 
changes in the Dutch healthcare system. The government's idealistic and ideological reasoning behind the reforms -ensuring tailor-made care, delivered closer to home, with the support of a caring and involved society- is considered by many as being mainly rhetoric, with the real driving force behind the reforms being the need for austerity measures. Indeed, cutbacks on healthcare expenditure and social welfare benefits are often seen by policy makers as a short-term solution to alleviate budgetary pressure. This in turn can be considered as a breach of the European Union's overarching healthrelated values of solidarity, universality, equity and access to good quality care. The latter particularly appeared to hold for the new Social Support Act. It was argued that although the new law appears to emphasise such ethical principles as social beneficence and respect for autonomy, the lack of emphasis on notions of social justice threatens to impede the effectuation of the intended goals in practice. Moreover, the Social Support Act 2015 seems to be mainly directed towards achieving a certain outcome (the maximisation of social beneficence through the creation of a participation society), instead of stipulating how that outcome should exactly be achieved in a fair manner. As such, the Social Support Act 2015 insufficiently seems to provide equality of opportunity with regard to long-term care access, both between citizens within the same municipality, as (and perhaps especially) between different municipalities.

\section{Policy recommendations}

Taking into account the above-mentioned overarching results, in the following the most striking principal findings of the studies are compared to recent developments within society. Point-by-point (again in the form of statements) it will be examined whether 'predictions' made in the various studies have actually been fulfilled. Simultaneously, recommendations for policy makers and/or public health professionals are made as suggestions of how to deal with these findings.

1. Societal trends in elderly care are inevitable: continue on the chosen path, but monitor the process constantly.

Social developments such as ageing in place and the changing position of care recipients, as well as technological developments such as the growing use of e-health, are certainly influenced by but not solely dependent on a reform to evolve. In line with this observation, the study of Chapter 6 showed that the concept of 'positive health' (which implies that health should be considered in a proactive manner as the ability to adapt and to self-manage instead of as in terms of merely a state of complete physical, mental and social well-being) is gaining acceptance in Dutch society. This observation is reinforced by a report of The Netherlands Institute for Social Research (SCP) of 2015, showing that in the period between 2004 and 2011 (so prior to the 2015 reform) Dutch elderly have become more independent and stay home for longer (SCP, 2015). Whether or not this trend is influenced by government policy, society is changing. 
Therefore, it is argued that it would not be desirable to try to reverse the chosen reform path, as it (at least partly) follows a normal evolution process. Instead, governments (both local and national) are encouraged to monitor the change process more thoroughly. The latter not only applies to the organizational change process within health care organizations and municipalities, but also (and foremost) to the societal change process. Now that municipalities have largely implemented the 2015 reform in organizational terms, the time seems right for them to further elaborate their actual long-term care responsibilities.

2. A reform requires resources/investment instead of budget cuts.

Several studies in this dissertation concluded that respondents were seriously worried about the sustainability and availability of long-term care resources. This point was reinforced by Greenhalgh et al. (2004) arguing that a social innovation is more likely to be assimilated if it "starts out with a budget and if the allocation of resources is both adequate and continuing". In the past months, also the Dutch media expressed worries about the budget cuts accompanying the long-term care reform, including a fear for increased moonlighting in the long-term care sector (NOS, 2016a), as well as to accusations that municipalities were refusing domestic help to needy elderly (ANP, 2016). Then, surprisingly, Binnenlands Bestuur reported in April 2016 that municipalities seemed to have surpluses in their long-term care budgets instead of shortages (Bekkers, 2016). Several client organizations, however, explained the surpluses by arguing that necessary care is simply not always delivered as a result of too stringent admission criteria, high own contributions or a non-transparent communication between municipalities and citizens about the care or support possibilities one is entitled to (Vleugels, 2016). In May 2016, the Central Appeals Tribunal (the highest Dutch administrative court) ruled that domestic help is definitely part of municipalities' long-term care responsibilities under the Social Support Act 2015 (after several municipalities stated the opposite) and that municipalities therefore cannot simply save on domestic help (ANP, 2016). Moreover, in June 2016, the Dutch government parties decided to reverse planned budget cuts in the long-term care sector (Nu.nl, 2016), which reinforces the argument made before that these initially planned budget cuts impede a successful transformation in the long-term care sector.

It is therefore recommended to the current, as well as subsequent, national governments to continue this path and to further invest instead of retrench in the longterm care sector, in order to achieve its intended goal of achieving a true participation society.

3. Focus particularly on equal opportunities for vulnerable groups of elderly.

In the study of Chapter 6 it was argued that under the Social Support Act 2015, social justice (people's capabilities of making use of their right to freedom of choice) is considered to be sufficiently present for the majority of people. However, it is also exactly 
this point that respondents in the study of Chapter 6 appeared to be most worried about when applying it to vulnerable groups in society. The legal text of the Social Support Act 2015, it was argued, hardly stresses the importance of such notions as 'equity', one of the core underlying values of the principle of social justice. In a recent news article, the director of The Netherlands Institute for Social Research argues that a decentralization of care tasks and a greater reliance on people's individual responsibilities indeed bears a risk: the most vulnerable people have the smallest networks and are the least capable of independently meeting the ultimate decentralization goals of selfsufficiency and social participation (Putters, 2016). The result is that older people with severe disabilities experience a shortage of social participation. Moreover, in another news item, the SCP indicates that 80 per cent of people subject to the Social Support Act are insufficiently self-sufficient (NOS, 2016b). One could argue, thus, that the 'claimmentality' of this group of people is actually overrated: those who ask for help under the Wmo mostly really need it.

Therefore, it is recommended that in the execution of the Social Support Act, more attention should be paid to vulnerable groups in society. Currently, the Dutch participation society sometimes requires Darwinian survival techniques.

4. Consider the limits to free market processes in long-term care.

Under recommendation 1 it was argued that the concept of 'positive health', as developed by Huber et al. (2011) is gaining importance in Dutch society and is therefore undeniable for policy makers. Notwithstanding the normative strength of the concept of positive health, it should be taken care that such concepts are not misused by policymakers as a way of justifying the gradual replacement of a traditionally sound healthcare system by a market driven healthcare system. As an example, Directive 2011/24/EU (the so-called 'patients' rights directive') that we already considered in the study of Chapter 7, is mentioned in this regard. In the Directive, EU member states are encouraged to stimulate cross-border cooperation in the field of health. However, one might wonder to what extent this cooperation is benefiting patients in the first place. It could be argued namely that the complete EU health strategy is basically based on the principle of 'health is wealth'. Moreover, Article 168(1) of the Lisbon Treaty (the article forming the legal basis for EU health policy making) basically emphasizes that health is no top priority policy domain for the EU but is largely subordinated to the functioning of the internal market, by stipulating that "[a] high level of human health protection shall be ensured in the definition and implementation of all Union policies and activities". A recent Dutch example in the same vein was the announcement by the liberal Dutch Minister of Health that the government will invest 20 million euros in the next four years for the stimulation of e-health (Van den Elsen, 2016). However, the money is intended for supporting entrepreneurs in scaling up good initiatives. One might wonder then whether this financial incentive primarily benefits the end user (the patient) or the entrepreneur. In the discussion of the limits to market driven forces in healthcare, Mo- 
lina-Mula \& De Pedro-Gómez (2013) remind us that in many countries healthcare is currently "debated through discourses regarding costs and economic values and not on the basis of their healthcare needs", while "[t]he Universal Declaration of Human Rights states that public healthcare shall be extended to the whole population in conditions of effective equality and overcoming geographical and social imbalances, based on a comprehensive approach to the healthcare system. All of this [...] should be taken into account before carrying out adjustments that will harm the health of citizens and options or alternatives that will not affect equity and healthcare should be weighed up". In the same vein, Schröder-Bäck, Stjernberg and Borg (2013) argued that in the wake of the Eurozone public debt crisis, cutbacks on healthcare expenditure and social welfare benefits are often seen by decision makers as a short-term solution to alleviate budgetary pressure. This in turn can be considered as a breach of the European Union's overarching health-related values of solidarity, universality, equity and access to good quality care.

Here, it is recommended that policy makers constantly reconsider the limits to freemarket processes in the long-term care sector, by taking into account Daniels \& Sabin's accountability for reasonableness approach of procedural justice when making tough decisions (Daniels \& Sabin, 2008). As argued (and further explained) in the study of Chapter 6 , this approach offers a minimal ethical standard when a scarcity of resources leads to an inability to satisfy all needs that might exist in a society. Moreover, initiatives such as the call for an annual debate in parliament on broad welfare topics -these are topics that are not easily or desirably expressed in economic figures, such as health, the environment and education- should be encouraged and effectuated (Van der Goot, 2016).

5. Stimulate cooperation between the social care domain and the healthcare domain.

The study of Chapter 4 emphasized the need for better cooperation and coordination between different organizations in the field of long-term care, especially as formerly clearly defined tasks of different types of organizations are ever more blurring. Jansen et al. add to this that "[j]oining the domains of practice, research and policy is an important aspect of boosting the quality performance required to tackle complex public health problems" (Jansen et al., 2012). A recent news item reported that in the Netherlands, there are insufficient arrangements for sick, frail older people who temporarily cannot live at home, but who are also not eligible for hospitalization (Pennarts, 2015). As a result, hospitals are often clogged with older people wrongly occupying a hospital bed. This situation could be considered a 'flaw' in the Dutch long-term care system.

It is therefore recommended that more attention is paid to a reinforced cooperation between social care and healthcare organizations, especially in light of the broad nature of the Social Support Act (encompassing both social as well as healthcare elements). 
6. As an addition to the previous recommendation: organize more local (public) health conferences.

An efficient way of achieving, or at the least stimulating, an increased cooperation between the social care domain and the healthcare domain, is by organizing more local public health conferences (covering a broad array of health topics). Brand \& Michelsen argue in this respect that "health conferences should establish cooperative structures and networks, create transparency, offer the opportunity for local discussions of health problems as well as the development of common solutions and recommendations" (Brand \& Michelsen, 2012). Additionally, Brand \& Michelsen (2012) argue that while health policies are strongly influenced by cost containment, health conferences are expected "to offer opportunities to develop more effective health services by collaboration and coordination in the fields of health and social care, prevention and health promotion". The local character of such conferences is emphasized, particularly in light of the decentralized Social Support Act, as one model might well apply in one region but not in another. Finally, while evidence-based policy-making is often not possible in the public health sector, local health conferences at the least provide the opportunity for 'evidence-informed' policy-making.

In line with the findings of the study in Chapter 7, it is recommended that such conferences serve a concrete purpose, consist of committed individuals, and are based on a shared interest among partners.

7. Proactively support ('empower') informal caregivers and citizens' initiatives.

In the study of Chapter 2, it was argued that for policy makers and health professionals it is of key importance to remember that increasing social participation of older people is a process, which cannot be achieved overnight. In the study of Chapter 5, attention was paid to the phenomenon of citizens' initiatives (such as 'care cooperatives' and 'city villages'), that is becoming of growing importance in the Netherlands. By means of such initiatives, citizens intend to make their own arrangements with regard to living, wellbeing and care, as a way of complementing the efforts of municipalities in the field of long-term care. A study by Aalvanger \& Beunen (2014) shows that such citizens' initiatives follow many different strategies, that however not always lead to the intended result. All too often, citizens' initiatives focus on broad themes, such as 'quality of life' and 'service provision', thereby lacking a targeted approach. Moreover, even though many citizens' initiatives have sufficient ambition, realizing their plans in practice often proves a bridge too far. Also in the study of Chapter 6 it was argued that although increasing social participation is an intended goal of the Social Support Act 2015, citizens are currently insufficiently supported to achieve that kind of participation. The latter also entails the worries as expressed on the study of Chapter 4, with regard to the perceived lack of preventive support measures, the concreteness of support measures, and 
the lack of attention for ethical dilemmas surrounding the expectations of informal care provision.

Therefore, it is recommended that local governments more proactively support the initiation and development of citizen's initiatives (either by providing financial support, or by providing technical support), as well as more proactively deploy targeted support measures for informal caregivers, in order to structurally contribute to the creation of a true participation society.

\section{STRENGTHS \& LIMITATIONS OF THE STUDIES IN THIS DISSERTATION}

The fact that the recent reform had created a new and unique context in which the accompanying analysis of this study was conducted, asked for an exploratory, in-depth, research approach. This implies that the specific conceptual models that were adhered to in this study, had not been previously applied to evaluate the impact of the recent Dutch long-term care reform. This approach might not be complete, due to the consequent absence of quantitative research data. At the same time, an exploratory research approach seemed to be the only viable option here, as quantitative data on the research topic were in most cases simply not yet available. Simultaneously, the uniqueness of the study context is one of its main strengths. In essence, the purpose of exploratory research is to know the unknown. As such, exploratory research is not intended to draw definite conclusions, but to improve our knowledge of a yet underexplored topic. It helps a researcher to determine, in detail, why and how things happened. Particularly the application of a broad ethical approach towards scrutinizing a new, and still sensitive, policy responsibility of Dutch municipalities (in the study of Chapter 6) is considered to be one of the main strengths of this dissertation. This (coherentist) approach entailed the application of a set of ethical principles derived from both rights-based and consequentialist strands of ethical reasoning.

The main limitation with regard to the exploratory research approach applied in the studies of this dissertation (and inherent to qualitative research in general) is the problem of transferability (or 'external validity'). The problem of transferability refers to the extent to which research results can be generalized or transferred to other settings or contexts. At the same time, several studies in this dissertation can be considered pilot studies for the operationalization of conceptual models that had not yet been (fully) exploited, or at least not in the long-term care research domain. Examples include the operationalization of some of the quality principles of the European Quality Framework for Long-Term Care Services, and the operationalization of the system readiness for innovation approach within the long-term care research domain. The operationalization of these models allows for the application of the same research approach in other contexts, for example other European countries facing similar challenges due to retrenchments in their long-term care system. 
Finally, as the studies of this dissertation were largely cross-sectional in nature, causal relationships between variables could not always (easily) be identified within these studies. At the same time, the accompanying analysis approach of the dissertation in general allowed for a longitudinal perspective, implying that findings in the earlier studies (relating to the 'pre-reform' phase) could be 'tested' in later (post-reform) studies. Nevertheless, the Dutch long-term care reform is considered to be ongoing. It will still take several years before one can accurately assess what the exact consequences of the recent policy reforms have been for the quality of the long-term care provision. As such, continuous confirmation and replication of the findings of this dissertation is required in order to firmly confirm its results.

\section{SUGGESTIONS FOR FUTURE RESEARCH}

With regard to future research options, it is suggested that the analysis of the unfolding of the Dutch long-term care reform will be further continued. Especially the argument made with regard to the allegedly insufficient support with regard to achieving a participation society leaves room for further research, as this is exactly a topic that holds a more long-term perspective. As such, it may be worth considering within a number of years to what extent the Social Support Act 2015 actually contributed (or not) to the creation of a true participation society. Within that regard, it may be worth considering the actual implications of the new long-term care reform in the Netherlands from the perspective of people in need of long-term care and their social networks themselves. A practical option for setting up such a monitoring study is provided by the concept of health system performance assessments (HSPA's). As was pointed out by Wholey \& Hatry (1992), often no attempts are made to estimate the extent to which aspects of a health system actually caused observed outcomes. Or, in other words, information on 'causality' is often lacking. The central purpose of performance measurement, then, is to "monitor, evaluate and communicate the extent to which various aspects of the health system meet key objectives" (Smith et al., 2009). Or, to assess whether progress is being made towards desired goals and whether appropriate activities are undertaken to promote achievement of those goals (Perrin et al., 1999; Behn, 2003). The WHO Regional Office for Europe (2009) emphasizes that a fully developed approach to assessing health system performance has several attributes. First, an HSPA should be conducted regularly, systematically and in a transparent manner. The WHO (2009) stresses that the HSPA should not be "bound in time by a reform agenda or national health plan end-point, although it might be revised at regular intervals better to reflect emerging priorities and to revise targets with the aim of achieving them". Next, the HSPA should be comprehensive and balanced in scope, thereby covering the whole health system and thus not being "limited to specific programmes, objectives or levels of care" (ibid.). Health system performance has -in comparison to health-care perfor- 
mance- been defined by Smith et al. (2009) as a "broader concept that also takes account of determinants of population health not related to health care, principally building on the health field concept advanced by Lalonde and thus subsuming health-care performance". Third, the HSPA should be analytical and making use of complementary sources of information to assess performance (WHO, 2009). "Performance indicators are supported in their interpretation by policy analysis, complementary information (qualitative assessments) and reference points: trends over time, local, regional or international comparisons or comparisons to standards, targets or benchmarks" (ibid.). To conclude, whatever the precise design of the HSPA and the health system is, Smith et al. argue that "the fundamental role of performance measurement is to help hold the various agents to account by enabling stakeholders to make informed decisions" (Smith et al., 2009).

Next, it is suggested that the research approach as applied in this study is extended to other European countries or European border regions (facing similar challenges due to retrenchments in their long-term care system), in order to allow for European-wide comparative research of recent long-term care reforms. Simultaneously, when considering the option of European wide research on this topic, we argued before that even today the information that is required for international comparison is lacking (Carrera et al., 2013). In the above we attributed this lack of information mainly to the complexity of the national long-term care systems of the various European countries. Carrera et al. (2013), however, also point to the possibility that "the absence of reliable data can be seen as a reflection of the failure to prioritize the construction of a relevant database at the European level to facilitate independent analysis of comparative statistical data. [...] Such data are also imperative for the European Union, which over time is likely to start taking more responsibility, albeit indirect, in this field". Studies on the likelihood of developing sophisticated European-side databases on long-term care data might therefore be equally relevant. The potential further development of the National Prevalence Measurement of Quality of Care (in Dutch: 'Landelijke Prevalentiemeting Zorgproblemen', LPZ) might prove an interesting starting point for such studies (Maastricht University, 2016). The LPZ was initiated in the Netherlands, but currently applied in already six countries around the world. 


\section{REFERENCES}

Aalvanger, A. \& Beunen, R. (2014). Het mobiliseren en benutten van bovenlokaal burgerinitiatief. De zoektocht naar nieuwe manieren van samenwerking om de leefbaarheid in Noord-Holland te vergroten. Wageningen: Wageningen University.

Aartsen, M., Béland, D., Edmondson, R., Ginn, J., Komp, K., Nilsson, M., Perek-Bialas, J., Sorensen, P., \& Weicht, B. (2012). Ageing in the Light of Crises: Economic Crisis, Demographic Change, and the Search for Meaning. Paper prepared for the conference Ageing in the light of crises: Economic crisis, demographic change, and the search for meaning, Umea, October 3-5.

ANP. (2016, May 18). Gemeenten mogen niet zomaar op huishoudelijke hulp korten. Retrieved from http://www.nu.nl/geldzaken/4263462/gemeenten-mogen-niet-zomaar-huishoudelijke-hulp-korten.html (accessed May 16, 2016).

Arie, S. (2013). Has austerity brought Europe to the brink of a health disaster? BMJ, 346(f3773). doi:10.1136/bmj.f3773

Behn, R. D. (2003). Why Measure Performance? Different Purposes Require Different Measures. Public Administration Review, 63(5): 586-606. doi:10.1111/1540-6210.00322

Bekkers, H. (2016, April 8). Gemeenten houden fors over op zorg. Retrieved from http://www.binnenlands bestuur.nl/financien/nieuws/gemeenten-houden-fors-over-op-zorg.9529724.lynkx (accessed June 6, 2016).

Bouman, A., Van Rossum, E., Ambergen, T., Kempen, G., \& Knipschild, P. (2008). Effects of a Home Visiting Program for Older People with Poor Health Status: A Randomized, Clinical Trial in the Netherlands. Journal of the American Geriatrics Society, 56(3): 397-404. doi:10.1111/j.1532-5415.2007.01565.x

Brand, H. \& Michelsen, K. (2012). Collaborative governance: the example of health conferences. In D. V. McQueen, M. Wismar, V. Lin, C. M. Jones, \& M. Davies (Eds.), Intersectoral Governance for Health in All Policies. Structures, actions and experiences (pp.165-184). Copenhagen: WHO Regional Office for Europe.

Brand, H., Rosenkötter, N., Clemens, T., \& Michelsen, K. (2013). Austerity Policies in Europe-Bad for Health. BMJ, 346(f3716). doi:10.1136/bmj.f3716

Carrera, F., Pavolini, E., Ranci, C., \& Sabbatini, A. (2013). Long-Term Care Systems in Comparative Perspective: Care Needs, Informal and Formal Coverage, and Social Impacts in European Countries. In C. Ranci, \& E. Pavolini (Eds.), Reforms in Long-Term Care Policies in Europe (pp. 23-52). New York: Springer-Verlag.

Cattan, M., White, M., Bond, J., \& Learmouth, A. (2005). Preventing social isolation and loneliness among older people: a systematic review of health promotion interventions. Ageing and Society, 25(1): 41-67. doi:10.1017/S0144686X04002594

Council of Europe. (2014). Local and regional authorities responding to the economic crisis. Retrieved from https://www.vng.nl/onderwerpenindex/decentralisaties-sociaal-domein/nieuws/decentralisatie-goedantwoord-op-economische-crisis (accessed October 10, 2014).

Council of the European Union. (2006). Council conclusions on common values and principles in European Union health systems (2006/C 146/01). Official Journal of the European Union, 49:C 146/1-3.

Daniels, N., \& Sabin, J. E. (2008). Accountability for reasonableness: an update. BMJ, 337(a1850). doi:10.1136/bmj.a1850

Delsen, L. (2014). From welfare state to participation society. Welfare state reform in the Netherlands: 20032010. NiCE Working Paper 12-103. Nijmegen: Nijmegen Center for Economics (NiCE).

Dickens, A. P., Richards, S. H., Greaves, C. J., \& Campbell, J. L. (2011). Interventions targeting social isolation in older people: a systematic review. BMC Public Health, 11(647). doi:10.1186/1471-2458-11-647

Eliasoph, N. (2011). Making Volunteers: Civic Life After Welfare State's End. Princeton: Princeton University Press.

European Commission. (2014). Adequate Social Protection for Long-Term Care Needs in an

Ageing Society - Report Jointly Prepared by the Social Protection Committee and the European Commission Services. Brussels: European Commission. 
Findlay, R. A. (2003). Interventions to reduce social isolation amongst older people: where is the evidence? Ageing and Society, 23(5): 647-658. doi:10.1017/S0144686X03001296

Gilmour, H. (2012). Social participation and the health and well-being of Canadian seniors. Ottawa: Statistics Canada.

Greenhalgh, T., Robert, G., Macfarlane, F., Bate, P., \& Kyriakidou, O. (2004). Diffusion of Innovations in Service Organizations: Systematic Review and Recommendations. The Milbank Quarterly, 82(4): 581-629. doi:10.1111/j.0887-378X.2004.00325.x

Grootegoed, E., \& Tonkens, E. (2015). Disabled and elderly citizens' perceptions and experiences of voluntarism as an alternative to publically financed care in the Netherlands. Health and Social Care in the Community. doi:10.1111/hsc.12299 [Epub ahead of print]

Halfens, R. J. G., Meesterberends, E., Neyens, J. C. L., Rondas, A. A. L. M., Rijcken, S., Wolters, S., Schols, J. M. G. A. (2016). Landelijke Prevalentiemeting Zorgproblemen. Rapportage Resultaten 2015. Maastricht: Maastricht University.

Huber, M., Knottnerus, J. A., Green, L., van der Horst, H., Jadad, A. R., Kromhout, D., Leonard, B., Lorig, K., Loureiro, M. I., van der Meer, J. W., Schnabel, P., Smith, R., van Weel, C., \& Smid, H. (2011). How should we define health? BMJ, 343(d4163). http://dx.doi.org/10.1136/bmj.d4163

Jansen, M. W., De Leeuw, E., Hoeijmakers, M., \& De Vries, N. K. (2012). Working at the Nexus between Public Health Policy, Practice and Research. Dynamics of Knowledge Sharing in the Netherlands. Health Research Policy and Systems, 10(33). doi:10.1186/1478-4505-10-33

Karanikolos, M., Mladovsky, P., Cylus, J., Thomson, S., Basu, S., Stuckler, D., Mackenbach, J. P., \& McKee, M. (2013). Financial crisis, austerity, and health in Europe. The Lancet, 381(9874): 1323-1331. doi:10.1016/S0140-6736(13)60102-6

Lapré, F. (2015, June 26). Echte transitie of reorganisatie? Retrieved from http://www.binnenlandsbestuur.nl/ bestuur-en-organisatie/kennispartners/tias-school-for-business-and-society/echte-transitie-ofreorganisatie.9481092.lynkx (accessed August 18, 2016).

Lee, H. Y., Jang, S. N., Lee, S., Cho, S. I., \& Park, E. O. (2008). The relationship between social participation and self-rated health by sex and age: a cross-sectional survey. International Journal of Nursing Studies, 45(7): 1042-1054. doi:10.1016/j.ijnurstu.2007.05.007

León, M. (2014). The Transformation of Care in European Societies. London/Chicago: Palgrave Macmillan.

Maarse, J. A. M., \& Jeurissen, P. P. (2016). The policy and politics of the 2015 long-term care reform in the Netherlands. Health Policy, 120(3): 241-245. doi:10.1016/j.healthpol.2016.01.014

Maarse, H., Jeurissen, P., \& Ruwaard, D. (2016), Results of the market-oriented reform in the Netherlands: a review. Health Economics, Policy and Law, 11(2): 161-178. doi:10.1017/\$1744133115000353

Maastricht University. (2016). Over de LPZ. Retrieved from https://nl.Ipz-um.eu/nl/Home/About (accessed August 19, 2016).

Mackenbach, J. P., Stirbu, I., Roskam, A.-J. R., Schaap, M. M., Menvielle, G., Leinsalu, M., \& Kunst, A. E. (2008). Socioeconomic inequalities in health in 22 European countries. The New England Journal of Medicine, 358(23): 2468-2481. doi:10.1056/NEJMsa0707519

Mayo-Wilson, E., Grant, S, Burton, J., Parsons, A., Underhill, K., \& Montgomery, P. (2014). Preventive Home Visits for Mortality, Morbidity, and Institutionalization in Older Adults: A Systematic Review and MetaAnalysis. PLOS ONE, 9(3). doi:10.1371/journal.pone.0089257

McKee, M., Karanikolos, M., Belcher, P., \& Stuckler, D. (2012). Austerity: a failed experiment on the people of Europe. Clinical Medicine, 12(4): 346-350.

Molina-Mula, J., \& De Pedro-Gómez, J. E. (2013). Impact of the Politics of Austerity in the Quality of Healthcare: Ethical Advice. Nursing Philosophy, 14(1): 53-60. doi:10.1111/nup.12000

Mot, E., Aouragh, A., De Groot, M., \& Mannaerts, H. (2010). The Long-term Care System for the Elderly in the Netherlands. Brussels: Centre for European Policy Studies.

Naiditch, M., Triantafillou, J., Di Santo, P., Carretero, S., \& Hirsch Durrett, E. (2013). User Perspectives in LongTerm Care and the Role of Informal Carers. In K. Leichsenring, J. Billings, \& H. Nies (Eds.), Long-Term Care in Europe (pp. 45-80). Basingstoke: Palgrave Macmillen. 
Newman, J., \& Tonkens, E. (2011). Participation, Responsibility and Choice: Summoning the Active Citizen in Western European Welfare States. Amsterdam: Amsterdam University Press.

NOS. (2016a, June 15). NOS Journaal 20:00. Retrieved from http://nos.nl/uitzending/16170-nos-journaal.html (accessed June 15, 2016).

NOS. (2016b, May 18). NOS Journaal 13:00. Retrieved from http://www.npo.nl/nos-journaal/18-052016/POW_02988644 (accessed May 18, 2016).

Nu.nl. (2016, June 13). Coalitie vindt 1,2 miljard om bezuinigingen op zorg en defensie te verzachten. Retrieved from http://www.nu.nl/politiek/4277095/coalitie-vindt-12-miljard-bezuinigingen-zorg-en-defensieverzachten.html (accessed June 13, 2016).

Pavolini, E., \& Ranci, C. (2008). Restructuring the welfare state: reforms in long-term care in Western European countries. Journal of European Social Policy, 18(3): 246-259. doi:10.1177/0958928708091058

Pennarts, J. (2015, November 25). 'Gapend gat' tussen het ziekenhuis en thuis. Retrieved from http://nos.nl/nieuwsuur/artikel/2071287-gapend-gat-tussen-het-ziekenhuis-en-thuis.html (accessed May 9, 2016).

Perrin, E. B., Durch, J. S., \& Skillman, S. M. (1999). Health Performance Measurement in the Public Sector: Principles and Policies for Implementing an Information Network. Washington: National Academy Press.

Public Health and the Environment (RIVM). (2014). Mantelzorg: Zijn er verschillen tussen Nederland en andere landen. Retrieved from http://www.nationaalkompas.nl/participatie/mantelzorg/mantelzorg-verschilleninternationaal/ (accessed October 10, 2014).

Putters, K. (2016, May 24). Nog eens goed naar werking Wmo kijken. Retrieved from http://fd.nl/opinie/ 1152888/nog-eens-goed-kijken-naar-werking-wmo (accessed July 25, 2016).

Quaglio, G., Karapiperis, T., Van Woensel, L., Arnold, E., \& McDaid, D. (2013). Austerity and health in Europe. Health Policy, 113(1-2): 13-19. doi:10.1016/j.healthpol.2013.09.005

Rychetnik, L., Frommer, M., Hawe, P., \& Shiell, A. (2002). Criteria for evaluating evidence on public health interventions. Journal of Epidemiology \& Community Health, 56: 119-127. doi:10.1136/jech.56.2.119

Schröder-Bäck, P., Brand, H., Escamilla, I., Davies, J. K., Hall, C., Hickey, K., Jelastopulu, E., Mechtler, R., \& Volf, J. (2009). Ethical evaluation of compulsory measles immunisation as a benchmark for good health management in the European Union. Central European Journal of Public Health, 17(4): 183-186.

Schröder-Bäck, P., Clemens, T., Michelsen, K., Schulte in den Bäumen, T, Sørensen, K., Borrett, G., \& Brand, H. (2012). Public health ethical perspectives on the values of the European Commission's White Paper "Together for Health". Central European Journal of Public Health, 20(2): 95-100.

Schröder-Bäck, P., Stjernberg, L., and Borg, A.M. (2013). Values and ethics amidst the economic crisis. European Journal of Public Health, 23(5): 723-724. doi:10.1093/eurpub/ckt092

Schröder-Back, P., Duncan, P., Sherlaw, W., Brall, C., \& Czabanowska, K. (2014). Teaching seven principles for public health ethics: towards a curriculum for a short course on ethics in public health programmes. BMC Medical Ethics, 15(73). doi:10.1186/1472-6939-15-73

Sirven, N., \& Debrand, T. (2008). Social participation and healthy ageing: an international comparison using SHARE data. Social Science \& Medicine, 67(12): 2017-2026. doi:10.1016/j.socscimed.2008.09.056

Smith, P. C., Mossialos, E., Papanicolas, I., \& Leatherman, S. (2009). Performance Measurement for Health System Improvement: Experiences, Challenges and Prospects. Cambridge: Cambridge University Press.

The Netherlands Institute for Social Research (SCP). (2014). Hulp geboden. The Hague: The Netherlands Institute for Social Research/SCP.

The Netherlands Institute for Social Research (SCP). (2015). Zicht op zorggebruik. The Hague: The Netherlands Institute for Social Research/SCP.

Van den Elsen, W. (2016, June 7). Schippers trekt 20 miljoen uit voor e-health. Retrieved from https://www.zorgvisie.nl/ICT/Nieuws/2016/6/Schippers-trekt-20-miljoen-uit-voor-e-health-/ (accessed June 6, 2016).

Van der Aa, M.J., Evers, S.M.A.A., Klosse, S., \& Maarse, J.A.M. (2014). Hervorming van de langdurige zorg. Blijft de solidariteit behouden? Nederlands Tijdschrift voor Geneeskunde, 158(A8253). 
Van der Goot, E. (2016, April 20). 'Kamer moet jaarlijks debatteren over brede welvaart'. Retrieved from http://www.nu.nl/politiek/4249866/kamer-moet-jaarlijks-debatteren-brede-welvaart.html (accessed April 22, 2016).

Van der Veer, J., Schalk, J., \& Gilsing, R. (2011). Decentralisatie: maatwerk of uniformiteit? Het Wmo-beleid van Nederlandse gemeenten [Decentralization: Customization or Uniformity? The Social Support Policy of Dutch Municipalities]. Beleid en Maatschappij, 38(3): 265-282.

Van Rossum, E. (2014). Proactieve ouderenzorg: wat heeft 25 jaar onderzoek opgeleverd? [PowerPoint slides]. Retrieved from https://hsr.mumc.maastrichtuniversity.nl/sites/intranet.mumc.maastrichtuniversity.nl/ files/health-services-research/symposia/erikvanrossum-maastricht26maart.pdf (accessed August 18, 2016).

Vleugels, A. (2016, May 5). Gemeenten houden miljoenen zorggeld over. Retrieved from http://nos.nl/artikel/ 2103303-gemeenten-houden-miljoenen-zorggeld-over.html (accessed May 9, 2016).

Wholey, J. S., \& Hatry, H. P. (1992). The Case for Performance Monitoring. Public Administration Review, 52(6): 604-610.

Willemé, P. (2010). The Long-term Care System for the Elderly in Belgium. Brussels: Centre for European Policy Studies.

World Health Organization (WHO Regional Office for Europe). (2009). The European Health Report 2009. Health and health systems. Copenhagen: WHO Regional Office for Europe.

World Health Organization (WHO). (2013). European Health for All Database. Retrieved from http://data.euro.who.int/hfadb/ (accessed September 2, 2013). 

Valorization addendum 

Knowledge valorization refers to the "process of creating value from knowledge, by making knowledge suitable and/or available for social (and/or economic) use and by making knowledge suitable for translation into competitive products, services, processes and new commercial activities" (adapted definition based on the National Valorization Committee 2011:8). Although knowledge valorization is an important element of Chapter 8 in this dissertation (the general discussion), the topic will be further elaborated here.

\section{RELEVANCE}

Under recommendation 1 in the general discussion of this dissertation it was argued that the concept of 'positive health' is gaining importance in Dutch society and is therefore undeniable for policy makers. Notwithstanding the normative strength of the concept of positive health, however, it is important to assure that such concepts are not misused by policy-makers as a way of justifying the gradual replacement of an equitable and needs-driven healthcare system by a less-equitable and profit-driven market-based healthcare system. Moreover, it was recommended that policy makers constantly monitor the limits to leveraging free-market pressures within the long-term care sector. This valorization chapter further discusses the social relevance of the dissertation's research results, as a way of contributing to the societal discussion on the future of the Dutch long-term care system. Indeed, although the value and necessity of decentralising responsibilities in the long-term care sector and reducing public expenditures on longterm care are generally accepted by policy makers and healthcare professionals in the Netherlands, the rigorous manner and fast pace with which the recent reform has been implemented could well be considered as flying in the face of the European Union's overarching health-related values of solidarity, universality, equity and access to good quality care. The government's idealistic and ideological reasoning behind the reforms ensuring tailor-made care, delivered closer to home, with the support of a caring and involved society - impacts large groups in society but is still far from being crystalized in practice. The research presented in this dissertation is intended to stimulate public debate on this topic and results in recommendations for improvement.

\section{TARGET GROUPS}

In line with the above, the research results could be of direct interest for several groups in society. A first group involves the Dutch municipalities due to their new responsibilities resulting from the Social Support Act 2015. Now that municipalities have largely implemented the 2015 reform in organizational terms, the time seems right for them to further elaborate their actual long-term care responsibilities. Here, one might think of 
dealing with a minimal ethical standard when a scarcity of resources leads to an inability to satisfy all needs that might exist in a society. For the Dutch municipalities, the current research results might provide a first source of inspiration. Moreover, the research results encourage governments (both local and national) to monitor the change process more thoroughly. The latter not only applies to the organizational change process within health care organizations and municipalities, but also (and even foremost) to the societal change process. Finally, the national Dutch government (particularly the new government following the March 2017 parliamentary elections) is encouraged to further invest, instead of retrench, in the long-term care sector in order to achieve its intended goal of a true participation society. Special attention in that regard should be paid to vulnerable groups in society, such as lonely elderly and overburdened informal caregivers.

A second target group includes healthcare and social care organizations, which are on the basis of the current research results encouraged to reinforce their cooperation. This type of cooperation mainly applies to their respective responsibilities under the scope of the Social Support Act, as it is especially this long-term care act that encompasses both social as well as healthcare elements.

A third target group is the general public (particularly informal caregivers and people in need of long-term care), as it was recommended that local governments more proactively support the initiation and development of citizen's initiatives (either by providing financial support, or by providing technical support). Moreover, it was recommended that local governments more proactively deploy targeted support measures for informal caregivers, in order to structurally contribute to the creation of a true participation society.

\section{ACTIVITIES/PRODUCTS}

Building on the previous point, the results of this dissertation have the potential to be translated and shaped into several concrete products, services or activities:

- Advice for social and/or healthcare organizations, particularly with regard to the need for better cooperation and coordination between different organizations in the field of long-term care, as a result of an increasing blur between tasks of different types of organizations that were formerly clearly defined.

- Policy recommendations for governments, of which several have already been made in Chapter 8 of this dissertation.

- Contributions to, or the stimulation of, public debates, such as an annual debate in parliament on broad welfare topics (including health and well-being of older people), as such topics are not easily or desirably expressed in economic figures.

- Contributions to the development of training programs (ranging from multi-day modules to one-day workshops) for public health professionals, social care pro- 
fessionals or employees of municipal organizations. Concrete examples of topics for such training programs might include: how to support informal caregivers, amongst others, in dealing with ethical dilemmas they might face; how to deal with emotions and aggression of informal caregivers; how to support specific groups of informal caregivers, such as young informal caregivers, or informal caregivers with a job and/or children; how to stimulate the interplay between different types of healthcare and social care organizations; social-legal aspects with regard to informal care.

- Contributions to the development of training programs (ranging from multi-day modules to one-day workshops) for informal caregivers (being practical in nature), either directed at somatic problems, or directed at psychosocial problems. Examples of topics for training programs directed at somatic problems might include: lifting and transfer techniques; providing support in home care and independent living. Examples of topics for training programs directed at psychosocial problems might include: how to deal with a demented family member; how to deal with loneliness and depression of an older relative; how to stimulate the self-reliance of an older relative; how to signal underlying problems in the living situation of an older relative.

- Contributions to the development of the Mosae Vita initiative in Limburg. Mosae Vita is a new innovative concept, directed at creating a healthy life by a conscious lifestyle. Mosae Vita will be part of the environment of the Maastricht Health Campus, and will involve health practitioners, patients, scientists and small and medium-sized enterprises (SME's) in the development of innovative products and services that help people consciously live a healthy life.

- Contributions to the development of a system for monitoring the societal consequences of (long-term) care reforms.

- The organization of local public health conferences (covering a broad array of health topics), and encompassing a large variety of stakeholders.

\section{INNOVATION}

The above suggested products and services can be called innovative in respect to the existing range of products, services and activities in various ways. First, the existing selection of available training options (such as workshops) around the above-mentioned topics by public educators in the Limburg region is limited. The same is true with regard to evidence-based (or evidence-informed) policy-making: directed and specific advice on the creation of a participation society is still limited in scope. Nevertheless, good examples exist, such as the pioneering development of several modules on informal care provision of Leeuwenborgh Opleidingen (a vocational school in South Limburg). Next, particularly innovative would be the situation wherein products such as training 
programs for informal caregivers would be developed in a cooperative way by the complete educational and knowledge chain in the region. In the field of healthcare technology a good example of such cooperation exists in the cooperation between the Centre for Care Technology Research (CCTR) of Maastricht University \& University of Twente, the Centre of Expertise for Innovative Care and Technology (EIZT) of Zuyd University of Applied Sciences and Fontys University of Applied Sciences, and the Zorgtechniek Limburg (Care Technology Limburg) program of several vocational schools in Limburg (Leeuwenborgh Opleidingen, Arcus College and Gilde Opleidingen). The same type of cooperation across organizations should be explored in public health fields such as informal care provision and/or healthcare reform impacts. Even more innovative, then, would be to include educators across the border in such a cooperation structure, at least when the added value thereof in terms of knowledge sharing has been demonstrated. A good context for exploring such initiatives might be provided by the Academic Collaborative Centre on Care for Older People in South-Limburg (Academische Werkplaats Ouderenzorg Zuid-Limburg) and the Academic Collaborative Centre for Public Health in Limburg (Academische Werkplaats Publieke Gezondheid Limburg). The academic collaborative centers serve as living labs for structural multidisciplinary collaboration between research, policy, education and practice. Finally, the current organization of local health conferences in Limburg is still limited in scope. The regular organization of such conferences, for example on the initiative of the academic collaborative centers, is therefore recommended here.

\section{SCHEDULE \& IMPLEMENTATION}

The valorization plans as outlined above could be given a first shape with the organization of a mini-symposium around the topic of this dissertation. Such a symposium would provide an accessible, low-risk and low-cost platform to give broad social publicity to the research results of this dissertation. By inviting several interesting speakers from various fields and organizations (such as academic public health staff of Maastricht University, lectors in fields such as innovation in healthcare for vulnerable elderly, autonomy \& participation of the chronically ill or informal care of universities of applied sciences) an inspiring program could be guaranteed. Subsequently, by inviting a broad audience, such as representatives of municipalities, representatives of healthcare organizations, representatives of social care organizations, and of course representatives of client organizations and informal care representatives, an initial regional debate could be held on the future of the Dutch participation society. As such, the minisymposium might constitute a prelude to more encompassing regional public health conferences. 
Summary 

Chapter 1, the introduction to this dissertation, gives an overview of the latest Dutch long-term care reform, which entered into force on January 1, 2015. The 2015 Reform can be seen as having a hybrid focus. It is characterized, on the one hand, by austerity measures intended to safeguard the long-term financial sustainability of the Dutch longterm care system; and on the other hand, by a normative discussion about public values such as solidarity versus individual responsibility. The 2015 Reform can be seen as part of a more long-term 'market-oriented' reform of the Dutch healthcare system in general, which began in 1987 with the recommendation of the Dekker Commission to introduce more (regulated) competition into the Dutch healthcare sector. This marketoriented reform has been directed at fostering efficiency, enhancing citizens' freedom of choice and reinforcing solidarity among citizens, while simultaneously upholding public values such as accessibility of care, quality of care, and the financial sustainability of the healthcare sector in general. The studies in this dissertation have one major and overarching goal: to examine the current status anno 2016 with regard to achieving the intended results of the recent long-term care reform.

In launching this study, we believed that it is more interesting at this point in time to examine the complexity of the reform process itself than to focus upon the Dutch longterm care reform in terms of general types of explanatory factors (the reform's 'input'), or in terms of general types of impact (the reform's 'outcome'). The studies in this dissertation provide 'accompanying' analyses of the recent Dutch long-term care reform, focusing upon various aspects of this reform, and applying these to its most prominent implementers and executors (being local governments and long-term care providers). As such, the studies in this dissertation provided a first insight into the recent reform by accompanying the reform process itself. Both the period leading up to the reform (in the aftermath of the economic crisis) and its first year of implementation were examined. A limited cross-border perspective/approach was applied in several of the studies. The fact that the recent reform had created a new and unique context within which the accompanying analysis of this study was conducted required an exploratory research approach: the specific conceptual models that were adhered to in this study had not previously been applied to evaluate the impact of the recent Dutch long-term care reform.

Chapter 2 considers, as a prelude to the rest of the dissertation, the concept of social participation of older people, a concept that constitutes one of the core themes of the 2015 Dutch long-term care reform. On the basis of the study of Chapter 2, it can be concluded that the most effective type of interventions aimed at promoting social participation amongst older people are group interventions 1 ) with a strong interactive character, 2) having an educational input or offering social support, 3) targeted at specific groups of older people and 4) including the older people in the development and implementation of the interventions. Although the study presented in Chapter 2 did not provide us with a definite answer to the potential paradox of encouraging living longer at home while at the same time encouraging social participation of these same people, 
exactly this indefinite conclusion cleared the road for continuing our accompanying analysis of the Dutch long-term care reform.

Chapter 3 examines the influence of the recent 2007/2008 economic crisis on the quality of long-term care for older people in Belgium and the Netherlands. For the study in Chapter 3, a qualitative (multiple case study) research design was applied consisting of semi-structured qualitative interviews supported by quantitative elements. Indeed, Dutch long-term care organizations seem to have adopted a much more 'innovative' response to the economic crisis than their Belgian counterparts. However, as the study of Chapter 3 concluded, this 'innovative' response of Dutch long-term care organizations has mainly been the result of a 'forced' sense of urgency, as well as a disproportionate time-frame for conducting changes and concerns about the sustainable availability of sufficient financial resources.

The study in Chapter 4 examined, in the pre-2015 period, the preparedness of Dutch municipalities for the challenges that would result from their new responsibilities under the 2015 long-term care decentralization. For the study in Chapter 4, a qualitative research design was applied, consisting of semi-structured qualitative interviews. A general conclusion of the study in Chapter 4 was that municipalities considered themselves to be largely prepared for their new responsibilities resulting from the long-term care reform, but that this perception mainly applied to practical changes (related to municipalities' organizational preparation for their new responsibilities) occurring in the shortterm transition phase, instead of to the more long-term transformation phase wherein such challenges as the development of a true participation society lie.

Chapter 5 explores the quality of long-term care provision for older people in Belgium and the Netherlands following the recent long-term care policy changes in both countries. Although Chapters 3 and 4 thus both considered the pre-2015 period, Chapters 5 and 6 both focused on the post-2015 period, following the formal entry into force of the 2015 long-term care reform. For the study in Chapter 5, a qualitative research design was again applied, consisting of semi-structured qualitative interviews. A general conclusion of the study in Chapter 5 was that in the wake of the recent long-term care reforms, certain vulnerable groups of older people in Belgium and the Netherlands (particularly those from lower socio-economic backgrounds) are at risk of being deprived of long-term care that is available, affordable and person-centered. While national and regional governments set the stage through regulatory frameworks and financing mechanisms, an increased reliance on social networks and informal caregivers is seen as vital to ensure the sustainability of the long-term care systems in Belgium and in the Netherlands. Simultaneously, a greater reliance on local social networks and informal caregivers to provide value within high-quality long-term care provision introduces new challenges. As a way of responding to these new challenges, structural governmental measures have to be introduced to support and protect informal caregivers and informal care networks. 
Chapter 6 explores the extent to which municipalities in the Netherlands have taken ethical dilemmas into account when implementing and executing the new social support policies that have resulted from the 2015 decentralization. The main conclusion drawn in this study was that while municipalities are indeed aware of (potential) moral conflicts in executing the new Social Support Act, the nature of the new law itself leaves insufficient room for municipalities to act in a proactive and supportive/empowering manner to these challenges. The same is true with regard to the Act's long-term aim of achieving a true participation society, wherein people are expected to take on more individual and social responsibility in fulfilling long-term care needs. The reasoning behind this line of argument is that although the new law appears to emphasise such ethical principles as social beneficence and respect for autonomy, the lack of emphasis on notions of social justice threatens to impede the effectuation of the intended goals in practice.

Chapter 7 can be considered a case study, considering how cross-border cooperation initiatives can contribute to public health policy making in an individual country. In doing so, dementia care -being a key priority policy theme of the Dutch governmenthas been chosen as a case study. For the study in Chapter 7 a mixed-method research design was applied, consisting of an online survey with closed questions, and in-depth semi-structured interviews. Despite the interest that respondents (being representatives of various organizations involved in dementia care) showed in learning more about the way dementia care is organized in other countries, our results showed that structural cross-border cooperation in that field was practically non-existent in the Euregio Meuse-Rhine. The absence of such cross-border cooperation initiatives appeared to be mainly due to the absence of a direct sense of urgency among respondents to develop such initiatives. A general conclusion of this study was that cross-border cooperation in public health is not an aim in itself, but is only of added value when there is a direct necessity to search for additional know-how.

In Chapter 8, the general findings of this dissertation are discussed, including recommendations for decision-makers in long-term care organizations and policymakers in the long-term care sector in both the Netherlands and other European countries. Overall, it appeared from the principal findings of the various studies that the value and necessity of decentralising responsibilities in the long-term care sector and reducing public expenditures on long-term care are generally accepted by policy makers and healthcare professionals in the Netherlands. Organising and providing care on a local level with the support of volunteers, social networks and informal caregivers is a new, emerging, reality that probably constitutes the only suitable solution to ensure the sustainability of long-term care provision in the Netherlands. As such, the chosen reform path can be considered to follow (at least partly) a normal evolution process. However, the Dutch national government is criticised for the rigorous manner and fast pace with which the recent reform has been implemented. Recent research shows that the prevalence of common basic care problems amongst elderly in all health care set- 
tings (such as pressure ulcers, incontinence, malnutrition, falls, and use of restraints) did not decline in 2015 after several years of positive developments, meaning that the quality of adequate basic care provision is at stake. The attention paid to such problems appears to be waning, possibly as a result of the attention that is demanded by the big changes in the Dutch healthcare system. The government's idealistic and ideological reasoning behind the reforms -ensuring tailor-made care, delivered closer to home, with the support of a caring and involved society- is considered by many as being mainly rhetoric, with the real driving force behind the reforms being the need for austerity measures. Indeed, cutbacks on healthcare expenditure and social welfare benefits are often seen by policy makers as a short-term solution to alleviate budgetary pressure. This in turn can be considered as flying in the face of the European Union's overarching health-related values of solidarity, universality, equity and access to good quality care. The latter particularly appeared to hold for the new Social Support Act. It was argued that although the new law appears to emphasise such ethical principles as social beneficence and respect for autonomy, the lack of emphasis on notions of social justice threatens to impede the effectuation of the intended goals in practice. Moreover, the Social Support Act 2015 seems to be mainly directed towards achieving a certain outcome (the maximisation of social beneficence through the creation of a participation society), instead of stipulating how that outcome should exactly be achieved in a fair manner. As such, the Social Support Act 2015 seems to provide insufficient guarantees of equality of opportunity with regard to long-term care access, both among citizens within the same municipality, as (and perhaps especially) across different municipalities. Throughout the dissertation, recommendations for policy makers and/or public health professionals are made, focusing on, among other things: the thorough monitoring of the reform process, the stimulation of cooperation between the social care domain and the healthcare domain (e.g. through the organization of local (public) health conferences), and the support for informal caregivers and citizens' initiatives. 
Samenvatting 

Hoofdstuk 1, de inleiding van dit proefschrift, geeft een overzicht van de meest recente hervorming van de Nederlandse langdurige zorg, die op 1 januari 2015 in werking trad. De hervorming van 2015 lijkt een hybride focus te hebben. De hervorming wordt namelijk aan de ene kant gekenmerkt door bezuinigingsmaatregelen, bedoeld om de financiële houdbaarheid van het Nederlandse langdurige zorgsysteem op de lange termijn veilig te stellen; en aan de andere kant door een normatieve discussie over publieke waarden zoals solidariteit versus individuele verantwoordelijkheid. De hervorming van 2015 kan worden gezien als onderdeel van een meer lange termijn 'marktgerichte' hervorming van de Nederlandse gezondheidszorg, die haar oorsprong heeft in 1987 en begon met het advies van de Commissie Dekker om meer (gereguleerde) concurrentie in de Nederlandse gezondheidszorg te introduceren. Deze marktgerichte hervorming is gericht op het bevorderen van efficiëntie, het vergroten van de keuzevrijheid van burgers en het versterken van de solidariteit tussen burgers, maar tegelijkertijd ook op het handhaven van publieke waarden zoals toegankelijkheid van de zorg, kwaliteit van de zorg en betaalbaarheid van de zorg. De studies in dit proefschrift hebben één overkoepelend doel: te onderzoeken wat de stand van zaken anno 2016 is met betrekking tot het bereiken van de beoogde resultaten van de recente hervorming van de langdurige zorg.

Bij de start van dit onderzoek was de perceptie dat het op dit moment in de tijd interessanter is om de complexiteit van het hervormingsproces zelf te onderzoeken, dan om de hervorming van de Nederlandse langdurige zorg te onderzoeken op basis van algemene categorieën van verklarende factoren (de 'input' van de hervorming), of op basis van algemene categorieën van gevolgen (de 'output' van de hervorming). De studies in dit proefschrift bieden 'begeleidende' analyses van de recente hervorming van de Nederlandse langdurige zorg, met de nadruk op verschillende aspecten van deze hervorming, en toegepast op haar meest voorname uitvoerders (zijnde lokale overheden en de langdurige zorgaanbieder). Door het hervormingsproces zelf te volgen, bieden de studies in dit proefschrift een eerste inzicht in de recente hervorming. Zowel de periode voorafgaand aan de hervorming (in de nasleep van de economische crisis) en het eerste jaar van de uitvoering werden onderzocht. Een beperkt grensoverschrijdend perspectief werd gehanteerd in een aantal van de studies. Het feit dat de recente hervorming een nieuwe en unieke context bood waarin de 'begeleidende' analyse van dit proefschrift werd uitgevoerd, vereiste een exploratieve onderzoeksaanpak: de specifieke conceptuele modellen die werden toegepast in dit onderzoek zijn nog niet eerder toegepast om de gevolgen van de recente hervorming van de Nederlandse langdurige zorg te evalueren.

Hoofdstuk 2 behandelt, als een opmaat naar de rest van het proefschrift, het concept van maatschappelijke participatie van ouderen, een concept dat een van de belangrijkste thema's van de hervorming van de Nederlandse langdurige zorg van 2015 vormt. Op basis van de studie van Hoofdstuk 2 kan geconcludeerd worden dat de meest effectieve vorm van interventies gericht op het bevorderen van maatschappelijke participatie van ouderen, interventies zijn 1) met een sterk interactief karakter, 2) met een 
educatief karakter of gericht op het bieden van sociale steun, 3) gericht op specifieke groepen ouderen en 4) waarbij ouderen zelf worden betrokken in de ontwikkeling en implementatie van de interventies. De studie van Hoofdstuk 2 voorziet ons weliswaar niet van een sluitend antwoord op de mogelijke paradox van het stimuleren van langer thuis blijven wonen van ouderen en tegelijkertijd het stimuleren van de maatschappelijke participatie van deze zelfde groep mensen. En precies dit ontbreken van een sluitende conclusie onderstreepte de noodzaak tot het uitvoeren van een begeleidende analyse van de hervorming van de Nederlandse langdurige zorg.

Hoofdstuk 3 gaat in op de invloed van de recente economische crisis van 2007/2008 op de kwaliteit van de langdurige ouderenzorg in België en Nederland. Voor de studie in Hoofdstuk 3 werd een kwalitatieve (multiple casestudy) onderzoeksopzet toegepast, bestaande uit semigestructureerde interviews aangevuld met kwantitatieve elementen. Uit de onderzoeksresultaten bleek dat Nederlandse zorgorganisaties een veel 'innovatievere' houding hadden aangenomen ten opzichte van de gevolgen van de economische crisis dan Belgische zorgorganisaties. Echter, zoals de studie van Hoofdstuk 3 concludeerde, deze 'innovatieve' houding van Nederlandse zorgorganisaties bleek vooral het gevolg te zijn van een 'noodzakelijke' sense of urgency, een disproportioneel tijdsschema voor het uitvoeren van veranderingen in de langdurige zorg en een bezorgdheid over de lange termijn beschikbaarheid van voldoende financiële middelen in de langdurige zorg.

De studie in Hoofdstuk 4 onderzocht, in de periode vóór 2015, de 'systeem paraatheid' (system readiness) van Nederlandse gemeenten op de uitdagingen die zouden gaan voortvloeien uit hun nieuwe verantwoordelijkheden in het kader van de decentralisaties in de langdurige zorg. Voor de studie in Hoofdstuk 4 werd een kwalitatieve onderzoeksopzet toegepast, bestaande uit semigestructureerde interviews. Een algemene conclusie was dat gemeenten zichzelf grotendeels voorbereid achtten op hun nieuwe verantwoordelijkheden ten gevolge van de hervorming van de langdurige zorg. Echter, deze perceptie bleek vooral betrekking te hebben op de meer praktische veranderingen (met betrekking tot de organisatorische voorbereidingen van gemeenten op hun nieuwe verantwoordelijkheden) die zich in de korte termijn transitiefase zouden manifesteren, in plaats van op de meer lange termijn transformatiefase waarin het veel meer gaat om uitdagingen als het stimuleren van een participatiemaatschappij.

Hoofdstuk 5 onderzoekt de kwaliteit van de langdurige zorg voor ouderen in België en Nederland naar aanleiding van de recente beleidsveranderingen op dit gebied in beide landen. Daar waar Hoofdstukken 3 en 4 dus de periode vóór 1-1-2015 beschouwen, hebben Hoofdstukken 5 en 6 betrekking op de periode ná de formele inwerkingtreding van de hervorming van de Nederlandse langdurige zorg. Ook voor de studie in Hoofdstuk 5 werd een kwalitatieve onderzoeksopzet, bestaande uit semigestructureerde interviews, toegepast. Een algemene conclusie was dat in de nasleep van de recente hervormingen van de langdurige zorg in beide landen, bepaalde kwetsbare groepen ouderen in België en Nederland (vooral ouderen vanuit een lagere sociaaleconomische 
achtergrond) het risico lopen om langdurige zorg mis te lopen die voldoende beschikbaar, betaalbaar en persoonsgericht is. Hoewel de nationale en lokale overheden de brede contouren bepalen van het langdurige zorgsysteem door middel van wet- en regelgeving en financieringsmechanismen, wordt een verhoogde afhankelijkheid van sociale netwerken en mantelzorgers als onontbeerlijk gezien om de duurzaamheid van de langdurige zorg in België en in Nederland te waarborgen. Tegelijkertijd, echter, brengt een grotere afhankelijkheid van lokale sociale netwerken en mantelzorgers binnen de langdurige zorg nieuwe uitdagingen met zich mee. Als een manier om te reageren op deze nieuwe uitdagingen, zullen er structurele maatregelen van overheidswege moeten worden ingevoerd ter ondersteuning en bescherming van mantelzorgers en informele zorgnetwerken.

Hoofdstuk 6 onderzoekt de mate waarin gemeenten in Nederland rekening houden met ethische dilemma's bij de implementatie en uitvoering van hun nieuwe verantwoordelijkheden op het gebied van maatschappelijke ondersteuning als gevolg van de decentralisatie die in 2015 in werking trad. De belangrijkste conclusie van deze studie was dat hoewel gemeenten zich wel degelijk bewust zijn van (potentiële) morele conflicten bij de uitvoering van de nieuwe Wet maatschappelijke ondersteuning (Wmo 2015), de aard van de nieuwe wet zelf onvoldoende ruimte laat voor gemeenten om op proactieve en ondersteunende wijze in te spelen op deze conflicten. Hetzelfde is waar met betrekking tot het lange termijn doel van de Wmo 2015, zijnde het bewerkstelligen van een echte participatiesamenleving waarin van burgers wordt verwacht dat men meer eigen en maatschappelijke verantwoordelijkheid op zich neemt bij het vervullen van de langdurige zorgbehoeften. De redenering achter deze argumentatie is dat hoewel de nieuwe Wmo ethische principes als 'maatschappelijk weldoen' (social beneficence) en respect voor autonomie lijkt te benadrukken, het gebrek aan aandacht voor principes als sociale rechtvaardigheid de effectuering van de beoogde doelen in de praktijk dreigt te belemmeren.

Hoofdstuk 7 kan worden beschouwd als een casestudy, waarin wordt onderzocht hoe grensoverschrijdende samenwerkingsinitiatieven een bijdrage kunnen leveren aan het volksgezondheidsbeleid in een individueel land. Het thema dementiezorg is hierin gekozen als voorbeeldcase, aangezien dit een prioritair thema vormt binnen het Nederlandse volksgezondheidsbeleid. Voor de studie in Hoofdstuk 7 werd een gemengde onderzoeksopzet toegepast, bestaande uit een online enquête met gesloten vragen enerzijds en semigestructureerde interviews anderzijds. Ondanks het belang dat de respondenten in deze studie (bestaande uit vertegenwoordigers van diverse organisaties betrokken bij dementiezorg in Limburg) toeschreven aan het leren van de wijze warop dementiezorg is georganiseerd in andere landen, toonden de resultaten van deze studie aan dat structurele grensoverschrijdende samenwerking op dat gebied nagenoeg nihil is binnen de Euregio Maas-Rijn. Het ontbreken van dergelijke grensoverschrijdende samenwerkingsinitiatieven lijkt voornamelijk te wijten aan het ontbreken van een directe sense of urgency onder respondenten om dergelijke initiatieven te 
ontwikkelen. Algemene conclusie van dit onderzoek was dat de grensoverschrijdende samenwerking op het gebied van de volksgezondheid geen doel op zich is, maar alleen van toegevoegde waarde is als er een directe noodzaak bestaat om te zoeken naar aanvullende kennis.

In Hoofdstuk 8 worden de algemene bevindingen van dit proefschrift besproken en worden er aanbevelingen gedaan voor besluitvormers en beleidsmakers in de langdurige zorgsector in Nederland en andere Europese landen. Over het algemeen bleek uit de belangrijkste bevindingen van de verschillende studies in dit proefschrift dat het belang en de noodzaak van de decentralisatie van verantwoordelijkheden in de langdurige zorg en het verminderen van de overheidsuitgaven voor langdurige zorg worden gedragen door beleidsmakers en zorgprofessionals in Nederland. Het organiseren van de zorg op lokaal niveau met de steun van vrijwilligers, sociale netwerken en mantelzorgers is een nieuwe, opkomende, werkelijkheid die waarschijnlijk de enige geschikte oplossing vormt om de duurzaamheid van de langdurige zorg in Nederland te waarborgen. Tot dusver kan men dus stellen dat het door de Nederlandse overheid gekozen hervormingspad (in ieder geval gedeeltelijk) een normaal evolutieproces volgt. Echter, de Nederlandse nationale overheid wordt bekritiseerd voor de rigoureuze wijze en het snelle tempo waarmee de recente hervorming is geïmplementeerd. Uit recent onderzoek blijkt bijvoorbeeld dat de prevalentie van algemene basiszorgproblemen onder ouderen in alle gezondheidszorginstellingen (zoals decubitus, incontinentie, ondervoeding, vallen, en het gebruik van dwangmiddelen) niet is afgenomen in 2015 na enkele jaren van positieve ontwikkelingen, hetgeen betekent dat de kwaliteit van de basiszorg in het geding kan zijn. De aandacht voor deze problemen lijkt af te nemen, mogelijk als gevolg van de aandacht die wordt opgeëist door de grote veranderingen in de Nederlandse gezondheidszorg. De idealistische en ideologische redeneringen van de Nederlandse overheid achter de hervormingen (het leveren van zorg op maat dichter bij huis, met de steun van een zorgzame en betrokken samenleving) worden door velen beschouwd als retorisch, terwijl de echte drijvende kracht achter de hervormingen de behoefte aan bezuinigingsmaatregelen is. Bezuinigingen op de gezondheidszorguitgaven en de sociale uitkeringen worden vaak door beleidsmakers beschouwd als een korte termijn oplossing om de budgettaire druk te verlichten. Dergelijke bezuinigingen kunnen op hun beurt worden beschouwd als een inbreuk op de gemeenschappelijke waarden en beginselen van de gezondheidsstelsels van de Europese Unie (universaliteit, toegang tot hoogwaardige zorg, rechtvaardigheid en solidariteit). Dit argument lijkt vooral betrekking te hebben op de nieuwe Wmo. Aangevoerd wordt dat hoewel de nieuwe Wmo ethische principes als 'maatschappelijk weldoen' (social beneficence) en respect voor autonomie lijkt te benadrukken, het gebrek aan aandacht voor principes als sociale rechtvaardigheid de effectuering van de beoogde doelen in de praktijk dreigt te belemmeren. Bovendien lijkt de Wmo 2015 met name gericht te zijn op het bereiken van een bepaald resultaat (het maximaliseren van maatschappelijk weldoen door het creëren van een participatiemaatschappij), zonder te stipuleren hoe dat resultaat precies moet worden bereikt. Als zodanig lijkt de Wmo 2015 
onvoldoende garanties te bieden voor gelijke kansen met betrekking tot de toegang tot langdurige zorg, zowel tussen burgers binnen dezelfde gemeente, als (en misschien vooral) tussen burgers van verschillende gemeenten. In het proefschrift worden aanbevelingen gedaan voor besluitvormers en beleidsmakers, gericht op onder andere: het grondig monitoren van het hervormingsproces, het stimuleren van de samenwerking tussen het gezondheidszorg- en het sociale zorgdomein (bijvoorbeeld door middel van het organiseren van lokale (volks)gezondheidsconferenties) en de ondersteuning van mantelzorgers en burgerinitiatieven. 

Dankwoord 
Het was al enkele jaren mijn droom om te promoveren. Die droom is nu uitgekomen. Ik ben ontzettend dankbaar dat ik mijn twee grote passies (ouderenzorg en schrijven) heb kunnen combineren in dit proces. Ik wil graag een aantal mensen bedanken, zonder wier hulp en steun ik deze droom nooit had kunnen waarmaken.

Allereerst dank aan jullie, mam en pap, voor jullie eindeloze steun en interesse. Mam, mijn passie voor het schrijven dank ik aan jou. Al op jonge leeftijd, toen ik nog op de basisschool zat, hielp je mij bij het voorbereiden van spreekbeurten en werkstukken. Samen zochten we een interessant onderwerp uit en vervolgens gingen we naar de bibliotheek om informatie op te zoeken in documentatiemappen. De passie voor het schrijven is gebleven. Mijn fijnste momenten waren dan ook de dagen dat ik thuis aan een hoofdstuk bezig was, met een kopje koffie erbij, en onze kat spinnend op een stoel naast me. Uiteraard zat het niet altijd mee. Pap, van jou heb ik geleerd om nooit op te geven, dromen na te jagen en ze te realiseren. Opgeven is geen optie. Dankjewel voor je waardevolle aanmoedigingen op de momenten dat het even tegen zat.

Mijn grootste dank gaat uit naar Sanne, mijn partner en soul mate. Alle mooie momenten deel ik eerst met jou. Op de momenten dat ik het nodig had, bood jij me een luisterend oor. Ook inhoudelijk kon ik met je discussiëren en je voorzag me vaak van een kritische noot. Zonder jou had ik dit niet kunnen doen.

Het is ook mede dankzij Sanne dat ik in 2012 de stap heb gezet om opnieuw te gaan studeren. In de jaren daarvoor, toen ik al werkte en zij Gezondheidswetenschappen studeerde aan de UM, ging ik haar na mijn werk vaak ophalen. Om de tijd te overbruggen zat ik dan meestal een paar uur in de mensa van de Faculty of Health, Medicine \& Life Sciences met een goed boek erbij op haar te wachten. Het kriebelde steeds meer om zelf ook opnieuw te gaan studeren. Uiteindelijk hebben we gelijktijdig ons master jaar gevolgd; ik kan wel zeggen één van de leukste jaren uit mijn leven.

Toen ik in 2007 mijn broer zag promoveren, en een jaar later als paranimf aanwezig was bij de promotie van mijn schoonzus, was het voor mij duidelijk: dit wil ik ooit ook. Uiteindelijk deed de kans zich voor om te starten aan mijn eigen proefschrift, hetgeen ik te danken heb aan drie bijzondere mensen: mijn promotoren prof. dr. Helmut Brand en prof. dr. Jos Schols en mijn copromotor dr. Matthew J. Commers. Helmut heb ik leren kennen tijdens mijn master studie European Public Health. Ik ben in september 2012 begonnen met deze master na enkele jaren gewerkt te hebben in een totaal andere sector. Mijn interesse in de volksgezondheid, met name de ouderenzorg, werd aangewakkerd door alle veranderingen die op stapel stonden in de Nederlandse gezondheidzorg, alsook die van veel andere Europese landen. Deze veranderingen werden voor een groot deel geïllustreerd door mensen in mijn eigen omgeving die er in de dagdagelijkse praktijk mee geconfronteerd werden, zoals mijn moeder en schoonmoeder, beiden 
werkzaam in de zorg. Het was een hele aanpassing om vanuit een baan weer terug naar de collegezaal te gaan, maar ik heb er geen seconde spijt van gehad. Ik herinner me met name Helmuts colleges, die keer op keer stof tot nadenken gaven door zijn interessante kijk op onderwerpen die ik voorheen voor lief nam. Aan het eind van het studiejaar had ik het geluk dat Helmut mijn supervisor was bij het schrijven van mijn master thesis. In de loop van het jaar leerde ik Jos kennen, tijdens een interview dat ik met hem had vanuit zijn functie bij een grote zorginstelling in Zuid-Limburg. Zijn bevlogenheid inspireerde mij en liet me niet meer los. Ik ben dan ook dankbaar dat Jos als promotor aan dit proefschrift wilde meewerken. Matt heb ik in eerste instantie leren kennen toen ik tijdens mijn studiejaar als tutor werkzaam was binnen de bachelor European Public Health. Vanuit die rol heb ik altijd op aangename wijze met Matt samengewerkt. Ik was dan ook bijzonder blij toen Matt als copromotor van mijn promotie werd aangewezen.

Ook wil ik graag de leden van de beoordelingscommissie bedanken, bestaande uit prof. dr. Ruud Kempen, prof. dr. Jacques Scheres, prof. dr. Katrien Luijkx en prof. dr. Alice de Boer, voor hun inspanningen en hun bereidheid om dit proefschrift te beoordelen. Daarnaast wil ik ook de diverse coauteurs van de reeds gepubliceerde artikelen bedanken voor hun intensieve medewerking en hun onmisbare adviezen.

Mijn twee paranimfen, Cynthia en Richard, wil ik bedanken voor hun bereidheid om mij bij te staan tijdens de promotieceremonie. Beiden zijn vrienden voor het leven en hebben meermaals hun oprechte interesse getoond in mijn werk; het was voor mij dan ook vanzelfsprekend om hen te vragen als paranimf.

Een bijzonder woord van dank wil ik ten slotte wijden aan Anita Creusen, de secretaresse van de afdeling International Health. Anita's betrokkenheid, haar tomeloze energie en haar inlevingsvermogen verbaasden mij keer op keer. Ik zou niet weten wat we zonder haar moesten! 



\section{About the author}

Wesley Jongen was born in Heerlen, the Netherlands, on July $11^{\text {th }}, 1985$. After he finished secondary school (VWO) at the Sophianum College in Gulpen in 2003, he started his studies at Maastricht University. In 2007, he obtained a Bachelor's degree in European Studies, and in 2008 a Master's degree in European Studies. Subsequently, Wesley worked for the regional government of Limburg (Provincie Limburg), which led him to a decision to further his career in the field of public health. In September 2012, Wesley matriculated into the European Public Health Master at the Faculty of Health, Medicine and Life Sciences at Maastricht University. In August 2013, Wesley graduated with his thesis on the influence of the 2008-2012 economic crisis upon quality of care. This thesis was the basis for his PhD research on elderly care at the Department of International Health within the School for Public Health and Primary Care (CAPHRI). Next to his academic activities, Wesley is employed as a business consultant at Aranco Consultancy \& Interim Management. Moreover, he teaches part-time within the Bachelor of the European Public Health Programme at Maastricht University. 



\section{List of publications}

Jongen, W., Commers, M.J., Schols, J.M.G.A., Burazeri, G., \& Brand, H. (in press). Crossborder capacity assessment in dementia care. Das Gesundheitswesen.

Jongen, W., Commers, M.J., Schols, J.M.G.A., \& Brand, H. (2015). Wandel in der niederländischen Langzeitpflege: Folgen für die Gemeinden. Das Gesundheitswesen, 78(8/9), 514-515. doi: 10.1055/s-0035-1564251

Janssen, D., Jongen, W., \& Schröder-Bäck, P. (2016). The impact of austerity-driven policy reforms on long-term care quality: evaluating the long-term care provision for older people in Belgium and the Netherlands using European quality benchmarks. Journal of Aging Studies, 38, 92-104. doi: 10.1016/j.jaging.2016.05.003

Jongen, W., Commers, M.J., Schols, J.M.G.A., \& Brand, H. (2015). The Dutch Long-Term Care System in Transition: Implications for Municipalities. Das Gesundheitswesen. doi: 10.1055/s-0035-1564251

Jongen, W., Burazeri, G., \& Brand, H. (2015). The Influence of the Economic Crisis on Quality of Care for Older People: System Readiness for Innovation in Europe. Innovation: The European Journal of Social Science Research, 28(2), pp. 167-191. doi: 10.1080/13511610.2015.1019839

Jerliu, N., Burazeri, G., Toçi, E., Kempen, G. I., Jongen, W., Ramadani, N., \& Brand, H. (2014). Social networks, social participation and self-perceived health among older people in transitional Kosovo. European Journal of Public Health, 24(2), pp. 333-337. doi: 10.1093/eurpub/ckt064

Jongen, W., Schröder-Bäck, P., \& Brand, H. (2013). Evaluating interventions aimed at promoting social participation of older people: A review of the literature. Albanian Medical Journal, 1, 55-61.

Jongen, W., \& Schröder-Bäck, P. (2013). Albania's potential accession to the EU: A gain for the Albanian public health? Albanian Medical Journal, 4, 80-88. 


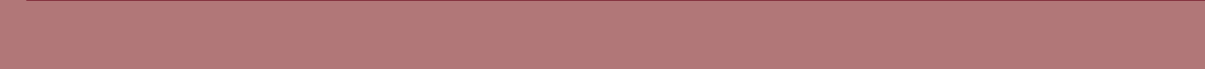

